\title{
Data Colonialism in Canada: Decolonizing Data through \\ Indigenous data governance
}

by

Donald Leone

A thesis submitted to the Faculty of Graduate and Postdoctoral Affairs in partial fulfillment of the requirements for the degree of

Master of Arts

in

Communication with specialization in Data Science

Carleton University

Ottawa, Ontario

(c) (1)(8) (2)

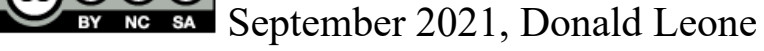




\begin{abstract}
The current states of First Nations, Inuit, and Métis data are not distinctive of the current moment but are practically linked to the historical operation of the colonial enterprise to denigrate and marginalize Indigenous peoples and knowledge through data colonialism. There is an international movement emerging that calls for Indigenous data governance (IDG) to resist and reconcile these colonial histories. In this context, this thesis is a study of how Indigenous data were constructed as colonial objects in Canada and what it means to decolonize these data and the practices which produce, manage, and govern them. First, the conceptual and practical foundations of data colonialism, Indigenous data, and decolonization are explored both in concept and in practice, including how Indigenous governance employed data as a tool for classification and control, including the modern continuities of these practices, and emerging First Nations, Inuit, and Métis-led approaches to govern their data and produce their own knowledge about and for themselves to inform the governance of their peoples, communities and lands. To understand how Indigenous data governance operates and what might lead to data decolonization, I framed my analysis with three theoretical approaches: dynamic nominalism, (Hacking, 1986; 2007), assemblage theory (Kitchin, 2014), and international discourse on IDG (Kukutai \& Taylor, 2016). These frameworks inform a directed content analysis investigating a selection of key Indigenous data governance texts and four semi-structured research interviews. The coding of the content analysis was based on data governance in the DAMA DMBOK (2017), which is an industry association approach used by enterprises big and small globally. This approach highlighted not only how colonial classifications, data, and data governance are constructed, but also how these might be deconstructed and reformulated with Indigenous perspectives and worldviews. It is argued that IDG provides the foundation for data decolonization in Canada, however this is fledgling work emerging at a critical juncture where there are ever changing technological innovations, a context of complex social issues, and legacies of colonial governance arrangements. To conclude, the thesis provides a discussion of these greater implications, the limitations and where future work might go, especially as First Nations, Inuit, and Métis continue to assert sovereignty and governance over their data, data that will be used to inform the governance of their futures according to their values and world views.
\end{abstract}




\section{Acknowledgements}

Thank you to my supervisor, mentor, and friend Dr. Tracey P. Lauriault, who has supported my academic development and aspirations since my undergraduate degree and into the finish of my master's program. I would not be the researcher, academic, and person I am today without her guidance, and I am eternally grateful for the opportunities, encouragement, and support she has provided me throughout my academic career.

Thank you to my thesis committee, Dr. Jonathan Dewar and Dr. Patricia McGuire, for providing me with feedback and for accommodating a tight review and defense schedule to get this project completed. I would also like to express my gratitude and thanks to Erin Corston, Pat Foster, Chris Gall, and my participant from CIRNAC who took the time to join me and share their knowledge, expertise, and perspective on these issues. Each of our chats were greatly insightful and really drove and enlightened my understanding of these issues and what is important at the end of the day.

Thank you to all and everyone with the Department of Communication and Media Studies that I had the pleasure to meet and grow with as a master's student, including my peers, professors, and the administrative staff who hold everything together. Special thanks to Dr. Dwayne Winseck for supporting my aspiration to pursue a master's degree and the funding needed to do so; to Dr. Rena Bivens for her guidance and support as our graduate supervisor; and to my peers and cohort, specially to my friend Blue for always checking in on me and my work and supporting me the whole way through this project.

A very special thank you to my partner Colleen, who has gone the lengths to support me and my health, and was the voice of reason and comfort throughout my entire thesis and master's degree. Words cannot express my gratitude for everything she has done to get me to this point, and for shaping who I am today.

I also want to extend thanks to all my friends and family, who despite being far away and isolated in these times, have supported my progress and success to whole way.

Last but not least, thank you to the Social Science and Humanities Research Council (SSHRC) for seeing the value in my project and for financially supporting this thesis with the SSHRC Canada Graduate Scholarships - Master's (CGS-M) Grant. 


\section{Table of Contents}

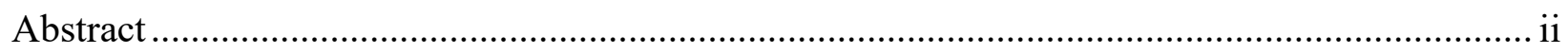

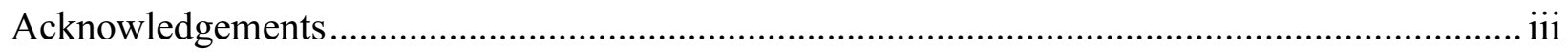

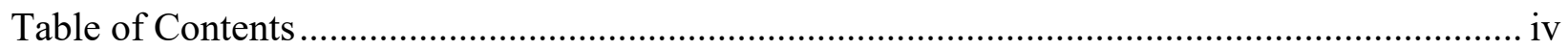

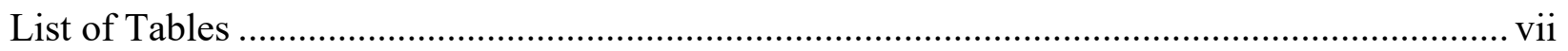

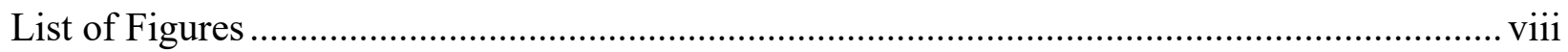

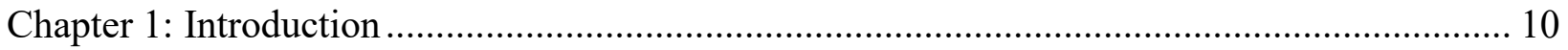

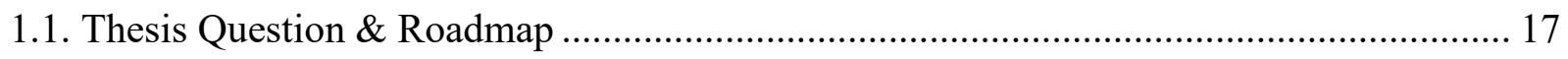

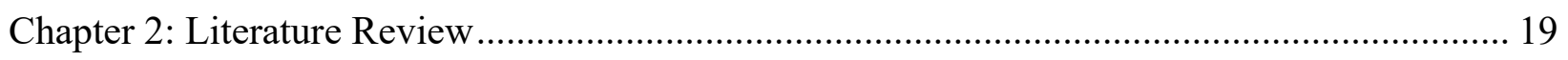

2.1. Colonial data, classification, and epistemologies ........................................................... 20

2.1.1. Colonial classification and data in Canada ………………………………………... 31

2.2. Indigeneity and Indigenous Data ecosystems .............................................................. 42

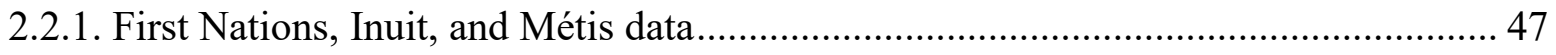

2.3. Toward the decolonization, governance $\&$ sovereignty of data ……………………......... 55

2.3.1. The Indigenous data sovereignty movement .......................................................... 59

2.3.2. First Nations, Inuit, and Métis Data Sovereignty \& Governance in Canada .............. 67

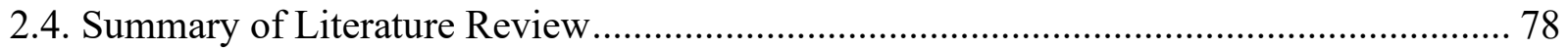

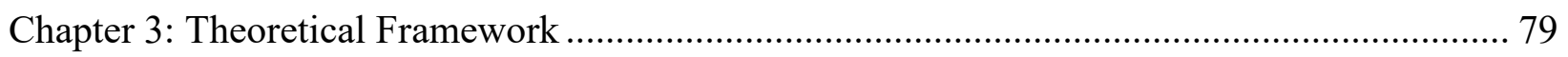

3.1. Dynamic nominalism and making up peoples in data ..................................................... 80

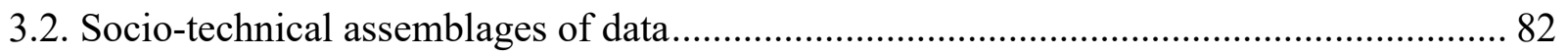

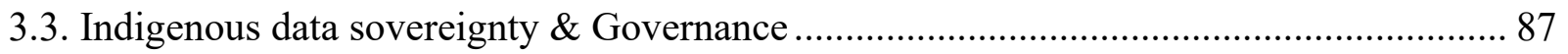

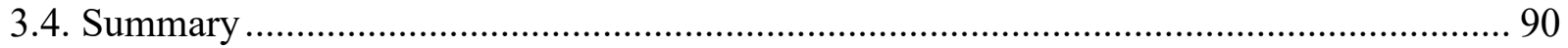




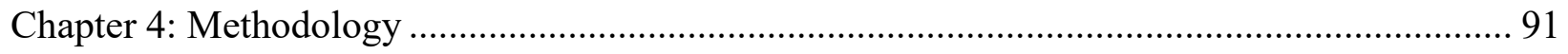

4.1. DAMA DMBOK Data Management Framework................................................................ 94

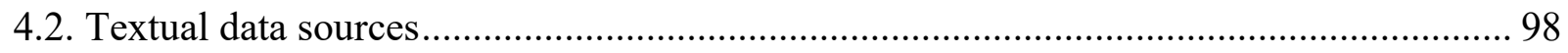

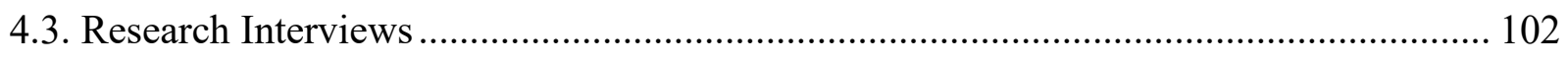

Chapter 5: Observations of Directed Content Analysis ........................................................... 104

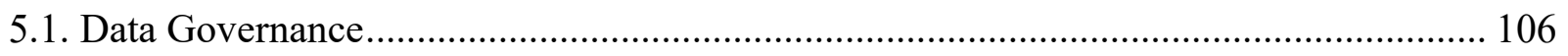

5.1.1. Data Governance Activities .................................................................................. 109

5.1.2. Data Governance Technical Drivers ...................................................................... 112

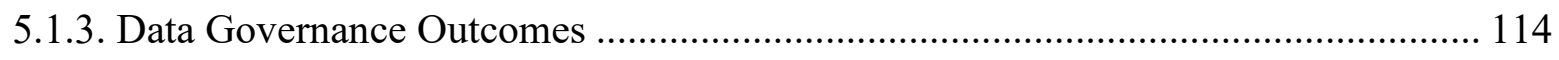

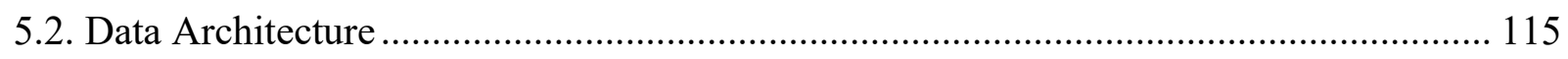

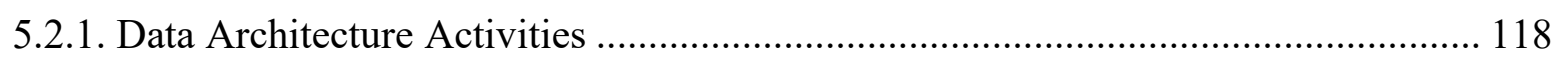

5.2.2. Data Architecture Technical Drivers ......................................................................... 121

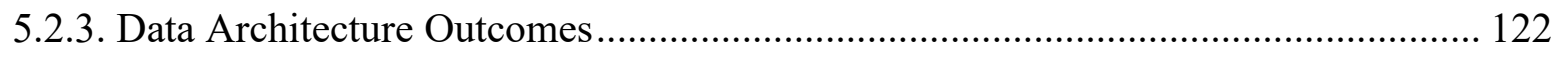

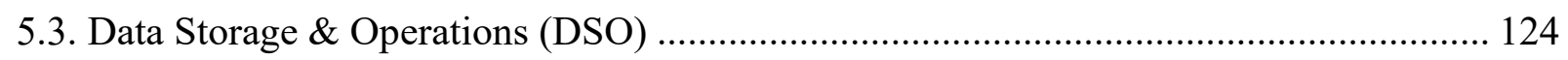

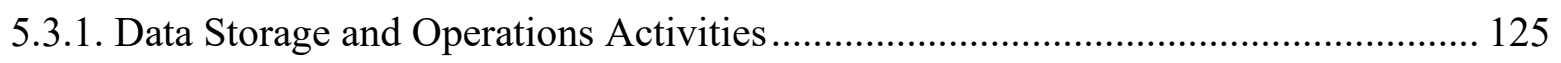

5.3.2. Data Storage and Operations Technical drivers...................................................... 128

5.3.3. Data Storage and Operations Outcomes ………................................................... 129

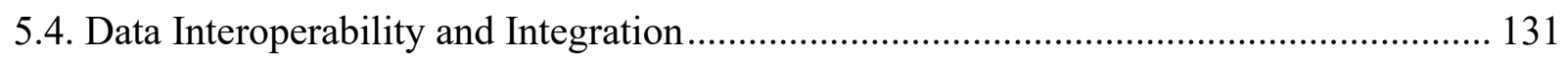

5.4.1. Data Interoperability and Integration Activities .................................................. 133

5.4.2. Data Interoperability and Integration Technical Drivers ......................................... 135

5.4.3. Data Interoperability and Integration Outcomes.................................................... 137 
5.5. Data Security. 138

5.5.1. Data Security Activities

5.5.2. Data Security Technical Drivers

5.5.3. Data Security Outcomes

5.6. Data Quality 146

5.6.1. Data Quality Activities 148

5.6.2. Data Quality Technical Drivers ...... 152

5.6.3. Data Quality Outcomes. 153

5.7. Document and Content Management...... 154

5.7.1. Document and Content Management Activities 156

5.7.2. Document and Content Management Technical Drivers 158

5.7.3. Document and Content Management Outcomes 160

5.8. Summary of Directed Content Analysis .... 162

Chapter 6: Discussion 164

6.1. Indigenous Data Governance, Resistance, and Making Up People 165

6.2. Reconstructions of Indigenous Data Assemblages 170

6.3. Decolonizing Data in Canada: Key Considerations. 172

Chapter 7: Conclusion. 177

7.1. Limitations and future work. 182

Appendices. 184

Appendix 1: Ethics Approval Documentation. 184 
Appendix 2: Research Interview Semi-Structured Question Base 186

Appendix 3: BCFNDGI Data Governance \& Accountability Model (BCFNDGI, n.d.)........ 187

Appendix 4: Statistics Canada (2018), First Nations Health and Wellness Indicators........... 188

Appendix 5: BCFNDGI Data Standard Template (BCFNDGI, 2015b) ............................... 190

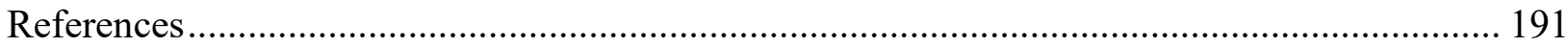

\section{List of Tables}

Table 1: Prominent Indigenous statistics challenges in Canada. ............................................... 50

Table 2: Institutional Indigenous data sources in Canada ............................................................ 53

Table 3: Citizen-led data governance and management practices and mechanisms..................... 65

Table 4: Apparatuses and elements of a data assemblage (Kitchin \& Lauriault, 2018) .............. 86

Table 5: Elements of Indigenous data governance, derived from Kukutai \& Taylor (2016) ...... 89

Table 6: High-level data governance content analyzed in the directed content analysis........... 100

Table 7: Practical applications of data governance that are analyzed in the directed content

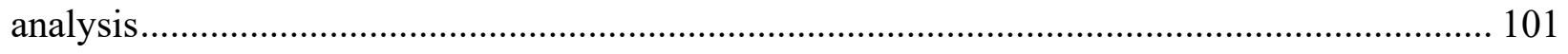

Table 8: Research interview participant biographies ............................................................. 103

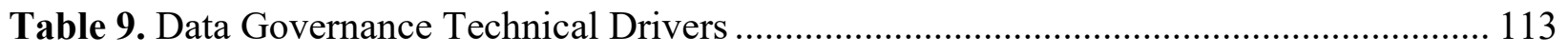

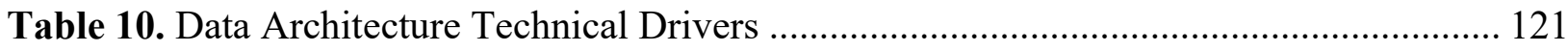

Table 11. Data Storage and Operations Technical Drivers....................................................... 129

Table 12. Data Interoperability and Integration Technical Drivers .......................................... 136

Table 13. Data Security Technical Drivers .............................................................................. 144

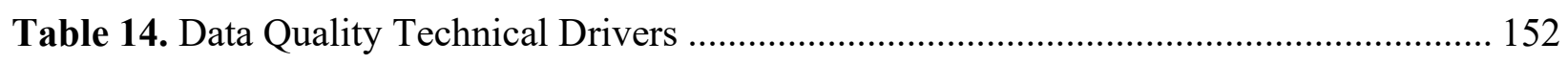

Table 15. Document and Content Management Technical Drivers .......................................... 159

Table 16. Summary Table of the Directed Content Analysis from Chapter 5 ........................... 162 
Table 17: Apparatuses and elements of data assemblages in a colonial context and in the context of Indigenous data sovereignty and governance in Canada. 171

\section{List of Figures}

Figure 1: Data governance as a reciprocal relationship that advances IDS (Carroll et al., 2019, p.4). 63

Figure 2: The "Objectively Verifiable Process" for Métis citizenship in B.C. (MNBC, n.d.a)... 76

Figure 3: Summary of the Literature Review ..... 78

Figure 4: The DAMA Wheel and Knowledge Areas of data management (DAMA, 2017, p.36).

Figure 5: Knowledge Area Context Diagram Template (DAMA, 2017, p.37). 97

Figure 6: Modified Knowledge Area Context Diagram used in the content analysis to study IDG in Canada (based on DAMA context diagram (DAMA, 2017, p.37). 98

Figure 7: The governance structure of First Nations data in B.C. that is centered on important types of First Nations data, visualized in the BCFNDGI Data Governance Framework (2015a, p.38).

Figure 8: Modified context diagram for the Data Governance Knowledge Area 115

Figure 9: Modified context diagram for governance in the Data Architecture Knowledge Area

Figure 10: Modified context diagram for Data Storage and Operations (DSO)..... 130

Figure 11: Modified context diagram for the Data Integration and Interoperability Knowledge Area. 138

Figure 12: Modified context diagram for Data Security Knowledge Area 146

Figure 13: Modified context diagram for governance in the Data Quality Knowledge Area ... 154

Figure 14: Modified context diagram for Document and Content Management 161 
Figure 15: The looping of colonial Indigenous classification in Canada's history, with a sample of interacting elements....... 166

Figure 16: A broad scope on the shifts in Indigenous classification looping in Canada, resulting from assertations of IDG and IDS 169 


\section{Chapter 1: Introduction}

In 1991, the Government of Canada mandated the Royal Commission on Aboriginal Peoples (RCAP) to investigate the relationship between First Nations, Inuit, and Métis peoples of Canada, the Crown, and citizens of Canada. The call for the RCAP was the result of centuries of colonization of Indigenous peoples, that included mistreatment, subjugation, and paternal oversight in Canada which led to unrest, resistance, and violence ${ }^{1}$. The resulting five-volume report by the RCAP published in 1996 tells the haunting history of injustice, misunderstanding, and the struggles of Canada's Indigenous peoples both historically and in the post-colonial settler society context, highlighting vast inequities across the economic, social, and political situations of Indigenous communities and peoples across Canada. It also describes what a new relationship based on mutual respect and trust with First Nations, Inuit, and Métis peoples might look like². In addressing questions of self-government and the state of Indigenous institutions and communities in Canada at the time, the RCAP reported, among many things, the lack of

\footnotetext{
${ }^{1}$ The RCAP was a direct response to the Oka Crisis, a land dispute turned violent between Mohawk peoples and the Quebec police, Canadian military, and RCMP at the Mohawk settlement of Kanesatake. The crisis lasted 78 days and was a response to the proposal to turn the disputed Mohawk territory into townhouse developments and a golf course. It was later cancelled after the resolution of the crisis (Marshall, 2020).

${ }^{2}$ See Volume 5 of the RCAP report, Renewal: A Twenty-Year Commitment: https://www.baclac.gc.ca/eng/discover/aboriginal-heritage/royal-commission-aboriginal-peoples/Pages/final-report.aspx
} 
Indigenous engagement and processes regarding data collection, management, and access to data and the fact that these data are most often externally collected and imposed, and are generally irrelevant to the needs and priorities of peoples and communities (1996a, p.498). These observations reflect the systematic role of the Canadian colonial project in the denigration of Indigenous knowledge and systems of knowledge production, which have largely been usurped by Western colonial research and statistical methodologies. Today, three decades since the original call by the Commission, First Nations, Inuit, and Métis peoples, organizations, and national representatives in Canada continue to resist colonial data systems and assert their desire for control and governance over data about them, their communities, and their lands (Rowe et al., 2021; FNIGC, 2020a; ITK, 2018).

Data are an important resource globally, and the modern data revolution toward big data analytics and data-based decision making has exacerbated this informational need (Kitchin, 2014). Understood here through a critical lens ${ }^{3}$ and at their broadest and most basic, data are "raw elements that can be abstracted from (given by) phenomena - measured and recorded in various ways" (Kitchin, 2014, p.3). Data may come in many shapes and forms, such as qualitative/quantitative, structured/unstructured, or they may be captured, derived, and may describe other data (metadata); data may also be framed technically, spatially and temporally, ethically, philosophically, or politically, and they serve as the basis of knowledge production "data precedes information, which precedes knowledge" (Kitchin, 2014). Importantly in this sense, data provide a critical foundation for knowledge about people, places, and resources that are essential in contemporary governance, and there is a strong relationship between effective

\footnotetext{
${ }^{3}$ A critical data studies (CDS) lens challenges the neutrality and objectivity of data, instead opting to critically reflect "on the nature of data and how they are employed" across the "larger institutional landscape of researchers, institutions, and corporations" (Kitchin \& Lauriault, 2018, p.5-6). The first call for CDS was made in 2014 by geographers Dalton and Thatcher who suggested looking past technical framings of data and instead to look at how data becomes wrapped up in problems of locality and identity (Iliadis \& Russo, 2016 provides a succinct overview of the field).
} 
governance and achieving developmental outcomes and increasing socio-economic well-being

(FNIGC, 2020a). Data are important in all dimensions of governance, serving as a tool to evaluate priorities, set standards, and maintain accountability (Smith, 2016, p.124). It is also understood that better, higher-quality data that are timely, relevant, and complete enable better governance by allowing Indigenous leadership to make informed decisions that meet the needs of their communities within a greater governance landscape that must balance federal/provincial/territorial obligations as well as local priorities (FNIGC, 2020a). Beyond practical power, data also contain inherent ontological power in the ways they identify, sort, and classify people and things - often, how people and things are represented in data forms an imaginary where this representation becomes taken as reality by those represented (Beer, 2019; Anderson, 1983, Hacking, 1986).

In this thesis I am not concerned with one type of data but rather a wide range of data that might describe and represent Indigenous peoples: these may be data that are collected by Western states like Canada, such as by way of national survey and census instruments; research data about peoples and their communities; or data collected by the peoples that they describe, which may be derived from many sources such as community-level indicators or local and traditional knowledge (TK) sources ${ }^{4}$. Data are framed in this thesis philosophically - whereby data are not considered to be neutral, benign objects with no inherent meaning, but rather that data "do not pre-exist their generation" and are "epistemological units" that are designed, measured, and interpreted within a specific set of values and worldviews (Kitchin, 2014, p.18). Within such a framing, First Nations, Inuit, and Métis peoples have long recognized power

\footnotetext{
4 Traditional knowledge (TK) refers to cumulative bodies of knowledge that are culturally transmitted across generations and which are defined by the relationships of peoples with the environment. These are not static catalogues and may consist of oral collections (stories, songs, folklore, etc.), cultural values and beliefs, local laws, and languages, as well statistics and maps (Montenegro, 2019; Scassa et al., 2014).
} 
imbalances in the production and construction of data about their peoples, communities, and lands, as well as the embedded political and cultural epistemologies of the colonial state which constitute most Indigenous data and their governance in Canada today (Andersen, 2016; FNIGC, 2019; Rowe et al., 2021).

Indeed, the power of data in constructing knowledge for policy, governance, and nation building is a main driver of the colonial state's obsession with enumerating, classifying, and administering the Indigenous peoples of colonized lands into informational mechanisms of the state. Control over Indigenous peoples in Western colonial states was most often expressed not only though force, the dispossession of land, and violence, but also through the domination of information and sources of knowledge. Information mechanisms of the colonial project served to identify, classify, and group Indigenous peoples in ways that served the needs and priorities of the state, while systematically replacing and denigrating Indigenous approaches to information and knowledge which were deemed as 'inferior' and irrational (Kavita, 2015). Recent academic literature has characterized and framed the link between information, colonialism, and power conceptually as data colonialism ${ }^{5}$, unfortunately the way this concept has been defined by Western communication and media studies scholars only investigates capitalistic, corporate data extraction processes through smart devices/data brokers and notably omits the continuities of colonial data practices as lived and experienced by First Nations, Inuit, and Métis peoples and the colonial logics that continue to persist in settler society Indigenous data arrangements. For this thesis, I explore the conception of data colonialism that instead recognizes and engages with the histories of colonial data practices which underpin Indigenous data in settler nations, understood here as: a colonial model of dispossession and dominance that operates through the

\footnotetext{
5 The concept of "data colonialism" in a context of corporate data extraction and accumulation was first posed by Thatcher, Mahmoudi and O’Sullivan (2016) and has later expanded upon by Couldry \& Mejias (2019).
} 
control of information and data that is about or is created by Indigenous peoples. This model emphasizes the close relationship between data and the historical administration of the colonial enterprise, which have defined modern Indigenous data practices in post-colonial nation states like Canada.

Today, legacies of data colonialism persist, and data institutions remain as structures of power, while the control of Indigenous data ${ }^{6}$ is a point of controversy regarding data ownership, sovereignty, and governance for First Nations, Inuit, and Métis peoples (RCAP, 1996a; FNIGC, 2020a; Rowe et al., 2021). Canada, since 1996 and the release of the RCAP report, has been committed to an agenda of Reconciliation in recognition of the destructive and assimilative Indigenous policies that were conducted by the state throughout the colonial project. The Truth and Reconciliation Commission (TRC), established by the Federal government in 2008 to investigate the devastating impacts of the residential school system ${ }^{7}$, define reconciliation as "a process of healing of relationships that requires public truth sharing, apology, and commemoration that acknowledge and redress past harms" (TRC, 2015a, p.3). In this era of reconciliation, Indigenous leadership in Canada continues to call back to the recommendations of these Commissions in their pursuit to repatriate their data, identities, and peoples - while significant efforts have been made as I will discuss in this thesis, the decolonization of Indigenous data is complex, and operates on multiple levels, and it is ongoing (FNIGC, 2020a; ITK, 2018).

\footnotetext{
${ }^{6}$ The varied nature of Indigenous data in settler nations makes it difficult or near impossible to capture a single definition of these types of data. In Chapter 2.2., I explore conceptions of Indigenous data as well as the forms of First Nations, Inuit, and Métis data that are collected, managed, and used in Canada.

${ }^{7}$ Part of the Canadian Indigenous policy of assimilation, residential schools were boarding institutions that incarcerated Indigenous children who were forcefully removed from their homes and families. The purpose of these schools was to eradicate Indigenous cultures and traditions and replace them with Western religion, languages, and worldviews (TRC, 2015b). I discuss residential schools further in chapter 2.1.1.
} 
Approaches to the decolonization of Indigenous data also currently sit at a critical juncture of cutting-edge technologies, advancing international Indigenous rights, and current intellectual and epistemological movements for Indigenous-led data sovereignty and data governance ${ }^{8}$. Within international discourse and literature, Indigenous-led data governance approaches in Canada have been utilized as a prominent example (Kukutai \& Taylor, 2016; Gupta et al., 2020); however, there has been little scholarship on the structures of colonial power in Canadian Indigenous data practices and how to decolonize these realities ${ }^{9}$, which is a gap this thesis hopes to address. It is critical in the movement toward reconciliation and decolonization in data that there begins to be a recognition and full understanding of how processes of data colonialism have and continue to operate in Canada - as the TRC asserts,

Reconciliation requires constructive action on addressing the ongoing legacies of colonialism that have had destructive impacts on Aboriginal peoples' education, cultures and languages, health, child welfare, the administration of justice, and economic opportunities and prosperity (TRC, 2015a, p.3).

\section{On terminology}

In this thesis I use several terms to describe different groups and arrangements of peoples in a broad, general lens as well as a specific, national focus in Canada. As I explore the histories, logics, and processes of identification and classification at the core of data colonialism in Canada, I distinguish these terminologies to ensure clarity in the framing of peoples

\footnotetext{
${ }^{8}$ Data sovereignty and data governance are understood by data professionals as conceptions related to the jurisdiction and oversight over data and their collection, use and management (DAMA, 2017); Indigenous data sovereignty on the other hand is an assertation of control and authority over any and all information by, for, and about Indigenous peoples, and this is operationalized through Indigenous-led data governance. I discuss this movement in Chapter 2.3.1.

${ }^{9}$ The FNIGC has published multiple academic articles that address First Nations data governance and sovereignty (see: FNIGC, 2016; FNIGC, 2019), however there is little Canadian scholarship that directly analyses these developments within a larger scope of data colonialism and IDS/IDG movements more broadly. One notable and recent development is a book chapter in Walter, Carroll, Kukutai \& Rodriguez-Lonebear, 2021 that begins to situate First Nations, Inuit, and Métis data sovereignty within the larger international IDS/IDG movement.
} 
throughout, as listed below and more so in chapter 2 where I explore issues of identity, data, and policy related to these definitions.

- Indigenous peoples is a classification and a concept used in a general and broad sense to encompass the common colonial experiences and situation of many communities, nations, and peoples and to discuss international movements that see Indigenous communities and peoples coming together to strive for common political, social, and cultural goals. I mostly use Indigenous peoples to describes the three sovereign political and cultural groupings recognized in the Canadian Constitution: First Nations, Inuit, and Métis peoples of Canada. I use this terminology when I am discussing general experiences, situations, and issues that are dependent on their political and social circumstances in relation to the colonial settler state.

- When discussing First Nations, Métis, or Inuit peoples in their own capacity as distinct political and social groups of people, I generally use the qualifiers peoples and communities. When talking about a specific community or groups of people that fall within one of these broader identities, I utilize their self-determined community name and identity (e.g., Mohawk, Ktunaxa, Cree, etc.). There are also political and social organizations in Canada and many communities that collectively share a sense of identity as a Nation, either through treaty agreements with the Federal Government or through self-determination and self-identification (for example, the Métis Nation) and they are identified as such.

- As I am discussing the political and social construction of classification in colonial information systems, I also make use of colonial identifiers that were historically used or continue to be used today. For instance, I refer to the terms Aboriginal (First Nations, Inuit, and Métis), Indian (First Nations) and Eskimo (Inuit) in my discussion of colonial classification and Indigenous governance in Canada; these terms however only emerge within their own context, and they are not considered synonyms to Indigenous, but rather are colonial pre-cursors to commonly accepted nomenclature. 


\subsection{Thesis Question \& Roadmap}

This thesis examines how data become colonial objects to identify and how they have been used to govern peoples in Canada, what it means to decolonize people, and how these processes emerge in the current socio-political landscape in Canada related to the advancement of First Nations, Inuit, and Métis data rights, sovereignty, and governance. As such, this thesis explores the following research question: How does data colonialism operate in Canada, and can these practices be decolonized through Indigenous data governance? I utilize a stepwise methodological approach to answer these research questions. Chapter two provides a literature review of a wide range of interdisciplinary scholarship, grey and governmental literature, organized into three primary topics:

1. The positivist foundations of data colonialism which seeks to enumerate, identify, and classify Indigenous peoples in place of their own traditional and local systems of knowledge, including how colonial classification has evolved in the Canadian public policy and legal context;

2. Conceptualizing 'Indigenous data' and the state of First Nations, Inuit, and Métis data in Canadian public and private institutions; and

3. Understanding decolonization in the context of data, knowledge, and international movements for Indigenous data sovereignty based on the United Nations Declaration on the Rights of Indigenous Peoples (UNDRIP), and how this movement emerges in a First Nations, Inuit, and Métis context.

Chapter three describes the theoretical framework of this thesis which conceptualizes the colonial construction and classification of Indigenous peoples, how data that classify become socio-technically constructed within colonialism, and what it means to resist colonial data and incite epistemological paradigm shifts through practices of data governance. This framework informs and guides the understanding of data decolonization in the analysis and is based upon three main theoretical developments: 
1. Ian Hacking's (1986) theory of dynamic nominalism and the 'making of people' through classification;

2. Assemblage theory as applied to the socio-technical constitution of data, based on work of Deleuze and Guattari (1987) and later by Rob Kitchin (2014).

3. Conceptions of Indigenous data sovereignty (IDS) and Indigenous data governance $(I D G)$ building from international workshops and discourse, and introduced in a seminal collection of essays edited by Kukutai and Taylor (2016).

Chapter four explains the conduct of the directed content analysis as the methodological approach I applied to study the decolonization of data through First Nations, Inuit, and Métis data governance approaches and practices in Canada. There I describe the DAMA DMBOK ${ }^{10}$ (2017) which I use to inform technical and institutional data governance from a Western professional association and industry standard perspective, as well as the main sources of First Nations, Inuit, and Métis data governance materials that are analyzed; both high-level strategic approaches and practical applications of data governance. I also conducted research interviews to enhance my perspective and understanding of data governance issues in Canada. Chapter five includes the observations of the directed content analysis, organized according to the DAMAdefined 'Knowledge Areas' of data governance and integrated with Indigenous-defined approaches to data governance. I discuss these findings within the context of classification, assemblages, and sovereignty in Chapter 6. In the conclusion in Chapter 7 I provide an overview of this research conducted for the thesis, discuss limitations of the methodology and framework, and consider what First Nations, Inuit, and Métis peoples across Canada might need in the future to continue to assert sovereignty over data and practices.

\footnotetext{
${ }^{10}$ Created by Data Management Association International (DAMA), the DMBOK (Data Management Body of Knowledge Version 2) is a comprehensive framework for data management professionals that assists organizations in gaining value from the data assets they collect, manage, and use. The DMBOK was developed over thirty years through DAMA's community of member experts and practitioners (DAMA, 2021).
} 


\section{Chapter 2: Literature Review}

This literature review surveys a broad range of scholarly and grey literature concerning Indigenous data and colonialism generally as well as in the First Nations, Inuit, and Métis context in Canada. It investigates key concepts across the literature selected for this thesis, including data colonialism, Indigenous data, and decolonization, while also situating and foregrounding the theoretical framework, methodology, and analysis/discussion on Indigenous data governance. This will answer the first part of the thesis question, how does data colonialism operate in Canada, and it will setup the necessary contexts to investigate how these practices may be decolonized through Indigenous data governance, both conceptually and in practice.

The works examined exemplify an international perspective about data, colonialism, and governance in addition to Canadian governmental and NGO literature related to the administration of First Nations, Inuit, and Métis peoples and data. International perspectives are primarily taken from the CANZUS (Canada, Australia, New Zealand, and the United States) countries as these nation states share common histories of settler colonialism and common realities of marginalization for Indigenous peoples and communities even though the US is not based on a Westminster form of Governance which is the case for Canada, Australia, and New 
Zealand (Carroll, Lonebear-Rodriguez \& Martinez, 2020). It is recognized that there are Indigenous data issues in other post-colonial arrangements as well, such as in the Global South (Segura \& Waisbord, 2019); however, the focus of this research is on prominent Western states in the Global North where Indigenous peoples continue to be subject to colonial institutions and logics of governance when it comes to the control and production of information about them (Duarte \& Belarde-Lewis, 2015). This review also adopts a multi-disciplinary approach. Included is academic literature from fields such as critical data studies, Indigenous studies, colonial studies, and social science, and grey literature including international reports and documents, Canadian governmental, NGO, and civil society reports, federal/provincial data strategies, policies concerning Indigenous peoples, and local and traditional knowledge sources. Indigenous data issues fall within several domains and levels of government, and so this approach is necessary to produce a high-level understanding of data colonialism, decolonization, and Indigenous data governance internationally and in Canada.

The review is organized as follows: first, I discuss the conceptual foundations of data colonialism that are based upon positivist logics of classification, truth and research, and I discuss the history of Indigenous classifications and colonial data practices in the context of First Nations, Inuit, and Métis governance in Canada; second, I explore conceptualizations of Indigeneity and of Indigenous data, including an overview of First Nations, Inuit, and Métis data sources in Canada; third and final, conceptions of decolonization regarding knowledge, information, and data are discussed and situated within the movement for Indigenous data sovereignty and Indigenous data governance occurring globally and in Canada.

\subsection{Colonial data, classification, and epistemologies}

The current states of Indigenous data are not distinctive of contemporary social and technical data arrangements; however, they are because they are theoretically and practically 
linked to histories and legacies of colonialism. The colonial project enacted by major Western powers was fuelled by an expansionist ideology of conquering, exploiting, and profiting from 'unclaimed' territories and resources that were in fact inhabited and occupied for thousands of years by many distinct Indigenous communities and peoples (Reinhard, 2015). To expand, historical colonialists operated through socioeconomic policy "in which one social group continually and habitually profits by exploiting the living environments, bodies, social organization, and spiritualities of another social group" (Duarte \& Belarde-Lewis, 2015, p.681). Indigenous social scientists Duarte and Belarde-Lewis (2015) note that the extent of Indigenous exploitation inherent to the policy of colonialism is not occasional but is "marked by generations of subjugation" that involves the establishment of "social structures and institutions around [colonists] to support the belief in their superiority as well as their means of exploitative and violent profit-making" (p.681). The recent experiences of generations of Indigenous peoples subjected to colonial systems has been connected to the wide range of socio-economic issues that many Indigenous peoples in settler countries around the world face today (Richardson \& Crawford, 2020; Carroll et al., 2019). Alongside colonial institutions of power, Western imperial science has served as a hand maiden of the colonial project to demarcate and classify Indigenous peoples through processes of data colonialism.

The evolution of colonial information practices and the situation of colonial logics in institutions are intrinsically tied to knowledge, information, and data. Data are, as Pool (2016) muses, "colonialism's almost universal fellow traveller" (p.66). In establishing the control of territories, resources, and peoples, the colonial enterprise also required data and the control of information and knowledge for governance which consequently "rendered many colonized peoples open to invasive and destructive regulatory and research practices" (Anderson, 2015, p.771), resulting in peoples being labelled and sorted in ways that they were not even aware of 
(Anderson, 1983). Empire building was practically set in stages through settlement and the displacement of Indigenous communities, a process that was accomplished through data collection and administrative techniques (Pool, 2016). Further, expansionist ideals were systematically entrenched through the suppression of Indigenous histories and knowledge systems (Duarte \& Belarde-Lewis, 2015). Central to the colonial modus operandi is the "systematic denigration of intellectual infrastructures" and the endorsement and expansion of "imperialist notions of technical, governmental, administrative and moral superiority", resulting in histories, methods, and information being centered on "Euro-American expansion" (Pool, 2016, p.62). Colonial knowledge institutions, policies and laws have worked to disrupt and override Indigenous data practices, traditional roles and responsibilities, and Indigenous authority over knowledge production and governance while also being inserted into the "daily fabric of indigenous peoples' lives" for purposes defined by colonizers (Smith, 2016, p.121).

The information activities of Western states and data colonialism are structured around a particular notion of 'truth' and 'knowledge' based within a positivist epistemology ${ }^{11}$ driven by classificatory logics, measurable 'facts', and natural sciences (Saetnan, Lomell, \& Hammer, 2010; Shapin, 2001). At its most basic, classification is the "assignment of objects to classes" objects might show some form of characteristic or property or relation to other objects, to which they are labelled or classified within a greater system of definitions, understandings, and worldviews (Feger, 2015, p.805). Classification however relies on an assumption that the object being classified is part of the class that the classifier envisions, which is inherently difficult and otherwise impossible when the 'objects' are Nations and communities of socially, culturally, and

\footnotetext{
${ }^{11}$ Positivism is a sociological approach which champions the scientific and empirical study of the social world proponents of positivism believe there is an objective reality that can be measured, analyzed, and evaluated through empirical means and methodologies. In this model, it is accepted that social phenomenon and peoples can be attributed and characterized in universal and neutral ways that are 'true' to their nature (Outhwaite, 2015).
} 
politically distinct peoples who already have an understanding of their own selves and identities, and especially when dominant, hegemonic colonial classifications and identifiers are counter or adverse to the social systems and conceptions of identity that communities already practice (Feger, 2015; Pool, 2016).

The unique systems of identity, knowledge, governance, and political organization at the foundation of Indigenous communities only served as a logistical and idealistic barrier to the classificatory drive of state research and population enumeration, and so colonizers sought to perpetuate and solidify dominant and hegemonic categories of peoples and citizens in social hierarchies by having these replace the traditional and local ways in which Indigenous peoples identify and classify themselves. Colonial identifiers designated by the settler state historically served (and continue to) as "terms of conflation designed for governmental racial and class management" which identify "population in aggregate, regardless of the social, political, and philosophical distinctions" of different groups of peoples (Duarte \& Belarde-Lewis, 2015, p.6801). In simple terms, "[f]orms of government, concepts of citizenship, and statistical practices closely interact" and this has serious implications for Indigenous sovereignty when all three are out of the control of the peoples being counted (Saetnan, Lomell, \& Hammer, 2010, p.1-3). Keeping in mind that the counting was not for liberatory purposes, but was conducted to formalize the administration, read exploitation, of those being governed and relegated to the bottom of the social and political structures of the emerging nation states - counting was about putting them in their place, and governing them accordingly.

Braun et al. (2013) refer to Eurocentric perspectives and colonial epistemological activities as the positivist research paradigm, whereby the "researcher is cast as expert, distant, and value free" and there is only "a single truth to be discovered" making 'scientific' knowledge "far more valuable than subjective of experiential knowledge" (p.118). Such a perspective is 
based within the confines of natural sciences that mark this understanding of truth as contextfree, rational, and universal, consequently situating Indigenous approaches to truth and knowledge as irrational, contextual, and cultural. The positivist research paradigm thereby upholds asymmetric power in information by situating other systems of knowledge as oppositional, which has been shown to reinforce cultural prejudice and biases against forms of knowledge that do not fit within the paradigm, effectively marginalizing these systems as a result (Anderson, 2015; Kavita, 2015). The harms of this paradigm are not always apparent, and the imposition of this paradigm is not always deliberate, however researchers in the West may not be aware of the critical effects due to having been trained within the paradigm themselves, and "[t]hus we likely embrace it until challenged otherwise" (Braun, 2013, p.119). Some scholars ${ }^{12}$ have challenged this paradigm and suggest that engagements with empirical thinking in the production of knowledge are necessary to and give recognition that those dominant approaches are only some of many legitimate ways to gather observations, analyze findings, and establish 'truths' (Shapin, 2001).

Through cataloguing and classifying or what has been commonly referred to as the 'power to name', colonial powers sought a "way of organizing, of itemizing, of making information and knowledge accessible" that represents Western empiricist logics and obscures Indigenous methodologies and knowledge (Duarte \& Belarde-Lewis, 2015). This process is not a by-product of colonialism but is built and designed into the overlapping mechanisms of Indigenous colonization as highlighted by Duarte \& Belarde Lewis (2015):

\footnotetext{
12 This school of thought has been dubbed as the sociology of scientific knowledge (SSK), which emerged only around the 1970's in social sciences circles to critically assess the "textbook idealizations of natural scientific knowledge and how it is produced" and to better understand what it means for research to have "scientific credibility", which underpins Western societal institutions and the legitimacy they maintain and transmit (Shapin, 2001, pp.673, 677).
} 
Broadly, colonization - the verb, or enactment, of colonialism-is based on four overlapping mechanisms: (1) the classification of diverse Indigenous peoples as a single lesser class of sub-humans deserving of social subjugation at best and extermination at worst; (2) the theft and settlement of Indigenous lands and social spaces by an elite Settler class; (3) the articulation of institutions to support this class system and the elite control of the environment; and (4) the disciplining of elite forms of knowledge through the marginalization of Indigenous languages, philosophies, spiritualities, and modes of self-government (Duarte \& Belarde-Lewis, 2015, p.682).

Using empirical data techniques and classificatory logics, the colonial state harnessed data to govern Indigenous communities. Classification occurred at the macro-level involving race and identity, and typically at the meso/micro (community/family) level which underpinned "social engineering" and colonial interference in Indigenous social order and labour economies (Pool, 2016, p.69). Such power dynamics in settler societies resulted in the privileging of "only some accounts while silencing the perspectives of marginalized communities through the establishment of "normalized" and universal fields of description" (Montenegro, 2019, p.734). Most of the time, these universal indicators and descriptors presuppose poor conditions, risk, and a lack of 'development' in Indigenous communities as defined by Western standards, and consequently universal Indigenous fields of description overemphasize deficit narratives of negative issues, vulnerabilities, and risk in Indigenous communities instead of positive indicators of wellness, growth, and progress (Phillips, 2017; Cormack et al., 2019; Walker et al., 2018).

The establishment of colonial settler society in territories occupied by communities and peoples with distinct cultures and knowledge systems posed an idealistic barrier to the nationalistic and expansionist direction of the colonial enterprise. Consequently, Western state interests with Indigenous peoples have been and remain to be political and are formalized into action in public policy arrangements, "the core business of the state" (Walter \& Carroll, 2021, p.8). These 'interlocking' infrastructures "simultaneously emphasize and disguise Indigenous difference, as required"; importantly in this context, "[h]ow the state "sees" its Indigenous 
population/s... serves and shapes the policy infrastructure with Indigenous data, the lens by which Indigenous Peoples are made visible" (Walter \& Carroll, 2021, p.9). It is through this "Indigenous data/policy nexus" that Walter and Carroll (2021) note the perpetuation of national narratives of Indigenous identification, and while they recognize that this arrangement may not be deliberate and is "genuine as it is mistaken", it is still embedded with colonial classificatory logics that place superiority in Western methodologies and that views them as a means to ““'advance” Indigenous peoples” or to “"help” the sad plight of the Indigene” (p.9).

Academic studies have long connected information practices to the policies and administration of the colonial state, however the accounting for people and places as a significant element of the historical record of colonialism was perhaps most succinctly discussed by Benedict Anderson in Imagined Communities (1983). Anderson (1983) points to three major and distinct data instruments of the colonial administrative order, the map, census, and museum, which establish an "imagination" and national narrative of the Indigenous peoples and territories that the Crown assumed governance over through colonization ${ }^{13}$ :

- The census is a political and administrative system, and it commands power in the ability to name, categorize, and define peoples; the resulting statistics form the "language of the state", and this language is often at odds with Indigenous understandings of identity and peoples (Anderson, 1983; Andersen, 2016, p.79). These data artifacts are never neutral but are constructed within dominant hegemonic discourses, norms, and values (Walter, 2016). Visibility in the census has many implications for Indigenous communities: being

\footnotetext{
${ }^{13}$ Given the wide scope of data and governance that this thesis explores, I do not take a deep dive into these colonial data instruments of the state. I do however elicit broader issues of settler colonialism and data, classification, and governance through reference to these instruments, especially the census and in relation to governance over the data these produce. There are some very comprehensive analyses which perform a deep look into the connection between these tools and the Canadian state: Lauriault (2012) looks at how census and geospatial data 'imagine' Canadian and Indigenous peoples and places, building from Anderson (1983) and Hacking (1986); Sparke (1998) unpacks the map and Atlas in Canada and their ways of narrating the nation, and Huggan (2008) looks to deconstructing the coloniality of mapping in Canada; McCracken (2019) provides an extensive analysis of colonial archival research practices and institutions, and Gupta et al. (2020) investigate data ownership in Canada in the context of archaeological databases and museums.
} 
visible means being identified under the classificatory and deficit ${ }^{14}$ mechanisms of the state, however it also means visibility in the distribution of resources and rights by the state; not being visible to colonial structures may afford a sense of sovereignty, however this approach has also been equipped by the state to obscure cultural differences and assimilate peoples in the national identity of the state. Even where they are visible, misinformed colonial classifications can obscure self-identification and often do not accurately represent Indigenous peoples and communities (Andersen, 2016; Peters, 2011; Bishop, 2016; Walter, 2016). The colonial basis of identification narrated by the census was "imagined by the (confusedly) classifying mind of the colonial state", subject to desires of completeness by census-makers who were intolerant of "politically 'transvestite', blurred, or changing identifications" (Anderson, 1983, p.165-6). The realities derived from these data operate under a guise of mathematical formulation, however these methodologies are developed under "the social, racial and cultural standpoint of their creators who make assumptive determinations to collect some data and not others, to interrogate some objects over others, and to investigate some variable relationships over others" (Walter \& Suina, 2019, p.136).

- Western conceptions of the map and the cartographic practices which develop them are another process of imagination of the nation state to enclose, capture, and reinforce their worldview of a space, and usually within a form that serves to benefit their governance and reinforce power in the production of knowledge (Huggan, 2008; Sparke, 1998). The division of space and the drawing of invisible boundaries and lines are decided upon to serve the makers of the maps, and these divisions in colonized territories meant lines drawn across the territories and homelands of Indigenous peoples and demarcated reserve spaces for these communities (Harley, 1989). The nature of cartography in the colonial state was largely driven by positivist logics of truth at the core of data colonialism, with the state accepting constructed maps as "mirrors of nature" and showcases of empirical precision and progress, while misrecognizing other cartographic forms constructed through competing epistemologies as inferior or incorrect (Harley, 1989).

\footnotetext{
${ }^{14}$ The administration of Indigenous peoples into the colonial state, the denigration of cultural practices and traditions, and colonial intervention into the lives of communities and peoples caused many socio-economic and health issues in Indigenous communities; consequently, the state would justify intervention in Indigenous lives by collecting data and reporting via a deficit model of indicators, which have an overemphasis on risk, problems, and vulnerability in Indigenous communities (Cormack et al., 2019; Phillips, 2017; Walker et al., 2017; Walker et al., 2018).
} 
- Anderson (1983) highlights the museum as a tool for legitimizing 'guardianship' over local and traditional cultures by curating artifacts that are important local and traditional knowledge and cultural sources; here however I opt to look to another system which achieves a similar function and operates as an institution of knowledge keeping and protection in the context of colonial governance, the archive. The documentation and collection of knowledge and data about colonial activities with Indigenous peoples in colonial archival repositories has historically operated as a mechanism of communicating a national identity and memory, and such functions have continued to perpetuate hegemonic and hierarchical Indigenous-settler relations thereby marking the institution of national archives as "crucial sites for the exercise of political power" (Yale, 2015, p.341). Archives are "never neutral but, rather, exist to reinforce existing colonial hierarchies as inevitable and natural by classifying some individuals (settlers) as observers and others as observed (Indigenous peoples)" (McCracken, 2019, p.186). They contain masses of reports, documents, and files about Indigenous peoples and often without their consent, and while they operate to try to protect and maintain historical documents, concerns have been expressed from an Indigenous perspective about misappropriation, misuse, and privacy concerning information access laws (McCracken, 2019; FNIGC, 2020a; Montenegro, 2019). National archives in settler nations are "upholders of colonial recordkeeping systems" and the ways that colonial histories are preserved and represented as sources of knowledge have "direct implications on social policies, public opinion, and Indigenous lives (McCracken, 2019, p.198).

Anderson states that these colonial instruments and the forms of knowledge they produce were fundamental to trace the "imaginings of the colonial state", an ambition which became materialized in the "grammar" of the institutions which administered national objectives over Indigenous peoples (1983, p.163-4). The information tools and institutions utilized by the colonial enterprise to express a sense of legitimacy over settled lands however also did not occur in a knowledge vacuum. As Pool (2016) observes, "Imperialists did not enter data deserts, but the existing systems they encountered did not fit their world view" that is marked by universal 
standard methodologies, empirical indicators, and measurements, and "a passion for 'moral statistics"” (p.68).

Colonization has imposed many structures and systems on Indigenous communities, and perhaps one of the least "explored area[s] is the role of data as a tool to marginalize Indigenous peoples, eradicate their ways of life, and rewrite their histories to advance the colonial project" (Carroll et al., 2019, p.3). This has led to a state of epistemicide or "the killing and co-optation of knowledge systems" through systematic marginalizing, silencing, and destruction of Indigenous knowledge in settler nations (p.3). Prefixes of 'local', 'indigenous' or 'ethno-' were often adopted as an identifier and attached to knowledge or science when discussing Indigenous approaches, and "served to mark the embeddedness and context dependence of indigenous truths, in implicit contrast to the context-free, singular truth of science" (Kavita, 2015, p.779). In terms of epistemology, oppositional binaries of 'us' versus 'them' in colonial knowledge production practices and discourse worked to obscure that all knowledge "is specific to its particular cultural context” (Kavita, 2015, p.779; Anderson, 2015; Shapin, 2001).

Notions that natural sciences produce 'universal truth' and that "the proper goals of scientific inquiry as the production of such truth" have also historically positioned Indigenous peoples as a research subject of the colonial gaze (Shapin, 2001, p.674). These logics have been the basis of a wide range of dehumanization, abuse, and exploitation of Indigenous peoples as research subjects. For instance, American doctor and "father of physical anthropology" Samuel Morton collected the skills of Indigenous peoples "to establish inferiority of the "savage" via empirical support", the findings of which were embraced by the U.S. to "justify ongoing genocide" (Marley, 2019, p.723). Communities of Indigenous peoples were also commonly exploited by colonial researchers as test subjects for the study of the body, such as in Canada where it came to attention in the TRC study on residential schools that Indigenous children were 
used for nutritional studies and to test new medicines before public use (CBC News, 2013).

These are only a couple of countless atrocities committed in the name of empirical science and research. Unsurprisingly, the horrible experiences and histories of subjugation imposed on Indigenous peoples in research is a significant factor in the continued and justified mistrust of Western research institutions by Indigenous communities.

In recognition of historical abuses in the search of empirical knowledge, contemporary research practices have worked to included research ethics boards and ethics application processes to hold potentially unethical research accountable, such as Chapter 9 of the TriCouncil Policy Statement (TCPS 2) in Canada which outlines ethics protocols for any research involving Indigenous peoples or their information (CIHR, NSERC, \& SSHRC, 2019). Despite such protocols giving "some reassurance that research relationships today are ethical and mutually beneficial", Di Leo Browne (in the context of Inuit research in the North) suggests that research participants may continue to see “today's academics yet another group of outsiders coming in to make things "better" according to Western standards" $(2012, \mathrm{p} .10)$.

The operation of data colonialism is founded on structures of power in colonial administration that work to impose and prioritize positivist methodologies, colonial classification, and the governance objectives of the empire over Indigenous systems of knowledge and data practices, enumerating and simplifying Indigenous worldviews and wellbeing into "quantitative datasets and indicators that [reflect] colonial preoccupations and values" (Smith, 2016, p.120). This perspective of data colonialism departs from recent definitions (Thatcher et al., 2016; Couldry \& Mejias, 2019) that centre more so on data capitalism $^{15}$ and rather looks to theoretical engagements which centre on power, knowledge, and

\footnotetext{
15 This is not to say however that capitalism is not intrinsically linked to colonial practices and their embedded empirical logics, as the continuities of colonial expansionist logics in the rise of capitalism and imperialism in the 1800 's is well documented by Harvey (2003) and many others. It is suggested here that data are not a binding link
} 
the institutions and logics of the nation state in relation to Indigenous peoples. Ultimately, understanding colonialism and information through this lens is required to understand and address emerging issues of Indigenous data governance, sovereignty, and the decolonization of knowledge, as explained by Indigenous information researchers Duarte and Belarde-Lewis (2015):

When we are cognizant of the ways colonialism works through techniques of naming, describing, collocating, classifying, and standardizing, we can better appreciate, formulate, imagine, and support Indigenous approaches to knowledge organization. However, before we can create spaces for Indigenous ontologies - that is, alternative information structures guided by Indigenous concepts of realities - we have to understand when and how cataloging and classification practices become techniques of colonization. (p.682).

\subsubsection{Colonial classification and data in Canada}

Canada is home to three distinct groups of Indigenous peoples ${ }^{16}$ that are officially recognized by the state under section 35 of the Canadian Constitution Act 1982, which includes "Indian [First Nations], Inuit and Métis peoples of Canada" (35(2)). This distinction of Indigenous peoples in Canada was only formalized in 1982 however, and Canada's colonial history of governance and classification with Indigenous communities, peoples and nations is much longer and more complex. The British claiming of North American territory in Royal Proclamation of 1763 first set the original foundation of the relationship between the colonial Canadian state and Indigenous peoples, specifically First Nations (identified with the misnomer "Indian" ${ }^{17}$ ). The Proclamation recognized First Nations land and title rights, as well as self-

\footnotetext{
between capitalist and colonial logics but rather have come to be colonial objects in of themselves and their role in the administering of both the nation state and Indigenous peoples, whom can not be excluded from this discussion.

${ }^{16}$ Indigenous is currently the accepted nomenclature to describe Canada's three constitutionally recognized peoples, being First Nations, Inuit, and Métis peoples (Government of Canada, 2021). Prior, Aboriginal was the accepted terminology however it has since fallen out of favour and usage.

${ }^{17}$ Indian is still used in the context of the Indian Act and the Indian Register, however in Canada it is now commonly accepted to use the self-determined identifier of 'First Nations' instead. The first use of First Nations was formalized in 1980 with the signing of A Declaration of First Nations by hundreds of First Nations chiefs in Ottawa, and the National Indian Brotherhood changed their name to the Assembly of First Nations in 1982 to reflect this (Gadacz, 2019). 'First Nations' has no legal definition in Canada; however, it operates for the purposes of political
} 
government rights; this arrangement however would slowly unravel post-confederation in 1867 with the Constitution Act, 1867 (formerly the BNA Act of 1867) which did not acknowledge First Nations as distinct peoples with inherent rights and sovereign communities and interests and rather it placed responsibility and authority over "Indians, and Lands reserved for Indians" into control of the Federal Government (see: section 91(24) of the Canadian Constitution Act, 1867). Métis and Inuit peoples were not recognized at this time.

Canadian expansionist policies, negotiated through several treaties ${ }^{18}$ with First Nations across what is now Central and Western Canada and the Northwest Territories, were designed to bring Indigenous peoples and communities under the Crown (Government of Canada, 2013). As a result, "First Nations were progressively pressured into surrendering vast amounts of land and territories, renouncing their traditional beliefs and ways of life, and integrating into the European cultures" (FNIGC, 2019, p.48).

The establishment of responsibility over First Nations peoples and interest in governing their lives and locations spurred the enactment of legislative and policy efforts designed for "the colonization, extermination, and assimilation" of First Nations peoples, communities, and cultures (FNIGC, 2019, p.48). Accomplishing this was inherently tied to social constructions and classifications of culture and race that were designed into the public policy and legal arrangements of the colonial state. Some notable and major colonial efforts to assimilate First Nations peoples into Canadian society include:

organization of many distinct communities and peoples (Assembly of First Nations, n.d.a; Library \& Archive Canada, n.d.).

${ }^{18}$ Between 1871 and 1921, eleven treaties were signed between different Indigenous peoples and the Crown as a means of addressing Indigenous land claims. The treaties promised "reserve lands, annuities, and the continued right to hunt and fish on unoccupied Crown lands in exchange for Aboriginal title [Indian status]"; the treaties however also worked in clauses and measures that required signatories to assimilate into "civilisation programs" and they were generally "land surrenders on a huge scale" and in the Crown's eye brought First Nations into their system of laws and governance (Government of Canada, 2013). 
- The Indian Act, 1867, which establishes rules for having Indian "status" and registration with the state "in relation to the federal government's fiduciary responsibility" that stems from the Royal Proclamation of 1763 and treaties (Assembly of First Nations, n.d.a; Library and Archives Canada, n.d., p.12). Under this Act, First Nations in Canada are classified in one of three ways: status Indians who are registered with the state and receive state-mandated benefits; treaty Indians who belong to communities that signed treaty agreements with the Federal Government; and non-status Indians who are unable to register legally as Indian, according to generational and termination rules set by the Crown (FNIGC, 2019, p.49). The Act also governs First Nations reserves, which are designated territories by the Crown for First Nations communities, as well as First Nations 'band governments' ${ }^{19}$. Status Indians and their administrative information are held by the government in the Indian Register, as set out by section 5 of the Act, and those recognized as status are eligible for certain benefits and rights including tax exemptions, housing on-reserve and education. These benefits only apply to those registered as status, and not for non-status First Nations, Inuit, or Métis peoples (Government of Canada, 2020a). It has seen several legislative amendments over time; however, the Indian Act and the Register continue to operate today.

- The residential school system, where Indigenous children were separated from their homes and families and placed in church-operated and state-mandated boarding schools with the main purpose being the "cultural transformation of Aboriginal children" including the removal of cultural identity, traditions and practices, and languages (TRC, 2015a, p.7-8). The schools were central to the Federal government's Indigenous policy of eliminating Indigeneity and absorbing Indigenous peoples and cultures into the hegemonic systems of the state. They were also poorly maintained and built, and the children were subjected to harsh and cruel disciplinary practices, physical and sexual abuse, and overall neglect (Morris, 2021). Residential school activities were declared

\footnotetext{
${ }^{19}$ Band councils are elected First Nations governments that are mandated under the Indian Act to govern First Nations communities. These governments operate as representatives of the Crown and their land and resources are managed by the federal government, currently this responsibility is under CIRNAC. As of 2020, the Canadian government recognizes 619 First Nations communities within this system (Price \& Gadacz, 2020). Not all First Nations governments are band councils however and many have signed self-governance agreements (see: https://cirnac.gc.ca/eng/1100100032275/1529354547314).
} 
'cultural genocide ${ }^{20}$ by the state-mandated Truth and Reconciliation Commission in 2015 (a, pp.1-7), and the recent and disturbing discovery of over 1000 bodies of Indigenous children in unmarked graves at multiple residential school sites across the country (and counting) further compound notions of genocide in this dark chapter of Canadian history (Morris, 2021; The Canadian Press, 2021).

- The "Sixties Scoop", where Canadian welfare agencies took thousands of Indigenous children without consent from their homes, families, and communities, to be relocated to non-Indigenous foster homes and adopted by white families, sometimes "even in different countries" (FNIGC, 2019, p.48).

The lack of federal recognition or care for other Indigenous cultures and identities resulted with many non-status, Métis and Inuit peoples being assimilated into these patriarchal, colonial policies and systems ${ }^{21}$. The residential school system for instance was originally designated for "Indians" under the Indian Act, however the TRC provides entire volumes ${ }^{22}$ dedicated to the experiences of misrecognized Métis peoples in the school system as well as the expansion of residential schools into the North in the past century (under the authority of Northern Affairs rather than Indian Affairs), which while distinct in some ways to the southern system, perpetuated similar themes of forced removal, assimilation, and abuse (TRC, 2015c, p.4)

Through these key tools and the institutionalized bias they perpetuate, the Canadian state enacted a colonial policy of assimilation of First Nations peoples that sought to eliminate

\footnotetext{
${ }^{20}$ Cultural genocide is defined by the TRC as "the destruction of those structures and practices that allow the group to continue as a group. States that engage in cultural genocide set out to destroy the political and social institutions of the targeted group" (TRC, 2015a, p.5).

${ }^{21}$ The reach of colonial Indigenous identification systems in the racial tactics of Canadian colonial systems have real, current implications for accountability of Canada's dark history of relationships with non-status Indians, Métis, and Inuit peoples. In response to the Sixties Scoop for example, an Ontario Supreme Court decision that the Federal Government is liable for harm and was settled with a 750-million-dollar settlement for harm done; however, as the Federal scope of the time only included status Indians in writing, non-Status peoples who were subjected to the Scoop are not included in the settlement. The National Indigenous Survivors of Child Welfare Network in Ottawa has advocated against the settlement and with the underestimation of peoples affected, as well as the lack of justice for Métis and non-Status peoples who were subjected to the Scoop (Omand, 2018).

${ }^{22}$ Volume 2, the Inuit and Northern experience: https://ehprnh2mwo3.exactdn.com/wpcontent/uploads/2021/01/Volume_2_Inuit_and_Northern_English_Web.pdf; Volume 3, the Métis experience: https://ehprnh2mwo3.exactdn.com/wp-content/uploads/2021/01/Volume 3 Métis_English_Web.pdf
} 
Indigeneity and markers of it, including knowledge and data - part of nation building for Canadian colonizers included bringing all people governed by the Crown in the Canadian territory under one system of identity and classification, and to systematically denigrate and destroy their distinctive cultures and social, political, and economic systems in place of that set by the state (TRC, 2015a, p.6). This was accomplished rather explicitly through the removal of Indigenous children from their homes and cultures to be forcefully adopted into white families or placed in residential schools that were designed to eradicate their cultural identities, and to be integrated forcefully and cruelly to the Canadian settler society and Catholicism instead; assimilation however was also institutionalized into the Indigenous administrative functions of the state. The Indian Act for instance was designed with generational termination rules that discriminate against women specifically through a "marrying-out provision"23 that would strip Indian status if a status women married a non-status male, effectively assimilating peoples through administration (Hurley \& Simeone, 2010). The patriarchy of the Indian Act and other First Nations policy instruments has led to a strong aspiration of First Nations communities and peoples to control information about them, and to self-determine who is a member of First Nations by terms defined by the community rather than the Federal government (Daniels, 2004; FNIGC, 2020a).

First Nations have a long and complicated legislated relationship with the Crown, however other Indigenous peoples have too endured colonial processes and attempts to systematically govern and classify them (Walter \& Andersen, 2013). Unlike First Nations and despite being subjected to the workings of the colonial state, the official visibility and

\footnotetext{
${ }^{23}$ An attempt to rectify this marrying out provision came with Bill C-31, which instead included a second generation cut off rule that eliminates the possibility for Status after "two successive generations of mixed Indian-non-Indian parentage" (Library of Parliament, 2010, p.4). This was subject to much criticism however for continuing to provision assimilation, and Bill C-31 was dismantled by Bill C-3 in 2009 which was spurred in the British Court of Appeals McIvor case. C-3 expands the scope of who can register in the Indian Act, and between 2011 and 2017 over 37,000 people were able to gain or regain status (Assembly of First Nations, n.d.b).
} 
relationship of Inuit and Métis peoples to the Canadian Crown formalized at a much later date and Métis and Inuit identity are not held as legal statuses akin to the Indian Act. Historically, Inuit peoples were misrecognized by the misnomer $E s k i m o^{24}$ and despite histories of hardship and subjugation resulting from colonial intervention in their ways of life, Inuit communities and their needs were largely ignored by the Federal Government. Responsibility for Inuit peoples however formed after a 1939 Supreme Court of Canada case titled Reference Re Eskimos ${ }^{25}$ which resulted in a determination that section 91(24) of the BNA Act that placed governmental responsibility over "Indians, and Lands reserved for Indians" also applies to Inuit peoples and communities. This decision would become conflated by World War 2 efforts at the time and the subsequent Cold War era of complicated geopolitics especially in the Northern regions, which resulted in a new visibility and policy drive in the Northern territories of Canada that are home to Inuit peoples. On one hand, the north in the 1950s-60s represented great strategic value and to the assertation of Canadian sovereignty, however the lack of industrial development complicated administrative functions (Clancy, 1987); on the other, Canada's desire to assimilate toward a single, Canadian culture, social infrastructure, and system of citizenship was challenged by Inuit ways of life and nomadic cultures in what came to be understood as the Eskimo Problem, or the question of how to assimilate Inuit peoples into the dominant Canadian culture and sociopolitical systems (Stern, 2019, p.62-3).

A consequence of this policy drive and interest in the north occurred with the High Arctic Relocation, where Inuit families and communities were relocated to the High Arctic North and faced barren lands, below-freezing temperatures, and extreme poverty and disconnect. It has

\footnotetext{
24 The racialized roots of this term and the abuse and subjugation that are attached to its history have resulted with negative and offensive connotations of its usage, and communities and peoples in the North prefer their own selfdetermined tribal names, or Inuit when speaking in a collective, national context.

${ }^{25}$ Reference Re Eskimo: https://scc-csc.lexum.com/scc-csc/scc-csc/en/item/8531/index.do
} 
been argued that this relocation was an exercise of Canadian national sovereignty and using Inuit as 'human flagpoles' and markers to political enemies across the Arctic; it has also been argued that this move was in response to the Eskimo problem and sought to remove the 'problem' far away from Canadian industrial society and interests (Marcus, 1995). The overarching sense of paternalism in Inuit and northern policy at these times showcases the uneasy state of visibility to colonizers and consequently as Stern notes, the "state needed an 'Eskimo problem' in order to exercise sovereignty over Inuit lives and territories" (2019, p.65).

Unlike First Nations or Inuit peoples, Métis peoples would not be officially recognized by Canada until 1982 with the Canadian Constitution Act 1982 despite a long history charting back to the 1800 s in the colonial territories which would eventually become Manitoba. Colonial land appropriation by the Crown after sale of Rupert's Land ${ }^{26}$ incited what is known as the Red River Resistance, where a violent uprising led by Louis Riel attempted to establish sovereignty in a provisional government to protect Métis land rights. The aftermath of the unrest resulted with the royal assent of the Manitoba Act, 1870 which established Manitoba as a province of Canada and provisioned land rights to Métis peoples ${ }^{27}$ (Rea \& Scott, 2006). The land provisions however never formed and a vast number of settlers impeded on this land, resulting in further skirmishes with the Canadian militia and many Métis peoples leaving to settle around Canada and the U.S. Consequently, "Métis individuals and communities were shoehorned into a state

\footnotetext{
${ }^{26}$ Rupert's Land was a large portion of the Canadian north and west and acted as the "commercial domain of the Hudson's Bay Company (HBC)" for purposes of the fur trade and trapping. It was purchased from HBC by the Crown of Canada three years after Confederation (Smith, 2019).

${ }^{27}$ The distribution of this land, which amounted to 1.4 million acres for Métis children, was largely ignored by Manitoba and Canada. In 2013, the Supreme Court of Canada ruled in Manitoba Métis Federation Inc. v. Canada (Attorney General) that the Federal government failed to meet this right in accordance with the Manitoba Act, 1870. In 2016, a Memorandum of Understanding on Advancing Reconciliation was signed by the Federal government and the Manitoba Métis Federation as a commitment to settling these forgotten land claims (see: http://www.mmf.mb.ca/docs/land_claims/MOU_English.PDF)
} 
taxonomy created to deal with First Nations rather than the Métis" (Walter \& Andersen, 2013, p.124).

Article 31 of the Manitoba Act marks the first form of legal recognition for peoples who identify as Métis, albeit with the racialized identification of half-breed that was commonly and "almost exclusively" used by the federal government at this time to distinguish peoples with mixed ethnicity (Library and Archives Canada, n.d., p.11). This racial identifier of mixed-race has become a point of misrecognition and misidentification in contemporary times where those with mixed ancestry might identify or be identified as Métis despite assertations that Métis identity is a distinct cultural and political identity formed after centuries of community and cultural development, and it is not a catch-all term for mixed Indigenous ancestry (Andersen, 2016). The prominent racialization of Métis identity was further obscured by the patriarchy of the Indian Act, where peoples who were stripped of their status often begun to self-identify as Métis (due to racial misrecognition of the term), as well as the emergence of the welfare state in Canada after WW2 which marked off-reserve Indigenous peoples nationally as "in need" while homogenizing cultures and identities under a deficit narrative of underdeveloped communities, despite a lack of accurate indicators about Métis peoples (Andersen, 2016, pp.5-6). Like Inuit peoples, despite being constitutionally recognized in 1982, Métis peoples and non-status Indians were only determined to be a responsibility ${ }^{28}$ of the Canadian government under the Constitution Act, 1867 following a 2013 Supreme Court Decision in Daniels v. Canada (Indian Affairs and Northern Development) ${ }^{29}$.

\footnotetext{
${ }^{28}$ It should be noted that while this decision and Re Eskimo determined that Métis, Inuit, and non-status First Nations peoples were responsibilities of the Federal government, this does not mean that they are subject to the mechanisms of the Indian Act, which continues to only contain status Indians according to State-defined definitions (Government of Canada, 2020a).

${ }^{29}$ Daniels v. Canada (Indian Affairs and Northern Development): https://scc-csc.lexum.com/scc-csc/scccsc/en/item/15858/index.do
} 
Colonial identities and classifications of First Nations, Inuit, and Métis peoples would begin to unravel post-civil rights movements in the 1960s with the reinvigoration of Indigenous political groups resulting from increased visibility and government assistance to Indigenous communities (Andersen, 2016). This era and beyond would see the formation of several prominent national political representatives for First Nations, Inuit, and Métis rights, such as the National Indian Brotherhood (now Assembly of First Nations) in the 1970s and Inuit Tapirisat of Canada (now Inuit Tapiriit Kanatami) in 1971 (ITK, 2021). Métis peoples would begin to politically organize in 1982 following the repatriation of the Constitution, forming the Métis National Council (MNC) which distributes governance provincially through ancillary organizations including: The Métis Nation of British Columbia (MNBC), the Métis Nation of Alberta (MNA), Métis Nations-Saskatchewan (MNS), the Manitoba Métis Federation (MMF), and the Métis Nation of Ontario (MNO) (Andersen, 2016, p.73).

The governance and policy environment facing Indigenous political representatives in the 1980s and beyond is one composed of misclassification, a lack of relevant information for historical and contemporary analysis, and institutionalized colonial biases and perspectives. The policy mechanisms of the Canadian state for Indigenous identification that have been described here not only worked to sort, classify, and govern, but also would come to influence the construction of data on Indigenous peoples that were collected and continue to be collected today. Collecting information about First Nations, for instance, requires context - over 600 communities are under band government leadership and here 'who is First Nations' is decided under the Indian Act; conversely, there are 43 First Nations communities that are part of 25 selfgovernment agreements in Canada, with 50 more agreements currently in negotiation ${ }^{30}$, in which First Nations have their own systems of membership and governance which are not subject to

${ }^{30}$ CIRNAC on self-governments in Canada: https://cirnac.gc.ca/eng/1100100032275/1529354547314 
colonial definitions (CIRNAC, 2020). A lot of data are just simply out of reach for First Nations, Inuit, and Métis communities due to institutionalized research cultures and biases. Most, if not all government workers and bureaucrats are products of high education and academia, which has long been mistrusted by First Nations, Inuit, and Métis peoples in Canada due to academic cultures which champion intellectual property over collected data, financial drives for using and applying research, and a "competitive" environment that "often prevents collaborative thinking and attribution of research credits to the subjects of their research" (FNIGC, 2020b).

The poor quality and availability of Indigenous information also presents limitations for effectively reaching Reconciliation, especially regarding notions of truth. Poor record keeping deriving from institutionalized biases has resulted with an incomplete picture of histories of discrimination and subjugation that are necessary to understand, acknowledge, and rectify as Canada seeks to mend their relationship with Indigenous peoples which was identified as essential by the TRC in 2015. The Missing and Murdered Indigenous Women (MMIW) cases are one prominent instance of this information gap, as Indigenous women in Canada are disproportionately and pervasively targeted by homicide and yet the available data on missing and murdered women vastly "oversimplifies and underrepresents the scale of the issue", with seemingly massive undercounts of cases in RCMP records (Assembly of First Nations, n.d.c).

Ultimately, as has been exemplified in this section of the literature review, emphasis is required in Canada-Indigenous discourse on the recent history of colonialism and colonial identification. While colonialism is often tied to notions of history and the past, it is only in recent decades that direct monikers of colonial rule in settler societies have begun to be dismantled. Legacies of colonial histories continue to be evident in settler nations around the world including Canada, marked by "the demarcation of reservation lands, long-standing economic inequality, vast environmental violations, and persistent Indigenous health disparities, 
among numerous other measures" (Carroll et al., 2019, p.3). The mechanisms of Indigenous colonization by the Crown in Canada likewise must be confronted as these institutions and realities are not just figments of forgotten pasts and peoples - the last residential school for instance only shut down in 1996, less than 30 years ago, and survivors of both residential schools and the Sixties Scoop continue to seek justice for their experiences perpetrated by the colonial state (Villani, 2021; Omand, 2018). Canada as a nation continues to grapple with these dark colonial histories as they continue to emerge in the present, from drinking water advisories ${ }^{31}$ and infrastructural challenges for producing basic needs to the recent and disturbing discovery of unmarked graves. While I focus primarily on classification and data in this thesis, the life and death realities behind the policies and political mechanisms of the state should always be recognized and noted as the country as a whole works toward healing, truth, and reconciliation with Indigenous peoples.

From state identification to residential schools, institutionalized colonial logics exist beyond historical colonial phenomena, and colonial "forces and structures continue to affect the well-being of Indigenous peoples worldwide” (Richardson \& Crawford, 2020, p.1098). Colonial forces have over time worked "to condition the present" in colonized lands in Western laws and legal systems, customs, and "institutions of the colonial state" which established "the frameworks and the conditions for colonial conquest, domination, and control" (Anderson, 2015, p.770). Colonialism operates beyond the historical colonial project and as Anderson (2015) notes it "is what makes modernity possible and it continues to function and underpin our modern social order" (p.770), and consequently Indigenous peoples in settler nations like Canada continue to

\footnotetext{
${ }^{31}$ As of July 2021, the Government of Canada has resolved class action litigation resulting from unsafe drinking water in many First Nations communities and has committed to paying compensation and funding the development of safe drinking water infrastructures on affected reserves (Indigenous Services Canada, 2021).
} 
face institutionalized and systematic colonial logics in systems of governance, identity, and information collection (Pool, 2016, p.67).

\subsection{Indigeneity and Indigenous Data ecosystems}

The systematic denigration of Indigenous knowledge systems and information practices by mechanisms of data colonialism has resulted in complex data ecosystems ${ }^{32}$ of Indigenous data in settler nations. On one hand, data are not foreign to Indigenous peoples, and communities have long collected and gathered information through observation and experience which inform distinct cultural approaches to governance, methodologies, and ways of knowing. On the other hand, data about Indigenous peoples have also long been collected, researched, and analyzed by external Western actors from settler colonial societies, including national governments, academia, and private corporations (Carroll et al., 2019). Conceptualizing these forms of data and information in general terms is inherently complicated: Indigenous as an identifier is not static, and different peoples and communities retain distinct cultures, languages, practices, and systems of governance, complicating the use of a single, homogenized identification.

Additionally, communities may be situated in different national and regional contexts which includes distinct Western legal and policy systems that classify, enumerate, and label Indigenous peoples within their own context, statistical methodologies, and information systems. Conceptual engagements with Indigenous data require a recognition that these data will not look the same in every local community, regional, or national context.

As explored in the previous section, classification and identification are hallmarks of data colonialism and the nationalistic drive of the state to imagine, enumerate, and govern the peoples native to colonized territories and whose presence on these lands pre-dates colonial

\footnotetext{
32 Data ecosystems have been described as "a network of actors that directly or indirectly consume, produce, or provide data and other related resources" (Schatsky et al., 2019, p.4).
} 
intervention and occupation (Carroll et al., 2019). Collective identifiers have long operated as a political and social tool for homogenizing distinct identities and cultures in colonialism, and they have been imposed on peoples and most often stand contrary to their self-determined cultural name that are central to their identity (Carroll et al., 2019; Snipp, 2016). Indigenous is the latest popular iteration of a long line of identifiers utilized by national and international bodies (including Canada) to collectively characterize distinct cultures, communities, and peoples and etymologically it means "produced, growing, living, or occurring natively or naturally in a particular region or environment" (Merriam-Webster, n.d.). Questions of who is Indigenous and by extension what are 'Indigenous' data in settler contexts however are vastly more complicated due local and regional politics, epistemological differences, and geographical location. Snipp (2016) highlights that this complexity of Indigeneity operates as a duality: Indigenous is a "group characteristic" and works on "qualities of collectivity"; conversely, Indigenous is a "personal characteristic" that both separates and binds the larger collective of people "deemed to be Indigenous" - depending on the political context, Indigenous may mean the "earliest presence of Homo sapiens", presence prior to colonial contact, or presence at a particular time on particular territory (p.41). This designation most often stems from the settler state that occupies and controls certain regions, and "for the sake of convenience" this usually operates on terms of precolonial intervention, "thereby making colonial contact one of the hallmarks of indigeneity everywhere in the world" (Snipp, 2016, p.41).

Today, a wholesome definition of Indigenous has been commonly rejected by most communities and peoples across the globe, and tribes and communities continue to resist colonial identification through means of self-determination and self-identification (United Nations, 2004). There has however been recognition at an international level that distinct communities and peoples have faced common structures of settler colonialism and that they share common 
aspirations for assuming control over their identities, peoples, and lives. This has been the basis for a subversion of collective identity from colonial racial constructions to a collective identity that is based on political and social aspirations, community, and self-determination. Such a distinction becomes increasingly important when identity according to the state is a critical mechanism for receiving important resources, rights, and recognition, while at the same time communities and peoples are seeking to establish their own self-determined understandings of identity into dominant discourses and knowledge production systems (United Nations, n.d.a).

One of the most heavily cited understandings of Indigenous was suggested by Special Rapporteur of the Sub-Commission on Prevention of Discrimination and Protection of Minorities, Mr. José Martínez Cobo in his famous 1982 Study on the Problem of Discrimination against Indigenous Populations, and it serves as the foundation of the United Nations understanding of the term Indigenous (Carroll et al., 2019; United Nations, 2004):

Indigenous communities, peoples and nations are those which, having a historical continuity with pre-invasion and pre-colonial societies that developed on their territories, consider themselves distinct from other sectors of the societies now prevailing on those territories, or parts of them. They form at present non-dominant sectors of society and are determined to preserve, develop, and transmit to future generations their ancestral territories, and their ethnic identity, as the basis of their continued existence as peoples, in accordance with their own cultural patterns, social institutions and legal system (Martínez Cobo, 1982, p.50).

Martínez Cobo's working definition of Indigenous emphasizes the importance of selfidentification and group consciousness when asking the question 'who is Indigenous'. Indigenous peoples self-identify as Indigenous and are accepted by their community as a member of the group, which "preserves for these communities the sovereign right and power to decide who belongs to them, without external interference" (Martínez Cobo, 1982, p.51). His work expresses that the most appropriate intellectual framework for Indigeneity allows communities themselves "to define what and who is indigenous" (United Nations, 2004, p.2). 
Building from this subversive notion of Indigeneity and emerging international discourse on Indigenous rights, Indigenous scholars from settler nations around the world have mobilized investigations ${ }^{33}$ into colonial data tactics, ecosystems, and policy/legal arrangements that are common across CANZUS states, and which limit the ability of Indigenous peoples to access and utilize data about them (Bruhn, 2014; Carroll et al., 2019; Cormack et al., 2019; Gupta et al., 2020; Rainie et al., 2017). In recognition of the diversity of Indigenous cultures and knowledge practices and the unique social and political situations that Indigenous peoples face, common suggestions to characterize Indigenous data sources includes:

- Knowledge about an Indigenous nation including about members/citizens, territories, resources, communities, cultures and demographics;

- Data collected at both the community and national level;

- And this includes any data created that are about Indigenous peoples and their communities, cultures, territories, or resources, no matter their residency - they can be created by and for Indigenous communities and organizations, or they may be created by non-Indigenous actors either alone or in collaboration with the Indigenous peoples they describe (Bruhn, 2014; Carroll et al., 2019; Rainie et al., 2017).

Indigenous data in this context may assume many different forms, be shaped by different epistemologies and methodologies, and they may be local and traditional knowledge (TK) sources.

In contemporary Indigenous data ecosystems, data about Indigenous peoples are a critical resource for the governance of their communities however they are often not in their control and are not used in ways that support the Indigenous peoples that the data describe; this situation is excelled by national legal systems and property law, information collecting

\footnotetext{
${ }^{33}$ This is not to say however that Indigenous data discourse has not been actively contributed to or studied. See for instance Linda Tuhai Smith's (1999) famous and revolutionary work Decolonizing methodologies, which charts a renewed and Indigenous-led path forward for methodological and epistemological thinking.
} 
institutions and government agencies, and socio-economic marginalization (Carroll et al., 2019; Pool, 2006; Walter \& Suina, 2019). This has resulted in a state of data dependency for many communities, whereby Indigenous peoples must rely on settler nations and other external actors for information about their community, including about their health, economic, and environmental status (Carroll et al., 2019, p.3). This state of dependency is "sustained through a paradox of scarcity and abundance: extensive data are collected about Indigenous peoples and nations, but rarely by or for Indigenous peoples' and nations' purposes" (2019, p.3).

The data that Indigenous leadership must rely on are also typically plagued by issues of quality; they are usually irrelevant to the communities priorities and aspirations; and they are produced by external institutions which have historically contributed to an environment of mistrust in data collection and research through a lack of engagement in the process and results, as well as abuse and exploitation for the benefit of colonial knowledge (Rainie et al., 2017; Fox, 2020; Hudson et al., 2020; Liebler, 2018). In some cases, data are not collected at all where Indigenous people live, as is the case with the Canadian Social Survey, among others. As mentioned earlier, indicators and units of measurement derived from colonial, paternalistic epistemologies also predominantly focus on negative, deficit-based indicators that often frame Indigenous peoples within a discourse of risk, problems, and vulnerability, rather than affirmative or strength-based approaches which documenting progress and positive population identifiers (Cormack et al., 2019; Phillips, 2017; Walker et al., 2017; Walker et al., 2018). As a result of dominant deficit models of Indigenous statistical representation in settler countries, much of the available data about Indigenous peoples are characterized by what some call the "5D's of Indigenous data": disparity, deprivation, disadvantage, dysfunction, and difference (Walter, 2016, p.80-1; Wilks et al., 2018). 
The colonial logics embedded in national institutions, statistical programs, and information systems as well as Western-dominated discourses of epistemology continue to be "evident in the ongoing devaluation and suppression of Indigenous knowledge systems in contemporary data environments", and as Pool (2016) highlights, the data produced in these systems most often cater to "the needs of the politically and demographically hegemonic cultural groups" (p.58). There are however common aspirations to regain control and determination over these data and ultimately to rebuild identities, cultures, and governance across communities. As Walter and Suina (2019) suggest, "Indigenous self-determination relies on data selfdetermination" - despite vast differences in culture, knowledge systems and data needs, there is a common aspiration $^{34}$ for data generally that meet Indigenous self-determined needs, from affirmative narratives and disaggregated data, to data "that reflect the embodied social, political, historical, and cultural realities of Indigenous people's lives" and national/local agendas and spatial understandings of where communities are (Walter \& Suina, 2019, p.36). As colonialism persists in the fabric of social and political settler institutions, knowledge systems, statistical programs, and the legal and regulatory institutions that impact how Indigenous data are managed, controlled, and accessed in settler countries, achieving these aspirations demands new ways of thinking, organizing, and classifying Indigenous data in ways that are self-determined.

\subsubsection{First Nations, Inuit, and Métis data}

In Canada, First Nations, Inuit, and Métis peoples and communities have had little to no engagement and inclusion with the dominant information processes of Canadian authorities. This situation was noted in the 1996 RCAP report which states:

\footnotetext{
${ }^{34}$ This common aspiration to gain self-determination over data is a prominent topic and focus that has emerged at the United Nations Permanent Forum on Indigenous Issues and derives from "concerns about the relevance of existing statistical frameworks and the lack of Indigenous participation in data processes have long been raised" (Walter \& Suina, 2019, p.36).
} 
The gathering of information and its subsequent use are inherently political. In the past, Aboriginal people have not been consulted about what information should be collected, who should gather that information, who should maintain it, and who should have access to it. The information gathered may or may not have been relevant to the questions, priorities, and concerns of Aboriginal peoples (RCAP, 1996a, p.498).

Along with a lack of relevance, these colonial data and the systems which produce them hinder the development of Indigenous approaches and methodologies by replacing these with systems that only work to benefit the needs and priorities of the external actor. In an era of reconciliation where self-governance and nation rebuilding in the wake of recent colonial histories are aspirations of peoples and communities across the country, the information situation of First Nations, Inuit, and Métis peoples demands critical attention. Indigenous governments need culturally relevant, high-quality data to understand their peoples and communities and to plan around their distinct cultural, political, social, and economic situations; this was also noted by the RCAP report in 1996, and this need continues to persist today (Bruhn, 2014; RCAP, 1996b).

The modern continuities of data colonialism in the Indigenous data ecosystem in Canada are vast and complex and each could demand an entire thesis or study devoted it; here however I provide a sample of prominent modern data issues related to the relationship between the state, private institutions, and Indigenous peoples and communities in Canada:

- Legislative barriers. Indigenous information priorities in Canada are often overridden or overlooked by information legislation, and they often result with a lack of Indigenous authority over how the data are accessed or used. Three prominent legislative barriers include: the Library and Archives Canada Act, which allows any officially archived records, including personal and community information, to be released publicly after 20 years. This has serious implications given the amount of colonial records and Indigenous information collected by the LAC, which after 20 years are completely out of Indigenous control about how they are used or represented; the Access to Information Act, where virtually any personal or community data held by the government can be released publicly and without discretion; and the Privacy Act, which only protects notions of 
personal privacy and not community-level privacy (Gupta et al., 2020; Rowe et al., 2021; FNIGC, 2020b);

- Deficit models and indicators. Indigenous data in Canada are often reported within a deficit model with an overemphasis on negative findings and often frame Indigenous peoples within a discourse of risk, problems, and vulnerability, rather than and affirmative or strength-based approaches to documenting progress and positive population identifiers. Elder Gwen Phillips of Ktunaxa in B.C. questions this phenomenon and it drives much of her work on First Nations-defined indicators: why determine well-being through indicators such as suicide, alcoholism, and disease prevalence, rather than affirmative indicators like success in education, cultural participation (i.e., knowing language, traditions, etc.) or community strengths (2017)? How people are framed in data ontologically constructs dominant perceptions of how people are represented, and this has the potential to construct these issues as a biological or cultural deficit and may reinforce the colonial and discriminatory determinants of these health crises (Beer, 2019; Cormack et al., 2019; Phillips, 2017; Walker et al., 2017; Walker et al., 2018), and as Hacking would say this 'makes up kinds of people' (1986).

- Siloed data. The Federal Government collects a vast amount of socio-economic information that is relevant to and used by several different departments across these domains (i.e., health, housing, environment, education, etc.). As there are currently no Federal Indigenous data standards, these data have been collected in different ways and with different methodologies, and there is a lack of cross-governmental integration on Indigenous data. As a result, Indigenous data are incredibly siloed across the government, and this represents a major hurdle for finding relevant data sources and employing mechanisms to repatriate these data (FNIGC, 2020a).

- Researched to death. Poor and unethical research practices also have a cumulative effect on the socio-economic conditions and culture of communities. The FNIGC highlights a taxonomy of potential community harms that come with the misuses and appropriation of First Nation information: physical harm owing to direct subjugation to unethical research practices; psychological harm brought on by cultural denigration and stigmatization; social harm resulting from social discrimination and stereotyping; economic harm or the loss of economic resources, like important data for governance; and legal harm that undermines Indigenous rights to sovereignty and self-determination (FNIGC, 2020b). 
- Statistics \& enumeration. As explored in section 2.1., the census is one of the dominant information tools of the state to administer and govern peoples and places. In Canada, Statistics Canada is the federally mandated agency which conducts Canadian national surveys, notably including the census, as well as the post-census Aboriginal Peoples Survey (APS) among others. These statistically census and survey derived data provide the foundation of Indigenous socio-economic information collected by the Crown and they inform much of the state's Indigenous programs and policies; they are however also designed by and for the Federal government and this has a wide range of implications for the construction of Indigenous data, in addition to sampling. This construction of the Indigenous statistics in Canada is interwoven into state politics and national directives and this history is vast and complex (see: Lauriault, 2012; Walter \& Andersen, 2013). Below in Table 1 I provide a snapshot of prominent Indigenous statistical issues in Canada.

Table 1: Prominent Indigenous statistics challenges in Canada.

\begin{tabular}{|c|c|c|}
\hline Issue & Description & Source \\
\hline $\begin{array}{l}\text { Racialization } \\
\text { and self- } \\
\text { identification }\end{array}$ & $\begin{array}{l}\text { Colonial racialization and classification have obscured Indigenous self- } \\
\text { identification, which has particularly been an issue for Métis self- } \\
\text { identification in the statistics due to historical conflations of distinct } \\
\text { Métis identity as a category of 'mixed race'. }\end{array}$ & Andersen, 2016 \\
\hline Representation & $\begin{array}{l}\text { Histories of relocation and reservations have left Indigenous peoples } \\
\text { often overrepresented in rural areas, which complicates census and survey } \\
\text { practices of mailing questionnaires to locales with no mailing addresses } \\
\text { or postal codes. This is also a barrier for Indigenous representation in the } \\
\text { electoral process, such as in Ontario where the electoral voting list is } \\
\text { produced by the Municipal Property Assessment Corp. (MCAP) and } \\
\text { those without a postal code are not included in the Registry. }\end{array}$ & $\begin{array}{l}\text { Liebler, 2018; } \\
\text { Peters, 2011; } \\
\text { MPAC, 2021; }\end{array}$ \\
\hline Accuracy & $\begin{array}{l}\text { Western, national statistical methodologies have a broad scope of } \\
\text { enumeration and usually fail to accurately enumerate Indigenous } \\
\text { communities that, in relative population size, are often too statistically } \\
\text { insignificant to be included in the national sampling frame. The Canadian } \\
\text { census for example only includes Indigenous identifiers on the long-form } \\
\text { census which is distributed to } 25 \% \text { of households, and the rest is } \\
\text { extrapolated. Without accurate data, census enumeration is useless to } \\
\text { Indigenous communities. }\end{array}$ & $\begin{array}{l}\text { Statistics } \\
\text { Canada, 2020; } \\
\text { Bishop, 2016; } \\
\text { Liebler, 2018 }\end{array}$ \\
\hline $\begin{array}{l}\text { Needs and } \\
\text { priorities }\end{array}$ & $\begin{array}{l}\text { As is evident in the state of Indigenous data generally, priorities and } \\
\text { needs in information practices often reflect the interests of the state rather } \\
\text { than the Indigenous peoples being enumerated, which typically centers on } \\
\text { social and economic areas as defined by the state as well as political } \\
\text { lobbying interests. }\end{array}$ & $\begin{array}{l}\text { Bishop, 2016; } \\
\text { Peters, 2011; } \\
\text { Walter, 2016; } \\
\text { Smith, } 2016\end{array}$ \\
\hline
\end{tabular}




\begin{tabular}{|llc|}
\hline Issue & Description & Source \\
\hline & The models that support Indigenous statistics collected by the state have & \\
& long been designed without Indigenous input and lack First Nations, \\
& Inuit, and Métis worldviews that advance their priorities and goals. In & \\
response, many Indigenous organizations and communities in Canada are & FNHA et al., \\
Models and & now articulating their own models for tracking the socio-economic well- & 2020; Geddes, \\
worldviews & being of their communities and peoples. The First Nations Health & 2015 \\
& $\begin{array}{l}\text { Authority (FNHA) in B.C. for instance have implemented holistic and } \\
\text { affirmative models to track First Nations health with the province, and } \\
\text { these are based on First Nations self-determination and traditions. }\end{array}$ & \\
& &
\end{tabular}

As a result of the intricate colonial mechanisms and relationships formed through data colonialism, identification, and colonial governance of Indigenous peoples in Canada, the Indigenous data ecosystem in Canada is vast, complex, and varied. Data about Indigenous peoples are collected at all levels of government, Federal, provincial, and municipal, and these data also vary internally across departments, agencies, and institutions, each with different mandates ${ }^{35}$. Much of these data were collected at varying points in time and spatial extent and with different methodologies, and there is no standard ${ }^{36}$ for 'Indigenous data' across Federal Government departments and provincial governments (Andersen, 2016). Private research institutions (i.e., CIHI, ICES) as well as academic institutions (i.e., Universities) also collect community and aggregated data about Indigenous peoples for research purposes, and these are sometimes held in trust by the institution, taken and claimed by the institution/researcher, or are held by the community themselves. Currently in Canada, research ethics with Indigenous communities are directed by the Tri-Research Council (The Canadian Institutes of Health

\footnotetext{
${ }^{35}$ Federal departments might include Employment \& Social Development Canada (ESDC); the Canadian Mortgage and Housing Corporation (CMHC); Public Health Agency of Canada (PHAC); and Natural Resources Canada (NRC), to name a few. Provincially, First Nations, Inuit, and Métis socio-economic data are usually gathered at the community level through surveys. Some examples include: the B.C. Adolescent Health Survey (www.mcs.bc.ca/ahs).

${ }^{36}$ There are however some provincial Indigenous administrative data standards, particularly in B.C. (https://www2.gov.bc.ca/assets/gov/government/services-for-government-and-broader-public-sector/informationtechnology-services/standards-files/aboriginal_administrative data_standards.pdf), and Newfoundland \& Labrador (https://www.nlchi.nl.ca/images/NL_Indigenous_Administrative_Data_Identifier_Standard_FINAL_2017-1212.pdf).
} 
Research (CIHR), the Natural Sciences and Engineering Research Council (NSERC), and the Social Sciences and Humanities Research Council (SSHRC)) through section 9 of the TriCouncil Policy 2 (TCPS2) ${ }^{37}$.

In addition to external actors, First Nations, Inuit, and Métis peoples recognize the vital importance of information about them and have actively for decades promoted and asserted their interest in owning and controlling data that are about them and their communities. There are many Indigenous-led national and regional organizations who collect both community-level and aggregated national data about their peoples and communities, including the First Nations Information Governance Centre (FNIGC), Inuit Tapiriit Kanatami (ITK), and the provincial arms of the Métis National Council (in section 2.3.2. I describe these organizations and their efforts in movements for First Nations, Inuit, and Métis data sovereignty and governance). The policy environment surrounding these collections in Canada is also rapidly advancing and evolving in the wake of Federal reconciliation efforts led by the Trudeau liberal government. On June 21, 2019, the Department of Indigenous Services Act progressively dissolved the primary Federal Indigenous governance department, Indigenous and Northern Affairs Canada (INAC), into two new Federal departments: Crown-Indigenous and Northern Affairs Canada and Indigenous Services Canada (ISC). The mandates for these institutions are centered on advancing Indigenous self-determination and self-governance through the gradual transfer of governance responsibilities and capacities (FNIGC, 2020a). Regarding the development of capacity for the control and governance of information, section 13 of the Department of Indigenous Services Act states:

${ }^{37}$ TCPS2: https://ethics.gc.ca/eng/policy-politique_tcps2-eptc2_2018.html 
[T]he Minister may support the Indigenous bodies that specialize in research and statistics, in relation to their activities involving the collection, analysis, interpretation, publication and distribution of documents, information or data relating to the provision of services to Indigenous individuals (S.C. 2019, c.29, s.336).

The dissolution of INAC has significant implications for self-governance and the role of ISC in information management and program delivery should diminish as governance shifts into Indigenous control - as the FNIGC states, "when self-determination is a reality for all, this department may no longer need to exist" (FNIGC, 2020a, p.21). This having been emboldened in the Government of Canada's assertation that they will assist Indigenous groups to "build capacity and support their vision of self-determination" (Government of Canada, 2020b \& c).

As I have drawn out in this section, Indigenous data in Canada are complex and are approached in a myriad of different contexts and by several different actors with different mandates, priorities, and agendas. In Table 2 below I provide an overview of prominent sources of these data which indicates some of the major institutions, both Indigenous and nonIndigenous, who collect, manage, or steward First Nations, Inuit, and/or Métis data in Canada. This list in not meant to be exhaustive, and there are also many efforts occurring at a communitylevel, in other research institutions or in other representative organizations and governments; however, this provides a snapshot into the broader Indigenous data ecosystem in Canada and some of the prominent actors involved with the governance and management of Indigenous data.

Table 2: Institutional Indigenous data sources in Canada

\begin{tabular}{|lll|}
\hline Institution & Data Sources & Scope \\
\hline AFNIGC & $\begin{array}{l}\text { First Nations Labour and Employment Development Survey } \\
\text { (FNLED) }\end{array}$ & $\begin{array}{l}\text { First Nations } \\
\text { communities }\end{array}$ \\
& $\begin{array}{l}\text { Data Linkage between B.C. First Nations, Federal Government } \\
\text { and Government of B.C. in the Tripartite Data Quality \& }\end{array}$ & $\begin{array}{l}\text { First Nations } \\
\text { communities in }\end{array}$ \\
& Sharing Agreement (TDSQA) & British Columbia \\
$\begin{array}{l}\text { Canadian Institute } \\
\text { for Health } \\
\text { Information (CIHI) }\end{array}$ & $\begin{array}{l}\text { Canadian health and health-system data (types of health care; } \\
\text { patient-reported data; spending on health care; and healthcare } \\
\text { workforce) (CIHI, 2020a). }\end{array}$ & $\begin{array}{l}\text { National; Strategic } \\
\text { plan focused on First }\end{array}$
\end{tabular}




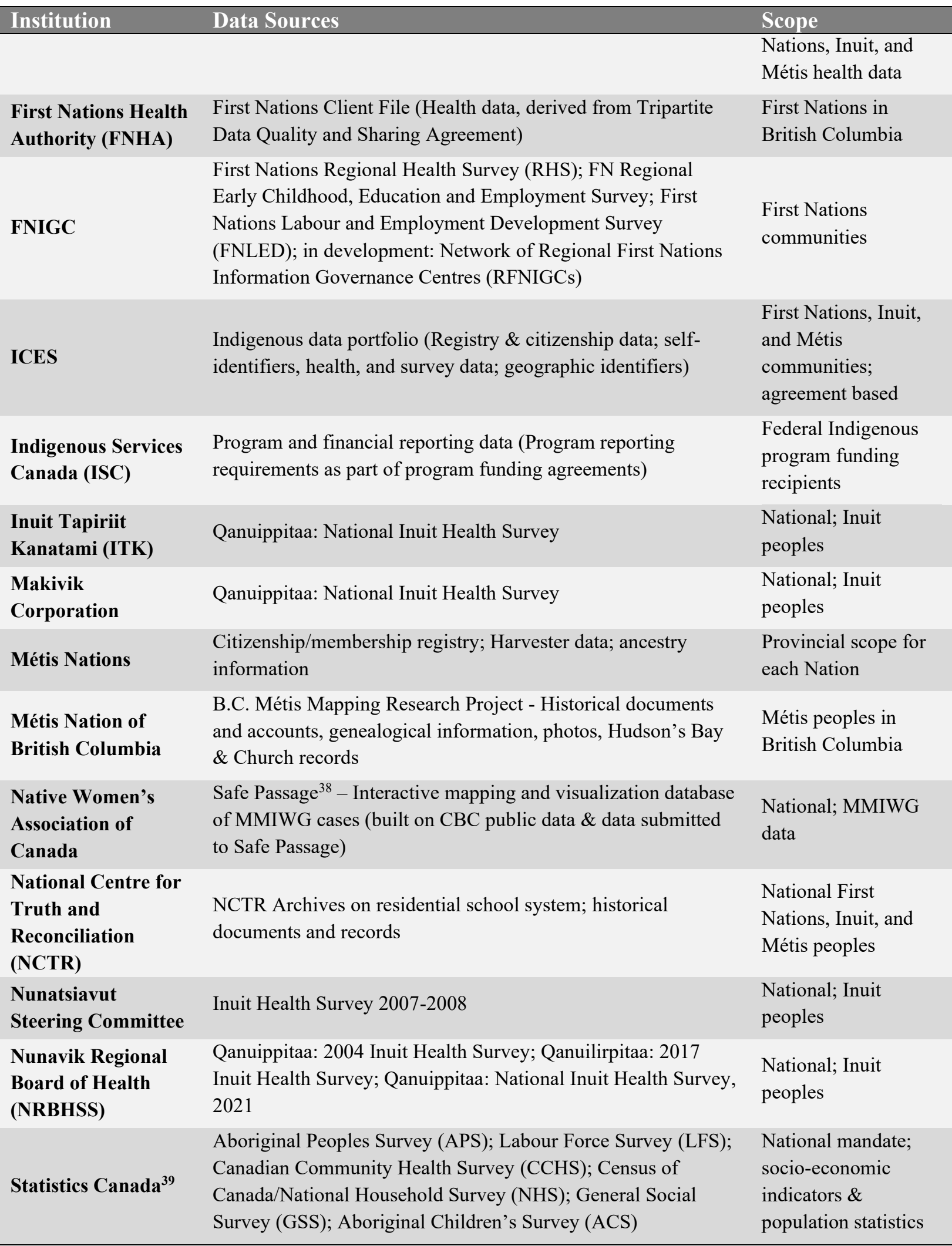

\footnotetext{
${ }^{38}$ Safe Passage: https://safe-passage.ca/

${ }^{39}$ Aboriginal data at Statistics Canada: https://cudo.carleton.ca/system/files/dli training/4145/englishfall-2017-dlipresentationaboriginal-datafinal.pdf
} 
The Indigenous data ecosystem in Canada positions a challenging terrain for First Nations, Inuit, and Métis communities in movements toward reconciliation and self-governance, however regaining control over and access to these data sources is essential for rebuilding Indigenous capacities in governance, information management, and knowledge production. Control and access to high-quality and relevant data that are defined and constructed by First Nations, Inuit, and Métis worldviews respectively along with the human and technical capital (i.e., skills, technologies, software, etc.) to manage these data are capacities to drive selfgovernance and the capacities of Indigenous leadership to plan, monitor, and report on matters they deem important in their community, and these capacities are of critical importance to decolonize data in Canada (Bruhn, 2014, p.9).

\subsection{Toward the decolonization, governance \& sovereignty of data}

The prominence and perseverance of colonial epistemologies, institutional cultures, and methodologies that limit the self-governance capacities of Indigenous governments has incited investigations into how to decolonize these institutions and practices. Decolonization as a concept emerged in the mid-twentieth century to not only characterize the physical departure of colonizers from colonized lands, but also to encompass the "[full] divestment of foreign occupying powers from Indigenous homelands, modes of government, ways of caring for the people and living landscapes, and especially ways of thinking" (Duarte \& Belarde-Lewis, 2015, p.678). It is through the "identification of and perceived dissociation from the empowering strategies of colonial discourse" in which Indigenous ways of doing and knowing are able to move away from colonial-imposed rationales and structures, and some definitions emphasize that decolonization importantly entails holding settler nations accountable to their histories of coloniality and their commitments to enable Indigenous peoples to maintain their distinct practices and knowledge systems (Huggan, 2008, p.25; McCracken, 2019). 
Decolonial work, as prominent Indigenous decolonization scholars Marisa Duarte and Miranda Belarde-Lewis (2015) suggest, is knowledge work - it invites non-Indigenous researchers and peoples to take a step back from normative assumptions about knowledge, including how it should be created, organized, and managed, and to consider why Indigenous peoples want to pursue their own approaches to these processes. There are three primary normative expectations that non-Indigenous peoples must acknowledge and challenge to effectively divest colonial power in knowledge: first, that "all knowledge in the world can be represented in document form"; second, that most information already is; and third, that "Indigenous ways of knowing belong in state-funded university and government library, archive, and museum collections, especially for the benefit of society's privileged elite" (Duarte \& Belarde-Lewis, 2015, p.678-9). Linda Tuhiwai Smith's famous investigation of decolonial methodologies noted the power of decolonization methods to incite "revolutionary thinking about the roles that knowledge, knowledge production, and knowledge institutions play in decolonization and social transformation" (1999, p.xii).

Diffusing and decolonizing the positivist research paradigm identified by Braun et al. (2013) however is not an easy nor simple task, and "actually building [knowledge] systems is easier said than done" (Duarte \& Belarde-Lewis, 2015, p.687). Inciting a real paradigm shift, Walters et al. (2017) suggest, requires "more than an adjustment in practices or knowledge" - it entails systematic and structural development, and both requires and results in "nothing less than a permanent change in world view" and an overcoming of the vested interests of the dominant paradigm (p.227). Braun et al. (2013) highlight the importance of critical theory to deconstruct positivist research notions and to challenge the "Euro-American ethnocentricity" that is so prevalent in Western Indigenous statistics and research, promoting investigation into societal power dynamics centered on race and ethnicity that are employed in Western positivist 
arrangements for "judging which research constructs are valid, determining how constructs are defined, and deciding which variables need to be controlled" (Braun et al., 2013, p.123).

Duarte and Belarde-Lewis (2015) suggest the conceptual approach of imagining for those experts, professionals, and scientists who wish to align themselves and support Indigenous decolonial work by studying epistemology, classification, and the "theoretical nature of Indigenous knowledge work as a decolonization prerequisite" (p.679). Imagining "consists of creating figurative and literal spaces for the work of building, analyzing, and experimenting with Indigenous knowledge organization", primarily through two key mechanisms: envisioning a future that overcomes the challenges of the past and which "bind[s] people together politically" to achieve this vision; and discovering the beauty of Indigenous knowledge, employing this knowledge to the benefit of communities, and sharing and shaping cultural information that are self-determined to establish relationships and develop community resiliency (Duarte \& BelardeLewis, 2015, p.687). They also emphasize the broader epistemological efforts that make the method of imagining work:

[N]on-Indigenous epistemic partners will want to step outside their comfort zone, sensitize themselves to Indigenous histories and political realities, learn to listen in new ways, and position themselves as followers in collaborative projects with Indigenous specialists leading the way... Simultaneously, as Indigenous thinkers, in order to imagine, we must not allow the trauma of past harms to cloud our future vision. Just as non-Indigenous partners must not underestimate the neartotal devastation of colonialism for Indigenous peoples, Indigenous partners must also be open to creative new possibilities toward the flourishing of Indigenous peoples. (Duarte \& Belarde-Lewis, 2015, p.679).

The authors identify an order to the process of imagining as follows:

(1) understanding the processes of data colonialism and the subjugation of Indigenous knowledge;

(2) recognizing and analyzing the tools, logics, and institutions of data colonialism;

(3) encouraging epistemological study and building partnerships with allies; 
(4) identifying Indigenous epistemic partners or those with deep Indigenous ontological knowledge; and

(5) encouraging Indigenous-led development and design and building knowledge capacity to support decolonization efforts everywhere.

It is ultimately this capacity that will be the foundation for the rebuilding of Indigenous knowledge systems and imagining a future defined by and for Indigenous peoples (Duarte \& Belarde-Lewis, 2015, p.687). This is a useful set of values for actors both Indigenous and nonIndigenous, who are involved in the collection, management, and/or use of Indigenous data and who want to do so in a way that both recognizes the impact of colonialism on the production of Indigenous knowledge and also the need to empower Indigenous peoples in colonial arrangements to build effective systems and capacities which divest control over the representation and understanding of Indigenous peoples, communities, and resources.

The production of data is central to the production of knowledge, identity, and mechanisms of governance and as a result Indigenous scholars are also investigating what it means to decolonize data. At its most simple, data decolonization occurs when Indigenous peoples and communities "replace external, [non-Indigenous] norms and priorities with Indigenous systems that define data, and inform how [they are] collected and used" (Carroll, Rodriguez-Lonebear, \& Martinez, 2019, p.4). The actual process of doing so however is much more complex as Indigenous data are intertwined with Western, colonial-era statistical methodologies and research practices which have reinforced colonial notions of natural truths, science, and classification systems. The policy and information structures of the colonial state are complicated, contain many intersecting elements and actors, and to realize conceptions of decolonization, it will in many cases require "paradigmatic change" and a rethinking of how we enumerate, classify, and imagine peoples and things in data as Duarte and Belarde-Lewis would suggest (Walter et al., 2021, p.226). Snipp (2016) identifies three primary preconditions that 
must be met for data to be effectively decolonized: first, Indigenous peoples require the 'power to name', or to decide who is counted and how; second, data that are collected by, with or about Indigenous peoples should reflect Indigenous interests and priorities - "nothing about us without us" as the slogan goes; and third, that Indigenous nations need to control access to and the use of data about them.

Ultimately, it is important that decolonization methodologies and strategies articulate what is meant by 'decolonization' (see Chapter 3: Theoretical Framework for how this thesis conceptualizes decolonization in the context of data). There is a recognition that, just as other classificatory definitions and logics tend to operate, there is a danger to overusing and saturating conceptions of 'decolonization' in a way that homogenizes experience and opens possibilities for mis-informed co-option. McCracken (2019) observes that the "overuse of the term decolonization has impacted its meaning, often resulting in the term being attached to preexisting frameworks of social justice and removing its connection to the realities of Indigenous life and settler colonialism" (p.200).

\subsubsection{The Indigenous data sovereignty movement}

The call for Indigenous data sovereignty (IDS) by a multitude of Indigenous communities, organizations, and circles of Indigenous scholars has initiated a new agenda and direction for the decolonization of data, information, and by extension knowledge practices. Data sovereignty generally is a recent conception that has emerged in response to the massive growth of data collection and management enabled by information and communication technologies (ICT) and 'smart' devices, which has resulted in a wide array of data being widely accessible across geographical borders. It simply refers to the management of data in a way that "is consistent with the laws, practices and customs of the nation-state in which [they are] located" and is meant to keep information policies and laws consistent across nation states (Snipp, 2016, 
p.39-40; Rainie et al., 2017). Indigenous data sovereignty conceptually seeks to extend and realign this conception within an Indigenous worldview that asserts "the right of Indigenous peoples to determine the means of collection, access, analysis, interpretation, management, dissemination and reuse of data pertaining to the Indigenous peoples from whom it has been derived, or to whom it relates" (Walter \& Suina, 2019, p.237; Rainie et al., 2017). This is sovereignty over all data that Indigenous peoples collect themselves as well as all data that are collected about them, and it is derived from the inherent rights of Indigenous peoples "to govern their peoples, lands, and resources" (Carroll et al., 2019). Data sovereignty is fundamental to decolonization, acting as resistance to colonial structures of information and asserting "control over a resource that is of vital importance to Indigenous peoples" and their own defined wellbeing (Tsosie, 2021, p.221).

The IDS movement emerged only in recent years, building from the momentum of the 2015 'Data sovereignty for indigenous peoples: current practice and future needs' workshop held in 2015 in Canberra, Australia. The workshop saw the gathering of "an international group of scholars, representatives of indigenous organizations and government personnel" from CANZUS nations to establish "an Indigenous data sovereignty agenda" in response to the omission of Indigenous voices in discussions of data sovereignty and the increasing importance of data for governance (Kukutai \& Taylor, 2016, p.1). Drawing from papers and discussion at this workshop, a group of Indigenous scholars led by Kukutai and Taylor compiled the first book ${ }^{40}$ to engage with the concept of Indigenous data sovereignty, a collection of essays which unravel a wide range of legal and ethical issues in Indigenous information governance contexts. Kukutai and Taylor also identify the vision of these seminal works at the beginning of the collection:

\footnotetext{
${ }^{40}$ In early 2021 another collection was released covering IDS within a variety of national policy contexts. This collection was edited by Walter, Carroll, Kukutai \& Rodriguez-Lonebear and features returning authors from the first collection as well as new additions.
} 
The broad aim of this book is to stimulate new thinking and uncover emergent practices regarding the generation of demographic, wellbeing and community development information in ways that better respond to the self-determination aspirations of indigenous peoples. To do so it also considers the implications of UNDRIP for the collection, ownership and application of statistics pertaining to indigenous peoples and what these might mean for indigenous peoples' sovereignty over data about them, their territories, and ways of life. (Kukutai \& Taylor, 2016, p.1-2).

The IDS movement leverages the legal framework of the United Nations Declaration on the Rights of Indigenous Peoples (UNIDRIP) ${ }^{41}$ to assert the "inherent and inalienable rights and interests of indigenous peoples relating to the collection, ownership, and application of data about their people, lifeways and territories" (Kukutai \& Taylor, 2016, p.1-2). The positioning of the UNIDRIP framework in IDS is significant as endorsement by settler states raises questions about the shifts in governance that are required by Article 42, which "calls on states to promote the full application of UNDRIP provisions and to follow-up on their effectiveness", meanwhile “Articles 3, 4, 5, 15(i), 18, 19, 20(i), 23, 31, 32, 33, 38 and 42 of UNDRIP all raise urgent questions about the manner in which these nations statistically represent their indigenous citizens" (Kukutai \& Taylor, 2016, p.4-5). UNDRIP also asserts in Article 19 the principle of "free, prior, and informed consent" which is the right of Indigenous peoples to be consulted for input and consent on any activities, including data collection and research, that may affect them or their communities (United Nations, 2007, p.16).

Within discourses of sovereignty in data, the governance of data "has emerged as a site of contestation between indigenous peoples and the colonial settler states within which they

\footnotetext{
${ }^{41}$ UNDRIP was adopted by the United Nations in 2007 and it establishes "a universal framework of minimum standards for the survival, dignity and well-being of the indigenous peoples of the world and it elaborates on existing human rights standards and fundamental freedoms as they apply to the specific situation of indigenous peoples" (United Nations, n.d.b; 2007). See here for the full UNDRIP document:

https://www.un.org/development/desa/indigenouspeoples/wpcontent/uploads/sites/19/2018/11/UNDRIP_E_web.pdf
} 
reside" (Smith, 2016, p.119). Data governance is a relatively recent conception and is defined by the Data Management Association International (DAMA) as "the exercise of authority and control (planning, monitoring, and enforcement) over the management of data assets", which includes strategies, policies, standards, oversight, valuation, and all other mechanisms to assist and oversee the functions of data management (DAMA, 2017, p.67-8). Although mainstream understandings of data governance largely stem from corporate and IT governance literature that consider the practical technological implications for managing data in the long term and most often centres on goals of efficiency and profits, data governance experts acknowledge the highly contextual constitution of data governance practices that depend largely on the vision, goals, and needs of any organization managing data assets (DAMA, 2017; Ladley, 2012; Gupta et al., 2020). While there are many approaches, they are generally directed by three interrelated data domains: Data Management (implementation/execution of plans and policies); Enterprise Information Management (data management mindset and direction); and Data Architecture (models, governance, standards, infrastructure) (Ladley, 2012).

Data governance is understood as quintessential to achieving IDS in modern, settler governance arrangements and relationships with Indigenous peoples. Diane Smith in Kukutai and Taylor (2016) makes a case for the critical importance of the governance of data and data for governance ${ }^{42}$ as a means of achieving the necessary capacities and data ecosystems for Indigenous sovereignty over data and information about them, and Smith's contribution is further iterated upon and conceptualized as Indigenous data governance (IDG) by scholars from the Native Nations Institute at the Udall Center for Studies in Public Policy, Stephanie Russo Carroll, Desi Rodriguez-Lonebear, and Andrew Martinez (2019) who define it as: "the act of

\footnotetext{
${ }^{42}$ Governance of data refers to the ability of Indigenous peoples to manage, control, and own their data; data for governance refers to the need to access timely, quality, and relevant data to have the capacity to govern (Smith, 2016; Carroll et al., 2019).
} 
harnessing tribal cultures, values, principles, and mechanisms-Indigenous ways of knowing and doing — and applying them to the management and control of an Indigenous nation's data ecosystem" (Carroll, Rodriguez-Lonebear, \& Martinez, 2019, p.5). They conceptualize IDG as a reciprocal relationship of data for governance and governance of data, which both contribute to the cycle of nation and data rebuilding and centers on Indigenous conceptions of sovereignty (Figure 1).

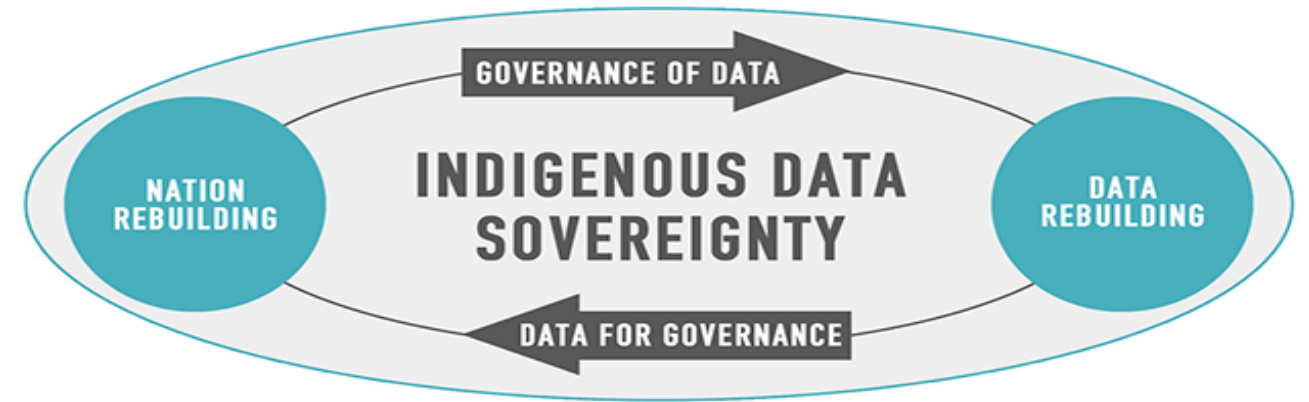

Figure 1: Data governance as a reciprocal relationship that advances IDS (Carroll et al., 2019, p.4).

IDS is "operationalized via Indigenous data governance, which harnesses Indigenous decision-making across data lifecycles and ecosystems to assert Indigenous rights" (Walter \& Carroll, 2021, p.10). Asserting IDG practices positions Indigenous peoples to develop the foundational capacity for the governance of their peoples, territories, and resources in a selfdetermined form and works to dismantle Indigenous data dependency on settler states (Bruhn, 2014; Carroll et al., 2019; Cormack et al., 2019; Gupta et al., 2020; Rainie et al., 2017). As such, the "principle of Indigenous data sovereignty rests on groups having the capacity for governance", and asserting sovereignty then requires that Indigenous peoples "form governance models to self-govern, make informed and internally accountable decisions about their current priorities and future direction" (Lourie et al., 2019, p.17). This process is fundamentally connected to relationships - exercising and implementing these concepts happens within larger settler data ecosystems where Indigenous data are controlled and in the possession of other non- 
Indigenous entities, which could include national governments, archives, corporations, and researchers. Building and maintaining relationships with these actors is necessary to ensure that Indigenous data are governed with Indigenous principles in mind and that there are clear intellectual property (IP) and ownership documentation (Carroll et al., 2019).

Within this framing and movement, data for governance elicits questions over the capability of Indigenous peoples to problem solve and plan using information about their people. It depends on "having collection, access and use procedures and policies for the governance of both qualitative and quantitative data, supported by technical skills and infrastructure" as well as what Smith calls "culture-smart data", or data that are produced locally by communities, which set out meaningful Indigenous-defined priorities, and that build upon "existing indigenous capabilities and knowledge" with "direct practical application" (2016, p.129). The governance of data positions issues of ownership, access, and control within Indigenous conceptualizations of community and stewardship, emphasizing that the governance "of data is not simply about the data" - rather its "about the people who provide and govern" the data assets, and the satisfaction of their "culturally based systems of knowledge, alongside delivering on their planning, servicedelivery and development aspirations" (Smith, 2016, p.130). Considered in unison, the IDS and IDG movement assert that both the governance of data and data for governance need to be engaged with to shift paradigms and to achieve a new vision for Indigenous data in policy, both of which necessitate Indigenous leadership and call for the building of "technical and human resource data capacities, policies and practices" from an Indigenous perspective (Walter \& Carroll, 2021, p.15).

It should be noted that although UNDRIP and current international discourse has fuelled a common movement toward the repurposing and repackaging of colonial systems to establish notions of Indigenous data sovereignty and governance, Indigenous peoples around the world 
have long asserted governance over information about them and resisted colonial systems of data and have done so outside of emerging international common frameworks, movements, and discourse. This activity, largely led by citizens and communities ${ }^{43}$, has worked to unravel many of the information tools of the colonizer to seek objectives and priorities that are defined by Indigenous peoples and communities. Below in Table $3 \mathrm{I}$ describe many of these Indigenousand citizen-led practices and mechanisms. This list does not attempt to be exhaustive, as citizenled efforts are far-reaching, many and situated across diverse contexts; however, it importantly highlights some prominent ways in which Indigenous peoples and communities have asserted control over the tools of the colonizer for their own self-defined purposes at the local level, which exemplifies emerging conceptions of sovereignty and governance in action.

Table 3: Citizen-led data governance and management practices and mechanisms

\begin{tabular}{|c|c|c|}
\hline Practice & Description & Source \\
\hline $\begin{array}{l}\text { Comprehensive } \\
\text { Community } \\
\text { Planning (CCP) }\end{array}$ & $\begin{array}{l}\text { Planning and reporting which includes full engagement with community } \\
\text { members and seeks to align planning objectives with the long-term } \\
\text { priorities of the community. Planning focuses on sustainability in this } \\
\text { model in areas including governance, land and resources, culture, health, } \\
\text { and more. }\end{array}$ & $\begin{array}{c}\text { Geddes, } \\
2015\end{array}$ \\
\hline Counter-mapping & $\begin{array}{l}\text { The use of technological developments and participatory politics to chart } \\
\text { alternative maps that challenge dominant hegemonic conceptions of } \\
\text { territory and resources. Counter-mapping positions Indigenous peoples to } \\
\text { utilize the grammar of the nation through cartographic text as a means of } \\
\text { advocacy and resistance. }\end{array}$ & $\begin{array}{c}\text { Peluso } \\
\text { (1995); Hunt } \\
\text { \& Stevenson } \\
\text { (2017) }\end{array}$ \\
\hline Cybercartography & $\begin{array}{l}\text { The practice of collecting, organizing, and presenting spatially data "in an } \\
\text { interactive, dynamic, multimedia, multisensory [cybercartographic atlas] } \\
\text { with the use of multimedia and multimodal interfaces" (Scassa et al., 2014, } \\
\text { p.135). The collaborative use of technologies to collect visuals and audio } \\
\text { in atlases effectively pairs with collective traditional knowledge, and the } \\
\text { focus on geonarratives compliments Indigenous beliefs and connections to } \\
\text { heritage and territory. }\end{array}$ & $\begin{array}{l}\text { Scassa et al. } \\
\text { (2014) }\end{array}$ \\
\hline
\end{tabular}

\footnotetext{
${ }^{43}$ Although my framework and analysis to follow focus on the current international/national level intellectual movement for Indigenous data sovereignty and governance, I draw on these practices to identify local data practices and governance which are effectively precursors to the current moment, and to exemplify that the current IDS/IDG movement that has emerged is not only a recent development but rather that this movement represents the establishment of a common international mechanism that is situated in diverse struggles for autonomy over information and governance that have lasted decades and have spanned a number of distinct communities and contexts.
} 


\begin{tabular}{|c|c|c|}
\hline Practice & Description & Source \\
\hline $\begin{array}{l}\text { Tactical } \\
\text { cartography and } \\
\text { informatic images }\end{array}$ & $\begin{array}{l}\text { The use of informatic mapping and images to "visualize the gaps in settler } \\
\text { data stories" and tactically reveal the settler spatial logics in map making } \\
\text { (p.10). Informatic mapping can take the form of an alternative mapping } \\
\text { practice like cybercartography however it can also take the form of } \\
\text { "Indigenous digital crowd maps and crowdsourced social media } \\
\text { photograph campaigns", which operate tactically to "disrupt data } \\
\text { paradigms with diffuse participation" (p.3). }\end{array}$ & Miner (2020) \\
\hline $\begin{array}{l}\text { Community-level } \\
\text { statistics }\end{array}$ & $\begin{array}{l}\text { Recognizing that community priorities can not be met through top down, } \\
\text { centralized statistical approaches, the FNIGC have developed a First } \\
\text { Nations Data Governance Strategy which seeks to establish a network of } \\
\text { First Nations-led regional statistical institutions to perform community- } \\
\text { level and regional statistics for First Nations peoples across Canada. I } \\
\text { explore this Strategy further as a data governance material in Chapter 5: } \\
\text { Analysis. }\end{array}$ & $\begin{array}{l}\text { FNIGC, } \\
2020 \mathrm{a}\end{array}$ \\
\hline Mana Tuturu & $\begin{array}{l}\text { An archival repository protocol established by Māori peoples in } \\
\text { partnership with the New Zealand Film Archive. This protocol assigns a } \\
\text { spiritual guardian over deposited Māori materials who would be consulted } \\
\text { in discussion of any future archival use of the content. This extends to their } \\
\text { "descendants, in perpetuity" to ensure the safeguarding of the media for } \\
\text { future Māori generations (p.123-124). Mana Tuturu was established to } \\
\text { resist New Zealand intellectual property and archival laws which allow } \\
\text { Māori sacred and archived materials to be entered into the public domain } \\
\text { after } 50 \text { years. }\end{array}$ & $\begin{array}{c}\text { Barclay } \\
(2005)\end{array}$ \\
\hline Mukurtu CMS & $\begin{array}{l}\text { An open-source content management system (CMS) and platform that } \\
\text { enables Indigenous communities to "define privacy settings and levels of } \\
\text { access to and circulation of their digital heritage materials according to } \\
\text { local cultural practices" (Montenegro, 2019, p.731). Core features of this } \\
\text { system includes TK labels (Indigenous-defined metadata tags that are } \\
\text { locally adaptable), cultural protocols, community records, and 'Roundtrip' } \\
\text { which is a metadata import/export system (Mukurtu, n.d.). }\end{array}$ & $\begin{array}{c}\text { Montenegro, } \\
\text { 2019; Centre } \\
\text { for Digital } \\
\text { Scholarship } \\
\text { and Curation, } \\
2021\end{array}$ \\
\hline Smart city design & $\begin{array}{l}\text { The Infrastructure Canada Smart City Challenge (2017/18) invited } \\
\text { municipalities and Indigenous communities across Canada to develop } \\
\text { proposals for Smart City }{ }^{44} \text { solutions for their issues. Among the finalists } \\
\text { for the competition was a proposal submitted by the Mohawk Council of } \\
\text { Akwesasne (MCA), who deployed smart technology to overcome distinct } \\
\text { and local community issues around food access, mobility, and access to } \\
\text { information (MCA, 2018). }\end{array}$ & $\begin{array}{c}\text { Infrastructure } \\
\text { Canada, } \\
\text { 2018; MCA, } \\
2018\end{array}$ \\
\hline
\end{tabular}

\footnotetext{
${ }^{44}$ Smart cities are municipalities and communities which employ urban technologies as a means of coping with local and global challenges while maximizing resource usage (Caragliu, D Bo, Kourtit, \& Nijkamp, 2015, p.113).
} 
Movements and concerns for Indigenous data sovereignty and governance also need to be considered within the rapidly evolving digital landscape of data politics, including the scale and scope of 'big' data which obscure Indigenous data in granular collections, or open data movements which emphasize open access to information over Indigenous control and possession of data, and standardized data sharing and linkage models which may limit Indigenous authority in the access and use of their data (Carroll et al., 2019; Gupta et al., 2020; Hudson et al., 2020; Isin \& Ruppert, 2019; Kukutai \& Taylor, 2016; Marley, 2019; Pool, 2016). These trends "sit at the nexus of issues around colonization, bias, and lack of knowledge about Indigenous rights" and have emerged into prominence as Indigenous peoples are now working towards deconstructing historical colonial information systems through data governance practices, marking yet another challenge to overcome in the realm of contemporary data collection and sovereignty (Pool, 2016).

\subsubsection{First Nations, Inuit, and Métis Data Sovereignty \& Governance in Canada}

Since the RCAP recommendations, First Nations, Inuit, and Métis representative organizations and communities in Canada have directed their focus toward gaining sovereignty and the governance of their data and information in recognition of the potential and "power of data as a resource that has far-reaching ethical, legal, medical and policy implications" (Rowe et al., 2021, p.91). Data governance efforts have been approached with distinction by communities and nations and are guided by community- and culturally-driven worldviews - there is no single movement or framework for "Indigenous data sovereignty" in Canada, however there are many efforts occurring at the community, regional/provincial, and national levels to advance First Nations, Inuit, and Métis governance over information about them (Rowe et al., 2021). In Chapter 5 of this thesis I analyze these data governance efforts through a wide range of materials and content developed by organizations and institutions on the frontlines of Indigenous data 
collection and management in Canada (see: 4.2.), and in the following sub-sections I provide an introduction and history to these efforts and to the principles and practices that First Nations, Inuit, and Métis peoples have asserted in pursuit of sovereignty and governance of their data and information.

\subsubsection{First Nations OCAP Principles \& Sovereignty}

First Nations political organizations and representatives have long actively supported and asserted aspirations for the control over First Nations data (any data collected by, about, or for First Nations and regardless of where those data are held or owned) based on their fundamental and constitutionally protected right as sovereign nations to self-govern their peoples, lands, and resources, which includes information about them (FNIGC, 2019, p.58). Efforts to build First Nations capacity in information management organized in the 1990s in response to the development of multiple Federal surveys that did not include on-reserve First Nations and some smaller First Nations communities, effectively producing yet another gap in socio-economic First Nations data which has characterized the First Nations data story up until this. The response to this development was the First Nations and Inuit Regional Longitudinal Health Survey in 1997, the first Indigenous-led health survey to be conducted in Canada. Subsequently, First Nations and Inuit peoples took control of their own regional surveys and created "Regional Steering Committees" to guide and direct these Regional Health Surveys (RHS). The First Nations steering committee that implemented the first RHS would later be mandated by the Assembly of First Nations (AFN) to oversee the advancement of First Nations data interests, under the name First Nations Information Governance Centre (FNIGC) (FNIGC, 2019). The FNIGC has since continued to conduct RHSs, as well as other socio-economic surveys including the First Nations Regional Early Childhood, Education and Employment Survey (FNREES or REES), First Nations Oral Health Survey (FNOHS), the First Nations 
Community Survey (FNCS), and most recently their new survey initiative, the First Nations Labour and Employment Development Survey (FNLED) (FNIGC, 2020a).

In the process of developing the RHS, the First Nations RHS Steering Committee also developed a framework to guide and establish First Nations data governance, which they called the OCAP principles (Ownership, Control, Access, Possession ${ }^{45}$ ). Each letter represents one pillar of First Nations data governance: Ownership, or the relationship of a First Nations community to their data, regardless of who physically possesses it; Control, or the ability of First Nations to have control and authority over their own data and lives; Access, or the ability to physically access First Nations data and to determine who else can access them; and finally Possession, or the physical ownership and stewardship of data - without possessing the data, First Nations are limited in their ability to own, control, and access them (FNIGC, 2020b). Taken together, OCAP represents "the inherent right to self-determination and jurisdiction in research and information management" (FNIGC, 2019, p.61). They operate as general guiding principles and importantly their determination and interpretation will depend on the community and context, as they are not meant to be prescriptive or a doctrine but rather are to be applied in ways that will benefit the vision and priorities of community. OCAP also acts as a collective framework, and the letters of OCAP are not meant to be picked and chosen from; they only work together, and each letter of the acronym depends on each other, meaning they are all fundamentally necessary and bound in operation (FNIGC, 2020b).

The OCAP principles offer a mechanism for First Nations to integrate into their governance and information structures to secure their interests, sovereignty, and control over

\footnotetext{
${ }^{45}$ Originally, the Committee decided on only OCA - the P was later added as they determined it is fundamental that First Nations possess their data if they are to apply the other letters (FNIGC, 2020b).
} 
their data ${ }^{46}$ (FNIGC, 2016). They act as an expression of First Nations data sovereignty, which the FNIGC defines as the "concept of First Nations authority, right, power to govern as sovereign Nations and make decisions or laws on the ownership, control, collection, access, analysis, application, possession and use of their own data" - First Nations possess "an inherent and constitutionally protected right to exercise authority and jurisdiction over their community's data, in addition to a duty and responsibility to protect and safeguard their people's data" (FNIGC, 2020a, p.90). As leaders in the journey to achieve First Nations data sovereignty, the FNIGC has three primary roles related to OCAP: first, employing OCAP in all First Nations-led surveys and statistical efforts; second, supporting FNIGC regional members and partners with implementing OCAP; and third and final, the FNIGC is the steward of OCAP training, outreach, and education. OCAP is also trademarked by the FNIGC "as a protective measure against misuse, misapplication or improper interpretation of what OCAP actually means and how it is to be applied" (FNIGC, 2020a, p.63-4).

First Nations communities and organizations across Canada have charted a path toward First Nations data sovereignty through OCAP principles in several capacities and at various levels of governance. Some of these prominent efforts include:

- First Nations Data Governance Strategy (FNDGS): Building from funding allocations in Budget 2018, the FNIGC in 2020 released the FNDGS which details their phased approach to implementing a national network of regional First Nations statistical institutions, which will govern First Nations statistical priorities at a regional/local level while also integrating with other First Nations communities and the Government at a national level. The Strategy is driven by OCAP principles and the build-up of Canadian calls-to-action for supporting reconciliation and First Nations self-governance, and it

\footnotetext{
${ }^{46}$ The FNIGC notes that the concepts behind OCAP can be adopted and applied by any Indigenous peoples in the world, however it will likely need to be adapted to local contexts and data challenges (FNIGC, 2016, p.153).
} 
presses for the need for a First Nations-led ${ }^{47}$ statistical agency (RCAP, 1996a; TRC, 2015a; FNIGC, 2020a). The FNDGS is one of the high-level strategies I analyze in Chapter 5.

- The British Columbia First Nations Data Governance Initiative (BCFNDGI): The BCFNDGI leads First Nations data governance efforts in British Columbia and as of 2016 they represent and support " 13 First Nations communities from six distinct nations", who are recognized as First Nations Governments through a tripartite agreement with the province and Federal government (FNIGC, 2019, p.62-3). The BCFNDGI is driven to enable value in First Nations data through building new models of wellness and investment in First Nation communities that shift the values and relationships behind information management processes toward "community-driven, nation-based" outcomes and priorities (BCFNDGI, 2016a, p.18). To accomplish this, they offer a wide range of data governance support through tools, guidelines, manuals ${ }^{48}$, many of which are analyzed in the content analysis in Chapter 5.

- The Tui'kn Partnership: This partnership ${ }^{49}$ was formed between five First Nations in Cape Breton, NS - "Eskasoni, Membertou, Potlotek, Wagmatcook, and Waycobah" along with the Nova Scotia Department of Health and Wellness, Health Canada, and Dalhousie University, to create and integrate a mutual platform for health information sharing that enables collaboration in planning, reporting, and data management (Tui'kn Partnership, n.d.). The partnership has enabled First Nations to employ OCAP principles to own, access, and control community health data while also accessing critical external health data sources from the Federal and Provincial government (FNIGC, 2019, p.62).

\subsubsection{Inuit research in the North}

Inuit conceptions of data sovereignty are inherently tied to research practices and Federal governance in the North. Historically, these have been driven by colonial approaches

\footnotetext{
${ }^{47}$ The FNIGC emphasizes the importance that this statistical entity must be led by First Nations. This a key lesson from the failure of the First Nations Statistical Institute (FNSI), which was a legislated institution created in 2005 to support First Nations development and statistical work. FNSI dissolved in 2012 for multiple reasons: it did not respect OCAP, data could be released under the Access to Information Act, and implementation failed due to lack of funding, direction, or alignment with other Government departments (FNIGC, 2020a, p.78-9).

${ }^{48}$ BCFNDGI Data Governance Tools: https://www.bcfndgi.com/data-governance

49 Tui'kn Partnership website: http://www.tuikn.ca/
} 
that have worked to prevent Inuit from "setting the research agenda, monitoring compliance with guidelines for ethical research, and determining how data and information about [Inuit] people, wildlife, and environment is collected, stored, used, and shared" (ITK, 2018, p.4). Much of research funding in what the Federal government calls the "Arctic" or the "North" (which do not describe conceptions of Inuit homeland; see below) is focused toward biological and natural sciences and Inuit are often excluded from eligibility for receiving funding or leading research (ITK, 2018, p.4). This situation has denigrated Inuit capacities and the building and support of Inuit Qaujimajatuqangit, which is understood as Inuit epistemologies, institutions, and technologies, and directly translates to "that which Inuit have always known to be true" (NCCAH, 2010, p.1).

Inuit voices in rights, research, and data collection are led by Inuit Tapiriit Kanatami (ITK). The ITK is a national Inuit representation organization that was established in 1971 as a main driver of advancing Inuit land claims and self-determination ${ }^{50}$, and they now focus on leading Inuit initiatives and advocating for Inuit interests and priorities through four main pathways: representation at the national level; research that is self-determined and inform a complete picture of Inuit peoples and communities; policy advancement; and a united Inuit voice to engage and connect the interests of distinct communities across vast territories (ITK, 2018). They currently represent Inuit peoples in 53 communities that live across Inuit Nunangat ${ }^{51}$ and it is collectively directed by four major Inuit lands claims organizations: the Inuvialuit Regional Corporation (IRC), Makivik Corporation; Nunavut Tunngavik Incorporated (NTI); and Nunatsiavut Government (NG). These organizations legally represent Inuit peoples in dealings

\footnotetext{
${ }^{50}$ In 1979, the ITK helped develop and establish the Inuit Committee on National Issues (ICNI) who played a role in the inclusion of treaty rights in section 35 of the Constitution of Canada (ITK, 2018).

${ }^{51}$ The ITK defines Inuit Nunangat as: "a distinct geographic, political, and cultural region that encompasses nearly one third of Canada's landmass, its entire Arctic coastline, and significant offshore areas"; these territories consist of the "Inuvialuit Settlement Region, Nunavut, Nunavik, and Nunatsiavut" (ITK, 2018).
} 
with the state "[a]s signatories to Inuit-Crown treaties signed between 1975 and 2008" (ITK, 2020, p.6; ITK, 2018).

The ITK is committed to advancing the transformation of research practices with Inuit peoples. In 2018 they published the National Inuit Strategy on Research (NISR) which "outlines the coordinated actions required to improve the way that Inuit Nunangat research is governed, resourced, conducted, and shared", in the words of ITK president Natan Obed (ITK, 2018, p.3). Along with advancing Inuit-led governance, building Inuit-led capacities, and advancing ethics in research, one of the priority areas of the NISR is to "[e]nsure Inuit access, ownership, and control over data and information" (2018, p.6). While there is no definition for what constitutes Inuit data sovereignty in the Strategy ${ }^{52}$, it asserts various elements of sovereignty over data that are necessary for Inuit repatriation of research practices, including: self-determination over data collection, management, and use; building Inuit-led and owned capacities and infrastructures; and adopting culturally relevant methodologies, standards, and indicators that prioritize Inuit knowledge and languages (ITK, 2018, p.32).

Although it was in 2018 that the ITK articulated a national Inuit assertation for control and ownership over data and information about them in the NISR, Inuit communities and organizations have actively pursued control and ownership over their data and research for decades and through several projects and initiatives. Some prominent examples include:

\footnotetext{
${ }^{52}$ The ITK recognizes current networks and movements for Indigenous data sovereignty however they also assert that work is still needed to develop "processes, protocols, standards, and agreements that allow for the safe sharing certain information and for the respectful incorporation of Inuit knowledge in data management and sharing design and implementation" (ITK, 2018, p.21).
} 
- The ITK and their directing organization partners have conducted a number of Inuit-led health surveys ${ }^{53}$ since the 2000's and the original RHS which included Inuit peoples. Recently in 2019, the ITK in partnership with the Inuit Nunangat regions, Makivik Corporation, and the Nunavik Regional Board of Health and Social Services (BRNHSS) are developing and leading a new national Inuit health survey titled Qanuippitaa: National Inuit Health Survey ${ }^{54}$.

- The Geomatics and Cartography Research Centre (GCRC) at Carleton University specializes in the practice of cybercartography (see Table 3 in 2.3.1.) and they have partnered with Inuit communities in the North to digitally document local and traditional Inuit spatial knowledge in cybercartographic atlases ${ }^{55}$. The GCRC maintain and offer a digital crowd-source mapping tool called Nunaliit to enable communities to build their own interactive maps that was created according to the TK, practices and cultural values knowledge of the Elders and Inuit researchers the GCRC works with ${ }^{56}$.

\subsubsection{Métis Nations \& Citizenship data}

After the watershed repatriation of the Constitution in 1982 and the inclusion of Métis as one of three legally recognized and distinct Indigenous peoples in the Canadian constitution, the Métis National Council (MNC) was created in 1983 to represent Métis national interests through provincial governing bodies (in Quebec, Ontario, Manitoba, Saskatchewan, and British Columbia) and these national representative organizations lead a number of legal, governmental, and contemporary reconciliation and self-government efforts in Canada and within specific provincial contexts ${ }^{57}$. At the current moment, the $\mathrm{MNC}$ and its provincial governing bodies have not adopted a unified plan or vision for data sovereignty however they have discursively been building this into the self-governance efforts of each governing Nation ${ }^{58}$.

\footnotetext{
${ }^{53}$ Inuit health surveys: https://nrbhss.ca/en/health-surveys

${ }^{54}$ Qanuippitaa: National Inuit Health Survey: https://www.itk.ca/qanuippitaa/

${ }^{55}$ Efforts in Indigenous knowledge by the GCRC: https://gcrc.carleton.ca/index.html?module=module.gcrcatlas indigenousknowledge

56 The Nunaliit Atlas Framework: http://nunaliit.org/

57 The Métis Nation Gateway portal contains a comprehensive set of legal and governmental documentation and agreements related to the political development of Métis Nations and rights, including instances of early legal and constitutional recognition of Métis rights, key court decisions, and contemporary efforts for Reconciliation including accords, self-government agreements, and governance structures: https://politics.Métisportals.ca/Menu/

${ }^{58}$ Each Métis Nation for instance has an established Constitution to mandate the activities of Métis governments, and data collection has been worked into provincial relationships and mandates - the Métis Nation Relationship Accord II (2016) in B.C. for example sets out information sharing and Métis identification and data collection as primary topics in building: https://www2.gov.bc.ca/assets/gov/british-columbians-our-governments/indigenouspeople/aboriginal-peoples-documents/Métis_nation_reconciliation_accord_ii_-_nov_16_2016.pdf
} 
Central to the self-governance aspirations of Métis Nations is the reclaiming of Métis identity and control over Métis citizenship, which has historically been skewed by colonial processes and the misrecognition of Métis as an identity of mixed European-Indigenous race (Andersen, 2016). In 2002, the Métis National Council and their provincial governing members assembled and provided a national definition for Métis citizenship:

"Métis" means a person who self-identifies as Métis, is distinct from other Aboriginal peoples, is of historic Métis Nation Ancestry and who is accepted by the Métis Nation. (MNC, 2021).

This understanding of Métis identity was reaffirmed in 2003 in the court case R. v. Powley where a local hunting land dispute resulted with the Supreme Court of Canada decision that upheld Métis harvesting rights in Ontario as laid out in section 35 of the Constitution Act, 1982, however with a stipulation that the application of these rights under s. 35 requires a comprehensive method for Métis citizenship identification, in a way that is "objectively verifiable" and which can support Métis right claims and assert their distinction from First Nations and Inuit peoples. The Court ruled in line with the national Métis definition that "[s]elfidentification, ancestral connection, and community acceptance are factors which define Métis identity for the purpose of claiming Métis rights under s. 35.” (R. v. Powley, 2003 SCC 43 p. 209; MNBC, n.d.a, p.22). Each Métis Nation conducts membership activities with their own application forms and processes for registering as a Métis citizen, however they are all based upon the national definition of Métis and the need for an "objectively verifiable process", as effectively illustrated by the Métis Nation of B.C. as seen in Figure 2: 


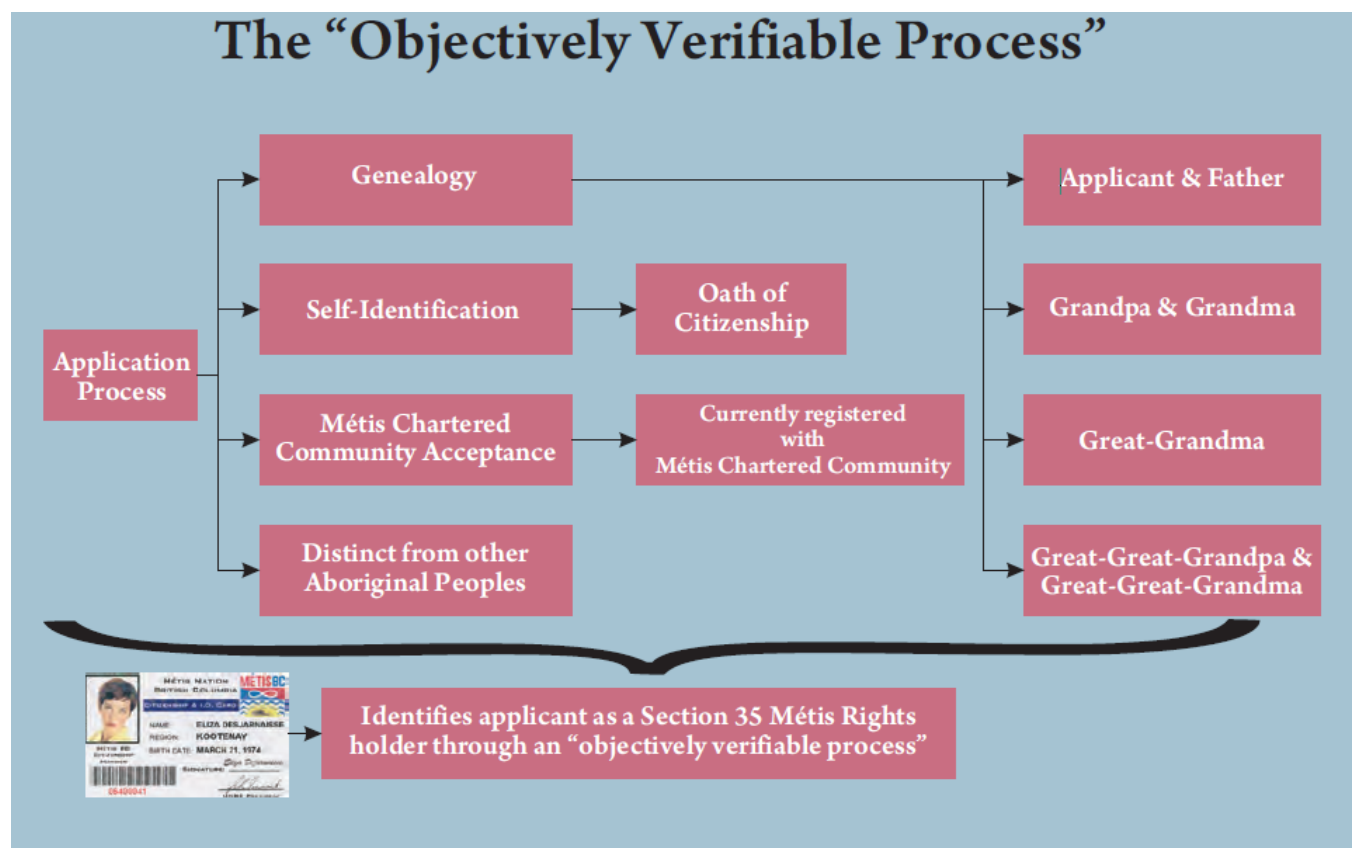

Figure 2: The "Objectively Verifiable Process" for Métis citizenship in B.C. (MNBC, n.d.a)

Efforts related to data governance have also largely been undertaken at a regional and provincial level by Métis Nation governing bodies who are stewards of their respective region's citizenship information and data, which are held in genealogy and citizenship registries that are controlled and governed by the respective Métis Nation. Multiple Nations, including the Métis Nation of Ontario (MNO), Métis Nation of Alberta (MNA), the Manitoba Métis Federation (MMF), and the Métis Nation of British Columbia (MNBC) have partnered with historical services firm Know History to build Métis-controlled databases to serve their information management needs (MNBC, 2021a), such as the Secure Archival Source Historical database (SASH) for the MNO which links citizens to historical and genealogical documentation or the current Wahkohtowin project with the MNBC which will effectively centralize and digitize their governance operations into one system/software, including membership administration, communication with citizens, and digital historical archives (Know History, 2021; MNBC, 2021a). Know History is the only Canadian firm who specializes in and develops custom registry 
systems to advance Indigenous rights and self-determination through "maintaining accurate, efficient citizenship details for Indigenous Nations" (2021).

Although not formalized at a National Métis level yet, some Métis Nations and organizations have also produced and adopted principles and frameworks related to research and data collection in Métis communities. For instance, the Manitoba Métis Federation (MMF) employs the OCAS principles to guide their data governance and management activities, which stands for: Ownership (legal possession of data); Control (the power to decide); Access (right to use something that is valuable or will produce benefits); and Stewardship (responsibility for Métis interests) (University of Manitoba, n.d., p.14). The Métis Centre at the National Aboriginal Health Organization (NAHO) has also produced a set of principles ${ }^{59}$ related to Métis-specific research, including principles related to building reciprocal relationships in research, directing outcomes toward Métis-determined goals and aspirations, and acknowledging the history of the Métis peoples to understand their complex socio-political situation in Canada (NAHO, n.d.)

${ }^{59}$ NAHO Métis ethical research principles: https://ruor.uottawa.ca/bitstream/10393/30555/1/2011_04_ethics.pdf 


\subsection{Summary of Literature Review}

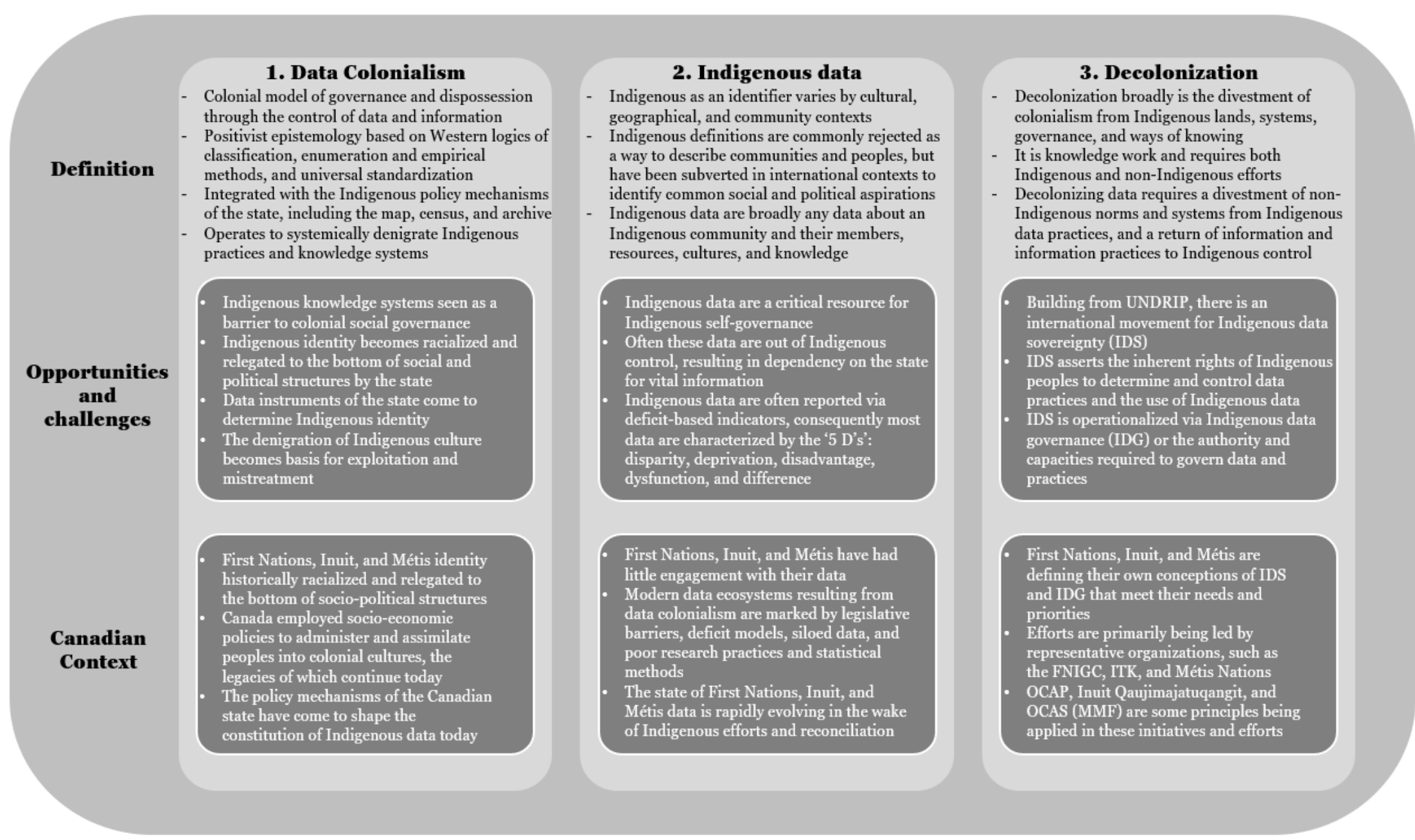

Figure 3: Summary of the Literature Review 


\section{Chapter 3: Theoretical Framework}

To answer the second part of this thesis' research question can data colonialism in Canada be decolonized through Indigenous data governance, I developed a theoretical framework to conceptualize data decolonization through three main theoretical developments: first, Ian Hacking's $(1986 ; 2007)$ theory of dynamic nominalism and the social construction of classification and "making up people"; assemblage theory as understood by Deleuze and Guattari (1987), DeLanda (2006) and later Rob Kitchin (2014) to characterize the socio-technical construction of data; and emerging conceptions of Indigenous data sovereignty and Indigenous data governance explored in Kukutai and Taylor (2016) that seek to shift and decolonize Indigenous information practices toward self-governed approaches. This approach will provide a blueprint for understanding how processes of data colonialism construct Indigenous peoples and the data that classify them, their communities, and their resources, as well as how these might be subverted, re-framed, and re-built by and for Indigenous peoples. In the following sections I describe each development and how they apply to this thesis and the analysis to follow. 


\subsection{Dynamic nominalism and making up peoples in data}

Ian Hacking, a philosopher of human sciences and the naturalistic order of classification systems, in Making Up Peoples and in subsequent works, developed what he calls a general theory of "making up people" whereby dominant conceptions of types of peoples are "invented" and become reinforced into societal constructions of peoples (1986). This understanding is based upon what Hacking calls the philosophy of dynamic nominalism:

The claim of dynamic nominalism is not that there was a kind of person who came increasingly to be recognized by bureaucrats or by students of human nature but rather that a kind of person came into being at the same time as the kind itself was being invented (Hacking, 1986, p.165).

While Hacking asserts that theories of making up people are contextual and "each category has its own history", he identifies two main vectors or poles that the process of making up people operates from: first, "labeling from above" by an expert class, who develop a "“'reality" that some people make their own"; and second, "autonomous human behaviour", which are the actions and 'pressure from below' of the classified, who create "a reality every expert must face" (Hacking, 1986, p.168). Hacking asserts that this process is inherently linked with power and social order, and argues that the category of race or ethnicity has "always been with us" and that "[c]lassifying kinds of subject people" has long developed as an imperial imperative, as the concept "that people just separate into overarching racial, ethnic, or linguistic groups is largely a product of a recent invention, the nation state" (Hacking, 2007, p.288).

While entrenched in social power, the process of making people is not static and how we see people "changes the space of possibilities for personhood" - both peoples and their classifications mutually develop and interact to shape how dominant understandings of different types of people become entrenched in societal discourse, through what Hacking later calls a looping effect or the "way in which a classification may interact with the people classified" (Hacking, 2007, p.286). Dominant understandings of peoples are "made" (constructed) and then 
"looped" (reinforced), typically by five key actors/elements": classifications of people, peoples who are classified, knowledge as bodies of understanding about peoples, experts as the peoples trained to create knowledge, and institutions which legitimize and authorize experts to create knowledge (Hacking, 2007, p.298). Hacking addresses seven ‘engines of discovery' or imperatives for making up people that have largely driven the classificatory activities of these actors/elements ${ }^{60}:$ (1) Counting peoples for all ranges of purposes from administration to research; (2) Quantifying peoples and characteristics into systems of measurement and standards; (3) Setting norms and identifying deviancy; (4) Correlating people to other phenomena and conditions; (5) Medicalising deviancies from the norm as medical problems/issues and then (6) biologizing types of peoples as biological and further (7) as based in genetics; he also adds three more engines that derive from organisation, control, administration and power: the (8) normalisation of deviancy through treatment; (9) Bureaucracy and the need to objectively determine how to distribute resources and assistance to different categories of peoples; and (10) resistance to classifications by the classified (Hacking, 2007, pp.306).

Hacking provides a general framework for how people are made, and I am interested in investigating how the power to "make people" specifically through control over data is shifting and being resisted by Indigenous peoples who since early colonization been classified, studied, and relegated to limited engagement with their own data and information. The 'engines of discovery' have long been in control by settler institutions including the state, and as explored in the literature review, settler classifications in data are driven by logics of counting, quantifying, and correlating Indigenous peoples for purposes and interests of the state and of external

\footnotetext{
${ }^{60}$ Hacking (2007) is interested in the human sciences and thus his framework for making up people addresses focuses on the drive to scientifically explore conceptions of different humans, which have been dominantly taken up by studies of medicine, biology, and genetics (throughout his framework he uses the examples of BMI and autism to illustrate his points).
} 
institutions, even to the point of extending cultural differences and socio-economic issues (largely put on by intervention by the colonial state) as markers of medical issues, biology and genetics (Kavita, 2015; FNIGC, 2019). In the nationalistic drive of the state to create model citizens of Indigenous peoples and communities, the state has also been driven by engines of normalisation and "treating" Indigeneity (i.e., cultural genocide at residential schools) and colonial classifications have been embedded in the bureaucratic practices, behaviours, and cultures of the state (FNIGC, 2020b). The policies, mechanisms, and tools of data colonialism explored in 2.1. and in Canada in 2.1.1. represent distinct processes of "making" Indigenous peoples in the eyes of the state, which as explored has and continues to carry negative implications for Indigenous governance, wellness, and inherent rights as sovereign peoples.

As I am studying the decolonization of data through current and emerging Indigenousled approaches to data governance in Canada, I focus my use of dynamic nominalism on emerging engines of resistance in which Indigenous peoples in Canada are effectively trying "to take back control from the experts and the institutions, sometimes by creating new experts, new institutions" and in the context of this thesis, new, culturally relevant data that are designed and self-determined within Indigenous worldviews and methodologies (Hacking, 2007, p.312). To characterize the operation of this engine of resistance that is centered on data, decolonization, and Indigenous control over data and practices involving them, I also adopt elements of assemblage theory as well as conceptions of IDG that have emerged in international IDS literature.

\subsection{Socio-technical assemblages of data}

Like classifications and the making of people, data are socially constructed artifacts and systems and they play a significant role in the building of knowledge and the looping of classifications across peoples, experts, and institutions - data are not classifications themselves 
but classifications may be embedded into the construction and design of data, ultimately shaping how these objects represent people and the ways in which they are deployed, managed, and used in governance and knowledge production. Data however also exist in vast ecosystems comprised of many actors, infrastructures (both human and digital), and technical processes which define their constitution, usage, and governance. Engaging with socio-technical constructions of Indigenous data is critical to understand how data ecosystems become colonized in both the social and technical domains and to attain a broad, systematic scope on how these arrangements might be resisted, restructured, and decolonized.

Assemblage theory is one approach which can effectively conceptualize data as a large, socio-technical assemblage and it usefully frames objects through an itemized catalogue of nonstatic elements that constantly are evolving and adapting. In A Thousand Plateaus (1987), philosopher Gilles Deleuze is credited (DeLanda, 2006) with first introducing the study and theory of assemblages: studying organisms and things within terms of multiplicity and components, each of which constitute the whole and operates through relations of exteriority, described by Deleuze concerning the object of the book:

A book has neither object nor subject; it is made of variously formed matters, and very different dates and speeds. To attribute the book to a subject is to overlook this working of matters, and the exteriority of their relations. It is to fabricate a beneficent God to explain geological movements. In a book, as in all things, there are lines of articulation or segmentary, strata and territories; but also, lines of flight, movements of deterritorialization and destratification. Comparative rates of flow on these lines produce phenomena of relative slowness and viscosity, or, on the contrary, of acceleration and rupture. All this, lines, and measurable speeds, constitutes an assemblage. A book is an assemblage of this kind, and as such is unattributable. It is a multiplicity... (1987, p.3-4).

Deleuze conceptualizes the nature of assemblages along segmented axis: a horizontal axis balanced between content and expression, consisting of both a "machinic assemblage of bodies, of actions and passions, an intermingling of bodies reacting to one another" as well as a "collective assemblage of enunciation, of acts and statements, of incorporeal transformations 
attributed to bodies"; and a vertical axis which stabilizes or de- then re-territorializes these dimensions when they come to interact and integrate (Deleuze, 1987, p.88). It is along these axes that the elements of an assemblage intermingle ${ }^{61}$, and where bodies of both content and expression independently and interdependently "affect bodies of all kinds in their relations to one another" (Deleuze, 1987, p.90).

Manuel DeLanda further builds on work by Deleuze and redefines assemblage theory as a means of developing a 'realist social ontology' ${ }^{62}$ which asserts the "autonomy of social entities from the conceptions we have of them" (2006, p.7). DeLanda challenges traditional social constructivist theory which takes an idealistic understanding of 'construction' as metaphorical: applying the work of Hacking himself which highlights the role of institutions and practices in social constructions (i.e. it is not only the act of classification itself that 'loops' and shapes perception of peoples and things, but also institutions, people, knowledge, experts that predicate on these classifications), DeLanda suggests that the construction of assemblages can be "conception-independent" and are constructed not as a Hegelian totality but rather as an actual assembly and "synthesis of the properties of the whole not reducible to its parts" (2006, p.9). Like Deleuze, DeLanda's framework operates upon both material and expressive axis to varying degrees and the identities of these assemblages may be stabilized with increased "internal homogeneity" or destabilized and changed into new forms of assemblages (2006, p.14). This conception and that originally explored by Deleuze highlight key elements of the nature of assemblages: the parts do not make the whole; assemblages are not static and shift; and the

\footnotetext{
${ }^{61}$ Deleuze explores this in the context of a feudal assemblage: one must consider the bodies related to class, land, social order, or the symbioses of material relations such as the machinic relation of a knight to a horse and to their tools used for riding and combat; they must also consider contexts of expression, including oaths, law, heraldry, and other enunciations that define this assemblage, and the territorialization of these elements within a greater social contexts of the time, such as the Crusades (1987, p.89).

${ }^{62}$ The realist stance is defined by DeLanda as a "commitment to the mind-independent existence of reality" - that people and things exist independent of social constructions and classifications (2006, p.1).
} 
assembly of material and expressive elements interact and form the foundation from which social constructions are formed, reproduced, or resisted.

Geographer Rob Kitchin (2014) adopts and reformulates assemblage theory within the context of studying data as a larger socio-technical system, from which he employs a critical data lens that suggests that data "are constitutive of the ideas, techniques, technologies, people, systems, and contexts that conceive, produce, process, manage, and analyze them" - data are not ever fully "raw" but are always “cooked” (Kitchin \& Lauriault, 2018, p.5-6). Like DeLanda, Kitchin highlights how assemblage theory can effectively conceptualize socio-technical constructions of interacting, independent actors, and infrastructures, and in Kitchin's case this assemblage centres on data: a data assemblage operates through entwined material and contextual apparatuses that constitute the production, collection, and management of data (2014). This assemblage of actors, institutions and materialities and infrastructures will develop and mutate over time and each element of the system interacts within a "complex web of multifaceted relationships" which "frame what is possible, desirable and expected of data" - in essence, the assemblage frames data but also supports and manages how data are produced, and "thus [data and their assemblage are] co-determinous and mutually constituted, bound together in a set of contingent, relational and contextual discursive and material practices and relations" (Kitchin, 2014, p.22-23).

Kitchin and Lauriault (2018) provide a structured and itemized overview of a data assemblage which identifies the contextual and material elements that intersect and form the political, social, cultural, and economic contexts in which data are generated, managed, and governed. A description of each element and their constituting attributes is provided in Table 4 below. I also provide examples of each element in a colonial framing, derived from the literature 
review in Chapter 2, to provide a general snapshot of how a colonial data assemblage is constituted.

Table 4: Apparatuses and elements of a data assemblage (Kitchin \& Lauriault, 2018)

\begin{tabular}{|c|c|c|}
\hline Apparatus & Elements/Actors & Examples of colonial data assemblage \\
\hline $\begin{array}{l}\text { Systems of } \\
\text { thought }\end{array}$ & $\begin{array}{l}\text { Theories, philosophies, } \\
\text { ideologies, etc. }\end{array}$ & $\begin{array}{l}\text { Colonialism; Western science; Epistemologies \& } \\
\text { truth; Positivism; Empiricism; local \& traditional } \\
\text { knowledge (TK) }\end{array}$ \\
\hline $\begin{array}{l}\text { Forms of } \\
\text { Knowledge }\end{array}$ & $\begin{array}{l}\text { Texts, reports, guides, webpages, } \\
\text { etc. }\end{array}$ & $\begin{array}{l}\text { Cartography; Census \& population statistics; archival } \\
\text { records; labels \& classifications; indicators; } \\
\text { governance }\end{array}$ \\
\hline Finance & $\begin{array}{l}\text { Funding, business models, } \\
\text { investment, etc. }\end{array}$ & $\begin{array}{l}\text { Federal funding and budgets; educational, health, and } \\
\text { social services; research grants; treaties }\end{array}$ \\
\hline Political Economy & $\begin{array}{l}\text { Policy, taxes, political climate, } \\
\text { etc. }\end{array}$ & $\begin{array}{l}\text { ICT-driven economies; data colonialism; Indigenous } \\
\text { data/policy nexus }\end{array}$ \\
\hline $\begin{array}{l}\text { Governmentalities } \\
\text { \& Legalities }\end{array}$ & $\begin{array}{l}\text { Regulations, protocols, standards, } \\
\text { laws, etc. }\end{array}$ & $\begin{array}{l}\text { Intellectual property; heritage protection; Indian } \\
\text { status; assimilation; privacy }\end{array}$ \\
\hline $\begin{array}{l}\text { Materialities \& } \\
\text { Infrastructures }\end{array}$ & $\begin{array}{l}\text { Hardware, software, databases, } \\
\text { sensors, etc. }\end{array}$ & $\begin{array}{l}\text { Digital infrastructures; databases; archives; } \\
\text { repositories }\end{array}$ \\
\hline Practices & $\begin{array}{l}\text { Techniques, behaviours, } \\
\text { methodologies, etc. }\end{array}$ & Epistemicide; Indigenous enumeration \\
\hline $\begin{array}{l}\text { Organizations \& } \\
\text { Institutions }\end{array}$ & $\begin{array}{l}\text { Agencies, academia, civil society, } \\
\text { government, etc. }\end{array}$ & $\begin{array}{l}\text { Federal, provincial, municipal governments; } \\
\text { Universities and research institutions; national } \\
\text { statistical organizations; national archives; museums }\end{array}$ \\
\hline $\begin{array}{l}\text { Subjectivities \& } \\
\text { communities }\end{array}$ & Experts, analysts, citizens, etc. & $\begin{array}{l}\text { Indigenous communities; technical experts; settlers; } \\
\text { the State }\end{array}$ \\
\hline Places & Offices, data centres, servers, etc. & $\begin{array}{l}\text { CANZUS settler states; data centres; reserves; } \\
\text { communities }\end{array}$ \\
\hline Marketplace & $\begin{array}{l}\text { Licensing, consultation work, } \\
\text { analytics, etc. }\end{array}$ & Big data extraction; commodification \\
\hline
\end{tabular}

This framework to study data is useful to organize and identify how colonial assemblages of data and their elements adapt in response to shifts in power over data governance and the decolonization of data and the means of making people, toward Indigenous control. I incorporate the data assemblage elements into my analysis of Indigenous data governance approaches in chapter 5 and later in chapter 6 I revisit this broad catalogue of colonial data to discuss how elements of Indigenous data assemblages in Canada have shifted, and challenges in this ecosystem as First Nations, Inuit, and Métis peoples continue to assert and express their right to sovereignty over data about them. 


\subsection{Indigenous data sovereignty \& Governance}

To study Indigenous data governance in Canada as an engine of resistance to colonial mechanisms of classification and data assemblages, I developed a high-level framework (see Table 5 below) of common Indigenous data governance elements that are derived from Kukutai and Taylor's (2016) seminal collection of essays in Indigenous data sovereignty (IDS) discourse (see: section 2.3.1.). IDS is conceptualized at different levels, contexts, and cover a wide range of issues according to Kukutai and Taylor (2016) however the editors provide a general direction for what IDS achieves in their introduction to the book:

The broad aim of this book is to stimulate new thinking and uncover emergent practice regarding the generation of demographic, wellbeing and community development information in ways that better respond to the self-determination aspirations of indigenous peoples. To do so it also considers the implications of UNDRIP for the collection, ownership and application of statistics pertaining to indigenous peoples and what these might mean for indigenous peoples' sovereignty over data about them, their territories, and ways of life. (Kukutai \& Taylor, 2016, p.1-2).

Within this context, Kukutai and Taylor provide a general description of IDS based upon the UNDRIP and the fundamental right of self-determination to be "the proper locus of authority over the management of data about indigenous peoples, their territories and ways of life" (2016, p.14).

Although sovereignty is the focus of the compilation, governance takes a centre stage in discussing the mechanisms that can enable IDS in settler nation states. Smith's (2016) chapter identifies data governance as the 'everyday practice of Indigenous sovereignty' that operates along two dimensions: "data for governance", or having control and access to data that support governance capabilities; and "governance of data", or the necessary governance arrangements to reframe dominant deficit narratives in Indigenous data toward Indigenous-defined priorities and determination (Smith, 2016, pp.123 \& 130). Walter and Carroll (2021) formally conceptualize Indigenous data governance (IDG) based on Smith's work as: the operationalization of IDS by 
harnessing "Indigenous decision-making across data lifecycles and ecosystems to assert Indigenous rights and interests", which is a "reciprocal relationship between data for governance and governance of data" (Walter \& Carroll, 2021, p.10-11; as derived from Smith, 2016 and Carroll et al., 2019).

Although there is no formal or structured framework provided in the book for what IDS or IDG look like ${ }^{63}$, below in Table 5 I explore some principles and elements of IDG that enable IDS that are derived from the compiled essays in Kukutai and Taylor (2016). These elements intersect with Indigenous data and practices, and I structured them around achieving three preconditions for data decolonization set out by Snipp in Kukutai and Taylor's (2016):

1. Indigenous peoples require the power to name, aka to decide who is counted within their group, and how;

2. Data collected by, with, or for Indigenous peoples should reflect Indigenous interests and priorities - 'nothing about us without us' as the slogan goes; and

3. Indigenous communities need to control access to and the use of data about them. It is argued here that it is with these preconditions that Indigenous peoples can decolonize knowledge institutions, rebuild, and imagine new approaches and methodologies for enriching their peoples and cultures, and community knowledge (Snipp, 2016).

It is important to note that the framework suggested here is not prescription; IDS will emerge differently in distinct cultural, national, and political contexts, and definitions of sovereignty and governance are also likely to take on different forms across these arrangements (Kukutai \& Taylor, 2016, p.2). A general theory of IDS however is useful to characterize common innovations, aspirations, and experiences in Indigenous data and their governance - as Smith (2016) highlights, despite having "distinctive cultural traditions, histories, and legal

\footnotetext{
${ }^{63}$ Kukutai and Taylor's introduction sets the tone of this compilation as a beginning point, but not the full conversation; the content of the book is focused on where the authors have "collective expertise - as data users in research, policy, planning, and governance" while leaving complex considerations of "legal, ethical, commercialisation, and technological issues" for future work (2016, p.2).
} 
rights", Indigenous peoples in settler CANZUS nations consider common questions related to the governance of their data (p.118). Importantly, a general approach must remain conceptual and theoretical - since there is no one 'Indigenous peoples', and each community and group of peoples will need to apply IDS to their own contexts, priorities, and legal and policy arrangements.

Table 5: Elements of Indigenous data governance, derived from Kukutai \& Taylor (2016)

\begin{tabular}{|c|c|}
\hline Element & Description \\
\hline Capacity & $\begin{array}{l}\text { IDG requires capacity in terms of both digital infrastructures and the expertise, knowledge, and } \\
\text { the skills to apply these in practice. Governance depends on having the necessary technical } \\
\text { infrastructures for effective and secure data management (Smith, 2016). Critical to harnessing } \\
\text { these technologies is expertise in "the production and management of data of all types", } \\
\text { including statistical and survey skills, administrative data skills, and technical skills (Snipp, } \\
\text { 2016, p.53). As communities and peoples seek to appropriate colonial systems of data } \\
\text { management and governance, developing expertise and capacities is necessary to make informed } \\
\text { decisions on how these systems operate, to reframe them for their own purposes (Morphy, 2016). }\end{array}$ \\
\hline $\begin{array}{l}\text { Community- } \\
\text { driven }\end{array}$ & $\begin{array}{l}\text { IDG must be driven by community in both design and process. Data and practices must "reflect } \\
\text { the interests, value and priorities" of the Indigenous peoples they describe (Snipp, 2016, p.52). } \\
\text { This is important but challenging: communities may not share unanimous views about what is } \\
\text { important or valuable, however Snipp asserts that core values "that transcend narrower interests" } \\
\text { must shape decisions about Indigenous data to protect both individuals and the community from } \\
\text { harm (2016, p.52). Heterogeneity over homogeneity. IDG importantly places emphasis not just } \\
\text { on data but on the "people who provide and govern an asset that happens to be data" (Smith, } \\
2016, \text { p.130). Leadership on a macro scale is important and required; however, it must rely on } \\
\text { transparency, inclusion, and collaboration with communities, as the effects of data collection } \\
\text { occur at both a wide and national/regional level and within each community (Smith, 2016). }\end{array}$ \\
\hline Control & $\begin{array}{l}\text { IDG places control over data collection, management, and governance into the hands of } \\
\text { Indigenous peoples and communities. Often, pervasive '5D Data' (disparity, deprivation, } \\
\text { disadvantage, dysfunction, and difference; Walter, 2016) and a lack of capacities (see Capacity in } \\
\text { this table) means that Indigenous peoples must rely on external sources which compromises } \\
\text { control over data and practices. Exercising sovereignty over data implies being in control of data, } \\
\text { their content, and what is collected and how (Snipp, 2016, p.50). }\end{array}$ \\
\hline $\begin{array}{l}\text { Ethics \& } \\
\text { Research }\end{array}$ & $\begin{array}{l}\text { IDG provides an opportunity to begin overcoming histories of poor ethics and abuse in research } \\
\text { by implementing ethics and research protocols into governance strategies. Research about } \\
\text { Indigenous peoples have long been conducted without their participation or input, and these } \\
\text { processes generate data that may produce harm on both an individual and collective level, } \\
\text { concerning issues such as privacy, confidentiality, and commodification. The role of research } \\
\text { ethics boards (REBs) is limited to ensure ethical conduct and trust; therefore, institutional } \\
\text { oversight and Indigenous collaboration in research by, for and about Indigenous peoples can } \\
\text { ensure protection of TK and intellectual property (Snipp, 2016). Rights to life, security, and the } \\
\text { maintenance and protection of cultural customs and traditions are protected under UNDRIP } \\
\text { Articles 7-13 (Davis, 2016). }\end{array}$ \\
\hline Ownership & $\begin{array}{l}\text { The ownership of data is an issue of governance (Smith, 2016). Intellectual property issues over } \\
\text { both digitalised data and cultural data (i.e., TK) are prominent in settler nations. Although } \\
\text { ownership and property are primarily Western concepts, IDG seeks to reposition ownership over } \\
\text { information about Indigenous peoples to their respective communities as a form of 'community } \\
\text { ownership' (Hudson et al., 2020). The indexed understanding of ownership in Kukutai and } \\
\text { Taylor (2016) follows the FNIGC in Canada and their OCAP principles framework, which } \\
\text { defines ownership as "the relationship of a First Nations community to its }\end{array}$ \\
\hline
\end{tabular}




\begin{tabular}{|c|c|}
\hline Element & Description \\
\hline & $\begin{array}{l}\text { cultural/knowledge/data/information... a community or group owns information collectively" } \\
\text { (FNIGC, 2016, p.149; Hudson et al., 2020). The FNIGC article asserts that this is distinct from } \\
\text { stewardship/custodianship, as communities can retain ownership on data while they are being } \\
\text { stewarded by another actor. }\end{array}$ \\
\hline $\begin{array}{l}\text { Relationships } \\
\& \\
\text { Accountability }\end{array}$ & $\begin{array}{l}\text { Relationships with external actors are necessary for the historically one-way relationship of } \\
\text { dependency to shift toward Indigenous sovereignty, control, and ownership (Morphy, 2016, } \\
\text { p.104). Governance is also related to internal relationships; self-determination of group } \\
\text { membership enables demographic data collection that can "reveal a lot about the future demands } \\
\text { on governance and services" (Smith, 2016, p.126). Accountability is critical at both ends: to } \\
\text { ensure that effective and proper data management and governance is practiced, and to hold } \\
\text { national governments accountable for data practices, and any commitments they make to } \\
\text { empowering IDG. UNDRIP was designed to guide domestic policy and law developments and to } \\
\text { provide a legal framework for the relationship of nation-states and Indigenous peoples; Articles } \\
37-46 \text { of UNDRIP provide direction on integrating Indigenous rights into domestic legal and } \\
\text { policy systems (Davis, 2016). }\end{array}$ \\
\hline $\begin{array}{l}\text { Self- } \\
\text { determination }\end{array}$ & $\begin{array}{l}\text { Snipp (2016) identifies self-determination as the "most significant feature of decolonised data" } \\
\text { (p.52). Determination over data practices, including who is counted, how, and the purposes of } \\
\text { this collection and how the data are used, are necessary for IDS (Snipp, 2016). Communities } \\
\text { must also have control and authority over access to these data (Snipp, 2016). Article } 3 \text { and } 4 \text { of } \\
\text { UNDRIP assert Indigenous rights to self-determination, including political status, socio- } \\
\text { economic development, and self-government; implementation of self-determination in social, } \\
\text { political, and economic contexts are described in Articles 32-36 (Davis, 2016). }\end{array}$ \\
\hline $\begin{array}{l}\text { Stewardship } \\
\text { \& Access }\end{array}$ & $\begin{array}{l}\text { The governance of Indigenous data is most effective when an Indigenous community is the } \\
\text { steward of these data - meaning they have the physical possession of these data and decisions } \\
\text { made about them, as well as complete access. Access to data is a critical aspect of self- } \\
\text { governance: to effectively set self-governance into motion, communities and groups need "access } \\
\text { to a range of culturally relevant and accurate information about themselves; they need data they } \\
\text { can trust" (Smith, 2016, p.118). }\end{array}$ \\
\hline
\end{tabular}

\subsection{Summary}

This theoretical framework provides the conceptual foundations to study Indigenous data governance and the decolonization of data in Canada. Dynamic nominalism, assemblage theory, and elements of Indigenous data governance theoretically situate the literature review and data colonialism and together they inform the methodology described in Chapter 4. Dynamic nominalism provides the basis for understanding how classifications are constructed, resisted, and reframed; assemblage theory itemizes and catalogues the construction of data that classify and identifies elements of colonial data assemblages to resist and reframe; and conceptions of Indigenous data governance identify the means of conducting this resistance and reframing through governance. In Chapter 6, I return to this framework to further discuss the decolonization of data and data governance in the Canadian context. 


\section{Chapter 4: Methodology}

To better understand the intersection of decolonization, sovereignty, and data governance in a First Nations, Inuit, and Métis context, this thesis applies a directed content analysis of data governance strategies, frameworks, principles, and of other documentation and knowledge produced by First Nations, Métis and Inuit organizations, the Government of Canada, international data governance frameworks, and the DAMA DMBOK Data Management Framework to identify how these systems relate and interact. As described by Hsieh and Shannon (2005), a content analysis works to find meaning and common themes across different sources of qualitative textual data and has been described as "a family of analytical approaches ranging from impressionistic, intuitive, interpretive analyses to semantic, strict textual analyses" (p.1277). Textual data for analysis in this method are found in verbal, print or electronic media forms that "might have been obtained from narrative responses, open-ended survey questions, interviews, focus groups, observations, or print media such as articles, books, or manuals"; these content forms are then examined to classify the textual data "into an efficient number of categories that represent similar meanings" (Hsieh \& Shannon, 2005, p.1278). This analysis of data governance approaches is informed by the theoretical framework described in Chapter 3 and 
it seeks to produce insight into the second part of this thesis' research question, can [data colonialism in Canada] be decolonized through Indigenous data governance?

Hsieh and Shannon (2005) define qualitative content analysis as "a research method for the subjective interpretation of the content of text data through the systematic classification process of coding and identifying themes or patterns" and highlight different approaches that are distinguished by how "coding schemes" are formulated, including conventional, directed, and summative content analyses (p.1278). Coding schemes in content analyses act as the defined categories that organize textual data around common themes or ideas. For this thesis I will utilize a directed approach which establishes coding schemes through existing theory and research as a starting point, unlike a conventional approach that derives coding categories through the textual data themselves or a summative approach which utilizes keyword counting and linguistic/rhetorical analyses (Hsieh \& Shannon, 2005, p.1277). This method is useful in the context of this thesis as I can utilize Western and/or industry conceptions of data governance and management as a starting point in the content analysis, to effectively organize and identify how processes of data governance in Canada are being reconstructed and redefined to shift colonial constructions of Indigenous data and peoples toward Indigenous determination and control.

To identify how data governance processes are reconstructed requires a framework for their constitution from a Western and industry perspective, and for this purpose I adopt the Data Management Association (DAMA)'s Data Management Body of Knowledge v.2 (DMBOK) Framework to guide my analysis and initial categories of codes. I chose the DAMA DMBOK for multiple reasons: DAMA is a global non-profit and vendor-independent professional association "dedicated to advancing the concepts and practices of information and data management and supporting DAMA members and their organizations to address their information and data management needs" (DAMA, 2021). To this end DAMA is an international leader in data and 
information management and they offer certification, training courses for data and information professionals concerning all aspects of data management, and publications including their central work, the DMBOK, the latest iteration of which was developed over 30 years through their community of experts and practitioners (DAMA, 2021).

DAMA's framework for data management and governance is extensive and provides a useful organizational structure for this analysis that is high-level, covers a wide range of contextual processes related to effective data management from a technical and organizational standpoint, and situates this discussion within a general framework that is widely adaptable to the interests of any organization or actor involved with the management and governance of data. As the concept of data governance was constructed in a Western techno-corporate context, the flexibility and adaptability of the DAMA framework makes this approach an effective starting point to begin considering how data governance processes are being subverted, reconstructed, and redefined within the epistemologies and priorities of Indigenous peoples.

The following sections will describe the foundations of the directed content analysis to follow. First, I describe the DAMA Data Management Framework, how governance is conceptualized by DAMA, and how it will be applied to coding method for the content analysis; second, I review the compiled First Nations, Inuit, and Métis data governance materials including both high-level strategic documents and applications of data governance in practice and process, which are analyzed through the lens of decolonizing data (see: Chapter 3. Theoretical Framework) and organized/coded according to the DAMA framework; and finally, I describe research interviews that were conducted with data governance experts in Canada to enhance the analysis and framing of the overall thesis study. In the following chapter I report on observations from the directed content analysis and a discussion of the analysis in the greater context of Indigenous data assemblages and classification is provided in Chapter 6. 


\subsection{DAMA DMBOK Data Management Framework}

The DAMA DMBOK provides a comprehensive framework for data management to assist organizations in deriving value from the data assets they collect, manage and use. Data management is defined by DAMA as "the development, execution, and supervision of plans, policies, programs, and practices that deliver, control, protect, and enhance the value of data and information assets throughout their lifecycles" (2017, p.17). The means and purpose of data management are far-reaching and depend on the strategic goals and visions of the organization. While the primary driver for effective data management regimes is gaining value from data, other goals could include ensuring integrity, quality, and privacy in data, protecting data from unauthorized access and use, or in the context of this thesis, repositioning control and stewardship over data and their construction. These processes importantly call for technical and non-technical governance perspectives and collaboration between, as data management encompasses both high-level management and leadership as well as technical direction for deployed technologies and systems. Although DAMA operates within organizational business language and emphasizes incentives for corporate growth and profit through data management, effective data management protocols are relevant to any organization or community involved in the management of data assets and who wishes to maintain a direction for how these assets can be effectively protected, organized, and used (DAMA, 2017). DAMA conceptualizes data management within eleven primary functions or 'knowledge areas', which are intersecting and interrelated processes that "describe the scope and context of data management activities" (DAMA, 2017, p.45). Each of these areas are illustrated in the "DAMA Wheel" (see Figure 4 Below). 


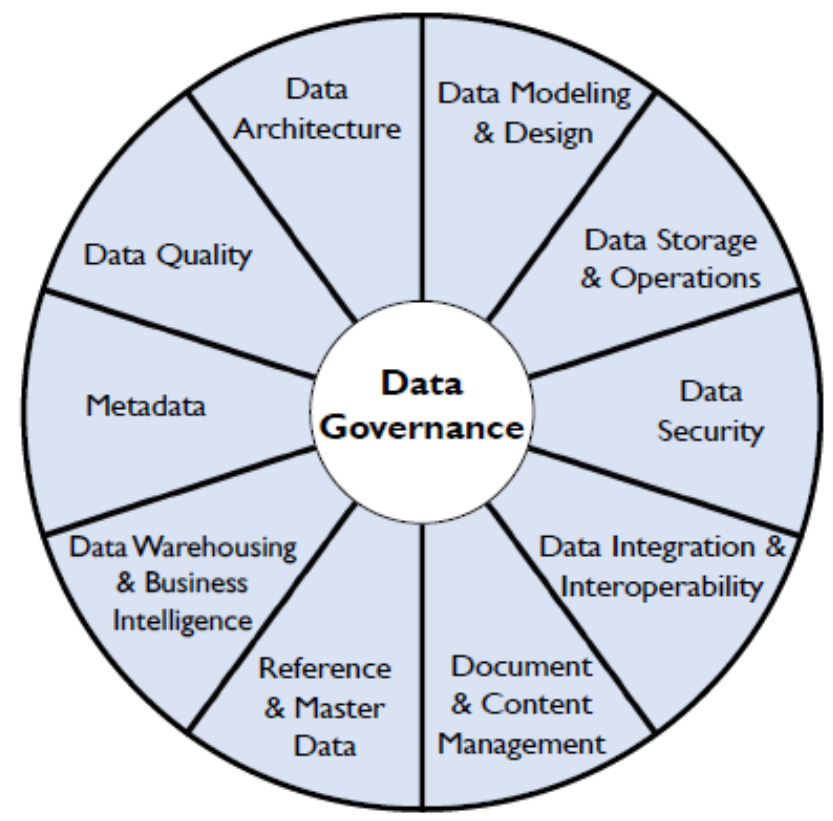

Figure 4: The DAMA Wheel and Knowledge Areas of data management (DAMA, 2017, p.36).

The core foundation to effective data management according to the DMBOK is data governance, which they define as the exercise of authority and control (planning, monitoring, and enforcement) over the management of data assets" (2017, p.67). These are processes and decisions that must be considered about data in any arrangement, however establishing a formal program for data governance allows organizations to "exercise authority and control with greater intentionality", thereby allowing them to "increase the value they get from their data assets" (DAMA, 2017, p.67). DAMA asserts that a data governance program in principle must aim to be sustainable, or an "ongoing process that requires organizational commitment"; embedded, where it is implemented across all data activities and not just as an "add-on process"; and measured, so starting points can be identified and improvement can be planned (2017, p.71). Data governance is itself a knowledge area, however it has a special role and is placed at the centre of the wheel "since governance is required for consistency and balance between functions" (DAMA, 2017, p.35). 
DAMA identifies how governance is technically applied to each Knowledge Area and this thesis will extend this foundation and identify how Indigenous data governance in Canada works to reconstruct data governance processes within Indigenous-defined principles. To accomplish this, I adopt the Knowledge Areas as defined by DAMA as the initial codes for the directed content analysis. The content across all compiled materials are analyzed and organized by these codes and within each of these areas I apply the theoretical framework to identify how IDG elements emerge in a First Nations, Inuit, and Métis context; key Indigenous-defined activities and planned outcomes; and specific technical drivers (tools, techniques, and metrics) that have been and are being deployed to reconstruct data governance arrangements and assemblage elements and actors that intersect with each Knowledge Area.

I also take inspiration from DAMA's framework which uses context diagrams to conceptualize data management in each Knowledge Area and the related business drivers, inputs/activities/outputs, and technical drivers. Figure 5 below is a template provided by DAMA of a generic context diagram, which is notably machine-like in organization and function: 


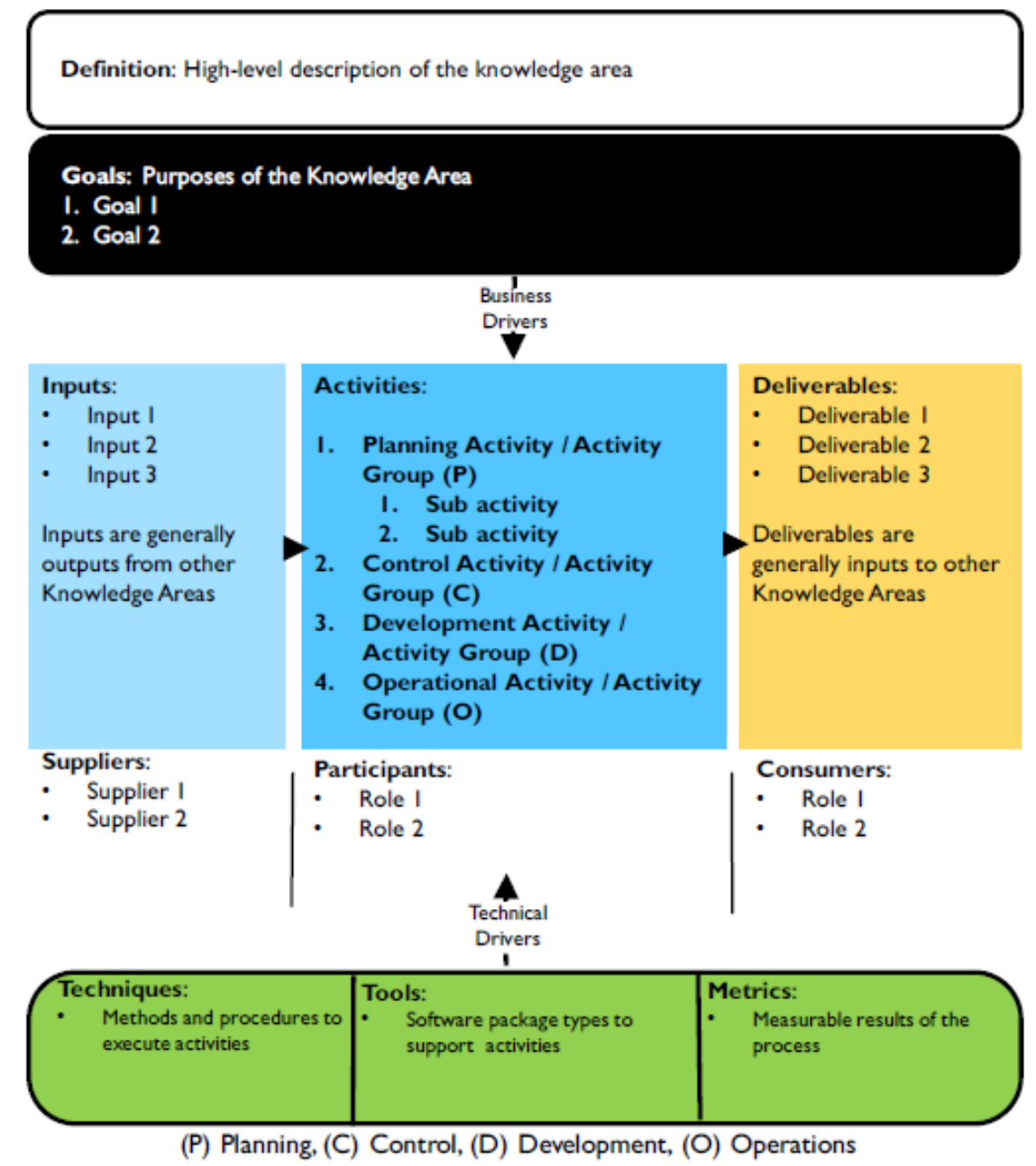

Figure 5: Knowledge Area Context Diagram Template (DAMA, 2017, p.37).

To fit the context of this thesis and for the sake of brevity, I focus the context diagram's scope to data governance specifically rather than all data management functions broadly and I emphasize IDG elements from the theoretical framework over business-driven incentives and outputs. I opt to include technical drivers to illustrate how high-level, Indigenous-defined governance principles emerge in practice and I also refer to intersecting assemblage actors and elements and guidance materials in the Canadian context (manuals, guides, frameworks, templates, etc.). This modified context diagram (see the template in Figure 6 below) illustrates how each Knowledge Area was internally coded and is used to guide the analysis of each Knowledge Area in the following chapter. 


\section{Name of Knowledge Area}

Definition: High-level description of this Knowledge Area, as derived from the DAMA-DMBOK2 Data

Management Framework.

Governance: Description of how data governance is situated within this Knowledge Area, as defined by the DMBOK2. Includes an overview of the main goals and purpose of governance in this Area and why governance is necessary here for effective data management.

\begin{tabular}{|c|c|c|}
\hline & Governance Drivers & \\
\hline $\begin{array}{l}\text { IDG Elements + } \\
\text { Themes } \\
\text { This section identifies } \\
\text { the primary elements } \\
\text { of IDG that intersect } \\
\text { with this Knowledge } \\
\text { Area, as understood } \\
\text { and derived from the } \\
\text { theoretical framework } \\
\text { (section 3.3). } \\
\text { I also provide } \\
\text { governance sub-themes } \\
\text { for each element that } \\
\text { emerged as sub-codes } \\
\text { in the DCA and that are } \\
\text { specific to the Canada- } \\
\text { based governance } \\
\text { materials explored. }\end{array}$ & $\begin{array}{l}\text { Activities } \\
\text { Here I identify primary activities in this Knowledge Area } \\
\text { that were derived from the analyzed data governance } \\
\text { materials. An activity is defined by DAMA as: "actions } \\
\text { and tasks required to meet the goals of the Knowledge } \\
\text { Area" (p.38); for the purposes of this thesis, they } \\
\text { describe actions and tasks required to address preceding } \\
\text { governance themes in pursuit of the outcomes that } \\
\text { follow. } \\
\text { This list is not meant to be exhaustive or to define the } \\
\text { only approaches to governing this Knowledge Area, } \\
\text { however it will provide a snapshot of approaches being } \\
\text { applied by major First Nations, Metis, and Inuit } \\
\text { organizations and communities in Canada as well as } \\
\text { other governmental- and NG-organizations and agencies } \\
\text { which collect, manage, and govern First Nations, Metis, } \\
\text { and/or Inuit data. They are defined here at a very high- } \\
\text { level and it is emphasized that these emerge differently } \\
\text { depending on context and in practice they rely on self- } \\
\text { determination by First Nations, Inuit, and Metis } \\
\text { communities }\end{array}$ & $\begin{array}{l}\text { Outcomes } \\
\text { This section will } \\
\text { identify the main } \\
\text { ambitions, goals, and } \\
\text { desired results of using } \\
\text { IDG approaches in this } \\
\text { Knowledge Area. These } \\
\text { are generally derived } \\
\text { from the priorities } \\
\text { stated in the data } \\
\text { governance materials } \\
\text { analyzed. } \\
\text { These outcomes are } \\
\text { linked to governance in } \\
\text { this Knowledge Area } \\
\text { however they may also } \\
\text { intersect across Areas } \\
\text { and relates directly to } \\
\text { decolonization (as } \\
\text { conceptualized through }\end{array}$ \\
\hline
\end{tabular}

Socio-technical Actors

Here I conceptualize the socio-technical assemblage actors (see section 3.2. of Theoretical Framework) that intersect and interact with this Knowledge Area of data governance. This will identify how data governance in this Area interacts with the socio-technical construction of data as well as the primary elements and actors that IDG seeks to reframe and rearrange in favour of Indigenous-defined methods, activities, and outcomes.

\begin{tabular}{|c|c|c|}
\hline & Technical Drivers & \\
\hline $\begin{array}{l}\text { Techniques } \\
\text { Techniques are "the methods and } \\
\text { procedures used to perform } \\
\text { activities", including conventions, } \\
\text { best practices, standards, and } \\
\text { protocols (DAMA, 2017, p.39). }\end{array}$ & \begin{tabular}{l}
\multicolumn{1}{c}{ Tools } \\
Tools are "the applications and \\
other technologies that enable the \\
goals of the Knowledge Area" \\
(DAMA, 2017, p.39).
\end{tabular} & \begin{tabular}{l}
\multicolumn{1}{c}{ Metrics } \\
Identifies "measurable facets of the \\
work that is done within each \\
Knowledge Area" (DAMA, 2017, \\
p.39). I will include important \\
metrics to track defined by First \\
Nations, Metis, and Inuit groups.
\end{tabular} \\
\hline
\end{tabular}

Figure 6: Modified Knowledge Area Context Diagram used in the content analysis to study IDG in Canada (based on DAMA context diagram (DAMA, 2017, p.37).

\subsection{Textual data sources}

For the content analysis I compiled a range of data governance documents and textual sources from major First Nations, Inuit, and Métis organizations in Canada, the Federal and Provincial government(s), international organizations, and Canadian institutions who work with Indigenous data. The sources primarily take the form of high-level strategies and frameworks for data governance as well as practical applications and tools for implementing and enforcing a data 
governance program in Canada. These textual sources are critically analyzed in the following chapter through a lens of decolonizing data, as discussed in Chapter 3: Theoretical Framework. This analysis is organized using the DAMA DMBOK Knowledge Areas as an overarching framework and the modified context diagrams to conceptualize how First Nations, Inuit, and Métis -led organizations are reconstructing data governance approaches, and by extension the colonial assemblages of First Nations, Inuit, and Métis data in Canada.

High-level conceptualizations of data governance in an Indigenous context are derived from the frameworks, strategies, and principles (Table 6) that are developed by organizations in Canada who are on the frontlines of Indigenous data collection, management, and governance. This list is not meant to be exhaustive, however it should be noted that Indigenous approaches for data governance in Canada are beginning to emerge as they sit at the critical juncture of cutting-edge data processing technologies, Indigenous-led movements for sovereignty, and histories of institutional marginalization and technology divides within Indigenous communities. Formal data governance structures are also developing in terms of capacity, they are skill- and asset-intensive, in the Canadian Indigenous context they will require agreements and collaboration with Federal and Provincial governments, and ultimately a lot of time and effort will be required to form and normalize these relationships and technical capacities.

In addition to high-level data governance approaches, applications of data governance in practice were investigated and are analyzed in the directed content analysis (Table 7). There is a broader range of producers surveyed here - although many organizations may not yet have an overarching and defined high-level Indigenous data governance program, they may produce and utilize policies, tools, and guides for performing and governing effective functions of information management. Perspectives come from First Nations, Métis and Inuit national representatives and organizations, the Government of Canada, and international organizations. 
Table 6: High-level data governance content analyzed in the directed content analysis

\begin{tabular}{|l|l|l|l|}
\hline Producer & Title & Year & Type \\
\hline \multirow{4}{*}{ BCFNDGI } & BCFNDGI Data Governance Framework & $2015 \mathrm{a}$ & Framework \\
\cline { 2 - 4 } & BCFNDGI Strategic Framework & $2016 \mathrm{a}$ & Strategy \\
\cline { 2 - 4 } & Data Governance \& Accountability Model & n.d. & Model \\
\hline \multirow{3}{*}{$\begin{array}{l}\text { First Nations Information } \\
\text { Governance Centre }\end{array}$} & First Nations Data Governance Strategy & $2020 \mathrm{a}$ & Strategy \\
\cline { 2 - 4 } & OCAP® principles & $2020 \mathrm{~b}$ & Principles \\
\hline \multirow{2}{*}{$\begin{array}{l}\text { Government of Nunavut } \\
\text { (NCCAH, 2010) }\end{array}$} & $\begin{array}{l}\text { A Data Strategy for the Federal Public } \\
\text { Service }\end{array}$ & 2018 & Strategy \\
\cline { 2 - 4 } $\begin{array}{l}\text { Inuit Tapiriit Kanatami } \\
\text { (ITK) }\end{array}$ & $\begin{array}{l}\text { Indigenous research and training in } \\
\text { Canada 2019-2022 }\end{array}$ & $2020 \mathrm{c}$ & Strategy \\
\hline \multirow{2}{*}{ ICES } & Inuit Qaujimajatuqangit & 2010 & Principles \\
\cline { 2 - 4 } & National Inuit Strategy on Research & 2018 & Strategy \\
\hline
\end{tabular}

In addition to document resources, I enrolled in and completed The Fundamentals of $O C A P \circledR(2020)$ training course that is offered by Algonquin College in partnership with the FNIGC. This course explores the meaning of OCAP principles, how they apply in practice, and the barriers to their implementation through seven modules on topics including OCAP implementation, community harm, and barriers and levers for OCAP (FNIGC, 2020b). Transcriptions of the modules offered through the course are utilized in the analysis as textual data concerning OCAP principles. The course offers a thorough and example-laden walkthrough of the development of OCAP principles and how they operate in practice, and can benefit any individual or organization interested in research involving First Nations peoples or in data governance approaches more broadly ${ }^{64}$.

\footnotetext{
${ }^{64}$ The Fundamentals of $O C A P \circledR$ is a paid program that requires registration through Algonquin College's corporate training Brightspace platform. More details can be found at https://fnigc.ca/ocap-training/take-the-course/
} 
Table 7: Practical applications of data governance that are analyzed in the directed content analysis

\begin{tabular}{|c|c|c|c|}
\hline Producer & Title & Year & Type \\
\hline \multirow[t]{2}{*}{ AFNIGC } & $\begin{array}{l}\text { Framework for a Data Sharing } \\
\text { Agreement }\end{array}$ & n.d.a & Guidelines \\
\hline & Privacy Law Template & n.d.b & Guidelines \\
\hline \multirow{5}{*}{ BCFNDGI } & The Data Governance Policy Manual & $2015 b$ & Manual \\
\hline & The Privacy and Security Policy Manual & $2015 c$ & Manual \\
\hline & $\begin{array}{l}\text { Measuring Wellness: An Indicator } \\
\text { Development Guide for First Nations } \\
\text { (Geddes, 2015) }\end{array}$ & 2015 & Guidelines \\
\hline & CRIMSIN (Phillips, n.d.) & n.d. & Tool \\
\hline & $\begin{array}{l}\text { The } 7 \text { C's: A First Nations Guide to } \\
\text { Planning and Reporting Standards }\end{array}$ & $2016 b$ & Guidelines \\
\hline $\begin{array}{l}\text { Centre for Digital } \\
\text { Scholarship and Curation }\end{array}$ & Mukurtu CMS & 2021 & Tool \\
\hline CIPPIC \& Carleton GCRC & $\begin{array}{l}\text { An Open Licensing Scheme for } \\
\text { Traditional Knowledge }\end{array}$ & 2016 & License \\
\hline \multirow{2}{*}{$\begin{array}{l}\text { First Nations Information } \\
\text { Governance Centre (FNIGC }\end{array}$} & $\begin{array}{l}\text { First Nations RHS - Code of Research } \\
\text { Ethics }\end{array}$ & 2007 & Code of Ethics \\
\hline & Fundamentals of OCAP $\AA$ & $2020 \mathrm{~b}$ & Training \\
\hline Government of Canada & $\begin{array}{l}\text { Tri-Council Policy Statement } 2 \text { (CIHR, } \\
\text { NSERC, \& SSHRC, 2019) }\end{array}$ & 2019 & Policy \\
\hline ITK & $\begin{array}{l}\text { Inuit Nunangat Research Program - } \\
\text { Program Guide }\end{array}$ & n.d. & Guidelines \\
\hline \multirow{2}{*}{$\begin{array}{l}\text { Métis Nation of B.C. } \\
(\mathrm{MNBC})\end{array}$} & MNBC Citizenship Act & 2019 & Legal Act \\
\hline & MNBC Registry Database RFP & n.d.b & $\begin{array}{l}\text { Request for } \\
\text { proposals }\end{array}$ \\
\hline Métis Nation of Ontario & MNO Registry Policy & 2019 & Policy \\
\hline $\begin{array}{l}\text { Natural Resources Canada } \\
\text { (NRC) }\end{array}$ & $\begin{array}{l}\text { Dissemination of Open Geospatial Data } \\
\text { under the Open Government Licence- } \\
\text { Canada through OCAP }{ }^{\circledR} \text { principles } \\
\text { (Hackett et al., 2019) }\end{array}$ & 2019 & Report \\
\hline \multirow[b]{2}{*}{ Statistics Canada } & $\begin{array}{l}\text { Aboriginal Peoples Survey (APS) } \\
\text { Concepts and Methods Guide }\end{array}$ & 2017 & Guidelines \\
\hline & $\begin{array}{l}\text { First Nations in Canada Health and } \\
\text { Wellness Indicators, Quick Stats, } 2018 \\
\text { Edition }\end{array}$ & 2018 & Guidelines \\
\hline $\begin{array}{l}\text { Tripartite Partnership } \\
\text { (FNHA; Gov. of B.C.; Gov. } \\
\text { of Canada) }\end{array}$ & $\begin{array}{l}\text { Tripartite Data Quality and Sharing } \\
\text { Agreement }\end{array}$ & 2020 & $\begin{array}{l}\text { Data Sharing } \\
\text { Agreement }\end{array}$ \\
\hline Tui'kn Partnership & $\begin{array}{l}\text { Privacy Policy and Procedures - } \\
\text { Unama'ki Health Centres Template }\end{array}$ & 2015 & Guidelines \\
\hline
\end{tabular}




\subsection{Research Interviews}

To supplement the compiled data governance materials and to advance my understanding of complex issues of governance and sovereignty in Indigenous data, I consulted a small sample of data governance experts and professionals working in Canada at organizations that actively manage and govern First Nations, Inuit, and Métis data and/or who seek to advance Indigenous rights over this governance. The interviews were conducted to clarify conceptions and principles of data governance from a First Nation, Métis, and Inuit as well as a Federal Government perspective. These discussions greatly enhance the content analysis by providing and clarifying information about approaches to various aspects of data management and governance that may be lacking in literature and documentation - approaches are contextual, varied, and may be situated in different phases of a data management strategy's evolution. In addition, the interviews assisted in guiding my own understanding of current Indigenous data issues in Canada, how they have developed historically, and what it means to decolonize these realities in Canada.

I reached out to organizations in Canada including the FNIGC, Métis Nation of Alberta, Métis Nation of Manitoba, Métis Nation of Ontario, Inuit Tapiriit Kanatami, and multiple public servants with data-related roles and across various departments under Crown-Indigenous Royal Affairs Canada (CIRNAC). From this outreach four interested participants were identified (I provide a brief bio for each in Table 8 below). The interviews were about sixty minutes each and followed a semi-structured interview format. This consisted of open-ended questions about the organization's work on data governance and the principles, practices and frameworks followed to achieve it. Participants were consulted on whether they were to be attributed in the work of this thesis, so some participants are referred to generally here to ensure discretion and anonymity in these cases. Transcriptions of the interviews, obtained with the informed consent of the 
participants, are included in the directed content analysis as textual data. This work was reviewed and cleared by the Carleton University Research Ethics Board A (see the Ethics Approval documentation in Appendix 1, and the semi-structure question base in Appendix 2). Upon completion and the successful defence of this thesis, I will share the final document and presentation of this with each of the participants listed in Table 8 to thank them for their efforts. Also, should they request it, I will happily present the work to them.

Table 8: Research interview participant biographies

\begin{tabular}{|c|c|c|}
\hline Participant & Institution & Biographical background \& Topic expertise \\
\hline Chris Gall & $\begin{array}{l}\text { Métis Nation of } \\
\text { British Columbia }\end{array}$ & $\begin{array}{l}\text { Chris is the Chief Public Affairs Officer and General Legal } \\
\text { Counsel at the MNBC. He has an extensive background in } \\
\text { research and cartography, including community-level research } \\
\text { where he assisted in digitizing and archiving the TK of a local } \\
\text { community in B.C. Chris has also worked to advance Indigenous } \\
\text { interests at a national and international level, including } \\
\text { representing Canada at the UN Framework Convention on } \\
\text { Climate Change (UNFCCC) in } 2019 \text { (MNBC, 2021b). }\end{array}$ \\
\hline $\begin{array}{l}\text { Erin } \\
\text { Corston }\end{array}$ & $\begin{array}{l}\text { First Nations } \\
\text { Information } \\
\text { Governance } \\
\text { Centre (FNIGC) }\end{array}$ & $\begin{array}{l}\text { Erin is a member of the Chapleau Cree First Nation (including } \\
\text { being an elected Treaty Land Entitlement Trustee) and she works } \\
\text { with the FNIGC as a Senior Advisor on Partnerships \& Capacity } \\
\text { to implement their First Nations Data Governance Strategy } \\
\text { (FNIGC, 2020a). Erin is passionate about gaining control over } \\
\text { data about the environment and she has over twenty years of } \\
\text { experience working toward the advancement of First Nations } \\
\text { policies and programs, including work with the Native Women's } \\
\text { Association of Canada (NWAC). }\end{array}$ \\
\hline Pat Foster & $\begin{array}{l}\text { First Nations } \\
\text { Information } \\
\text { Governance } \\
\text { Centre (FNIGC) }\end{array}$ & $\begin{array}{l}\text { Pat is a former project manager at Statistics Canada and he has an } \\
\text { extensive background in Federal statistics and accounting. He is } \\
\text { also a long-time business owner and continues to operate his } \\
\text { company Bearfoot Data Solutions. Pat has now has taken on a role } \\
\text { with the FNIGC in his retirement to assist in implementing the } \\
\text { FNDGS (FNIGC, 2020a) on the Partnerships \& Capacity team. }\end{array}$ \\
\hline $\begin{array}{l}\text { Government } \\
\text { of Canada } \\
\text { Public } \\
\text { Servant }\end{array}$ & $\begin{array}{l}\text { Crown- } \\
\text { Indigenous } \\
\text { Relationships and } \\
\text { Northern Affairs } \\
\text { Canada } \\
\text { (CIRNAC) }\end{array}$ & $\begin{array}{l}\text { At the request of the participant, they will remain anonymous here } \\
\text { and in the analysis. I spoke with a public servant at CIRNAC on } \\
\text { emerging topics in the relationship between the Crown and } \\
\text { Indigenous peoples related to data, including on the topic of } \\
\text { capacity building, institutional change, treaties, and self- } \\
\text { governance. }\end{array}$ \\
\hline
\end{tabular}




\section{Chapter 5: Observations of Directed Content Analysis}

This chapter contains the results of the directed content analysis described in Chapter 4 . This analysis of Indigenous data governance materials in Canada is guided and organized using elements from the DAMA Data Management Framework (chapter 4.1.), which acts as the foundational approach of data governance from an industry standard which is used to 'direct' the coding and analysis through the data management Knowledge Areas identified by DAMA. Using the framing of Knowledge Areas, I analyze the data governance materials compiled from First Nations, Inuit, and Métis organizations and communities, provincial governments and the Federal government, and private institutions who work with First Nations, Inuit, and Métis, and I apply the theoretical framework (Chapter 3 ) to guide this analysis and to identify ways that Western data and data governance systems are being resisted, reframed, and reconstructed by and for Indigenous peoples through processes of IDG. All the Knowledge Areas identified by DAMA were utilized as the initial codes for the analysis of the data governance materials. Qualitative textual data were extracted from the materials and organized by code, and these collections were each further analyzed and coded by the elements/themes of IDG identified in chapter 3.1.2. (capacity, community-driven, control, ethics \& research, ownership, relationships, 
self-determination, and stewardship \& access). From the coding, I derived significant activities, outcomes, and technical drivers (tools, techniques, and metrics) that support Indigenous data governance in each Knowledge Area, which I highlight in the modified context diagrams for each Area (Figure 6). This approach not only establishes a structured way in which to study IDG in Canada, but it also serves to conceptually extend the DAMA DMBOK with Indigenous data principles, priorities, and epistemologies.

After the initial rounds of coding and assigning content to Knowledge Areas, I found that three Knowledge Areas were predominantly technical in nature and are better suited to be included within the context of other Knowledge Areas, specifically Metadata, Data Warehousing \& Business Intelligence, and Reference \& Master Data. This is not to say that these Areas are not important in IDG; on the contrary, they are vital technical functions of data management and do require governance in the form of oversight, reporting, and accountability mechanisms, and they were not absent in the materials analyzed; these Areas however are not prominent in high-level approaches and Indigenous contexts, and the focus of this analysis is on the intersection of social and political Indigenous data issues with technical design, processes and practices of data governance. Due to the overlapping nature of Knowledge Areas and of data governance, these Areas do emerge in the analysis of other Areas however they do not take a primary focus.

In the following sections, I explore observations from the content analysis of First Nations, Inuit, and Métis data governance materials and research interviews in the context of the remaining knowledge areas - Data governance, data architecture, data storage \& operations, data integration \& interoperability, data security, data quality, and document \& content management. Each section contains a modified context diagram which provides an overview and summary of IDG in that Knowledge Area and specific contexts related to Canada and First 
Nations, Inuit, and Métis data governance processes and practices. In each section I also highlight a sample of governance tools being employed to assert and advance First Nations, Inuit, and Métis conceptions of IDS and IDG in Canada. The final section of this chapter provides a summary of the observations and coding results and in Chapter 6 I discuss the findings within a broader scope related to data governance, sovereignty, and decolonization in Canada.

\subsection{Data Governance}

Data governance (DG) in the DAMA framework is a central process that enables data management and generally consists of vital oversight mechanisms, planning and reporting, and operational control over all other data management Knowledge Areas and activities. Although elements of data governance are critical in the management of data generally and across other Knowledge Areas (decisions about data must be made), data governance also constitutes a Knowledge Area in itself as establishing a data governance program allows data stewards to exercise control over data processes, gain value from the data they control, and to ensure that the management of these data follow established policies and best practices (DAMA, 2017, p.67).

These processes are not universal and will depend on the contexts and needs of the steward, but they generally include high-level and enterprise-wide ${ }^{65}$ mechanisms such as strategies, policies, standards, and other practices related to oversight, compliance, and management processes. The corporate IT-scope of the DAMA DMBOK broadly considers an enterprise to be a business organization that manages and governs data; in the context of this thesis and First Nations, Inuit,

\footnotetext{
${ }^{65}$ DAMA refers to an enterprise perspective as one that encompasses the entire "scope and range of data within an organization" - data move both horizontally and vertically through organizations, data are produced in multiple places, and sometimes they are unique to a department of section of the organization (DAMA, 2017, p.27). What enterprise entails to different organizations and communities will depend on their scope and mandate. Data governance is most effective when applied to a defined enterprise rather than as an isolated effort (DAMA, 2017, p.79).
} 
and Métis data governance, I consider an enterprise to be any Indigenous actor, including communities, self-governing Nations, band councils, representative organizations such as the FNIGC, or other Indigenous organizations, who are actively asserting and approaching data management and governance practices within their own context. An enterprise-level perspective in this understanding would be the scope of data that one of these actors aspires to govern and manage, whether it be community-level socio-economic indicators or national-level surveys and statistics, and whether it be within or a shared enterprise where many organizations agree as an entity to manage their data.

From a corporate/techno-business perspective, data governance is an essential Area to steer the visions, direction, and alignment of data to, from, and across enterprises to maximize the value derived from data assets (DAMA, 2017). It demands consideration for broader, system thinking and agenda planning that meets the needs, priorities, and visions of actors at multiple levels, and so governance and data architecture (5.2.) go together. As the directed content analysis overall focuses on data governance as it emerges across different Knowledge Areas, here data governance is explored and conceptualized as a Knowledge Area related to the production, articulation, and communication of high-level data governance programs that can be further applied to the contexts of other Knowledge Areas.

As explored in chapter 2.3 of the literature review, First Nations, Inuit, and Métis peoples are exploring their own conceptions of and methodologies for data governance, as would any organization, and this work is occurring at all levels, from community-based and citizenlevel monitoring to nationally scoped strategies (such as the First Nations Data Governance Strategy). The direction of a data governance strategy, according to DAMA, and how it is articulated, will depend on the values and principles around data management, organizational 
cultures $^{66}$, and what they aspire to gain from the data they create, manage, and use (DAMA, 2017). The values and organizational culture of Indigenous organizations, communities, and nations have data ecosystems (2.2.1) and histories of colonial governance, misrecognition, and classification (2.1.1), therefore high-level approaches are distinct, and are driven by common themes of community, relationships between communities and with external actors, and there is a common aspiration here for control over the governance and stewardship of data as follows:

- Community-driven/Ownership. Hundreds of distinct Indigenous communities in Canada since colonial intervention have had their interests grouped, homogenized, and defined by external systems of governance, without their engagement or consultation. As the national representatives of these communities now seek to assert data sovereignty and assume control over setting the data governance agenda as well as data that they own, these interests are being repositioned toward community-driven ideals, priorities, and visions for their information (BCFNDGI, 2015a; FNIGC, 2020a).

- Relationships \& Accountability. First Nations, Inuit, and Métis data are largely in control of external actors and governance efforts to access, link, or repatriate these data necessitates collaboration and interoperability with external actors and sources of data (FNIGC, 2020a). As First Nations, Inuit, and Métis are collaborating and determining data priorities and visions at national and regional levels, there are also critical relationships being managed with and between communities, to ensure that data governance benefits the collective interests of all communities and peoples.

- Self-determination/control. Interests in data governance by First Nations, Inuit, and Métis peoples in Canada are founded on a common understanding of the value in data assets for governance as well as a recognition that not only have these assets long been out of Indigenous control but also, they have been mobilized and equipped by external actors in ways which denigrate Indigenous systems and ways of knowing (see section 2.1). Shifting toward Indigenous control and the decolonization of data means that

\footnotetext{
${ }^{66}$ Organizational cultures, or the behaviours and dispositions of an organization/community, are important for aligning data governance activities in several ways: the level of detail required in standards and documentation, the definition of roles for management and governance activities, communication styles, ethical compliance, and in determining operating models (DAMA, 2017, p.61, 70, 89, 556, 608).
} 
ontological and epistemological values at the foundation of governance practices are defined and determined by Indigenous peoples, and they can represent culturally fit values rather than those defined by settlers (Smith, 2016).

\subsubsection{Data Governance Activities}

Data governance activities and efforts support the development, direction, and alignment of strategy which provides the foundation to employ data assets to meet goals and aspirations related to data. Establishing a formalized program or approach to data governance allows organizations and communities to distribute responsibility and roles for data-related decision-making; to communicate clearly "what is being governed and who is being governed, as well as who is governing"; and to enable enterprise efforts (see Data Architecture 5.2.) and integration (5.4.) (DAMA, 2017, p.79). Data governance as a program ideally becomes embedded deeply as a continuous process in data management and in the tools, techniques, and technologies which manage and handle data. It is "fundamentally about organizational behaviour", and governance issues are people centered - they are not problems "that can be solved through technology" (DAMA, 2017, pp.91-2).

First Nations, Inuit, and Métis communities and organizations are employing data governance activities, tools, and techniques to overcome challenges faced by colonial systems of information governance and to 'reimagine' new methodologies and epistemologies from an Indigenous perspective, as Duarte and Belarde-Lewis (2015) would suggest. Within this Knowledge Area of high-level governance planning, organizations and communities are actively (1) defining visions and scope of sovereignty over data; (2) developing and adapting high-level governance strategies, frameworks, and principles; and (3) implementing high-level governance in practice within communities. 


\section{- (1) Vision and scope.}

Articulating a vision for what data sovereignty means and the scope of governance to achieve it, positions First Nations, Inuit, and Métis toward strategizing and planning for the return of information capacities and governance over their peoples, communities, and resources. High-level direction is a fundamental element of data governance in DAMA, which states: "It is essential to clarify the particular business drivers for data governance within an organization and to align them with overall business strategy" (DAMA, 2017, p.70). First Nations, Inuit, and Métis are actively defining the values and principles (i.e., OCAP, Inuit Qaujimajatuqangit, OCAS) that drive their vision of data sovereignty and governance, and how these apply in practice will depend on community contexts and cultures ${ }^{67}$, as well as the scope of the data to be governed. ${ }^{68}$ Formalized and high-level conceptions of data sovereignty can also encourage and direct external actors and institutions to better understand and follow Indigenous data principles in their own practices. Principles that identify and define the vision and scope of data governance incite awareness to the assertations that First Nations, Inuit, and Métis are making regarding the control and ownership of their data, and they provide a framework for engagement with communities, the design of data collection methodologies, and what it means to respect and ethically engage with Indigenous data (CIHI, 2020b; Hackett et al., 2019; ICES, 2021).

\section{- (2) High-level strategies and frameworks.}

First Nations, Inuit, and Métis data sovereignty are operationalized through high-level data governance strategies and frameworks that provide a comprehensive guide to "strategy, structure, legislation and policy and related tools" that can be applied within different governance contexts (BCFNDGI, 2015b, p.6). High-level strategic thinking can articulate a distinct vision of data sovereignty and the governance objectives, activities,

\footnotetext{
${ }^{67}$ OCAP, for instance, is not a prescription. It does however provide a common framework for First Nations to build their governance vision from, and while the OCAP approach is specific for First Nations, "[t]he principles upon which OCAPTM were founded may be shared by other Indigenous Peoples, including Métis and Inuit" (FNIGC, 2014).

${ }^{68}$ Establishing the means of protecting data as a resource requires knowing what those data are. The BCFNDGI Data Governance Framework for instance identifies five primary types of First Nations data that are held externally and internally and to which it structures governance/stewardship roles and responsibilities around: Nation Data, or any data related to First Nations identity; Corporate data, or data related to the management of First Nations departments and organizations; Cultural data, or cultural bodies of "knowledge, beliefs, and practices"; and Human Related data, which are the personal information and data of individual First Nations members (BCFNDGI, 2015a, pp.22-24).
} 
tools, and deliverables needed to achieve this vision. Implementing strategies requires oversight, accountability, and management and so strategies and frameworks can communicate governance roles, structures, and the stewardship responsibilities and supports that are required to govern data. How this governance structure looks depends on the cultural and political context of the data steward, and their own defined values, vision, and scope for governance (the BCFNDGI Data Governance Framework, for example, structures governance responsibilities around important First Nations data types; see Figure 7 below). National and regional First Nations, Inuit, and Métis representative organizations are best situated to produce and govern high-level governance materials since they are mandated and culturally driven to advance the unified interests of their peoples and communities and to ensure that these interests are communicated at the Federal and provincial levels, including in the development of policy, legislation, and programs related to data (FNIGC, 2020a; ITK, 2018).

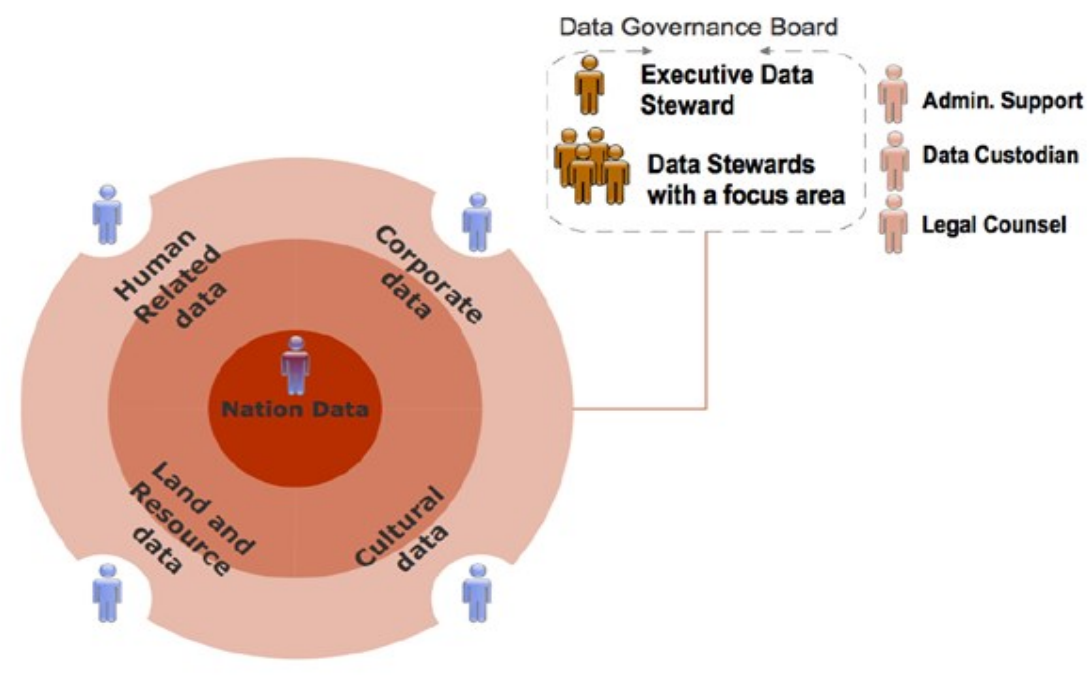

Figure 7: The governance structure of First Nations data in B.C. that is centered on important types of First Nations data, visualized in the BCFNDGI Data Governance Framework (2015a, p.38).

\section{- (3) Governance in community practices.}

The high-level strategies, frameworks, and principles that guide data governance and management practices according to First Nations, Inuit, and Métis worldviews are only effective when scalable, adaptable, and inclusive of local and community-level aspirations - for many Indigenous peoples in Canada, governance challenges and 
practices are often local and regional, and local engagement with data governance will reflect these interests (Carroll et al., 2019; CIRNAC, research interview, 2021). Planning at the community level is most effective when it is driven by community, when all citizens from Elders to youth have a voice, and when the plan meets the interests and needs of the community and gains their support and endorsement (P. Foster, research interview, 2021; NCFNG, n.d.b). Integrating data governance at the community level to produce community-driven data is key to overcome significant community data gaps that have been perpetuated by national mandates for Indigenous data (such as the census) and statistical aggregation methodologies which only obscure local challenges and governance. Without these data sources, local communities face serious information gaps for self-governance, and there is limited information available for advancing modern treaties and self-governance agreements which need useful, community-level data (CIRNAC, research interview, 2021). While community engagement at a local level is timely and costly, prioritizing engagement and planning with community advances understandings of critical community issues and enables comprehensive planning for governance activities and outcomes (FNIGC, 2020a; NCFNG, n.d.a \& b).

\subsubsection{Data Governance Technical Drivers}

The technical drivers (tools, techniques, and metrics) identified below in Table 9 are some ways that First Nations, Inuit, and Métis are planning, guiding, and advancing Indigenous interests in data to achieve emerging visions of data sovereignty and governance. These are related to high-level planning, decision-making, and accountability in data governance programs specifically and they can support the development and direction of Indigenous data practices in Canada. 
Table 9. Data Governance Technical Drivers

\begin{tabular}{|c|c|c|c|}
\hline Type & Driver & Description & Source(s) \\
\hline \multirow{3}{*}{ 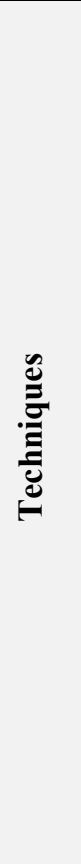 } & $\begin{array}{l}\text { Comprehensive } \\
\text { Community Planning } \\
\text { (CCP) }\end{array}$ & $\begin{array}{l}\text { Planning and reporting processes that are "community- } \\
\text { driven, nation-based" and which aim to develop the } \\
\text { foundations to achieve long-term community visions, } \\
\text { objectives, and development. CCP is centered on } \\
\text { sustainability and supporting culture, the environment, and } \\
\text { traditional languages in planning work. }\end{array}$ & $\begin{array}{l}\text { BCFNDGI, } \\
2016 b ; \text { Geddes, } \\
2015\end{array}$ \\
\hline & $\begin{array}{l}\text { Data governance } \\
\text { strategy/framework }\end{array}$ & $\begin{array}{l}\text { Collections of "strategy, structure, legislation and policy } \\
\text { and related tools" which are based within and evolve with } \\
\text { Indigenous interests and priorities in information } \\
\text { management (BCFNDGI, 2016, p.8). Prominent examples } \\
\text { in Canada include the First Nations Data Governance } \\
\text { Strategy and the BCFNDGI Data Governance Framework. }\end{array}$ & $\begin{array}{l}\text { FNIGC, 2020a; } \\
\text { BCFNDGI } \\
\text { 2015a }\end{array}$ \\
\hline & Change Management & $\begin{array}{l}\text { Data governance is an evolving process that builds } \\
\text { maturity over time, and therefore change in data and data } \\
\text { practices are inevitable. Change management can ensure } \\
\text { that the impacts of change are considered, and that change } \\
\text { continues to support the defined governance vision and } \\
\text { strategy/framework. }\end{array}$ & $\begin{array}{l}\text { DAMA, 2017; } \\
\text { BCFNDGI, } \\
2015 b\end{array}$ \\
\hline \multirow[b]{2}{*}{$\stackrel{0}{\varrho}$} & Decision Matrix & $\begin{array}{l}\text { Identifies authorities, assignments, and accountabilities } \\
\text { related to decisions about the governance of data, in a way } \\
\text { that aligns with Governance \& Security Policies and } \\
\text { communicates governance roles and responsibilities. }\end{array}$ & $\begin{array}{l}\text { BCFNDGI, } \\
2015 b\end{array}$ \\
\hline & CRIMSIN ${ }^{69}$ & $\begin{array}{l}\text { An "Accountability Tool for Self-Governing Nations", } \\
\text { CRIMSIN was created by Elder Gwen Phillips of the } \\
\text { Ktunaxa Nation in B.C. as a solution for guiding the } \\
\text { development of Indigenous-led information systems that } \\
\text { are based in affirmative community wellness and health. } \\
\text { CRIMSIN guides developments through communicating: } \\
\text { industry-standard tech; quality and security processes; } \\
\text { development criteria; and more. }\end{array}$ & $\begin{array}{l}\text { CRIMSIN } \\
\text { (Phillips, n.d.) }\end{array}$ \\
\hline \multirow{3}{*}{ 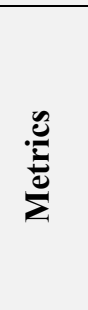 } & Accountability & $\begin{array}{l}\text { Measuring and reporting on key governance } \\
\text { accountabilities, roles, and responsibilities }\end{array}$ & FNIGC, 2020a \\
\hline & Representation & $\begin{array}{l}\text { How well represented Indigenous peoples are in the } \\
\text { governance of their data }\end{array}$ & $\begin{array}{l}\text { FNIGC, 2020a; } \\
\text { ITK, } 2020\end{array}$ \\
\hline & Compliance & $\begin{array}{l}\text { Monitoring compliance with data governance directives } \\
\text { and policies, to identify risks and increase awareness }\end{array}$ & $\begin{array}{l}\text { BCFNDGI, } \\
2015 b\end{array}$ \\
\hline
\end{tabular}

\footnotetext{
${ }^{69}$ Comprehensive Resource and Information Management System for Indigenous Nations (CRIMSIN). Available at: https://www.bcfndgi.com/data-governance
} 


\subsubsection{Data Governance Outcomes}

First Nations, Inuit, and Métis data governance efforts are critical for the decolonization of Indigenous data in Canada and for the assertation of First Nations, Inuit, and Métis data sovereignty in Indigenous information systems. Employing effective high-level strategic thinking and vision into data production and practices enables Indigenous leadership and organizations to meet the information and statistical needs of communities; to grow and empower Indigenous knowledge economies and governance strategies; to shift control of the construction of Indigenous peoples and data back toward Indigenous self-determination; and to direct building the capacities that will be the foundation of Indigenous data for decades to come (FNIGC, 2020a). By asserting and returning control of data governance to First Nations, Inuit, and Métis, efforts toward decolonization and reconciliation can be realized and historical imbalances in the production of knowledge can begin to be corrected and shifted toward Indigenous selfdetermination. Figure 8 below is a modified context diagram that summarizes this Knowledge Area including the governance and technical drivers, IDG elements, activities, actors, and outcomes central to Data Governance in a First Nations, Inuit, and Métis context. 


\section{Data Governance}

Definition: Authority and oversight over data management activities and decisions made about them. (DAMA. 2017).

Goals: Data Governance is central to all other Knowledge Areas and guides their operations and processes. Governance decisions must be made in any arrangement of managing data, however establishing a formal program allows greater control and increased value from data assets (DAMA, 2017).

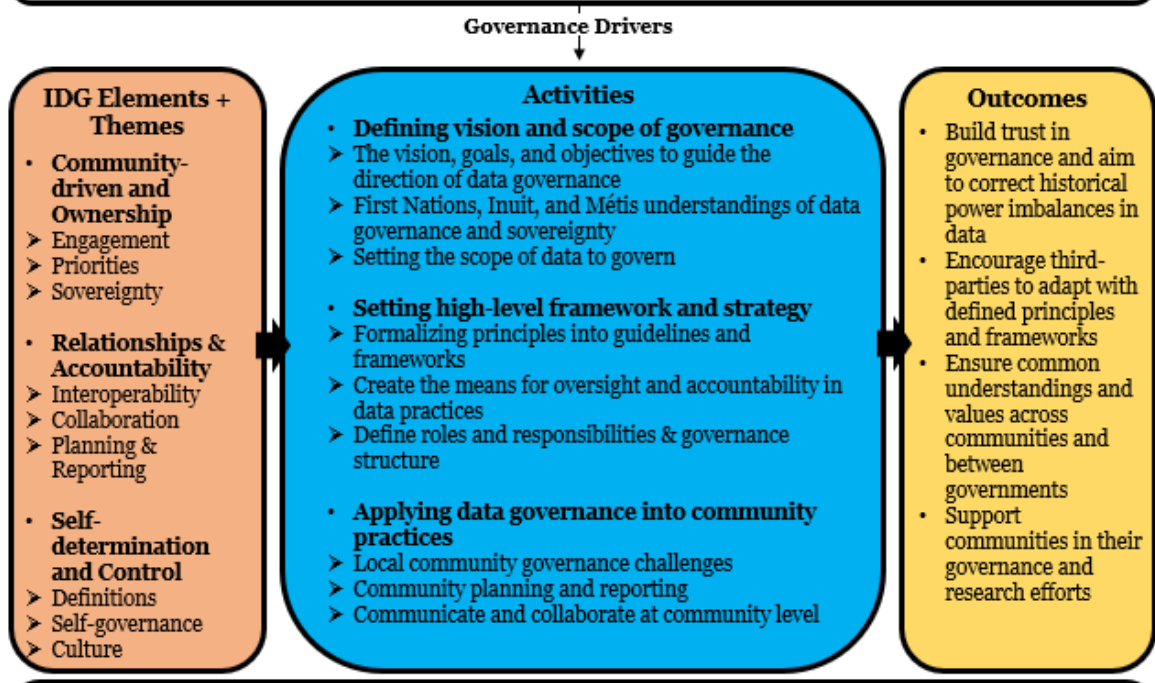

Socio-technical Actors

- Systems of thought: Self-determination; Self-governance; Data sovereignty

- Forms of knowledge: Principles; Strategies; Frameworks

- Organizations and Institutions: First Nations, Inuit, and Métis national and regional representatives

- Practices: Governance; Community-driven; planning and reporting

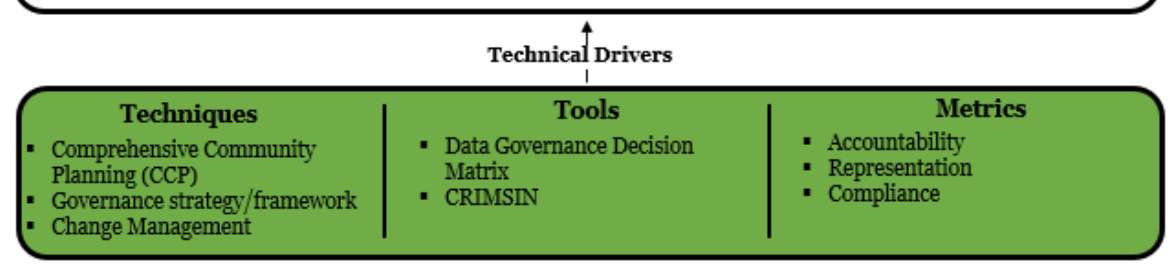

Figure 8: Modified context diagram for the Data Governance Knowledge Area

\subsection{Data Architecture}

Architecture is commonly understood as and related to the "process of building", and is understood generally by DAMA as "an organized arrangement of component elements intended to optimize the function, performance, feasibility, cost, and aesthetics of an overall structure or system" (2017, p.97). They note that context is important when discussing architecture as it is processed at different organizational levels and areas of focus: 
However, depending on the context, the word architecture can refer to a description of the current state of the systems, the components of a set of systems, the discipline of designing systems (architecture practice), the intentional design of a system or a set of systems (future state or proposed architecture), the artifacts that describe a system (architecture documentation), or the team that does the design work (the Architects or the Architecture team).

(DAMA, 2017, p.98).

Data Architecture (DA) in simple terms refers to formalized IM/IT frameworks to manage a high-level perspective of how all data are situated, linked, and function in the context of an enterprise. Communicating an architecture framework is recommended to illustrate how relationships in architecture are formed at the enterprise, domain, and project level and in different focus areas like infrastructure, applications, and data. Effective architecture management and oversight can assist data stewards to understand their systems, promote changes, and ensure compliance with policies and regulations in data processes (DAMA, 2017, p.98). DAMA asserts that data architecture is a fundamental element of data management to provide abstraction of incomprehensible amounts of data and how they move and operate across an organization and to and from external organizations. As Data Architecture operates to "support the alignment and control of data", it is therefore inherently linked to driving Data Governance strategies and to the governance and alignment of all Knowledge Areas (DAMA, 2017, p.119).

DA plays a fundamental role in aligning and directing strategies for the governance of data across many organizations, communities, and institutions and it can enable greater control and decision-making in First Nations, Métis, and Inuit information management. The current state of Indigenous data in Canada is marked by siloed data, lacking standardization, and a policy/legal environment that is in flux between government mandates and colonial information policies (see 2.1.1. \& 2.2.1.). There are also many distinct communities with unique priorities and systems of governance grappling with similar information issues, with leadership in data on 
a bigger scale informed by national and regional organizations such as FNIGC, ITK, and provincial Métis Nations. In this data ecosystem, data architecture governance in the context of Indigenous data centers on relationships and alignment between multiple levels of governance, capacities to govern data across an enterprise, and how to best control over data that are integrated and shared throughout data architecture:

- Relationships \& Accountability. As community access to data is often lacking, relationships are a vital element of building architecture in the Canadian context and management of these relationships in data is needed at multiple levels, between First Nations, Inuit, and Métis organizations and communities, tribal band councils, Federal/provincial governments, private industry and academia, and any other actor that collects First Nations, Inuit, and Métis data (see 2.2.1.). Local and regional integration thereby demands responsibility for accommodating the distinct priorities of up to hundreds of communities at the regional level, and such a network can benefit from a built architecture to support the adoption of effective models, to communicate standards, requirements, and best practices across all actors, and to align locally adaptable principles and priorities between Indigenous communities, governments, and external actors who are involved with data collection and governance (BCFNDGI, 2016a).

- Capacity. Building and implementing governance capacities across data architecture entails developing the capacities to manage data across one or many enterprises. Not only does this require establishing the necessary technical capacities to steward and manage data generally (discussed further in 5.3. Data Storage \& Operations) but it also requires expertise and literacy in the management and lifecycles of data and the ability to quickly adapt to constantly shifting digital technologies, standards, and regulation. These are costly objectives, in terms of built infrastructure/human resources expenditures and time.

- Control. Designing and building data architecture is resource intensive however it does enable control over other key Knowledge Areas including data integration, data security, and data governance. Abstracting data systems at a high-level is necessary for enterprisewide planning and especially when there are many actors and data movement between communities, organizations, and institutions. This high-level oversight also enables transparency and accountability in the management of resources across an architecture and in relationships with external actors, which is essential to secure trust in data and 
research practices and to enable community-oriented priorities in research and funding (ITK, 2018).

\subsubsection{Data Architecture Activities}

Data architectures are not static arrangements, and they continually evolve as more data are generated to manage and as new linkages and integration are introduced. Governance activities at an architectural level thereby are both quality-oriented or pertaining to improving cohesion across the enterprise and beyond, and innovation-oriented related to advancing data capacities and assessing and adopting technical innovations to achieve this. From these two perspectives of architecture, data governance both builds and guides transformational change in the short and long-term and across enterprise-wide architecture (DAMA, 2017, pp. 109-10).

Data architectures are complex IM/IT business functions that presuppose technical data storage, quality, and security infrastructures, and therefore many First Nations, Inuit, and Métis communities and organizations are in early stages of architectural thinking as they plan to support and scale their data governance efforts from local community levels to regional interests and provincial relations, and toward a national scope that supports Indigenous data interests at large and in relation with the Federal government (FNIGC, 2020a; ITK, 2018; ITK, 2020). These efforts are costly, they take time, and relationships need to be formed at all levels to form a meaningful architecture that supports the needs and interests of all. To support the development

of data architecture that are designed to include Indigenous leadership and that engage with local and regional interests in data, Indigenous organizations and communities are (1) planning for enterprise-wide architecture and assessing needs; (2) designing implementation plans to meet short, mid, and long-term priorities; and (3) engaging with Canadian funding efforts and calls-toaction for reconciliation. 


\section{- (1) Planning for architecture.}

The architectural needs of an Indigenous organization/community are heavily contextdependent and will rely on their stewardship situation, partnerships and agreements with other organizations/communities, and their information and data priorities. Defining data architecture needs is an essential high-level activity for governance at a large scale (regional/national) and to create a starting point to build a foundation for data governance between multiple actors and information systems and to ensure data governance systems are effectively integrated at multiple levels (DAMA, 2017). Due to the enterprise-wide scope of architecture planning, it is most effective when Indigenous communities and organizations understand where and how data flow, connect, and are processed across the architecture; high-level perspectives can be conceptualized through mapping data flows, and designing data models ${ }^{70}$ can also effectively articulate and design "how data fit together" (see: Table 10 in 5.2.2. below, DAMA, 2017, p.123). Communities and organizations may also benefit from understanding their organizational maturity in data governance functions (such as with the Gartner Maturity Model; see Table 10 below in 5.2.2.) which may reveal critical data gaps and where capacities can be focused to further enhance data governance operations across an enterprise.

\section{- (2) Implementation.}

Varying levels of maturity, infrastructural capacities, and architectural needs presents a complex ecosystem to navigate regarding the implementation of complex data architectures. Building and implementing the foundations for the governance of data is not a process that can be quickly undertaken, and much time is needed to build relationships, capacities, and infrastructures at an integrated and architectural level. As data architectures operate at a high-level, there is a need to balance national and regional coordination with the advancement of community-level interests. There are a number of innovative strategic approaches that seek to strike this balance, such as: the First Nations Data Governance Strategy helmed by the FNIGC is developing integrated regional data governance centres and statistical institutions that support local priorities by region while also integrating at the national level between regions and with Federal, provincial, and

\footnotetext{
${ }^{70}$ Data Modeling \& Design is a heavily technical Knowledge Area in the DAMA DMBOK that directly supports Data Architecture, and it is described as the design and communication of data requirements in the form of a 'data model' which may be conceptual (high-level requirements), logical (detailed requirements), or a physical model (detailed and specific to a technology) (DAMA, 2017, pp.144-8).
} 
territorial governments (2020a); in B.C. the First Nations Health Authority (FNHA), in a tripartite partnership with the Province and Federal government, is governing data interests at both a local and provincial level through designated Data Champions and engaged measuring, reporting, and data access (BCFNDGI, 2016a). Due to the complexity of implementing enterprise-wide architecture that spans multiple communities, contexts, and governments, both the FNIGC and BCFNDGI adopt phased implementation approaches that are designed with manageable goals that "create the space and time needed across regions for a better understanding of priorities, a clearer identification of key actions and solutions, opportunities to experiment, learn and adapt, and scale efforts appropriately" (FNIGC, 2020a, p.73).

\section{- (3) Funding and investment.}

Implementing data architecture is an expensive process and requires building technical and expertise capacities at a multiple levels of governance, including the physical infrastructures required to store and manage data (see: 5.3). In the wake of reconciliation and calls to action made by both the RCAP in 1996 and the TRC in 2015, the Federal government had dedicated financial resources to improve First Nations, Inuit, and Métis data management and governance functions as well as to build Indigenous-controlled technical capacities and infrastructures. Currently, Indigenous-led data governance and data architectures rely on Federal investment and support to be able to realize governance aspirations and control. Funding and investment in the building of architecture is continually needed to support efforts, as even pre-technical development and implementation including community engagement, high-level strategic planning, and development, and building the groundwork for data architecture is costly and time consuming. The FNIGC asserts that funding for their envisioned strategy and data architectures needs to be "sufficient, predictable, and flexible" and it needs to support data governance efforts as they advance and transform in maturity (2020a, p.74). To put the level of investment into perspective, some recent and prominent securing of funds include:

O In Budget 2017, the ITK secured $\$ 82$ million over a period of ten years to lead, develop, and administer Qanuippitaa: National Inuit Health Survey (ITK, 2020).

○ In Budget 2018, \$2.5 million was secured and invested over three years for the pre-implementation activities of the FNDGS (FNIGC, 2020a). In Budget 2021, 
$\$ 73.5$ million was allocated to support the continuation of the FNDGS (Department of Finance Canada, 2021).

- Budget 2021 aims to invest $\$ 8$ million over three years to "support Inuit and Métis baseline data capacity and the development of distinctions-based Inuit and Métis data strategies" (Department of Finance Canada, 2021).

- In Budget 2021, the Government of Canada plans to establish "distinctions-based investments" of 6 billion for the support and building of Indigenous infrastructures, including the Indigenous Community Infrastructure Fund which was allocated 4.3 billion over four years (Department of Finance Canada, 2021).

\subsubsection{Data Architecture Technical Drivers}

The governance of DA frameworks is driven by tools, techniques, and metrics (Table 10) related to governing and managing the implementation of nation- and region-wide data governance programs while aligning the interests and values of many diverse actors and contexts. This includes high-level conceptualizations of data and practices and the means of monitoring how data governance is being applied across an entire enterprise.

Table 10. Data Architecture Technical Drivers

\begin{tabular}{|c|c|c|c|}
\hline Type & Driver & Description & Source(s) \\
\hline \multirow{4}{*}{ :气 } & Data modeling \& design & $\begin{array}{l}\text { The "process of discovering, analyzing, and scoping data } \\
\text { requirements" that are communicated "in a precise form } \\
\text { called the data model" (DAMA, 2017, p.123). }\end{array}$ & $\begin{array}{l}\text { DAMA, 2017; } \\
\text { BCFNDGI, } \\
\text { n.d. }\end{array}$ \\
\hline & Data Champions & $\begin{array}{l}\text { Leaders in transformative data governance approaches } \\
\text { who work to align values and understandings of data } \\
\text { governance across data architectures, advocate for the } \\
\text { critical importance of data to community values, and } \\
\text { who monitor and report progress at all levels of } \\
\text { governance. }\end{array}$ & $\begin{array}{l}\text { BCFNDGI } \\
2016 \mathrm{a} ; \\
\text { FNIGC, } \\
\text { 2020a; }\end{array}$ \\
\hline & Phased Implementation & $\begin{array}{l}\text { An approach to managing the implementation of data } \\
\text { governance systems, functions, and visions that is } \\
\text { stepwise, planned with measurable results, and that } \\
\text { allows for the complex and time-consuming processes of } \\
\text { integrating multiple communities, governments, and } \\
\text { contexts. }\end{array}$ & $\begin{array}{l}\text { FNIGC, } \\
\text { 2020a; } \\
\text { BCFNDGI, } \\
2016 \mathrm{a}\end{array}$ \\
\hline & $\begin{array}{l}\text { Regional information } \\
\text { governance }\end{array}$ & $\begin{array}{l}\text { Semi-autonomous regional governance hubs and } \\
\text { integrated centres is the central approach of the FNDGS } \\
\text { and effectively act as a middle network to meet local }\end{array}$ & FNIGC, 2020a \\
\hline
\end{tabular}




\begin{tabular}{|c|c|c|c|}
\hline Type & Driver & Description & Source(s) \\
\hline & & $\begin{array}{l}\text { community priorities while "leveraging collaboration and } \\
\text { partnerships at the regional and national levels" (p.10). }\end{array}$ & \\
\hline \multirow{3}{*}{$\frac{n}{8}$} & Conceptual data model & $\begin{array}{l}\text { Conceptualizes 'core' information and how they related } \\
\text { to other data, practices, and business drivers and vision } \\
\text { (2017, p.412). The BCFNDGI has developed conceptual } \\
\text { data models to effectively abstract complex First Nations } \\
\text { data governance and accountability processes and } \\
\text { indicator development (see: Appendix } 3 \text { ). }\end{array}$ & $\begin{array}{l}\text { DAMA, 2017; } \\
\text { BCFNDGI, } \\
\text { n.d. }\end{array}$ \\
\hline & Data Flow Index & $\begin{array}{l}\text { Represents data that are stored both internally and } \\
\text { externally, including information about who collects/uses } \\
\text { and how these data are shared, types of data, and data } \\
\text { identifiers/attributes. }\end{array}$ & $\begin{array}{l}\text { BCFNDGI, } \\
2015 b\end{array}$ \\
\hline & Maturity Model & $\begin{array}{l}\text { A modelling tool which identifies the maturity level of } \\
\text { an organization's data capacities. The FNDGS adopts the } \\
\text { Gartner Data Maturity Model }{ }^{71} \text { (2017) which models } \\
\text { data analytics capacities on five levels of maturity from } \\
\text { basic - transformational (p.4). }\end{array}$ & FNIGC, 2020a \\
\hline \multirow{2}{*}{ 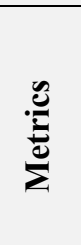 } & Implementation progress & $\begin{array}{l}\text { Evaluation of the progress in implementing a data } \\
\text { architecture, data governance program, etc. }\end{array}$ & $\begin{array}{l}\text { FNIGC, } \\
2020 \mathrm{a} ; \text { ITK, } \\
2018\end{array}$ \\
\hline & Investment allocation & $\begin{array}{l}\text { Tracking investments and funding to ensure they meet } \\
\text { Indigenous data needs and research priorities. }\end{array}$ & ITK, 2018 \\
\hline
\end{tabular}

\subsubsection{Data Architecture Outcomes}

Data Architecture activities can enable First Nations, Inuit, and Métis to develop a highlevel perspective of their information systems and data, and communicating architecture can work to align understandings of socio-technical and cultural priorities within an Indigenous community/organization and in their external and integrated partners. Through DA, processes such as implementation and securing funding for data governance can be made manageable, trackable, and accountable within the wider arrangement of the enterprise and these can be designed with forward-thinking and support for data governance in community contexts. Building high-level architectural perspectives establish the means and foundations for enterprise wide First Nations, Inuit, and Métis data governance planning and for the development of

\footnotetext{
${ }^{71}$ Gartner Maturity Model: https://www.gartner.com/en/newsroom/press-releases/2018-02-05-gartner-surveyshows-organizations-are-slow-to-advance-in-data-and-analytics
} 
meaningful and decolonized data structures that support their interests and aspirations. Figure 9

below provides a summary for Indigenous data governance in this Area and illustrates how these outcomes are reached through architectural thinking and planning.

\section{Data Architecture}

Definition: Designing master blueprints to guide overarching data management and integration strategy in a way that meets the needs of the data steward (DAMA, 2017).

Governance: Data Architecture activities operate at a high-organizational level and "directly support the alignment and control of data" (DAMA, 2017, p.119). This means that Architecture must align with and implement governance processes, for purposes of oversight, management, and consistency across practices (DAMA, 2017).

\begin{tabular}{|c|c|c|c|}
\hline \multicolumn{4}{|c|}{ Governance Drivers } \\
\hline $\begin{array}{l}\text { IDG Elements and } \\
\text { Themes } \\
\text { - Relationships \& } \\
\text { Accountability } \\
>\text { Alignment } \\
>\text { Local \& regional } \\
\text { integration } \\
>\text { Community } \\
\text { priorities } \\
\text { - Capacity } \\
>\text { Implementation } \\
>\text { Funding } \\
>\text { Planning \& } \\
\text { reporting } \\
\text { - Control } \\
>\text { High-level oversight } \\
>\text { Transparency } \\
>\text { Trust }\end{array}$ & \multicolumn{2}{|c|}{$\begin{array}{l}\text { Activities } \\
\text { - Planning for architecture } \\
\text { Reliant on context of data and stewardship } \\
\text { Map data flows and model linkages } \\
\text { > Identify maturity level and identify gaps and } \\
\text { opportunities in data governance } \\
\text { - Implementing architecture } \\
\text { Set time frame and short, mid-term, and long-term } \\
\text { objectives with a phased approach } \\
\text { Engaged with communities } \\
\text { Plan and align with Federal, Provincial, and other } \\
\text { First Nations/Métis/Inuit governments \& } \\
\text { communities } \\
\text { - Secure investments and bridge funding } \\
\text { Advancing reconciliation and Federal calls for action } \\
\text { Ensuring funding is "sufficient, predictable, and } \\
\text { flexible" (FNIGC, 2021, p.74). }\end{array}$} & $\begin{array}{l}\text { Outcomes } \\
\text { - High-level } \\
\text { architecture can } \\
\text { align understanding } \\
\text { of socio-technical } \\
\text { and cultural } \\
\text { priorities } \\
\text { - Establish } \\
\text { foundations for } \\
\text { meaningful and } \\
\text { decolonized data } \\
\text { structures } \\
\text { - Implementation is } \\
\text { made manageable, } \\
\text { trackable, and } \\
\text { accountable for } \\
\text { community interests } \\
\text { - Enable funding to } \\
\text { reflect needs and } \\
\text { priorities of the } \\
\text { peoples they support }\end{array}$ \\
\hline \multicolumn{4}{|c|}{\begin{tabular}{l}
\multicolumn{1}{c}{ Socio-technical Actors } \\
Forms of Knowledge: Data Models; Data Flows; \\
Finance: Federal budget investment; Bridge funding; Infrastructure development \\
Subjectivities \& Communities: Local/regional/national levels; Indigenous communities; Maturity \\
Organizations \& Institutions: First Nations, Inuit, and Métis governments and representatives; Provincial \& \\
Federal Governments
\end{tabular}} \\
\hline \multicolumn{4}{|c|}{ Technical Drivers } \\
\hline $\begin{array}{l}\text { Techniques } \\
\text { - Data Modeling \& Design } \\
\text { - Data Champions } \\
\text { - Phased implementation } \\
\text { gogional information } \\
\text { governance }\end{array}$ & \begin{tabular}{|l}
\multicolumn{1}{c}{ Tools } \\
- Conceptual data model \\
- Data Flow Index \\
- Maturity Model
\end{tabular} & & $\begin{array}{l}\text { Metrics } \\
\text { ntation Progress } \\
\text { int Allocation }\end{array}$ \\
\hline
\end{tabular}

Figure 9: Modified context diagram for governance in the Data Architecture Knowledge Area 


\subsection{Data Storage \& Operations (DSO)}

Data Storage and Operations (DSO) refers to the "design, implementation, and support of stored data, to maximize its value throughout its lifecycle, from creation/acquisition to disposal" (DAMA, 2017, p.169). DSO relies on information systems and technical capacities to be able to efficiently operate and manage data across their lifecycle and to ensure integrity in these data, however they also require human expertise to manage the store and its operations. These capacities intersect with the wider array of Knowledge Areas which build their governance operations around stored and maintained data (i.e., ensuring these data are high-quality at the time of storage (5.6.); effectively integrating databases and stores (5.4.); or building security into operational systems (5.5.).

As Indigenous peoples assume control over their information systems, develop new, relevant data sources, and repatriate data that are about them, they require capacities and infrastructures to effectively manage and govern their data. First Nations, Inuit, and Métis data governance efforts in DSO generally reflect aspirations for acquiring the necessary technical and human capacities for effective data management; shifting responsibility over Indigenous data toward Indigenous stewardship; and for gaining possession and thereby the ability to control data:

- Capacity. DSO relies on technical capacities and both material and human infrastructures to manage data assets effectively and securely. This is a critical Area for data governance capacities which is observed by the FNIGC who states that the "lack of human and modern IM/IT capacities is one of the biggest challenges (or gaps) faced by many communities, particularly those located in rural and remote locations" (FNIGC, 2020a). They also note how expensive these systems are to build and operate; the need for data and technical literacy; and the limited number of resources and capacities for data stewardship in First Nations communities (FNIGC, 2020a). Consequently, many communities are heavily enumerated and researched by external actors but have little capacity to perform data practices themselves, which has enabled and perpetuated the 
positivist research paradigm in Indigenous governance and research (Braun et al., 2013; ITK, 2018).

- Stewardship. The governance of DSO is a process of data stewardship, or the responsibility to manage data assets and systems and to ensure that they can be used effectively, securely, and with direction (DAMA, 2017; FNIGC, 2020a). There is great responsibility in the context of Indigenous data stewardship as Indigenous data are often aggregated at regional/national levels and the steward then has responsibility for the data of several peoples and communities - there is a large amount of trust required in Indigenous data stewards. When Indigenous data are not stewarded by the peoples as described, they are more likely to be misused and to cause community harm (FNIGC, 2020b). When in the stewardship of the Federal government and provinces/territories, Indigenous data are subject to the Federal Access to Information Act and provincial data access legislation which limits the ability of First Nations, Inuit, and Métis in governing and controlling their information assets (FNIGC, 2020b).

- Control. Having control and governance over DSO enables Indigenous organizations and communities to set the terms of access to their data and to physically manage and protect these assets from harm (see: 5.5). Possession as part of the OCAP principles exemplifies the fundamental importance of possessing data to be able to assert other interests related to Ownership, Control, and Access (FNIGC, 2020b), and possession entails producing the capacities necessary to house and store data in Indigenous possession.

\subsubsection{Data Storage and Operations Activities}

DSO in a corporate-technical framing primarily consists of two activities: database support, or the maintenance and tuning of database functions including "obtaining, backing up, and purging data" as well as "ensuring the database performs well"; and database technology support, which involves maintaining technical standards, requirements, and architecture, implementing technology, and handling technical issues (DAMA, 2017, p.169-70). DSO activities "are crucial to organizations that rely on data" and they are driven by the need to ensure that information systems and operations are reliable, continuous in operation, and that there is little risk of system disruption (DAMA, 2017, p.171). 
Capacity in the sense of DSO material and human infrastructures are critical functions

for Indigenous peoples to assume control of their data and systems, which has been a

fundamental drive of national and regional Indigenous organizations to develop these capacities.

To effectively implement these technical functions for data management and governance, communities and organizations are (1) planning for capacity based on their needs and priorities; (2) building and supporting technical and human infrastructures; and (3) developing governance materials for management functions.

\section{- (1) Planning for capacity.}

As noted under data architecture, Indigenous communities and organizations are in different stages of maturity in data management and therefore needs may vary for technical capacities and to overcome context-specific barriers and gaps in knowledge and capacity (FNIGC, 2020a). Planning for the building of capacity can be worked into highlevel architecture building plans (i.e., FNDGS phased implementation approach) to align with short-, mid-, and long-term objectives and outcomes or it can be dependent on a specific project and initiative with a domain-specific focus (i.e., the Tui'kn Partnership and health data; Inuit Nunangat university ${ }^{72}$ ). Planning is also necessary to identify compliances with the jurisdictional information and storage laws for where the data reside physically. ${ }^{73}$ Often, major sources of Indigenous data in Canada (primarily health data) contain sensitive personal information that are governed by Federal and provincial laws, which prevent the legal stewardship of these data by Indigenous peoples due to capacity issues (most often, security infrastructures and lack of technical security expertise). The Tui'kn Partnership overcame this issue by planning intermediate capacity through the Unama'ki Client Registry Centre, which acts as a linkage registry for Indigenous peoples to connect to and access critical health data held by the Government or provinces/territories in a secure process and form (FNIGC, 2014).

\footnotetext{
${ }^{72}$ As part of the National Strategy on Research, the ITK envisions the creation of an Arctic-based, Inuit Nunangat university that will "support research capacity building through the provision of education, training, and accreditation across disciplines" while also serving "to identify and advance Inuit research priorities and monitoring of adherence to ethical research guidelines" (ITK, 2018, p.33).

${ }^{73}$ Data residency is important to consider when designing data storage policies, to avoid missing legal obligations and data requirements. The BCFNDGI Privacy and Security manual for example prohibits storing First Nations data outside of Canada, and where access to data outside of Canada is needed, authorization is needed from the executive data steward role and from the applicable legislative authorities (BCFNDGI, 2015c)
} 


\section{- (2) Building technical infrastructures.}

Building physical data storage infrastructures is one of the primary aspirations of First Nations, Inuit, and Métis data governance efforts in Canada (FNIGC, 2020a; BCFNDGI, 2015a). This process is skill and labour intensive and requires access to cutting-edge technologies and software, and Indigenous representative organizations are actively employing procurement processes to contract technical experts to build capacities while ensuring that the system meets their defined vision and needs (for instance, see the MNBC Request for Proposal (RFP) ${ }^{74}$ for a new digital Citizen registry database, or the 2017 RFP from the First Nations Health Authority (FNHA) for data governance and access tool development ${ }^{75}$ ). Through the building and supporting of technical and human capacities, Indigenous peoples in Canada can translate high-level data principles and priorities into the operations and practices of data management and governance and can actively take control over the stewardship of their data and information. For some communities who might not have the capacity for DSO such as necessary security infrastructures, qualified technical expertise, or legal authority to manage data (i.e., personal health data) or when multiple communities are participating in stewardship, outsourcing DSO with trusted external partners and organizations ${ }^{76}$ while maintaining ownership through agreements is one approach to overcome technical gaps (FNIGC, 2020b). To ensure that third-party stewards respect Indigenous data principles and priorities, First Nations, Inuit, and Métis can employ legally binding agreements (i.e., data governance and sharing agreements; service contracts; licenses) to: define all parties involved; establish Indigenous authority and governance; regulate the sharing, use, or disclosure of data (5.4.); and to enforce security and privacy policies and frameworks (5.5.) (FNIGC, 2020b).

\footnotetext{
${ }^{74}$ MNBC RFP for a Citizen Registry database: https://www.mnbc.ca/news/2021/mnbc-launched-rfp-for-newcitizen-registry-database/

${ }^{75}$ FNHA RFP for data governance and access: https://www.fnha.ca/Documents/FNHA_2017RFP\%2011\%20Data\%20Governance\%20and\%20Access.pdf ${ }^{76}$ Building and supporting DSO capacities through a trusted third-party is also perhaps the most effective way to avoid the application of access to information legislation on Indigenous data, as both Federal and provincial/territorial are bound to disclose government-held information. This was the approach of the First Nations Chiefs of Ontario (COO) in agreement with ICES who, as a non-government organization, can "hold First Nations data and permit control and access by First Nations, while protecting the privacy of both personal and communitylevel data" (FNIGC, 2014, p.23). The Unama'ki Client Registry Centre accomplishes a similar role, and both initiatives adopt and follow OCAP principles (FNIGC, 2014).
} 


\section{- (3) Human infrastructures and support.}

Human infrastructures and expertise capacities also need to be developed and fostered to leverage technical capacities for governance, and this need has been recognized by First Nations, Inuit, and Métis organizations who are actively seeking to lead and provide the means for Indigenous data governance and management capacity development. Beyond technical knowledge, there is a need for building expertise on how First Nations, Inuit, and Métis data principles apply to the operations of data management. The FNIGC Fundamentals of $O C A P \AA$ training course for instance provides the foundations for both First Nations and non-First Nations peoples to better understand how OCAP emerges in practice and how they can support the development of Indigenous information management systems. Inuit-led human capacities in the north are being built through the Inuit Nunangat Research Program (INRP) ${ }^{77}$ which is led by the Inuit Advisory Committee (IAC) ${ }^{78}$, whose goals include enhancing "Inuit involvement and participation in research, building research capacity in Inuit communities, [and] addressing Inuit community concerns and improving Inuit livelihoods" (ITK, n.d.).

\subsubsection{Data Storage and Operations Technical drivers}

In Table 11 below, I identify a sample of tools, techniques, and metrics related to the governance of DSO in First Nations, Inuit, and Métis communities. These technical drivers are focused on the building and supporting of Indigenous-led storage and operational capacities and infrastructures, and they can enable First Nations, Inuit, and Métis to drive transformational change in their data governance capabilities and maturity.

\footnotetext{
${ }^{77}$ The INRP is a direct response to barriers for Inuit participation and engagement in research across Inuit Nunangut and it operates through a calls for proposals (CFP) process that does not fund based on "experience in the western scientific granting process" but rather based on engagement with Inuit peoples and communities and the building of Inuit capacities to perform data collection and research (ITK, n.d.).

${ }^{78}$ The IAC consists of representatives from: Inuvialuit Regional Corporation (IRC), Makivik Corporation, Kativik Regional Government (KRG), Nunavut Tunngavik Inc. (NTI), Nunatsiavut Government, Inuit Circumpolar CouncilCanada (ICC), and Inuit Tapiriit Kanatami (ITK) (ITK, n.d.). The INRP is part of a larger effort for northern research called the North-by-North Program: https://arcticnet.ulaval.ca/north-north
} 
Table 11. Data Storage and Operations Technical Drivers

\begin{tabular}{|c|c|c|c|}
\hline Type & Driver & Description & Derived from \\
\hline \multirow{3}{*}{ 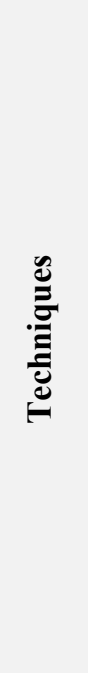 } & Procurement & $\begin{array}{l}\text { Structured processes where Indigenous peoples seek goods } \\
\text { and services from vendors and service providers while setting } \\
\text { the terms for what they require. Procurement approaches } \\
\text { enable First Nations, Inuit, and Métis to source technical } \\
\text { expertise and development for their data governance needs. }\end{array}$ & MNBC, n.d.b \\
\hline & $\begin{array}{l}\text { Data Governance } \\
\text { Agreement }\end{array}$ & $\begin{array}{l}\text { Comprehensive and collaborative agreements which transfer } \\
\text { DSO and stewardship functions to other actors while legally } \\
\text { ensuring that Indigenous peoples have full control over the } \\
\text { data and how they are used, access, and governed. }\end{array}$ & ICES, 2021 \\
\hline & $\begin{array}{l}\text { Operational and } \\
\text { governance } \\
\text { training }\end{array}$ & $\begin{array}{l}\text { Data governance and management training programs can } \\
\text { enhance human expertise and capacities to manage and govern } \\
\text { technical infrastructures, including both technical expertise } \\
\text { and data governance expertise that is culturally fit to the } \\
\text { context. }\end{array}$ & $\begin{array}{l}\text { ITK, n.d.; } \\
\text { FNIGC, 2020b }\end{array}$ \\
\hline \multirow[b]{2}{*}{$\stackrel{n}{\stackrel{0}{\theta}}$} & $\begin{array}{l}\text { Data Asset } \\
\text { Inventory Log }\end{array}$ & $\begin{array}{l}\text { Catalogues the data that are owned by a } \\
\text { community/organization, including where they are stored and } \\
\text { metadata about them. Can include both internal and external } \\
\text { information, and inventories both originals and copies of the } \\
\text { data. }\end{array}$ & $\begin{array}{l}\text { BCFNDGI, } \\
2015 b\end{array}$ \\
\hline & $\begin{array}{l}\text { Membership } \\
\text { Registry }\end{array}$ & $\begin{array}{l}\text { Databases which contain accurate information on the members } \\
\text { of an Indigenous community or nation. Controlling and } \\
\text { governing this list enables First Nations, Inuit, and Métis to } \\
\text { plan and deliver services, monitor, and report on communities, } \\
\text { and to link with other important Indigenous data. The Federal } \\
\text { Government operates the Indian Registry for status First } \\
\text { Nations, however First Nations as part of their sovereign } \\
\text { interests actively desire to govern and control these databases } \\
\text { (BCFNDGI, 2015b). Métis Nations on the other hand emerged } \\
\text { with full control over Métis membership and own and operate } \\
\text { their own registries (by each provincial Nation). }\end{array}$ & $\begin{array}{l}\text { MNO, 2019; } \\
\text { MNBC, n.d.a \& } \\
\text { b; BCFNDGI, } \\
\text { 2015b }\end{array}$ \\
\hline \multirow{2}{*}{ 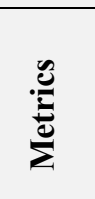 } & Accountability & $\begin{array}{l}\text { Assign and track responsibilities of data stewardship and } \\
\text { management }\end{array}$ & $\begin{array}{l}\text { BCFNDGI, } \\
2015 \mathrm{c}\end{array}$ \\
\hline & Industry standards & $\begin{array}{l}\text { Utilizing industry standard technologies for data storage and } \\
\text { management }\end{array}$ & $\begin{array}{l}\text { Phillips, n.d. } \\
\text { (CRIMSIN) }\end{array}$ \\
\hline
\end{tabular}

\subsubsection{Data Storage and Operations Outcomes}

Through the governance of DSO, First Nations, Inuit, and Métis communities and organizations can establish the capacities to advance their understandings and visions of data sovereignty and governance and to assert their interests in stewarding, possessing, and controlling their own data, for their own purposes. DSO capacities position Indigenous 
communities and organizations to benefit from the information and data they create; these

infrastructures enable Indigenous opportunities and participation in the rapidly evolving digital

economy (FNIGC, 2020a); and by possessing and stewarding their own data, First Nations, Inuit, and Métis can improve their administrative and community management functions, report on outcomes they self-determine and define (5.6.), and integrate with other sources of their data to ensure access and control (5.4.; See Figure 10 below).

\section{Data Storage \& Operations}

Definition: Implementing technical capacities for managing, supporting, and gaining value from stored data in databases (DAMA, 2017).

Governance: The governance of internal storage operations is essential to ensure that technical capacities are enabled, and that stored data are high quality, secure, and reliable. Oversight over storage enables essential planning, auditing, and reporting of data-based activities (DAMA, 2017).

\begin{tabular}{|c|c|c|}
\hline & Governance Drivers & \\
\hline \begin{aligned} & \multicolumn{1}{c}{ Themes } \\
& Thements + \\
& - Capacity \\
&$>$ Digital \\
& Infrastructures \\
&$>$ Expertise \& human \\
& resources \\
&$>$ Funding \\
& - Stewardship \\
&$>$ Custodianship \\
&$>$ Responsibility \\
&$>$ Trust \\
& - Control \\
&$>$ Terms of access \\
&$>$ Possession \\
&$>$ Data management \end{aligned} & $\begin{array}{l}\text { Activities } \\
\text { Plan for needed technical capacities } \\
\text { Align operations with vision of data sovereignty and } \\
\text { governance } \\
\text { Jurisdictional compliance } \\
\text { Linkage and sharing (DII) } \\
\text { Build technical data storage capacities } \\
\text { Procure \& collaborate with I/IT specialists } \\
\text { Outsource technical capacities to trusted partners } \\
\text { and stewards } \\
\text { Employ legally binding agreements, contracts, and } \\
\text { licenses } \\
\text { - Support the development of human } \\
\text { infrastructures } \\
\text { Training programs to align practices with vision } \\
\text { Encourage Indigenous participation in data } \\
\text { management and research }\end{array}$ & $\begin{array}{l}\text { Outcomes } \\
\text { Establishing the } \\
\text { capacities to advance } \\
\text { sovereignty, interests } \\
\text { and priorities of } \\
\text { communities } \\
\text { Infrastructures } \\
\text { enable opportunities } \\
\text { in the digital } \\
\text { economy as well as } \\
\text { for collaboration and } \\
\text { integration with data } \\
\text { sources, to ensure } \\
\text { control and access } \\
\text { Improve the } \\
\text { administrative and } \\
\text { management needs } \\
\text { of communities and } \\
\text { local/regional } \\
\text { governments }\end{array}$ \\
\hline
\end{tabular}

\section{Socio-technical Actors}

- Governmentalities and legalities: Access to information laws; Data residency; Governance agreement

- Practices: Technical and data literacy; Database support; Procurement; Stewardship

- Materialities \& infrastructures: Databases; Registries; Human infrastructures; Security

- Marketplace: Contracting and licensing IM/IT support

Technical Drivers

\begin{tabular}{|c|c|c|}
\hline $\begin{array}{l}\text { Techniques } \\
\text { - Procurement } \\
\text { - Data Governance Agreement } \\
\text { - Operational and governance } \\
\text { training }\end{array}$ & $\begin{array}{l}\text { Tools } \\
\text { - Data Access Inventory Log } \\
\text { - Membership Registry }\end{array}$ & $\begin{array}{c}\text { Metrics } \\
\text { - Accountability } \\
\text { - Industry standards }\end{array}$ \\
\hline
\end{tabular}

Figure 10: Modified context diagram for Data Storage and Operations (DSO) 


\subsection{Data Interoperability and Integration}

Data Integration and Interoperability (DII) is the backbone of basic data management functions and provides solutions to enable processes like data migration, data consolidation, data sharing, archiving, data interface management, integrating different data types, and management support. DII "describes processes related to the movement and consolidation of data within and between data stores, applications and organizations" and plays a central role in the management of Big Data which requires large-scale integration of different data sources (DAMA, 2017, p.269-70). As a central function of data management, DII depends on several other Knowledge Areas, including data governance for direction; data architecture for building relational structures for integration; data security to ensure that data are protected in movement; and data storage which become integrated and linked to other systems. In simple terms, DII is driven by "[t]he need to manage data movement efficiently" and in a way that adheres to enterprise architecture alignment, regulatory compliance, and governance strategies (DAMA, 2017, p.270$1)$.

DII is an important Area for Indigenous data governance approaches in Canada for a number of reasons that have been explored thus far in this analysis: Indigenous data are controlled by a number of different actors, including external, non-Indigenous actors; data sources vary by methodology, definitions, and aspirations for what the data are designed to do; and in contexts of reconciliation and shifts toward Indigenous self-governance and data decolonization, aspirations for the repatriation of data and information systems demands integration with external actors as well as interoperability between systems to ensure the secure transfer of data and ownership (FNHA et al., 2020; FNIGC, 2020a). Regional and national First Nations, Inuit, and Métis leadership also need to manage integration across potentially complex integration arrangements (as discussed in 5.2.) within their own contexts and this often involves 
engagement and integration with many distinct communities and local contexts as a necessary component of governance. DII issues in this framing are built on relationships across architectures, responsibilities and practices related to stewardship, and on ethical conduct which promotes equity in integration:

- Relationships. Data governance for Indigenous organizations and communities on the frontlines of data governance in Canada are complex and integration and interoperability needs to span multiple levels of governance, epistemologies, and worldviews, and both high-level and local priorities. Relationship governance, transparency, and interoperability between Indigenous communities and external governments and actors is necessary to foster community trust in data linkage and sharing (FNIGC, 2020a). This is particularly important as open data initiatives are prominent in the Federal government and provinces as a directive of open government (Government of Canada, 2018).

- Stewardship \& Access. Ensuring that data are effectively integrated across data architectures is a responsibility of stewardship. Integration and interoperability are necessary for First Nations, Inuit, and Métis to repatriate their data sources and information systems and their capacities need to be interoperable with existing capacities for this transference of information to Indigenous stewardship to occur in a way that is valuable and useable across distinct community contexts. The integration and repatriation of Indigenous data back into Indigenous control and stewardship relies on an understanding of the state of the data's stewardship, including where those data are; who is holding them; and how they are designed and constructed. In Canada where the largest Indigenous data stores are siloed across Federal departments and provincial governments, assessing the state of First Nations, Inuit, and Métis data is a necessary but challenging task (E. Corston, research interview, 2021; CIRNAC, research interview, 2021).

- Ethics. Integrating Indigenous governance into the integration and linkage of their data is not only necessary to meet their practical needs but it also is a matter of ethics and reconciling the past denigration of Indigenous knowledge systems for centuries in colonial Canada. Historically there have been massive power and knowledge asymmetries between Indigenous communities and organizations and settler state institutions (see: 2.1.) and these relationships can be rebalanced through effective governance of DII and a commitment to transparent integration with Indigenous 
governments and leadership able to make decisions about how their communities' data are shared and linked.

\subsubsection{Data Interoperability and Integration Activities}

DII activities are about "getting data where [they are] needed, when [they are] needed, and in the form in which [they are] needed" and this is conducted across the lifecycle of data, including planning, design, and implementation (DAMA, 2017, p.286). They encompass the integral movement of data across data architectures, and they work to ensure that data are cohesive, modeled, and that they benefit and provide value to all actors involved in integrating data sources. Governance in DII importantly must be centered on trust in the approach to DII else "there can be no effective business value" for data (DAMA, 2017, p.298). Trust can be generated through DII governance and the creation of data policies, agreements, and integration strategies which direct and enforce how data are shared, linked, and integrated internally and externally (DAMA, 2017).

DII activities are essential for First Nations, Inuit, and Métis to regain control over and access to their data and information systems. First Nations, Inuit, and Métis are actively integrating external and internal data sources into their systems of governance, and are effectively embedding Indigenous-defined data governance principles in DII approaches by (1) integrating architectures and infrastructures with other Indigenous and Canadian governments; (2) developing and maintaining meaningful information sharing and linkage arrangements with external partners and governments; and (3) asserting best practices for the dissemination of open data.

\section{- (1) Intergovernmental integration.}

Indigenous leadership at the national and regional levels are planning for governance (5.2.) that integrates multiple levels of Indigenous governance from national representatives to community leadership, as well as the Federal government and 
provincial governments. High-level, adaptable governance approaches (discussed in section 5.1) are key for approaching intergovernmental integration with First Nations, Inuit, and Métis-defined information and research principles. Defined data values and priorities can be considered in the context of federal and provincial information management systems to determine consistencies, gaps, and best practices, and they may be scalable to governmental approaches. Intergovernmental interoperability enables data discovery, gap bridging, as well as data access and repatriation (FNIGC, 2020a).

Effective integration is a responsibility of all governments and leadership in Canada and to provide the means for improving the sovereign interests and functions of First Nations, Inuit, and Métis peoples (BCFNDGI, 2016a).

\section{- (2) Meaningful Information Sharing.}

Data and information sharing are critical functions of DII, and they emerge as a prominent area of First Nations, Inuit, and Métis data governance which seek to shift control over data sources back toward Indigenous stewardship. As all Indigenous data that are collected are inherently owned by the peoples they represent (see: ownership in 3.3.), data sharing is an important mechanism for Indigenous communities and organizations to gain access to the data they own that are held by external actors. Indigenous governance over data sharing also enables communities and organizations to share their data assets securely and ethically with external partners and institutions, other Indigenous actors, and for compliance with Federal programs and funding requirements (BCFNDGI, 2016a). Data and information sharing approaches are many in Canada and depend on the context of the Indigenous peoples, institutions, and the jurisdiction where the data are stored; a common way to approach all sharing suggested by the NCFNG and successfully implemented in the community governance processes of both Miawpukek and Squiala First Nations is that this sharing should be meaningful to Indigenous communities and engaged with their governance desires and aspirations (NCFNG, n.d.a $\&$ b). Critical for meaningful engagement are data sharing agreements (Table 12 in 5.4.2.) with partners that legally protect and uphold community interests sharing and integration practices by communicating sharing requirements and acceptable data use between partners, based on the conditions and approval set out by First Nations, Inuit, and Métis. 


\section{- (3) Open data and integration.}

As First Nations, Inuit, and Métis communities and organizations integrate with external partners and governments to develop new and enriched sources of data, some consideration should be made for open data sources that may conflict with Indigenous assertations for control over access to their data. This is particularly important in the context of intergovernmental integration since the Government of Canada is actively invested in the production and dissemination of open data as part of open government initiatives (Government of Canada, 2018). There is a general misconception that open data initiatives are counter to and incompatible with Indigenous approaches to data governance that center on elements including control over access and use of data (such as the OCAP principles; Rowe et al., 2021). This however is only the case when those open data practices are not designed with Indigenous data principles and aspirations in mind open data can be integrated into Indigenous data governance, but this must be done in a way that acknowledges Indigenous control and access and that fosters "mutually beneficial data partnerships, including open data" (FNIGC, 2020a, p.66). The Federal Geospatial Platform operated by Natural Resources Canada is an example of a Federal open data initiative where it was illustrated that while some contradictions exist, First Nations-owned geospatial data in concept can be openly disseminated under an Open Government License (OGL-C) while respecting and being protected by OCAP principles. Furthering the balance of open data and Indigenous data sovereignty is necessary however and, in this case the "Government of Canada's dual commitment to reconciliation and open government presents a timely opportunity to support Indigenous data sovereignty (Hackett et al., 2019, p.25).

\subsubsection{Data Interoperability and Integration Technical Drivers}

To govern processes of DII and collaboration between Indigenous and external actors, First Nations, Inuit, and Métis can and are employing tools, techniques, and metrics related to data sharing, linkage, and the development of interoperability between actors. Below in Table 12 I provide a snapshot of some of the critical technical drivers for this governance and which enable First Nations, Inuit, and Métis to assert their interests and sovereignty over data when they are shared, linked, and integrated between sources. 
Table 12. Data Interoperability and Integration Technical Drivers

\begin{tabular}{|c|c|c|c|}
\hline Type & Driver & Description & Source \\
\hline \multirow{3}{*}{ 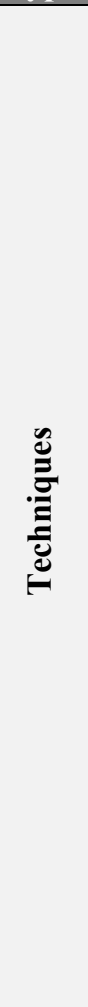 } & Repatriation & $\begin{array}{l}\text { The return of Indigenous data and data capacities to the peoples } \\
\text { and communities that the data describe. For this to be effective, } \\
\text { First Nations, Inuit, and Métis must know where their data are } \\
\text { held, the quality of these data, and protocols that structure } \\
\text { them. Repatriation can be direct when community technical } \\
\text { capacities exist; otherwise, data can be repatriated to a trusted } \\
\text { steward or national/regional Indigenous representatives who do } \\
\text { have the capacity. }\end{array}$ & $\begin{array}{l}\text { FNIGC, } \\
2020 \mathrm{a} ; \\
\text { FNIGC, } \\
2020 \mathrm{~b}\end{array}$ \\
\hline & Data Linkage & $\begin{array}{l}\text { The linking, sharing, and integration of data stores between } \\
\text { multiple parties, which creates a new source of information that } \\
\text { can be merged, compared, or can generate new insight. Data } \\
\text { linkage is a major approach for First Nations, Inuit, and Métis } \\
\text { to begin accessing vital information about their peoples and } \\
\text { communities, and to ensure that data are accessible across } \\
\text { community contexts and between levels of governance. }\end{array}$ & $\begin{array}{l}\text { MFNERC, } \\
2014\end{array}$ \\
\hline & $\begin{array}{l}\text { Meaningful } \\
\text { information sharing }\end{array}$ & $\begin{array}{l}\text { A principle for data sharing that is based on fostering long- } \\
\text { term, community-driven priorities and it is built on the } \\
\text { foundation of community engagement and buy-in. Meaningful } \\
\text { information sharing can only occur "when the exchange of } \\
\text { information happens frequently, openly and in all directions" } \\
\text { (NCFNG, n.d.a, p.2). }\end{array}$ & $\begin{array}{l}\text { NCFNG, } \\
\text { n.d.a. \& b }\end{array}$ \\
\hline \multirow{3}{*}{$\frac{n}{8}$} & $\begin{array}{l}\text { Data Access } \\
\text { Request (DAR) }\end{array}$ & $\begin{array}{l}\text { A standardized form where one may submit a request to access } \\
\text { Indigenous-owned and stewarded data. A DAR can provide } \\
\text { information about requesters including: "information regarding } \\
\text { the applicant, project overview, data access and project } \\
\text { methodology, data security, data analysis, dissemination plan } \\
\text { and anticipated project risks" (FNHA, et al., 2020, p.4). }\end{array}$ & $\begin{array}{l}\text { AFNIGC, } \\
\text { n.d.b; FNHA } \\
\text { et al., } 2020\end{array}$ \\
\hline & $\begin{array}{l}\text { Data Sharing } \\
\text { Agreement }\end{array}$ & $\begin{array}{l}\text { An agreement between multiple parties that set the terms of } \\
\text { data sharing and "specify anticipated use and access to the data, } \\
\text { restrictions on use, as well as expected service levels" (DAMA, } \\
\text { 2017, p.298). Through such agreements, First Nations, Inuit, } \\
\text { and Métis can ensure that data are governed within their } \\
\text { distinct methodologies and visions for data. }\end{array}$ & $\begin{array}{l}\text { FNIGC, 2014; } \\
\text { FNIGC, } \\
\text { 2020a; Tui'kn } \\
\text { Partnership, } \\
2015 \text { \& n.d.; } \\
\text { AFNIGC, } \\
\text { n.d.a }\end{array}$ \\
\hline & $\begin{array}{l}\text { Memorandum of } \\
\text { Understanding }\end{array}$ & $\begin{array}{l}\text { Supports the sharing and linkage of data internally between } \\
\text { departments in an organization/community by communicating } \\
\text { requirements, values, and priorities. }\end{array}$ & $\begin{array}{l}\text { BCFNDGI, } \\
2015 b\end{array}$ \\
\hline \multirow{2}{*}{ 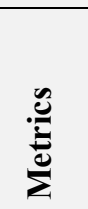 } & $\begin{array}{l}\text { Integration } \\
\text { tracking }\end{array}$ & $\begin{array}{l}\text { Tracking the impact of projects, initiatives, and actors that the } \\
\text { enterprise is integrated with. }\end{array}$ & $\begin{array}{l}\text { FNHA et al., } \\
2020\end{array}$ \\
\hline & $\begin{array}{l}\text { Standardization } \\
\text { progress }\end{array}$ & $\begin{array}{l}\text { Measuring progress of standard development to support } \\
\text { integration and interoperability. }\end{array}$ & FNIGC, 2020a \\
\hline
\end{tabular}




\subsubsection{Data Interoperability and Integration Outcomes}

First Nations, Inuit, and Métis are on the path toward securing the governance of their own data and information and DII is an important Area for Indigenous peoples to access and repatriate external sources of their data, to share knowledge and information for the betterment of Indigenous socio-economic and cultural well-being, and to integrate data capacities to create new, enriched data sources that meet Indigenous-determined needs and support Indigenous governance efforts. Integration and linking that are community-driven and distinction-based means that critical data stewardship functions can be returned to Indigenous peoples, and partnerships based on meaningful information sharing and trust can be formed and fostered between Indigenous communities and organizations, the Federal government and provinces, and external researchers and data collection agencies (FNIGC, 2020a). Figure 11 provides the modified context diagram for DII and summarizes the main points of analysis: 
Data Integration \& Interoperability

Definition: The migration and movement of data between databases, including between different applications, internal departments, and external organizations (DAMA, 2017).

Governance: Defining the terms and processes of data integration and movement can ensure trust, transparency, and accountability in internal and external data linking arrangements. Governance here can ensure value in data that flows between organizations and that this process is reliable and secure (DAMA, 2017).

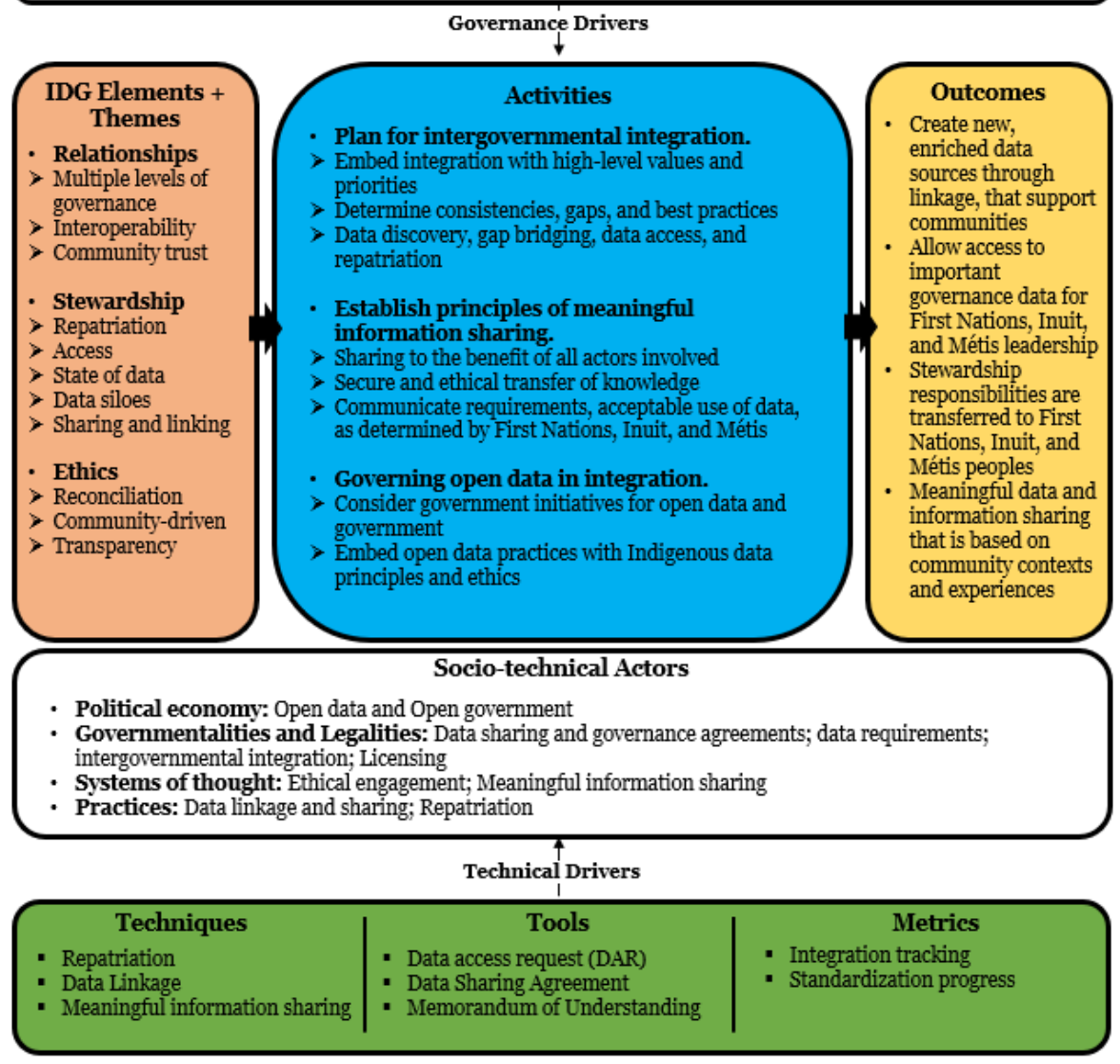

Figure 11: Modified context diagram for the Data Integration and Interoperability Knowledge Area

\subsection{Data Security}

Data security encompasses the "planning, development, and execution of security policies and procedures to provide proper authentication, authorization, access, and auditing of information assets" (DAMA, 2017, p.217). The central goal of data security is to protect data assets. The approach however will depend on the political and geographical situation of the organization. Security practices must align with "privacy and confidentiality regulations, contractual agreements, and business requirements" that come from: stakeholders, government 
regulations, organizational access needs, and industry standards and contractual agreements.

(DAMA, 2017, p.217-8). An effective data security strategy ensures that authorized individuals can access data, that all inappropriate access is prevented, and while complying with the needs and interests of all stakeholders (DAMA, 2017).

Data security is a critical function for any actors interested in protecting their data from breach, theft, harm, and to comply with Federal and provincial regulations designed in the interests of citizen privacy and confidentiality in information; in an Indigenous context however, values centered on the protection of data may frame this need further within a different discourse related to their own cultural priorities and aspirations. As First Nations, Inuit, and Métis identify and assert their own aspirations in protecting their information, these values and priorities can be built into the governance of data security and the design of measures to secure the state of data as well as practices surrounding their collection, use, and management. The governance of data security enables First Nations, Inuit, and Métis to guide research in Indigenous communities and to define what ethical engagement entails, to set the terms of access and stewardship of their data, and to assume responsibility over data as ownership entails:

- Stewardship \& Access. Security is a technical and system maintenance function and therefore it is linked to the technical processes and roles of data stewardship, and in this context Indigenous security over data carries heavy governance implications regarding the potential community harms that may result from the misuse of Indigenous data (FNIGC, 2020b). Effective governance of data security promotes control over how data are collected and used, and it can provide First Nations, Inuit, and Métis with the necessary stewardship mechanisms to protect their information and to define who can access their data and how, while preventing unauthorized access and use (BCFNDGI, 2015c; FNIGC, 2020a).

- Ownership. Strong governance over data security is not only necessary for practical reasons but is also a responsibility of data ownership, and there is a common aspiration across First Nations, Inuit, and Métis to protect the interests of their communities and 
citizens, including their data privacy and security. In the context of Ownership as a principle of OCAP, interests in data security and privacy are not only limited to data in the physical stewardship of Indigenous people's data, but of all data that have a relation to Indigenous peoples, communities, lands, and cultures (FNIGC, 2020b).

- Ethics. The misuse of First Nations, Inuit, and Métis data and unethical and inhumane research practices have resulted in an atmosphere of mistrust in data collection and research. Canadian institutions have attempted to overcome this atmosphere through ethics research boards (ERBs) and Federal research policies for Indigenous research, such as the Tri-Council Policy Statement: Ethical Conduct for Research Involving Humans which dedicates Chapter 9 to research involving First Nations, Métis, and Inuit peoples and requires key elements for review such as: informed consent, community engagement, respect for First Nations, Inuit, And Métis governing authorities, engaging communities of interest, research agreements and community privacy, and more (CIHR, NSERC, \& SSHRC, 2019). However, in essence these are self-regulating institutions and are usually not fully equipped to understand research principles from a diverse amount of community and local contexts (Di Leo Browne, 2012). Data security gives communities access to mechanisms to protect their interests in research about them, and to define what ethical research engagement means from an Indigenous perspective rather than a Western institutional perspective.

\subsubsection{Data Security Activities}

As DAMA notes, there "is no one prescribed way of implementing data security", and even with privacy and security regulations these often "focus on the ends of security, not the means for achieving it" (DAMA, 2017, p.245). How data security is implemented and governed will need to be designed to meet the context of the data steward while also meeting the end goals of security regulation and law. Activities in data security then focus on understanding and identifying security needs and requirements; noting gaps and risks; and utilizing data security tools, techniques, and processes to implement and provide oversight for data security (DAMA, 2017, p.245). 
In Canada, Indigenous data security activities are complicated by legislative barriers and existing practices: data privacy for instance is protected Federally under the Personal Information Protection and Electronic Documents Act (PIPEDA) and provincial health data privacy laws, however these only apply to personal, individual privacy and they do not cover privacy that applies to community data or collective cultural knowledge; access to information laws both federally and provincially enable the disclosure of Indigenous data held by the state and provincial departments, limiting Indigenous abilities to control how their information is used and interpreted; archived TK and colonial information about Indigenous communities are similarly not protected from disclosure by Library and Archives Canada (FNIGC, 2020b).

In addition to legal barriers, Indigenous research conducted by external actors and institutions often are out of Indigenous control and access or lack ethical engagement with Indigenous communities that are being researched and enumerated. While many private institutions often mean well through ethics review boards (ERBs) and oversight, these processes are not perfect and are not guarantees for the protection of Indigenous information and to avoid community harms (ITK, 2018; FNIGC, 2020b; Di Leo Browne, 2012). Overcoming these challenges is an activity and responsibility of Data Security processes. To direct First Nations, Inuit, and Métis data security as a practice of governance, communities and organizations are working within Canadian and Indigenous legal contexts to (1) develop and enforce privacy and security policies that protect their interests and values in information, and to (2) guide and enforce protection in community research practices based in ethics and authentic engagement.

\section{- (1) Privacy and security framework.}

To establish security priorities and enforcement mechanisms that ensure the protection of Indigenous data assets and privacy for the communities and individuals related to the data, robust and comprehensive privacy and security frameworks are being created and employed by Indigenous peoples in Canada to guide communities and organizations on 
the governance mechanisms, tools, and accountabilities that can secure and protect Indigenous data from unauthorized usage and access. There is however, as DAMA states, no one approach to what a data security framework will look like, and so below I provide a sample of key data security and privacy mechanisms being applied by Indigenous communities and organizations in Canada to secure and protect data and privacy, and which may be scalable to other governance contexts:

- Privacy and security policies. Establishing policies which communicate and enforce privacy and security requirements enables oversight, accountability, and reporting and they can articulate a common direction for the protection of information assets while informing Indigenous leadership and communities on the governance structures and roles needed to effectively protect data (BCFNDGI, 2015a). Privacy and security policies are standard data management techniques however when in Indigenous control, they can be constructed based on Indigenous data and research principles and sovereignty interests.

- Privacy law. Passing a privacy law may also be useful for self-governing Indigenous communities and nations to enforce control over the protection of personal and community privacy in data. The AFNIGC (n.d.b) offers an adaptable Privacy Law template that applies to First Nations and all their institutions and departments, and sets terms for the collection, use, disclosure, and access of personal and community information.

- Data sensitivity classification. Securing sensitive data additionally requires the classification of the adequate protections necessary for different types and levels of data. Data sensitivity classifications are a mechanism which can enable caution in handling data and identifies which level of security to apply. ${ }^{79}$ Assessing and classifying data by vulnerability enables communities to define what data are sensitive/important, how privacy is protected at both the individual and community level, and to be aware of the harms and impacts of compromised data when handling them (BCFNDGI, 2015c).

\footnotetext{
${ }^{79}$ For instance, the BCFNDGI Data Governance Policy Manual sets sensitivity classifications of low, medium, and high to each form of data it is set out the govern (Corporate; Cultural; Lands and Resources; Human-Related) with a description of the harm at each level; safeguard examples; and examples of data that fall into each classification (2015b, pp.18-23).
} 


\section{- (2) Ethical and authentic engagement.}

Indigenous peoples in Canada have been frequently researched peoples, but most often have little engagement or inclusion in designing and conducting research about them.

Data collection and information governance are primary drivers of research, and research practices and the knowledge they produce are key factors in the 'looping' of classification through experts and institutions (Hacking, 1986). As research practices in Canada have historically and continue to be out of Indigenous control and determination, this means that Indigenous peoples have little involvement in the dominant processes of 'making' their own peoples. First Nations, Inuit, and Métis data governance efforts in Canada however are shifting this pace toward ethical and authentic research engagement which sets the term for how First Nations, Inuit, and Métis are to be included and represented in research practices, how information collected in research is to be managed, governed, and shared with communities, and what 'ethics' and 'authentic engagement' mean from an Indigenous, community-driven perspective (FNIGC, 2020b).

High-level principles for data governance discussed in 2.3.2. (OCAP, Inuit Qaujimajatuqangit, OCAS) are not only to be applied by Indigenous peoples but they also operate as principles for ethical data governance in research practices by external institutions, organizations, and researchers, and they seek to engage in beneficial ${ }^{80}$ research partnerships while protecting Indigenous interests (CIHI, 2020b; FNIGC, 2020b). Frameworks for Indigenous-defined ethical conduct in research might also consider the ways that Indigenous research data are protected in Canada under the TCPS $2^{81}$, which is the dominant tool of reference for many institutions conducting Indigenous data collection for research. The development and enforcement of Indigenous research frameworks is also to the benefit of advancing how Indigenous research is conducted in Canada. The TCPS2 recognizes advancing Indigenous interests in data

\footnotetext{
${ }^{80}$ There are many misconceptions and myths that ethical research through Indigenous-defined principles are designed to impede or prevent research. In the context of OCAP, ideas that the principles "stifle" or "bias research" are unfortunately prominent, and highly misunderstood. As the FNIGC succinctly puts it, these ideas fail "to recognize that in all societies, both First Nation and non-First Nation, ethics require a balancing between considerations of social benefit and the potential for harm", and research should benefit all in participation (FNIGC, 2020b).

${ }^{81}$ Chapter 9 contains twenty-two provisions for Indigenous research that obligate researchers to engage with Indigenous communities, governing and cultural authorities, Elders and knowledge holders, and organizations and communities of interest; requirements for ethics planning and institutional review, research agreements, and the support of research capacity building; and oversight on the collection of sensitive information, intellectual property, and biological materials (CIHR, NSERC, \& SSHRC, 2019, pp.107-132).
} 
stewardship and governance and declares itself a "living document" that will co-develop with Indigenous engagement in research practices (CIHR, NSERC, \& SSHRC, 2019, p.107).

\subsubsection{Data Security Technical Drivers}

In Table 13 below I identify a sample of technical drivers that direct and manage the conduct of Data Security governance in First Nations, Inuit, and Métis community and organizational contexts. These tools, techniques, and metrics center on formalizing, guiding, and enforcing data security policies and mechanisms that are employed by Indigenous communities and organizations to protect their data assets and the personal and community privacy of First Nations, Inuit, and Métis peoples.

Table 13. Data Security Technical Drivers

\begin{tabular}{|c|c|c|c|}
\hline Type & Driver & Description & Derived from \\
\hline \multirow{3}{*}{ 产 } & $\begin{array}{l}\text { Privacy } \\
\text { impact } \\
\text { assessment } \\
\text { (PIA) }\end{array}$ & $\begin{array}{l}\text { An assessment of the potential privacy and security risks and harms } \\
\text { that may result from new data governance developments, initiatives, } \\
\text { programs, etc. These may also provide strategies and mechanisms for } \\
\text { risk mitigation. }\end{array}$ & FNIGC, 2014 \\
\hline & $\begin{array}{l}\text { Free, prior, } \\
\text { and informed } \\
\text { consent }\end{array}$ & $\begin{array}{l}\text { A community-driven approach to research in Indigenous } \\
\text { communities or about Indigenous peoples which is based on } \\
\text { Indigenous free will, consultations and engagement prior to research, } \\
\text { communities being fully informed about the research, and } \\
\text { communities must give their consent to conduct the research. }\end{array}$ & $\begin{array}{l}\text { B.C. } \\
\text { Environmental } \\
\text { Assessment } \\
\text { Office, n.d. }\end{array}$ \\
\hline & $\begin{array}{l}\text { Community- } \\
\text { based, } \\
\text { participatory } \\
\text { research } \\
\text { (CBPR) }\end{array}$ & $\begin{array}{l}\text { Research methodologies that emphasize relationship building } \\
\text { between Indigenous and non-Indigenous partners, community-driven } \\
\text { decision making, design, implementation, and reporting, and } \\
\text { importantly respect for Indigenous data and research principles. }\end{array}$ & $\begin{array}{l}\text { Smylie et al., } \\
2011\end{array}$ \\
\hline \multirow{3}{*}{$\stackrel{n}{8}$} & $\begin{array}{l}\text { Data } \\
\text { Sensitivity } \\
\text { Classification }\end{array}$ & $\begin{array}{l}\text { Classifications that describe the level of caution needed when } \\
\text { handling/processing certain data, based on the severity of impacts to } \\
\text { privacy if the data were breached/corrupted. }\end{array}$ & $\begin{array}{l}\text { BCFNDGI, } \\
2015 b\end{array}$ \\
\hline & Privacy Law & $\begin{array}{l}\text { Sets the terms of collecting, using, disclosing, and retaining personal } \\
\text { and community information and data. Aligns with international } \\
\text { personal privacy standards. }\end{array}$ & AFNIGC, n.d. \\
\hline & $\begin{array}{l}\text { Privacy and } \\
\text { Security } \\
\text { Policy }\end{array}$ & $\begin{array}{l}\text { The tools, procedures and requirements related to the protection of } \\
\text { Indigenous data and compliance with both personal (as set out in } \\
\text { Federal and provincial laws) and community (as defined by First } \\
\text { Nations, Inuit, and Métis) privacy. }\end{array}$ & $\begin{array}{l}\text { BCFNDGI, } \\
2015 \mathrm{a}\end{array}$ \\
\hline
\end{tabular}




\begin{tabular}{|c|c|c|c|}
\hline Type & Driver & Description & Derived from \\
\hline & $\begin{array}{l}\text { Code of } \\
\text { Research } \\
\text { Ethics }\end{array}$ & $\begin{array}{l}\text { Communicates the guiding vision, principles, responsibilities, and } \\
\text { processes behind research in a project/with a particular } \\
\text { organization/community (FNIGC, 2007) }\end{array}$ & FNIGC, 2007 \\
\hline 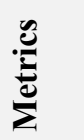 & $\begin{array}{l}\text { Privacy \& } \\
\text { security } \\
\text { awareness }\end{array}$ & $\begin{array}{l}\text { Tracking and logging privacy and security training completion by } \\
\text { those with access to Indigenous information. }\end{array}$ & $\begin{array}{l}\text { BCFNDGI, } \\
2015 b\end{array}$ \\
\hline
\end{tabular}

\subsubsection{Data Security Outcomes}

Data security is a practical function of data management and in a First Nations, Inuit, and Métis context it takes on even greater importance to prevent potential harms that may come from unauthorized access to and misuse of community and personal data. It is a responsibility of ownership (understood through OCAP) to protect data assets, and this includes Indigenous data that are collected and held by external actors and researchers. When First Nations, Inuit, and Métis have control and stewardship of their data, data security governance can enable the enforcement and application of security protocols that are embedded with Indigenous values and priorities and which ensure the privacy and confidentiality of both communities as well as individual First Nations, Inuit, and Métis peoples in data collection and use. Governance over data security also allows Indigenous communities and peoples to dictate the terms of collection, use, and access to data about them, including how research is conducted and the methodologies and definitions used; through such security policies and procedures, engagement, participation, and free, prior, and informed consent can be established as requirements for Indigenous research and data collection. Figure 12 below highlights the key aspects of First Nations, Inuit, and Métis governance in this Knowledge Area that can assist communities and organizations to reach these outcomes. 


\section{Data Security}

Definition: Ensuring the proper authorization, authentication, and access to data through technical policies and standards (DAMA, 2017).

Governance: Data Security is an essential aspect of Architecture that ensures that data are protected and that data protocols, rules, and external regulations are met. As part of governance, security enables effective and secure data integration and provides mechanisms of accountability and oversight for data practices (DAMA, 2017).

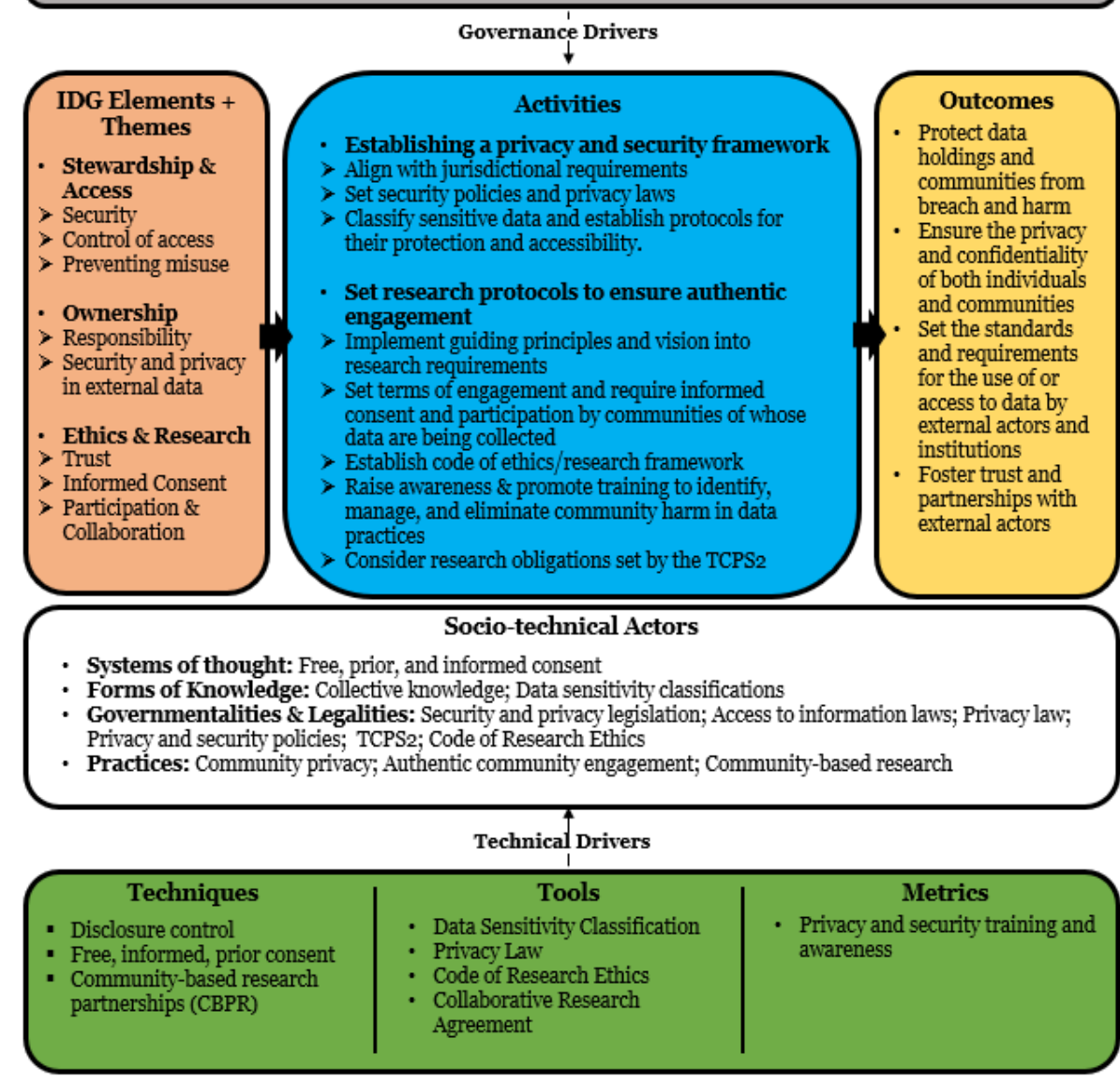

Figure 12: Modified context diagram for Data Security Knowledge Area

\subsection{Data Quality}

Data quality management refers to a formal program of processes that "enable an organization to use its data to achieve strategic goals" in a reliable and trustworthy fashion - high quality data can meet the needs of the organization and prevent poor planning, siloed systems, inconsistency and incompleteness, and lacking standards and governance (DAMA, 2017, p.449450). Organizations benefit from developing best practices in data quality management as processes and practices can never be perfect, so managing data quality can avoid problems and uninformed decisions. This requires "cross-functional commitment and coordination" in 
planning between business and technical professionals to ensure that "data [are] fit for consumption for a variety of purposes" (DAMA, 2017, p.450). Data quality management relies on reporting at multiple levels including in analysis, quantification, and issue management and thereby it depends on interactions and coordination at all levels of a data system. Like governance and management generally, it "is a program, not a project" (DAMA, 2017, p.450).

Faced by an ecosystem of siloed, incomplete data that are not defined by their interests and priorities, First Nations, Inuit, and Métis in Canada require high quality data to achieve visions of self-determination, control over governance, and Indigenous-defined systems of knowledge. Typically, technical components of data quality include completeness, validity, consistency, accuracy, and timeliness; however, the BCFNDGI asserts that quality through these principles is a legal and ethical responsibility and is only achieved when they "know that the data can be used for operational needs, decisions-making, and planning; and that it represents the real world" (BCFNDGI, 2015b). Indigenous DQ governance in Canada is centered on asserting selfdetermination over what quality in data entails; taking control over the design and standardization of data and the processes which produce them; and ensuring quality and value in data as a process of stewardship:

- Self-determination. 'Quality' data in the eyes of Western statistical methodologies and socio-economic indicators often lack Indigenous worldviews and engagement in their creation, resulting in an epistemological disconnect with the people they enumerate and describe. Quality needs to be defined from a First Nations, Métis, and Inuit perspective for data to be valuable to their own self-determined governance needs and priorities.

- Control. Control over data quality means control over key data management techniques and tools that are often embedded with colonial worldviews - standards and classifiers; metadata and ontologies; and the way data are communicated and reported within deficit narratives and indicators. 
- Stewardship \& Access. Maintaining data quality through governance is a practice of good stewardship and it enables First Nations, Inuit, and Métis to gain value from their information at multiple levels of governance and to achieve aspirations from the local to national level. High-quality data also enable consistency across enterprise architecture arrangements and interoperability (5.4.) between internal and external actors.

\subsubsection{Data Quality Activities}

Data quality activities relate to operational direction for maintaining quality data however these processes are also ontological in nature. Quality is often vaguely characterized by technical factors of timeliness, accuracy, and consistency but it might mean a number of different things and "high-quality" should be fit for purpose - determining what high-quality data are builds on an understanding of the needs and priorities of the organization, consensus on terminology and definitions, risks and opportunities with the data collected, and the structures of governance around data collection and management (DAMA, 2017, p.473). Data quality activities thereby directly align with high-level governance strategies and high-quality data can advance other Areas including Data Architecture (quality alignment), Data Integration and Interoperability (consistency and efficient integration through high-quality data), and Data Storage and Operations (implementing quality at collection and storage) (DAMA, 2017).

Concerns with data quality are on the forefront of Indigenous data governance efforts in Canada and these are driven by the desire to create and manage high-value, culturally fit, and useful information for First Nations, Inuit, and Métis communities and governments. First Nations, Inuit, and Métis can re-define what quality data and information are from their own perspectives and worldviews through data governance, and this includes through the production and employment of Indigenous-defined (1) standards, (2) "culture-smart" indicators to track community wellness and progress; and (3) governance mechanisms to manage quality. 


\section{- (1) Data standards.}

Data standards provide a structure of data collection requirements and rules, and they are critical for gaining value from data sources, aligning enterprise-wide understandings and approaches to data governance, and to maintain integrity, consistency, and accessibility across data governance functions (BCFNDGI, 2016b). Although they are a mechanism of Data Quality, data standards are an important function in almost all data governance Knowledge Areas: they communicate data governance priorities in collection practices; standards are required for data architecture-wide alignment and capacity building; they enable efficient data storage and operations by making data findable and consistent; and data integration and interoperability between different data sources and actors would be unfeasible without alignment of how the data are collected and managed, and standards are often communicated in data sharing agreements (BCFDNGI, 2015b). Data Standards for Indigenous identification in Canada exist in a statistical capacity at the federal level (i.e. Statistics Canada Indigenous identity self-identifier standards ${ }^{82}$ ) as well as at the provincial level, including the British Columbia Aboriginal Administrative Data Standard which was developed with a joint Indigenous/provincial led working group to improve socio-economic reporting; the Newfoundland and Labrador Indigenous Administrative Data Identifier Standard ${ }^{83}$ (NFLIADIS), which builds from the Statistics Canada self-identification and B.C. Aboriginal Data Standard approach; and the Ontario Data Standards for the Identification and Monitoring of Systematic Racism, which distinctly address issues of race and Indigenous identity, rather than holistic issues of colonialism at large ${ }^{84}$. Private and not for profit institutions may also develop Indigenous

\footnotetext{
${ }^{82}$ See the methodology and Appendix C of the Aboriginal Peoples Survey, 2017: Concepts and Methods Guide: https://www150.statcan.gc.ca/n1/pub/89-653-x/89-653-x2018001-eng.pdf

${ }^{83}$ The NFLIADIS was developed on the foundations of the B.C. Government Standard for Aboriginal Administrative Data and self-identification questionnaires used by Statistics Canada. The Standards also went through the consideration of a Working Group with members from Miawpukek, Mushuau Innu, Qalipu Mi'kmaq, and Sheshatshiu Innu First Nations; Nunatsiavut government and NunatuKavut Community Council; and various departments and public service sectors in Newfoundland and Labrador (Department of Health and Community, 2017, p.1).

${ }^{84}$ The Standard notes that the anti-racism approach should be understood as distinct from anti-colonialism (p.6). This is an important distinction that also appears in the proposed CIHI standards for race-based health reporting, which emphasizes that although there are similarities between ethnic/racial issues and Indigenous issues, First Nations, Inuit, And Métis in Canada are constitutionally recognized and self-determined peoples and their engagement is necessary to ensure their perspectives and priorities are met in practice (CIHI, 2020b, p.11). CIHI does note however that collecting "race-based" data is useful to root out systemic racialized issues, and that a distinctions-based identity question plus community engagement are necessary for effective, culturally fit standard development.
} 
data standards in their practices, such as the CIHI Proposed Standards for Race-Based and Indigenous Identity Data Collection and Health Reporting in Canada, which adopt a distinctions-based approach for Indigenous reporting.

\section{- (2) Culture-fit indicators.}

There is currently a need for Indigenous-defined indicators and planning at a community level and which are defined through engagement with communities and that represent their interests and priorities. Currently, socio-cultural indicators are primarily defined ${ }^{85}$, by governmental actors such as Statistics Canada, who have a national mandate for conducting surveys and censuses which ultimately limits engagement with the local communities they track (or often do not track) ${ }^{86}$. Limits on the collective capacities of First Nations, Inuit, and Métis to name and govern their communities in these arrangements demands leadership in processes of planning and monitoring at a community level, and by community-defined indicators that will produce data of value to Indigenous communities and governments. The BCFNDGI Indicator Development Guide highlights the importance of indicators as they can "create a complete picture of community life" that is highly relevant for governance and policymaking, program monitoring, tracking cultural development and investment, or highlighting issues in need of resolution (Geddes, 2015, p.2). As discussed in section 2.1., colonial indicators have long communicated a narrative and picture of Indigenous communities defined by deficit indicators which track negative socio-economic and health outcomes rather than positive, strength-based indicators (Phillips, 2017). Overcoming deficit and homogenized narratives through governance demands measuring wellness using meaningful, culturally fit, and community-driven indicators to measure community-defined ideas of progress and to build the foundations for effective governance planning and reporting (Geddes, 2015). The BCFNDGI guide effectively sets a general framework for the development of wellness indicators that can be adapted to diverse community priorities, cultural expressions, and values, based on:

\footnotetext{
${ }^{85}$ Appendix 4 contains the 2018 Statistics Canada guide for First Nations Health and Wellness Indicators, which gives a glimpse into both government-defined and First Nations-defined indicators that track health and wellness and their source.

86 The content of the 2017 Aboriginal Peoples Survey for instance is developed solely by governmental agencies (Statistics Canada, CIRNAC, ISC) and investigates socio-demographic and economic themes on a basis of group identity that is either self-identified or related to Government policy mechanisms (Statistics Canada, 2017).
} 
1. Learning and educating about indicators and their benefits, and choosing motivated leadership to engage with their development in communities;

2. Research on planning, data management, and technical capacities;

3. Engaging community to involve community in the definition and development of meaningful indicators;

4. Finalizing drafts, edits, and revision of indicators; and

5. Developing a baseline - integrating measurements into sources of data, identifying, and filling gaps, collecting community measurements of wellness (Geddes, 2015, p.14-15).

\section{- (3) Quality Governance.}

Standards and Indicators are two of the key areas where First Nations, Inuit, and Métis are building capacities and asserting and designing their own conceptions of 'quality' data that are not based within a deficit model and statistical aggregation methodologies, but rather are built on community engagement and priorities, Indigenous-determined ontologies, and on new models of Indigenous wellness and progress that are culturally fit and distinctions-based. While the most prominent in the compiled literature however, these are not the only technical quality governance tools which can be repurposed to support Indigenous capacity and epistemological development in data practices and here I provide a sample of other important Data Quality functions from the DMBOK which can be adapted for First Nations, Inuit, and Métis to control and govern the quality of their data and information by their terms:

- Data dictionary. A data dictionary is used to compile and manage metadata (Table 14 below) which are information that give context to other data, such as types of data, structures, and security requirements (DAMA, 2017).

○ Business glossary. A collection of concepts, ontologies, terminology, definitions, etc. that help align and direct how data are understood across an enterprise. Grows and develops with the maturity of an organization (DAMA, 2017).

- Master and Reference Data. A Knowledge Area in the DAMA DMBOK, Master and Reference Data are data types that detail what data an organization has and relationships between data and actors across an organization/enterprise. They are useful for business alignment and to facilitate internal and external data sharing (see section 5.4.; DAMA, 2017). 


\subsubsection{Data Quality Technical Drivers}

In Table 14 below, I provide a snapshot of technical drivers for Data Quality

governance. These are related to the definition, maintenance, and enforcement of Indigenous-

determined notions of 'quality', and they are adaptable and scalable to a wide range of contexts, approaches, and visions for data sovereignty and governance.

Table 14. Data Quality Technical Drivers

\begin{tabular}{|c|c|c|c|}
\hline Type & Driver & Description & Source(s) \\
\hline \multirow{2}{*}{ 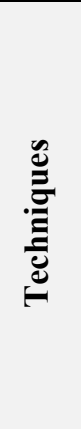 } & Distinctions-based & $\begin{array}{l}\text { Approaches which acknowledge "the distinct histories, interests } \\
\text { and priorities of First Nations, Inuit and Métis. For data to be } \\
\text { relevant and useful to the people who own it, First Nations, } \\
\text { Inuit, and Métis data needs to be delineated" (CIHI, 2020a, p.6). }\end{array}$ & $\begin{array}{l}\text { FNIGC, } \\
\text { 2020a; CIHI, } \\
\text { 2020a }\end{array}$ \\
\hline & $\begin{array}{l}\text { Data Quality } \\
\text { Control }\end{array}$ & $\begin{array}{l}\text { Processes "applied at the point of recording and storing original } \\
\text { data" that ensure data are timely, complete, consistent, and } \\
\text { accurate. This could include processes such as applying } \\
\text { standards (see below in this Table), cleaning data, or adding } \\
\text { metadata (BCFNDGI, 2015b). }\end{array}$ & $\begin{array}{l}\text { BCFNDGI, } \\
\text { 2015b; FNHA } \\
\text { et al., } 2020\end{array}$ \\
\hline \multirow{3}{*}{$\frac{n}{8}$} & Data standards & $\begin{array}{l}\text { Rules and requirements for structuring data to enable } \\
\text { consistency and ease of access across an organization's data } \\
\text { architecture, and are used to: identify data; integrate data } \\
\text { internally and externally; align understandings across } \\
\text { organizations and domains; and to monitor the quality of } \\
\text { collected data. A data standard template developed by the } \\
\text { BCFNDGI is provided in Appendix 5. }\end{array}$ & $\begin{array}{l}\text { BCFNDGI, } \\
2015 b\end{array}$ \\
\hline & $\begin{array}{l}\text { Indicators of } \\
\text { wellness }\end{array}$ & $\begin{array}{l}\text { Cultural-fit measurements designed to track social determinants } \\
\text { of health in a way that supports positive, Indigenous-defined } \\
\text { visions and values of wellness, such as related to } \\
\text { culture/nationhood; health; education; employment skills; etc. }\end{array}$ & Geddes, 2015 \\
\hline & Metadata & $\begin{array}{l}\text { Metadata convey a wide range of information, including about } \\
\text { business and technical practices, data requirements, or data } \\
\text { structures and architectures; they describe data, concepts that } \\
\text { the data represent, and concepts related to data (DAMA, 2017, } \\
\text { p.417). Metadata enrich data sources and add context to data, to } \\
\text { guide their usage and organization. }\end{array}$ & $\begin{array}{l}\text { DAMA, 2017; } \\
\text { FNIGC, 2020a }\end{array}$ \\
\hline \multirow{2}{*}{ 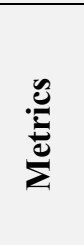 } & Quality Assessment & $\begin{array}{l}\text { Monitoring the quality of data, as self-determined by the } \\
\text { community or organization }\end{array}$ & $\begin{array}{l}\text { BCFNDGI, } \\
2015 \mathrm{~b}\end{array}$ \\
\hline & $\begin{array}{l}\text { Closing } \\
\text { information gaps }\end{array}$ & $\begin{array}{l}\text { Assessing if high-quality data meets the needs of the } \\
\text { community/organization, and if they help close information } \\
\text { gaps }\end{array}$ & FNIGC, 2020a \\
\hline
\end{tabular}




\subsubsection{Data Quality Outcomes}

Effective and culturally fit Data Quality governance enable First Nations, Inuit, and Métis to gain value from data collection and management processes. What this value means will depend on the community/organization however Data Quality ensures consistency and coherence across data sources and actors in a way that supports and aligns with a community/organization's data governance visions and direction. Data are essential for effective governance and planning, and access to high-quality data can support the needs of communities in terms of socio-economic reporting, community-based research, and to manage and govern the delivery of services to communities (Smith, 2016; BCFNDGI, 2015b). First Nations, Inuit, and Métis are better equipped to govern their information, peoples, and identities when they have access to highquality data that are defined by their terms and ontologies, and through the development of new models of standards and indicators that are not based within colonial systems and definitions but rather transformative new approaches for tracking progress, health, and well-being in Indigenous communities.

Figure 13 below summarizes Data Quality governance and the primary elements, activities, outcomes, and approaches that are driving transformative change in understandings of Indigenous data quality. 


\section{Data Quality Management}

Definition: Ensuring data meets the needs of the organization by embedding quality management processes in data practices (DAMA, 2017).

Governance: Data quality programs are an essential element of data governance programs - effective data quality enables enterprise wide integration and alignment, effective workflows and ease of access, and direction for management practices (DAMA, 2017).

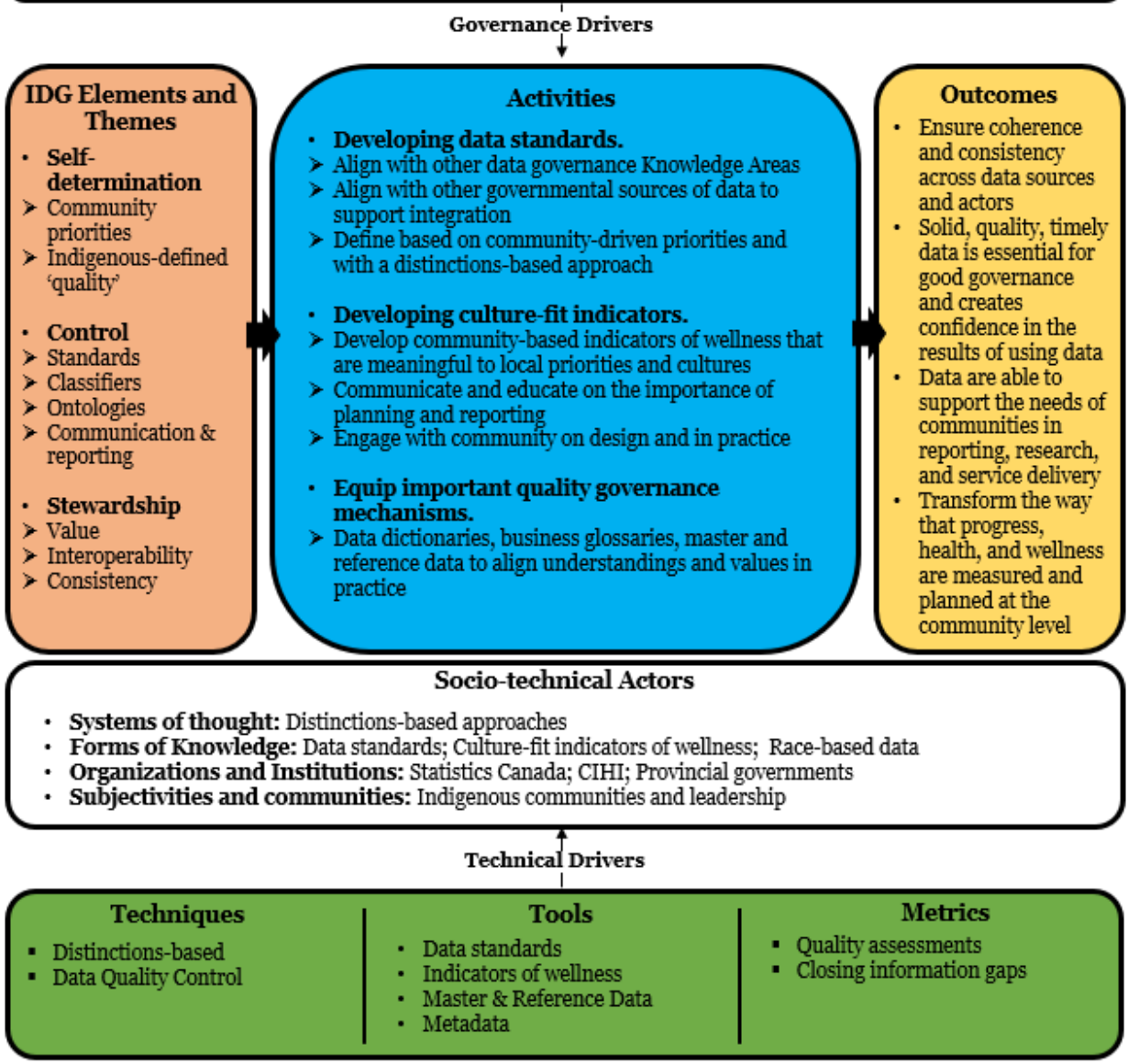

Figure 13: Modified context diagram for governance in the Data Quality Knowledge Area

\subsection{Document and Content Management}

Document and Content Management is defined by DAMA as "controlling the capture, storage, access, and use of data and information stored outside relational databases", particularly unstructured and semi-structured data and information found in documents and other textual content (2017, p.303). While different from structured data and relational databases, these forms of unstructured data still require effective decision making and management that is consistent with structured forms, and this data should still be protected and produced at high quality. To effectively manage Document and Content Management, an organization should employ strong 
"governance, reliable architecture, and well-managed Metadata" which enables quick and efficient "storage, retrieval, and use of Documents and Content" (DAMA, 2017, p.304). In a professional Western context, the primary driver of management and governance in this area is regulatory compliance, efficiency in organization and accessing data, and to improve document management and business continuity ${ }^{87}$ (DAMA, 2017).

Since I already adopt a broad understanding of data in this thesis that may include content and documents, I use this space to primarily investigate how local and traditional knowledge (TK) emerge in the governance of DCM. TK are often communicated through content and material forms of data that are outside of relational databases and these are important and critical cultural artifacts and information for Indigenous peoples and communities. Like statistical, research, and administrative data, TK can be effectively governed and managed to ensure security and protection and Indigenous control over decisions made about them. DCA in this governance context is matter of ensuring Indigenous stewardship and access to cultural and generational knowledge; asserting legal ownership of DCM data; and determining how these data are handled, cared for, and used:

- Stewardship \& Access. The stewardship of TK generally operates distinctly from the archival practices of Western institutions - often TK are communicated through data forms such as artifacts and oral histories, songs, and traditions (Scassa et al., 2014). Emerging digital storage and data management capacities that are Indigenous owned and led represent an opportunity for the preservation of tangible and fragile cultural content and to integrate these data into data governance strategies across the Knowledge Areas.

- Ownership. Intellectual property laws in Canada are generally not suited to protect TK due to two main obstacles: meeting requirements for copyright subject matter (work must be fixed/tangible; expressions and not knowledge itself; etc.) and in terms of ownership,

\footnotetext{
${ }^{87}$ Business continuity planning is an essential technical data management process where stewards plan for a "disaster or adverse event" that impacts their capacity and ability to access and use the data, through recovery plans involving physical databases; disk storage drives; corruption of indexes; or the loss/corruption of system and backup files (DAMA, 2017, p.197).
} 
as where IP laws are affixed to the life of an author (natural lifespan), TK often does not belong to an individual but rather to an entire community (CIPPIC \& GCRC, 2016, p.34). IP laws are also designed primarily for the protection of inventions and trademarks, and there is no mechanism that effectively protects TK. As a result, TK often is unprotected and outside of the scope of IP laws and may affect the ability of a community to control the use and access to their knowledge.

- Self-determination. Like statistical and relational data sources, how TK are managed and governed has long been appropriated by the settler state, acting within a paternalistic, guardianship-imaginary to 'legitimize' the dispossession and denigration of TK sources (Anderson, 1983). As First Nations, Inuit, and Métis assert control and governance over their TK sources, they can determine how traditional and local data are governed, stored, protected, and made accessible to future generations.

\subsubsection{Document and Content Management Activities}

Activities in DCA are usually driven by legal obligations in records management, producing policies and guidelines for organizing, labelling, finding, and handling content, and integrating and maintaining the lifecycle of document and content data and records (DAMA, 2017, p.304). These forms of activities in DCA take on further critical important in the context of TK, cartographies and geospatial data, and cultural artifacts from which communities and peoples derive generational knowledge and cultural histories. In this context, the governance of DCA centers on (1) the digitization and centralization of TK, documents, and content; and (2) direction in the protection of intellectual property that belongs to communities.

\section{- (1) Digitizing data.}

For many local First Nations, Inuit, and Métis community contexts, TK and generational sources of community knowledge often exist in a variety of forms, such as traditional mapping, hand-written documents, or even orally transmitted knowledge, stories, and traditions. As such, there is an inherent fragility to many TK sources and a risk of being damaged, lost, or destroyed by the elements or by human error; these risks are exacerbated over time and as politics shift, cultures evolve, and new generations become 
simply unaware to what knowledge is available ${ }^{88}$ (C. Gall, research interview, 2021). Digitizing and centralizing TK is one approach to modernizing Indigenous knowledge that can enable communities to both protect and preserve their information while building out systems that allow communities to access their cultural knowledge and heritage, and this is especially potent in a post-pandemic world. This is of course not a catch-all solution and digitization has its own challenges, from balancing accessibility and privacy to ensuring control and ownership over TK that are created and shared, and this is where technical drivers in this area (5.7.2.) can enhance the ability of Indigenous data stewards to balance digital challenges with great community and cultural benefits (C. Gall, research interview, 2021). There are of course a range of other performance benefits for governance that come from moving information systems to a digital space as well. The MNBC for instance is planning to become the first fully digital Indigenous government in Canada within the next few years, which is planned to greatly improve their administrative functionality and processing of Métis citizenship (C. Gall, research interview, 2021). Digital data portals on the internet are also being employed to share and make Indigenous cultural data, statistics, and knowledge available and visible. The FNIGC for instance operates FNIGC Data Online ${ }^{89}$ which gives access to FNIGC-led survey results, and the Métis National Council (MNC) and governing Métis Nations maintain the Métis Nation Self-Determination Gateway ${ }^{90}$ which is a "place to find information on the Métis Nation's attainment of self-determination as it pursues its own political status and social, cultural and economic development" (MNC, 2019).

\section{- (2) Intellectual property.}

Since Canadian law is limited in its protection of TK, Indigenous communities must employ other mechanisms to protect their governance and control of TK and material data sources. A proposed approach to this challenge suggested by the GCRC at Carleton University and the Canadian Internet Policy and Public Interest Clinic (CIPPIC) is the development and use of a TK License that is built on similar fundamentals as Creative Commons licenses ${ }^{91}$. A TK License adopts three mechanisms or "layers" of protection from $\mathrm{CC}$, including a legal code for enforceability; a "protection of unilateral contract"

\footnotetext{
${ }^{88}$ Stagnation in the passing of cultural knowledge is also a direct result of colonial intervention in Indigenous communities and with the denigration of their systems of knowledge (see section 2.1.).

${ }^{89}$ FNIGC Data Online service: https://fnigc.ca/dataonline/

90 The Métis Nation Self-Determination Gateway: https://Métisportals.ca/gateway/

${ }^{91}$ Creative Commons (CC): https://creativecommons.org/
} 
that are agreed-upon terms before accessing and using TK and data; and finally, normative obligations, which act as a "code of conduct" for anyone using the data, copyright available or not (CIPPIC \& GCRC, 2016, pp.12-13). The TK license scheme also utilizes terms for the repatriation of data collected under the license, necessary community consent, and a requirement that the use of TK be for only education and research (CIPPIC \& GCRC, 2016). Considerations for an Open Government License $(\mathrm{OGL})^{92}$ might also be relevant when the data in question is in the control of the Federal government, which was determined to be closely compatible (with some modifications) with OCAP principles in a study of open geospatial data held by Natural Resources Canada (Hackett et al., 2019). The Mukurtu Content Management System (Mukurtu $\mathrm{CMS})^{93}$ is another approach to TK intellectual property governance that utilizes a digital platform system embedded with Creative Commons protocols to "empower communities to manage, share, and exchange their digital heritage in culturally relevant and ethicallyminded ways" (Center for Digital Scholarship and Curation, n.d.).

\subsubsection{Document and Content Management Technical Drivers}

Table 15 below identifies a sample of technical drivers centered on asserting control, possession, and ownership over TK. Due to the varied nature of the forms of data and knowledge being governed in this Knowledge Area, I was not able to gleam any specific impact metrics from the compiled literature. As documents and content materials are also subject to governance from other Knowledge Areas, metrics identified for Areas such as Data Storage and Operations, Data Security, and Data Quality may be adaptable and applicable to measure and account for governance in this Area, but a deeper analysis that is beyond the scope here would be required to attest if that is the case.

\footnotetext{
92 Open Government License - Canada: https://open.canada.ca/en/open-government-licence-canada

${ }^{93}$ Mukurtu CMS: https://mukurtu.org/
} 
Table 15. Document and Content Management Technical Drivers

\begin{tabular}{|c|c|c|c|}
\hline Type & Driver & Description & Source(s) \\
\hline \multirow{3}{*}{ : } & Digitization & $\begin{array}{l}\text { Processes where tangible data forms (content and materials, } \\
\text { TK, documents, etc.) are converted to digital formats as a } \\
\text { means of protection and preservation. }\end{array}$ & $\begin{array}{l}\text { C. Gall, } \\
\text { research } \\
\text { interview, } \\
2021\end{array}$ \\
\hline & Licensing & $\begin{array}{l}\text { Standardized forms by which Indigenous peoples can grant } \\
\text { copyright permissions to utilize and access their data. }\end{array}$ & $\begin{array}{l}\text { CIPPIC \& } \\
\text { GCRC, } 2016\end{array}$ \\
\hline & Community Consent & $\begin{array}{l}\text { Community consent approaches can be worked into licensing } \\
\text { and intellectual property frameworks that oblige any users of } \\
\text { TK to receive consent from the community from which the } \\
\text { data were produced. How consent is defined is subject to the } \\
\text { community itself and therefore engagement is a prerequisite } \\
\text { for using TK. }\end{array}$ & $\begin{array}{l}\text { CIPPIC \& } \\
\text { GCRC, } 2016\end{array}$ \\
\hline \multirow{4}{*}{$\stackrel{n}{\varrho}$} & Data portal & $\begin{array}{l}\text { A digital application that acts as a repository and gateway to } \\
\text { data resources such as documents, datasets, and other } \\
\text { information. }\end{array}$ & $\begin{array}{l}\text { FNIGC Data } \\
\text { Online; MNC } \\
\text { Self- } \\
\text { Determination } \\
\text { Gateway }\end{array}$ \\
\hline & $\begin{array}{l}\text { Records Disposition } \\
\text { Authority (RDA) }\end{array}$ & $\begin{array}{l}\text { A request made to an archivist to permit the destruction or } \\
\text { return of important data and information which may cause } \\
\text { harm if they are released under information access protocols } \\
\text { or the Library and Archives Canada Act. While difficult to } \\
\text { obtain, an RDA effectively allows First Nations, Inuit, and } \\
\text { Métis to prevent harm resulting from the release of their data. }\end{array}$ & $\begin{array}{l}\text { FNIGC, } \\
2020 b ; \\
\text { CIPPIC \& } \\
\text { GCRC, } 2016\end{array}$ \\
\hline & TK License & $\begin{array}{l}\text { An open licensing approach developed by CIPPIC and the } \\
\text { GCRC for traditional knowledge that is derived from the } \\
\text { Creative Commons approach and that seeks to "facilitate } \\
\text { development in a way that allows indigenous communities to } \\
\text { publicly share TK for the benefit of others and future } \\
\text { generations, while at the same time allowing them articulate } \\
\text { their normative expectations around re-use" (CIPPIC \& } \\
\text { GCRC, 2016, p.9). }\end{array}$ & $\begin{array}{l}\text { CIPPIC and } \\
\text { GCRC, } 2016\end{array}$ \\
\hline & Mukurtu CMS & $\begin{array}{l}\text { Mentioned in 2.3.1., Mukurtu CMS is a digital platform that } \\
\text { offers multiple technical functions for Indigenous peoples to } \\
\text { govern their TK, including: TK Labels which are self- } \\
\text { determined metadata tags to attach to both owned and public } \\
\text { heritage materials; cultural protocols to define the range of } \\
\text { access to materials; community records to build culture and } \\
\text { TK; and roundtrip which allows for importation and } \\
\text { exportation to Mukurtu CMS. }\end{array}$ & $\begin{array}{l}\text { Center for } \\
\text { Digital } \\
\text { Scholarship } \\
\text { and Curation, } \\
\text { n.d. }\end{array}$ \\
\hline
\end{tabular}




\subsubsection{Document and Content Management Outcomes}

The governance of DCM in the form of traditional and local sources of community knowledge positions First Nations, Inuit, and Métis with the means to protect and preserve their cultural heritage and knowledge from unauthorized access and usage and to ensure that these sources of data are valued in both Western and Indigenous contexts. Digital solutions offer new ways to store and preserve TK and to make these important cultural objects accessible and understandable to Indigenous youth and emerging generations, who can continue to foster the growth and development of Indigenous knowledge and ways of knowing. Licensing for TK also presents an approach to fill the gaps in intellectual property laws, and open-source systems like Mukurtu Content Management System (CMS) can better enable First Nations, Inuit, and Métis to control, access, and direct the way that their TK are understood and used in Indigenous and nonIndigenous contexts. Data governance in DCM provides a way towards continuity in TK and to ensure that these important cultural resources are carried forward and not lost in time.

Figure 14 below is the modified context diagram for DCM and summarizes the main points of this analysis section. 


\section{Document and Content Management}

Definition: Data lifecycle management for unstructured data outside of models and relational data bases, such as documents and reports (DAMA, 2017).

Governance: The governance of information also requires considerations of risk, value, sensitivity; governance in this Area entails accountability, taxonomies and ontologies, and regulatory compliance (DAMA, 2017).

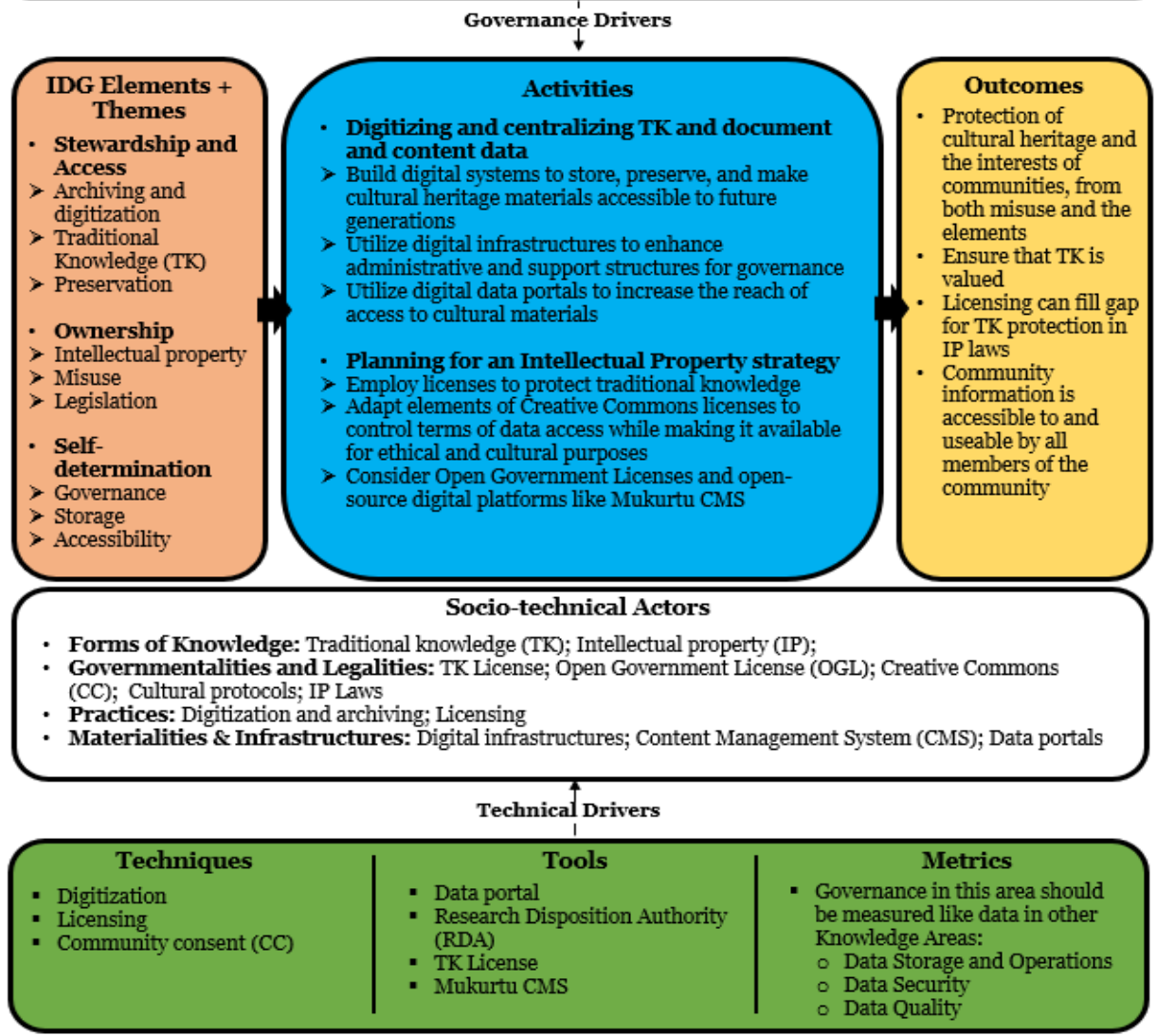

Figure 14: Modified context diagram for Document and Content Management

\subsection{Summary of Directed Content Analysis}

The results of the analysis (summarized in Table 16 below) showcase a high-level snapshot of Indigenous data governance efforts in Canada and this framework of study might be useful for any Indigenous or non-Indigenous actor interested in better understanding ${ }^{94}$ how data governance in Canada is being resisted, repurposed, and reconstructed for and by Indigenous peoples

\footnotetext{
${ }^{94}$ The understanding of IDG in Canada presented here is useful for broad conceptualizations and practical applications of domain-specific data governance, however this should not be taken as a replacement for understanding the distinct principles and approaches of First Nations, Inuit, and Métis communities or for engaging with this knowledge and communities in research practices.
} 
Table 16. Summary Table of the Directed Content Analysis from Chapter 5

\begin{tabular}{|c|c|c|c|}
\hline Knowledge Area & IDG Themes & Governance Activities & Outcomes \\
\hline $\begin{array}{l}\text { Data } \\
\text { Governance }\end{array}$ & $\begin{array}{ll}\text { - } & \text { Community- } \\
\text { driven/Ownership } \\
\text { - } \\
\text { Relationships \& } \\
\text { Accountability } \\
\text { - } & \text { Self- } \\
\text { determination/Control }\end{array}$ & $\begin{array}{l}\text { 1) Defining a vision and } \\
\text { scope for data sovereignty } \\
\text { 2) Developing high-level } \\
\text { strategies, frameworks, } \\
\text { and principles } \\
\text { 3) Applying governance } \\
\text { direction into community } \\
\text { practices }\end{array}$ & $\begin{array}{ll}\checkmark & \text { Trust in governance } \\
\checkmark & \text { Create and enforce the } \\
\text { terms of engagement with } \\
\text { Indigenous data } \\
\checkmark & \text { Align values in data } \\
\text { governance across } \\
\text { communities and } \\
\text { governments } \\
\checkmark & \text { Support community data } \\
\text { practices and research }\end{array}$ \\
\hline $\begin{array}{l}\text { Data } \\
\text { Architecture }\end{array}$ & $\begin{array}{ll}\text { - } & \text { Capacity } \\
\text { - } & \text { Control } \\
\text { - } & \text { Relationships \& } \\
& \text { Accountability }\end{array}$ & $\begin{array}{l}\text { 1) Planning for architecture } \\
\text { 2) Implementing high-level } \\
\text { architecture direction } \\
\text { 3) Securing investment and } \\
\text { funding to support } \\
\text { architecture and data } \\
\text { decolonization }\end{array}$ & $\begin{array}{ll}\checkmark & \text { Align priorities and } \\
\text { understandings across } \\
\text { data architecture } \\
\checkmark & \text { Enable Indigenous control } \\
\text { over data } \\
\checkmark & \text { Trackable and } \\
\text { manageable } \\
\text { implementation and } \\
\text { funding }\end{array}$ \\
\hline $\begin{array}{l}\text { Data Storage \& } \\
\text { Operations }\end{array}$ & $\begin{array}{l}\text { - Capacity } \\
\text { - Control } \\
\text { - Stewardship \& } \\
\text { Access }\end{array}$ & $\begin{array}{l}\text { 1) Planning for technical and } \\
\text { human capacities } \\
\text { 2) Building and supporting } \\
\text { data storage and } \\
\text { management capacities } \\
\text { 3) Producing operational } \\
\text { frameworks and } \\
\text { guidelines }\end{array}$ & $\begin{array}{ll}\checkmark & \text { Establish necessary } \\
\text { capacities for data } \\
\text { governance } \\
\checkmark & \text { Enable opportunities in } \\
\text { the digital economy } \\
\checkmark & \text { Improve the } \\
\text { administrative and } \\
\text { management functions of } \\
\text { Indigenous organizations } \\
\text { and communities }\end{array}$ \\
\hline $\begin{array}{l}\text { Data } \\
\text { Interoperability } \\
\text { \& Integration }\end{array}$ & $\begin{array}{ll}\text { - } & \text { Ethics } \\
\text { - } & \text { Relationships \& } \\
& \text { Accountability } \\
\text { - } & \text { Stewardship \& } \\
& \text { Access }\end{array}$ & $\begin{array}{l}\text { 1) Plan for } \\
\text { intergovernmental } \\
\text { integration } \\
\text { 2) Establishing practices that } \\
\text { encourage meaningful } \\
\text { information sharing } \\
\text { 3) Govern open data } \\
\text { integration }\end{array}$ & $\begin{array}{ll}\checkmark & \text { Create new, valuable data } \\
\text { sources for Indigenous } \\
\text { peoples } \\
\checkmark & \text { Enable access to } \\
\text { important data for } \\
\text { governance } \\
\checkmark & \text { Sharing and linkage that } \\
& \text { supports community } \\
\text { interests and priorities }\end{array}$ \\
\hline Data Security & $\begin{array}{l}\text { - Ethics } \\
\text { - Ownership } \\
\text { - Stewardship \& } \\
\text { Access }\end{array}$ & $\begin{array}{l}\text { 1) Developing a privacy \& } \\
\text { security framework } \\
\text { 2) Guiding and enforcing } \\
\text { ethical and authentic } \\
\text { research practices in } \\
\text { communities }\end{array}$ & $\begin{array}{ll}\checkmark & \text { Ensure privacy and } \\
\text { security of Indigenous } \\
\text { data } \\
\checkmark & \text { Set the terms for the } \\
\text { access to and use of data } \\
\checkmark & \text { Free, prior, and informed } \\
\text { consent \& trust }\end{array}$ \\
\hline
\end{tabular}




\begin{tabular}{|c|c|c|c|}
\hline Knowledge Area & IDG Themes & Governance Activities & Outcomes \\
\hline Data Quality & $\begin{array}{l}\text { - } \text { Control } \\
\text { - Self-determination } \\
\text { - Stewardship \& } \\
\text { Access }\end{array}$ & $\begin{array}{l}\text { 1) Establishing data } \\
\text { standards to improve } \\
\text { consistency and quality } \\
\text { 2) Developing culture-smart } \\
\text { indicators for community } \\
\text { monitoring and reporting } \\
\text { 3) Equip quality governance } \\
\text { mechanisms }\end{array}$ & $\begin{array}{ll}\checkmark & \text { Define and develop high- } \\
\text { quality data for } \\
\text { governance } \\
\checkmark & \text { Data that can support } \\
& \text { community needs } \\
\checkmark & \text { Transform how health and } \\
\text { wellness are measured and } \\
\text { reported at a community } \\
\text { level }\end{array}$ \\
\hline $\begin{array}{l}\text { Document \& } \\
\text { Content } \\
\text { Management }\end{array}$ & $\begin{array}{l}\text { - } \text { Ownership } \\
\text { - Self-determination } \\
\text { - Stewardship \& } \\
\text { Access }\end{array}$ & $\begin{array}{l}\text { 1) Digitizing and centralizing } \\
\text { important TK and cultural } \\
\text { knowledge } \\
\text { 2) Planning for the } \\
\text { protection of Indigenous } \\
\text { intellectual property (IP) }\end{array}$ & $\begin{array}{ll}\checkmark & \text { Protection and promotion } \\
\text { of valuable TK and } \\
\text { Indigenous cultural } \\
\text { heritage } \\
\checkmark & \text { Making community } \\
& \text { knowledge accessible and } \\
& \text { useable by the community } \\
\checkmark & \text { Fill the gap in Western } \\
\text { laws for the protection of } \\
\text { TK }\end{array}$ \\
\hline
\end{tabular}




\section{Chapter 6: Discussion}

This chapter discusses and analyzes the results and findings of the directed content analysis as seen in the observations in Chapter 5 and as described in Chapter 4, where I compiled and coded a broad range of First Nations, Inuit, and Métis data governance texts including both high-level strategic documents as well as practical applications and tools for data governance to answer the question, can practices of data colonialism in Canada be decolonized through Indigenous data governance? Based on the results of the content analysis and informed by the theoretical framework for decolonization described in Chapter 3, in this chapter I argue that First Nations, Inuit, and Métis-led and self-determined data governance provides the foundations for decolonizing practices of data colonialism in Canada. I also share practical and epistemological considerations from the directed content analysis and research of this thesis that become increasingly important to address as Indigenous peoples in Canada resist and repurpose colonial data systems to reclaim the means of governing, naming, and informing the vision of their peoples, communities, and territories.

In the following sections I discuss the results and findings of the directed content analysis and I inform and organize this discussion according to the theoretical framework 
(Chapter 3) which provides a blueprint for deconstructing and reconstructing colonial classification and data based on dynamic nominalism/the looping effect (3.1.), assemblage theory (3.2.), and the current intellectual movement for Indigenous data sovereignty and governance (3.3.). First, I address IDG as an engine of resistance to colonial classification; next, I look at the ways in which colonial data assemblages are shifting and evolving in the context of IDG; and finally, I discuss the broader implications of shifts in the making of peoples and assemblages of data within emergent discourses of sovereignty, decolonization, and reconciliation in Canada.

\subsection{Indigenous Data Governance, Resistance, and Making Up People}

As discussed in section 3.1., the process of 'making up people' and human classification is an activity of social construction, and it is these constructions that constitute dominant and hegemonic understandings of different types of people and how they become 'looped', normalised, and perpetuated through five interacting elements embedded in processes of creating human knowledge: peoples who are objects of study, classifications that seek to characterize types of peoples being studied, experts who produce or utilize classifications in their work which become embedded in the knowledge they create, and who are legitimized in this work by institutions (Hacking, 2007). In section 2.1. \& 2.2. I explore the ways in which Indigenous identity has long been an object of study by settlers, and especially by the state for purposes of governance, administration, and to assimilate Indigenous peoples into dominant, state-defined classificatory mechanisms. To mark Indigenous peoples in ways that do not make sense to their internal logics, cultures, and systems of governance, settler intervention in First Nations, Inuit, and Métis communities in Canada focused on the denigration of Indigenous ways of knowing and worked to relegate Indigenous communities and peoples to the margins of knowledge production and research about their peoples, communities, and cultures (Pool, 2016). Consequently, the dominant process and looping of 'making up people' in Canada have long 
been in settler control and have been designed to be out of reach for Indigenous peoples and cultural methods. Figure 15 below is a conceptualization of how the 'looping' of Indigenous identity by the Canadian state and institutions has historically operated in data colonialism, as derived from section 2.1. and 2.1.1. This loop illustrates how Indigenous identity was systemically entrenched into the grammar of the nation and constructed along values and conceptions defined by settlers.

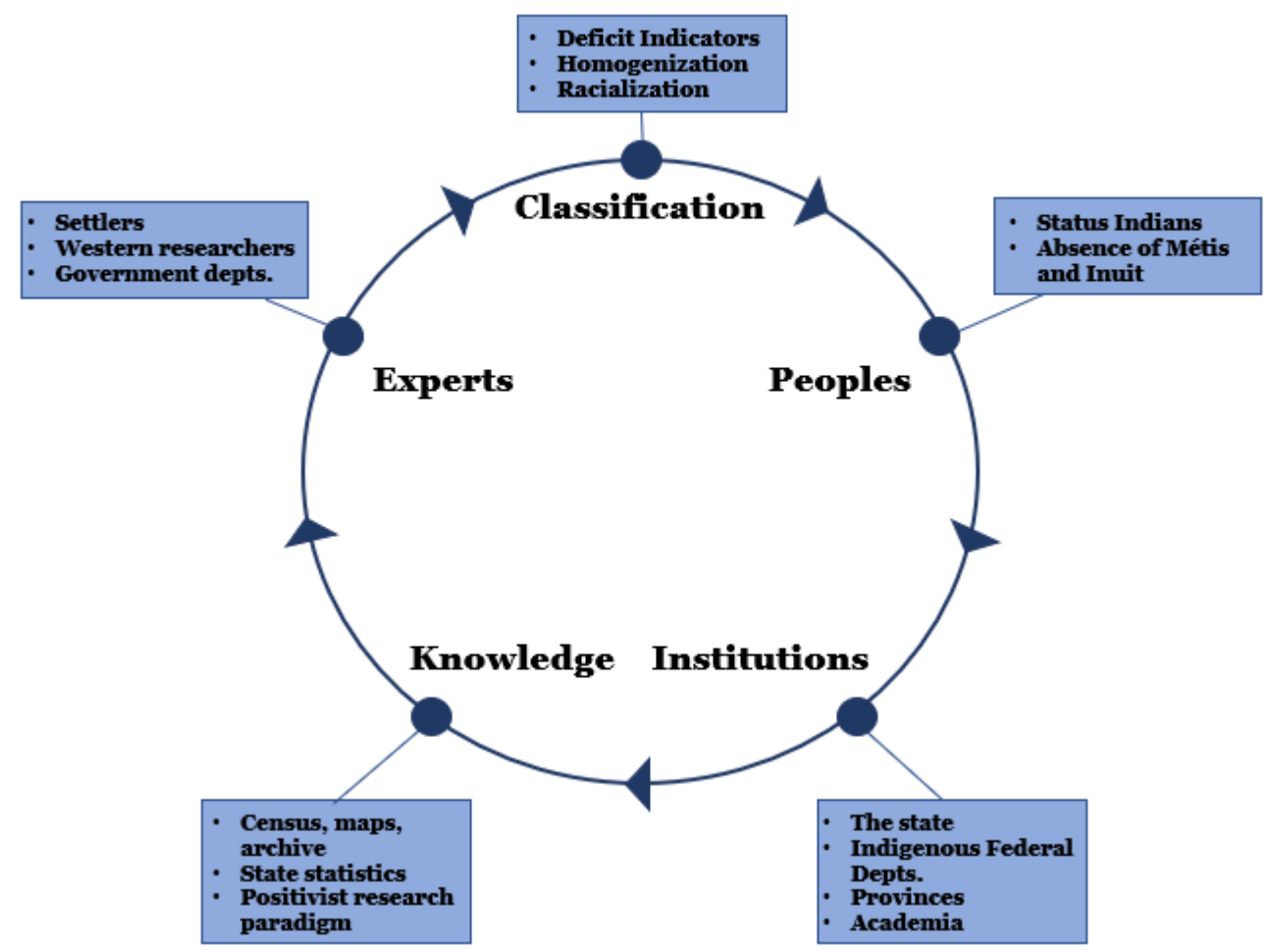

Figure 15: The looping of colonial Indigenous classification in Canada's history, with a sample of interacting elements

Hacking also asserts that these looping arrangements are not static, and he provides a list of different engines (see section 3.1) that drive these actors to classify and make peoples, and here I argue that the tenth and final engine he identifies, resistance, characterizes current movements, practices, and approaches in Canada toward First Nations, Inuit, and Métis conceptions of Indigenous data sovereignty and governance that were explored in the directed content analysis in Chapter 5. To recap, resistance is the process where "[k]inds of peoples who 
are medicalised, normalised, and administered, increasingly try to take back control from the experts and institutions" and this is often accomplished with the development of new experts, institutions, and domains of knowledge (Hacking, 2007, p.311). A similar ideology drives the core of IDS and IDG movements whereby Indigenous peoples and communities seek to resist colonial and settler data systems and research practices that have long identified them and to replace them with their own self-determined data and practices that reflect their own priorities and worldviews. This has been strategized and formalized through the repurposing of Western concepts of data governance and data sovereignty toward Indigenous-defined conceptions that are community-driven, holistic, and that represent distinct worldviews and perspective on the creation and sharing of knowledge and information. As explored throughout the directed content analysis, this engine of resistance in Canada is positioning First Nations, Inuit, and Métis to drive transformational change in the interacting elements of making up people:

- Classifications: Colonial identifiers and processes of homogenization and racialization have imagined types of peoples in the gaze of the state, be it Indians, Aboriginal, or other insensitive labels dictated by the state, and which have long been embedded into deficit worldviews that define First Nations, Inuit, and Métis data collected by external interests. IDG shifts this paradigm and instead classifications in data are self-determined by peoples and communities they describe. This has allowed Indigenous peoples to define the vision and methods by which they are named and counted, enabling approaches which do not ignore distinctions in political/cultural/social lives, and which can foster the development of positive and affirmative indicators and models of wellbeing, health, and culture (BCFNDGI, 2015a).

- Peoples: Indigenous peoples have historically only been visible or recognized when it is convenient for the state, be it for purposes of assimilation, administration, or legal obligations; consequently, there has been a lack of visibility at a community/tribe level, and for a long time First Nations, Inuit, and Métis were homogenized within the general classifications of the state (section 2.1.1.). IDG repositions the scope of peoples in data to 
multiple levels, community, regional, and national, and asserts Indigenous determination over the subject of study in research practices and enumeration that are conducted by external actors.

- Institutions: The creation, management, and dissemination of Indigenous data has long been fostered and controlled by state and settler institutions, including the Federal government and their Indigenous and social departments, provinces, and universities and academia. Indigenous-controlled institutions however are asserting their stake in the production of Indigenous knowledge. National and regional representatives such as the FNIGC, ITK, FNHA, the MNC, and Métis Nations are unifying the interests of many diverse communities in data practices and are establishing their own definitions and ways to legitimize knowledge that are produced through First Nations, Inuit, and Métis engagement and ethical collaboration. These aspirations and visions for data governance are also being asserted in existing settler institutions, through the communication of research and data principles, collaboration, guidance materials, and legal mechanisms and codes to protect their ownership and control of data.

- Knowledge: Indigenous data in the mechanisms of the state have been supported by Western instruments like the census, map, archive, and other statistical systems. These are based within Western understandings of knowledge that have historically reinforced processes of data colonialism and cultural denigration. IDG challenges the positivist research paradigm and asserts the importance of Indigenous worldviews and perspectives of knowledge and its production, inclusive of all forms of data about Indigenous peoples, including community-based, collective, and traditional forms of knowledge.

- Experts: First Nations, Inuit, and Métis know their own communities, cultures, and social systems best. Indigenous 'experts' in colonial classification however have dominantly been settlers looking into Indigenous societies and communities. Expertise in arrangements of IDG refocuses on Indigenous capacities within First Nations, Inuit, and Métis leadership and communities, who are leading the development, design, and implementation of IDG strategies and frameworks.

Consequently, the shifting of the interactive elements of making up people through processes of IDG is producing a new 'looping effect' (illustrated in Figure 16 below) in which Indigenous peoples are reclaiming the means of governing themselves from settler control. 


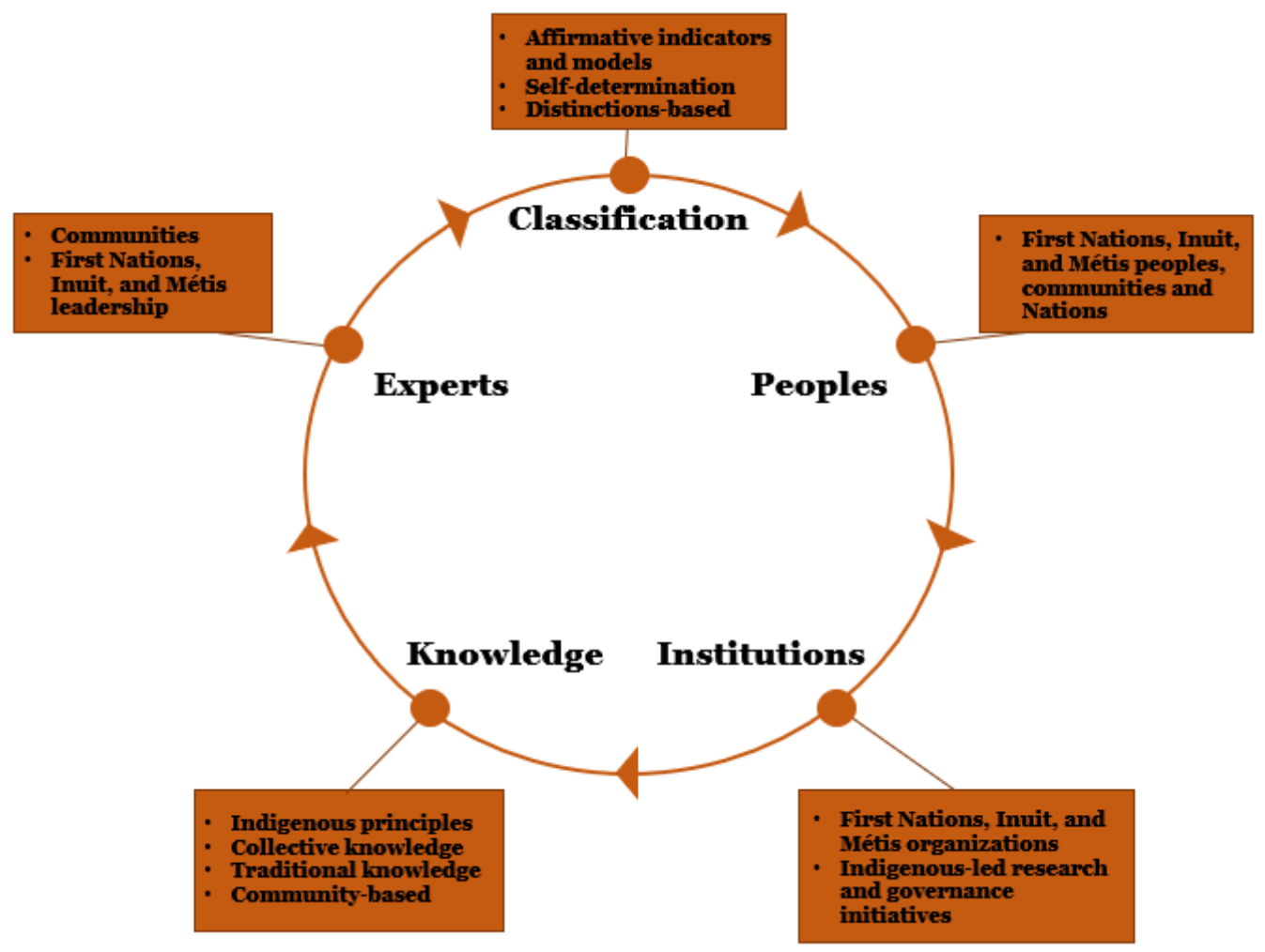

Figure 16: A broad scope on the shifts in Indigenous classification looping in Canada, resulting from assertations of IDG and IDS

Indigenous data governance (IDG) acts as an engine of resistance to processes of 'making up people' that are core to data colonialism and can be employed as a mechanism for First Nations, Inuit, and Métis to interact and engage with the production of knowledge, to assert themselves as experts of their own well-being, health, and identity, and to drive change and recognition for their perspectives in the dominant settler institutions that produce knowledge about Indigenous peoples, while also establishing their own institutions and initiatives to foster self-determined approaches for the collection, management, and use of Indigenous data. Hacking's framework usefully illustrates not only how Indigenous classifications become colonially constructed but also how these classifications dynamically evolve and change by those who are classified as objects of study. As a theory of social construction, processes of dynamic nominalism challenge the positivist research paradigm and oppositional binaries that are rooted 
in colonial epistemologies and instead suggest that the path to knowledge about peoples is not static and approaches are more so driven by internal cultural logics and ideologies.

The governance of information, as explored in section 2.1., is closely linked to the historical and contemporary administration of Indigenous peoples by the state of Canada, and emerging notions of First Nations, Inuit, and Métis data governance represent how Indigenous peoples in Canada are dynamically interacting with the means of their classification, subjugation, and exploitation to reconstruct models, communicate their priorities and interests, and assert their sovereignty as peoples and Nations recognized by the Constitution of Canada. While focused on data governance, the looping effect I show in Figure 16 above can be considered a microcosm of greater movements for Indigenous sovereignty that have grown since the early emergence of Indigenous political organization in the 1960 s, to the calls for supporting Indigenous governance and reconciliation by two Royal Commissions of Canada, and now as the rights of peoples and communities are on the forefront of national discourse, self-governance agreements, and modern treaties and funding efforts. Data are objects with great social, ontological, and governance power and this has been recognized and acted on by Indigenous peoples and communities who aspire for greater control over managing and governing their peoples, communities, and lives.

\subsection{Reconstructions of Indigenous Data Assemblages}

The First Nations, Inuit, and Métis approaches to data governance explored in Chapter 5 illustrate different ways that Indigenous peoples are actively becoming involved in the design, production, and governance of their data and information. Unsurprisingly, the Indigenous data ecosystem in Canada (section 2.2.1.) and the ways in which Indigenous data assemblages have been dominantly constructed in settler society are in a state of flux as a result. 
Returning to the assemblage of colonial data that I provide in section 3.2. and building from the socio-technical actors of each Knowledge Area that I identify in the modified context diagrams in Chapter 5, we can begin to see how the constitution of Indigenous data is shifting in response to assertations of First Nations, Inuit, and Métis to data sovereignty and practices of data governance. Table 17 below compiles the apparatuses and elements of Indigenous data assemblages that are present in histories of Canadian data colonialism as well as in the context of IDS/IDG movements occurring in Canada. This list is not exhaustive however it provides a glimpse into the ways that IDG practices are shifting and reconstructing the constitution of Indigenous data in Canada. It should also be noted that this perspective is not suggesting that elements from colonial data assemblages no longer exist in the wake of IDS and IDG; on the contrary, many of the colonial data elements listed are still in full effect and the emerging data assemblage that is defined by Indigenous peoples will interact and evolve with these colonial elements as Indigenous governance capacities mature and Indigenous approaches to making up peoples are further embedded and looped into dominant discourses, knowledge, and institutions.

Table 17: Apparatuses and elements of data assemblages in a colonial context and in the context of Indigenous data sovereignty and governance in Canada.

\begin{tabular}{|c|c|c|}
\hline Apparatus/Elements & Examples in colonial data assemblage & Assemblage in IDS/IDG context \\
\hline $\begin{array}{l}\text { Systems of thought } \\
\text { (Theories, philosophies, } \\
\text { ideologies, etc.) }\end{array}$ & $\begin{array}{l}\text { Colonialism; Western science; } \\
\text { Epistemologies \& truth; Positivism; } \\
\text { Empiricism; local \& traditional knowledge } \\
\text { (TK) }\end{array}$ & $\begin{array}{l}\text { Meaningful information sharing; Self- } \\
\text { determination; Self-governance; Data } \\
\text { sovereignty; Distinctions-based; } \\
\text { Community-driven; Free, prior, and } \\
\text { informed consent }\end{array}$ \\
\hline $\begin{array}{l}\text { Forms of Knowledge } \\
\text { (Texts, reports, guides, } \\
\text { webpages, etc.) }\end{array}$ & $\begin{array}{l}\text { Cartography; Census \& population } \\
\text { statistics; Archival records; Labels \& } \\
\text { classifications; Deficit Indicators; } \\
\text { Intellectual property }\end{array}$ & $\begin{array}{l}\text { Indigenous data principles, strategies, } \\
\text { architectures, and frameworks; Data } \\
\text { Models; Data Flows; Culture-fit } \\
\text { indicators; Collective knowledge; } \\
\text { Traditional knowledge (TK) }\end{array}$ \\
\hline $\begin{array}{l}\text { Finance (Funding, } \\
\text { business models, } \\
\text { investment, etc.) }\end{array}$ & $\begin{array}{l}\text { Federal educational, health, and social } \\
\text { services; Research grants; Treaties }\end{array}$ & $\begin{array}{l}\text { Federal budget investment in data and } \\
\text { IM systems; Bridge funding; } \\
\text { Infrastructure development }\end{array}$ \\
\hline$\frac{\text { Political Economy }}{\text { (Policy, taxes, etc.) }}$ & $\begin{array}{l}\text { ICT-driven economies; data colonialism; } \\
\text { Indigenous data/policy nexus }\end{array}$ & Opportunities in digital economies \\
\hline $\begin{array}{l}\text { Governmentalities } \\
\underline{\text { and Legalities }}\end{array}$ & $\begin{array}{l}\text { Intellectual property; Indian Act; } \\
\text { Assimilation; Access to information laws; }\end{array}$ & $\begin{array}{l}\text { Data sharing and governance } \\
\text { agreements; data requirements; } \\
\text { intergovernmental integration; }\end{array}$ \\
\hline
\end{tabular}




\begin{tabular}{|c|c|c|}
\hline Apparatus/Elements & Examples in colonial data assemblage & Assemblage in IDS/IDG context \\
\hline $\begin{array}{l}\text { (Regulations, protocols, } \\
\text { standards, laws, etc.) }\end{array}$ & $\begin{array}{l}\text { Privacy laws; Federal and provincial } \\
\text { Indigenous data standards; }\end{array}$ & $\begin{array}{l}\text { Indigenous-defined standards; TK } \\
\text { License; Creative Commons (CC); } \\
\text { Code of Research Ethics; Security } \\
\text { policies; Procurement; Cultural } \\
\text { protocols; Community consent }\end{array}$ \\
\hline $\begin{array}{l}\text { Materialities and } \\
\text { Infrastructures } \\
\text { (Hardware, software, } \\
\text { databases, sensors, etc.) }\end{array}$ & $\begin{array}{l}\text { State-owned and operated databases, } \\
\text { archives, repositories; Indian register }\end{array}$ & $\begin{array}{l}\text { Membership registries; Human } \\
\text { infrastructures; Data linkage centres; } \\
\text { Content Management System (CMS); } \\
\text { Data portals }\end{array}$ \\
\hline $\begin{array}{l}\text { Practices (Techniques, } \\
\text { behaviours, } \\
\text { methodologies, etc.) }\end{array}$ & $\begin{array}{l}\text { Epistemicide; Indigenous enumeration; } \\
\text { Statistics and surveying; Mapping }\end{array}$ & $\begin{array}{l}\text { Data literacy; Stewardship; Authentic } \\
\text { community engagement; Planning and } \\
\text { reporting; Digitization and archiving; } \\
\text { Community privacy; Community-based } \\
\text { research; Licensing }\end{array}$ \\
\hline $\begin{array}{l}\text { Organizations and } \\
\text { Institutions (Agencies, } \\
\text { academia, civil society, } \\
\text { government, etc.) }\end{array}$ & $\begin{array}{l}\text { Federal, provincial, municipal } \\
\text { governments; Universities and research } \\
\text { institutions; national statistical } \\
\text { organizations; national archives; museums }\end{array}$ & $\begin{array}{l}\text { First Nations, Inuit, and Métis national } \\
\text { and regional representatives; Regional } \\
\text { information governance centres }\end{array}$ \\
\hline $\begin{array}{l}\text { Subjectivities and } \\
\text { communities (Experts, } \\
\text { analysts, citizens, etc.) }\end{array}$ & $\begin{array}{l}\text { Technical experts; settlers; the State; } \\
\text { Citizens; Indian status; Band councils }\end{array}$ & $\begin{array}{l}\text { Local, regional, national levels; } \\
\text { Indigenous communities }\end{array}$ \\
\hline $\begin{array}{l}\text { Places (Offices, data } \\
\text { centres, servers, etc.) }\end{array}$ & $\begin{array}{l}\text { CANZUS settler states; Data centres; } \\
\text { Reserves; Communities }\end{array}$ & $\begin{array}{l}\text { Data governance centres; Indigenous } \\
\text { lands and resources }\end{array}$ \\
\hline $\begin{array}{l}\text { Marketplace } \\
\text { (Consultation work, } \\
\text { analytics, etc.) }\end{array}$ & Big data extraction; Commodification & $\begin{array}{l}\text { Contracting \& licensing IM/IT support; } \\
\text { Digital platforms and economies }\end{array}$ \\
\hline
\end{tabular}

\subsection{Decolonizing Data in Canada: Key Considerations}

Understood here as the full divestment and replacement of colonial norms, ways of thinking, and priorities from Indigenous systems of data collection and use (Carroll et al., 2019; Duarte \& Belarde-Lewis, 2015), the decolonization of data is a common thread and aspiration across practices of Indigenous data governance. Hacking's theory of making up people and the looping effect that is driven by engines of resistance and assemblage theory are two approaches that can deconstruct and highlight different ways that First Nations, Inuit, and Métis data governance practices are decolonizing colonial data paradigms in Canada and asserting conceptions of Indigenous data sovereignty that are community-driven, distinctions-based, and self-determined. As I illustrate in sections 6.1. and 6.2., Indigenous data governance establishes 
the foundations for decolonization in data and it can position Indigenous communities and organizations to control their identity and lives as well as the data that represent them.

That said, decolonization in data is far from near complete in Canada. As explored in section 2.1 , historical and contemporary processes of data colonialism have left many Indigenous communities and peoples at a disadvantage in having the capacities to perform mature data management functions like defining a formalized data governance program, including access to and possession of their information, and therefore many of the efforts are in their infancy. This is coupled with the fact that notions of formal data governance and conceptions of data sovereignty are relatively new here and are enabled by cutting-edge technologies and skilled workforces that are needed to operate data management and governance functions. As a result, First Nations, Inuit, and Métis are at a critical juncture in building and establishing data governance functions and many of these capacities are currently being formulated, planned, and developed by Indigenous leadership and communities. What Indigenous data governance in Canada looks like will ultimately drastically change and develop in the coming years and decades as agreements are made, technical capacities are established, and as First Nations, Inuit, and Métis communities and organizations continue to assert and implement self-governance and self-determination practices in data. Planning and building data governance and management programs takes time to put this into perspective, Erin Corston at the FNIGC informed me that the First Nations Data Governance Strategy, which is arguably the most comprehensive, national-level Indigenous data governance strategy developed in Canada to date, is expected to take a decade or more for the network of Information Governance Centres to be fully operational and to begin having an impact. It is the only national strategy, possibly in the world, to be authentically driven from the ground up, and high-level plans designed by and for community require extensive and ongoing 
local engagement ${ }^{95}$. Securing the buy-in of many and distinct communities and peoples, a lengthy and expensive process coupled with the pressing need for material and human infrastructures, was a prominent challenge expressed in every interview I conducted (E. Corston, research interview, 2021).

Efforts to assert data sovereignty in First Nations, Inuit, and Métis communities and organizations across this development and planning period will also need to grapple with emerging data innovations that were outside the scope of the thesis analysis but that are prominent tools being employed generally in Western statistical work. Pat Foster from the FNIGC expressed caution toward two technologies, specifically artificial intelligence and big data, both of which are already having impacts on Canadian statistical methodologies that are moving away from reliance on respondents to reliance on $\mathrm{AI}$ and big data sources to fill gaps with estimations and aggregations. These methodologies and approaches are built on logics of efficiency and aggregation that often lack compatibility with the worldviews and priorities of Indigenous peoples. Such developments represent the importance of the shifts in Indigenous data governance toward Indigenous control and definition, as Pat expressed:

The beauty of what's happening right now at FNIGC is that there is an opportunity to protect our people against this onslaught, and it is an onslaught what's happening right now. It won't be long before surveys aren't being done because AI can do it quicker, faster, and supposedly better, but the reality is that there's no way, there's such a difference in the way that cultures are. The world view that we have versus the rest of the western civilization, that can't be modeled, it can't be articulated in the form of artificial intelligence. So, it's critical that an Indigenous way evolves, and it will evolve as capacity increases and into what I don't know, but it will be profound change and hopefully you will see it in our lifetime (P. Foster, research interview, 2021).

\footnotetext{
${ }^{95}$ Engagement from an Indigenous perspective is often spoken in a different language between Western and Indigenous worldviews. Engagement from a government perspective might be a sample or focus group, or with a particular member or leader of a community. This differs drastically from say a First Nations perspective, where "everybody has a voice, even the youngest person in the community, anyone who can talk has a voice and their opinion" (P. Foster, research interview, 2021). This is one of many reasons why large-scale data governance and integration is timely and costly, but it is necessary to foster culturally fit values and systems for the future of Indigenous communities.
} 
There is a risk in IDG as First Nations, Inuit, and Métis repurpose and reconfigure the tools of the colonizer to fall into the same cultural inconsistencies and complacency to local cultural contexts and distinctions-based approaches. Many of these tools and systems are not designed with Indigenous worldviews and perspectives in mind, and as a social constructionist lens (most prominently explored by technological philosopher Langdon Winner) would suggest, technologies are embedded with politics into their design, and this has great implications when these settler-driven technologies and innovations emerge in an Indigenous context or within a community. Efforts to regain control of Indigenous data systems and data sovereignty need to consider the technologies and innovations of the colonizer and epistemologically engage with the potential challenges and affordances these allow, while driving these considerations from a community-level all the way to national interests.

How conceptions of IDS and IDG in First Nations, Inuit, and Métis contexts will evolve and adapt to these prominent and emergent developments in statistical capacities remains to be seen, however importantly attention must be placed on distinctions-based and community-driven values as new innovations and technologies are established and adapted to serve the interests of Indigenous peoples and organizations. Ultimately, the governance issues and challenges faced by communities can not be removed from their context. This is something that the Federal government in Canada is grappling with as they navigate Crown-Indigenous relations, selfgovernance in communities and Nations, and balancing the mandates of hundreds of departments and agencies, their commitments to Indigenous peoples, and the autonomy of the provinces and territories. The complexity of First Nations, Inuit, and Métis data issues are far reaching and many, and often the long-term goals of self-determination must be weighed against the immediate needs and realities faced by many communities in Canada today (CIRNAC, research interview, 2021). Context, as I have learned throughout the research of this thesis, is of primary 
importance to the success of First Nations, Inuit, and Métis data sovereignty, and while there are common mechanisms to assert IDS as I have explored, only First Nations, Inuit, and Métis can determine the best course of action to achieve it.

Here I have presented considerations to make as First Nations, Inuit, and Métis continue to actively contribute to the decolonization of data, but they should not diminish the profound and great progress that has been made in the past few decades in Indigenous-led governance and data production. It has now been just over twenty years since the first Indigenous-led statistical survey (First Nations and Inuit Regional Longitudinal Health Survey) led by First Nations and Inuit, and now First Nations, Inuit, and Métis are planning and building toward a future where they have the means of accessing their information for their own purposes and benefits. These efforts are situated within an emerging discourse of Indigenous data rights driven by Reconciliation, UNDRIP, and Indigenous data sovereignty as well as renewed commitments of the Federal government to build up Indigenous self-governance capacities, and these developments mark a watershed moment for Indigenous empowerment and sovereignty in Canada. Decolonization is a complicated process, and it will take the combined efforts of nonIndigenous peoples, organizations, and governments in ethical collaboration with Indigenous organizations and communities to begin realizing and imagining transformative change in Indigenous information practices. 


\section{Chapter 7: Conclusion}

In this thesis I set out to chart how Indigenous data become colonized, what it means to decolonize these data, and whether emerging movements toward and practices for Indigenous data governance can contribute to data decolonization. I explored these topics in the context of First Nations, Inuit, and Métis data governance in Canada and my research question was: how does data colonialism operate in Canada, and can these practices be decolonized through Indigenous data governance? In this chapter I will summarize how I went about answering these questions in each chapter and how they contribute to the thesis findings overall.

Chapter 1 introduced the prominent issues of First Nations, Inuit, and Métis governance and data stemming from histories of colonialism in Canada. I defined data in the broadest sense, from a critical data studies (CDS) lens and a philosophical framing that considers the social construction of data objects and the important role of data as a resource for governance and knowledge production, especially through the classifications of peoples and things. Based on this framing I offer a conceptualization of data colonialism that departs from mainstream understandings centered on capitalism and big data extraction and instead engages with the historical data practices of the colonial state that worked to dispossess and dominate the control 
of information and production of knowledge in the emerging nation state. This model acknowledges continuity in the practices of colonialism and suggests that the current state of Indigenous data in Canada is directly formed by these histories of Indigenous governance. At the end of the Chapter I provide a roadmap for the thesis study, the principal research question, as well as a note on the terminology I use to describe Indigenous peoples throughout the thesis.

I provide an interdisciplinary literature review in Chapter 2 which describes the context to this study of data colonialism in the Canadian context. The purpose of this review was to answer the first part of my research question, how does data colonialism operate in Canada, and to inform the analysis of Indigenous data governance that follows. I structured it around three topics: First, the historical and conceptual foundations of data colonialism that seek to classify and control Indigenous peoples and their knowledge, and how this emerged in the Canadian governance of First Nations, Inuit, and Métis peoples, second, I explore the state of Indigenous data as a result of data colonialism and what this ecosystem looks like in Canada; and third, I consider conceptualizations of decolonization concerning data and knowledge, how movements for Indigenous data sovereignty (IDS) and Indigenous data governance (IDG) have emerged as practices of decolonization, and how First Nations, Inuit, and Métis are asserting these concepts from their own worldviews. By taking this approach, I establish the necessary contexts to understand what Indigenous data are, how they have been dispossessed and dominated by practices of data colonialism, and how these practices might be decolonized in the wake of UNDRIP, reconciliation, and data governance approaches in Canada.

In Chapter 3 I describe and explain the theoretical framework of this thesis, which conceptualizes the decolonization of data through Indigenous data governance. I developed this framework based on three streams of theory: dynamic nominalism and 'making up people' through the looping effect as understood by Hacking (1986; 2007); assemblage theory as 
understood by Rob Kitchin (2014) who expanded on the work of Deleuze and Guattari (1987) and DeLanda (2006); and finally, conceptions of Indigenous data sovereignty and Indigenous data governance as derived from Kukutai and Taylor's (2016) seminal collection of essays on the topic. Together this framework provides the theoretical foundations that inform my analysis and that allow the conceptual 'deconstruction' of data and classifications to better understand how the divestment of coloniality is occurring through Indigenous data governance.

In Chapter 4 I describe the methodological approach I adopted which was a directed content analysis approach as defined and understood by Hsieh and Shannon (2005). A directed content analysis studies textual data for common themes and meanings through a directed coding technique, in which the categories of themes are developed using existing theory and research as a foundation. For my textual data I compiled a wide range of First Nations, Inuit, and Métis data governance materials including high-level strategies and practical applications of data governance. To direct the coding of these data I adopted the DAMA DMBOK, which is a professionally developed industry-based body of knowledge and data management manual, and utilized the main structure of the DMBOK based on Data Management 'Knowledge Areas' as the set of parent codes to conduct and organize my analysis. I also employed elements of the theoretical framework, specifically themes of IDG derived from Kukutai and Taylor (2016) to further code each Knowledge Area. To support this work and my research, I also conducted interviews with a small selection of data governance experts working on the frontlines of decolonization practices in Canada, who I introduce in section 4.3. The purpose of this approach was to answer the second part of my research question, can [data colonialism in Canada] be decolonized through Indigenous data governance? 
In Chapter 5 I present the findings of the directed content analysis and I organize these observations by DAMA DMBOK Knowledge Area. In each of these sections I: define the Knowledge Area and how it relates to governance; describe the importance and relevance of IDG to the Knowledge Area; describe key data governance activities in the Area that I identified across the textual data, and the aspired outcomes of these activities; and I provide a small sample of key technical drivers, including tools, techniques, and metrics that drive governance in the Area. In Chapter 6 I discuss and consider the results of the content analysis within the framing of the theoretical framework for decolonization, including how IDG resists and shifts the main interacting elements that drive and support "making up" Indigenous classifications and identifiers, and how the constitution of Indigenous data as a socio-technical assemblage consequently is shifting from this resistance. It is here that I answer my research question and I determined that IDG sets the foundation for decolonization as understood through my theoretical framework, but that further work and consideration will be needed as First Nations, Inuit, and Métis navigate a critical juncture of developing capacities, assertations of self-governance, and emerging technical innovations that may challenge processes and practices of IDG.

Overall, through this work and research, this thesis provides four main contributions to emerging and prominent Canadian discourses surrounding Indigenous data, governance, and sovereignty: 1) the conceptual basis of data colonialism to characterize the colonial practices and activities which have long denigrated Indigenous data and knowledge systems; 2) a theoretical framework which engages with the social construction of data and classifications in data colonialism; 3) an extension and reframing of the DAMA DMBOK as a framework to study Indigenous data governance and decolonization efforts; and 4) a study of data colonialism as it emerges in the Canadian context and a structured look into the ways that First Nations, Inuit, and Métis are approaching the governance and decolonization of their data. Taken together, these 
contributions form a comprehensive and structured overview of the current moment regarding Indigenous data governance in Canada that may be beneficial to any organization, community, government department, or individual actors and researchers who are interested in the management and governance of Indigenous data, or who wish to better understand these emergent issues and to plan their own practices in a way that promotes and supports First Nations, Inuit, and Métis sovereignty over data.

In conclusion, Indigenous data governance is a promising mechanism to advance the self-governance interests of First Nations, Inuit, and Métis in Canada and to work toward the decolonization of data. These approaches are culture fit and distinctions-based, and they champion the self-determination of Indigenous peoples which is vital to overcome histories of data colonialism that have dictated and determined the limits of Indigenous identity and governance. It is my hope that the work of this thesis might inspire both Indigenous and nonIndigenous peoples to break down siloes and barriers to Indigenous inclusion in data, to recognize the value of Indigenous-led approaches and data for governance, and to continue advancing Reconciliation in all aspects and forms. It is only through a combined effort for change, returning again to the inspirational framework of Duarte and Belarde-Lewis (2015), that we can begin to imagine a new direction for Canada where Indigenous peoples have full control over their lives and well-being, where they have access to the means of fostering their rich cultural heritages and traditional practices for the benefit of youth and the coming generations, and where Canada as a nation can begin to fully reconcile the totality of devastation and injustice that state-mandated practices of data colonialism aided and abetted. Finally, First Nations, Inuit, and Métis can use their own data to inform and steer their nation building endeavours and to have the necessary data and information to govern the health and well being of their peoples, communities and lands according to their own values and world views. 


\subsection{Limitations and future work}

The primary limitation of this thesis is the scope. In my pursuit to study the broad effects of data colonialism and Indigenous data governance, I chose to design my investigation to be inclusive of all constitutionally recognized Indigenous peoples in Canada (being First Nations, Inuit, and Métis), multiple governance levels from national approaches to communitybased data collection, and explorative of the broadest of definitions of data and data governance, to include all forms of knowledge and information as they appear in different cultural contexts and Knowledge Areas. Although I believe this was an appropriate way to have approached my research question, as all voices and all perspectives need to be included in such a discussion that is taking a broad look at decolonization and governance, this was a vast and complex undertaking and it required a large amount of context and abstraction to work within, and ultimately may be beyond the scope of a masters thesis that is limited by time and structure.

Another limitation of this thesis, inherently connected to the scope, is the timeframe I had to conduct it. The process of designing, planning, and conducting the research of a master's thesis is fast-paced and limited to the constraints of the program deadlines, and this is a major limitation given the complexity and scope of the topic. With a greater timeframe, I would have liked to speak with more professionals operating within different cultural contexts to gain more perspective about these issues. Due to the fast pace of timeframe for the end of the thesis, I was quickly moving into writing and did not have a chance to follow up and try again with organizations who did not get back, and I discovered a number more after whose knowledge would have been an asset to my understanding. As I explore in the directed content analysis in Chapter 5, there were several organizations, Indigenous and non-Indigenous, public, and private, etc. whose perspectives would have greatly benefitted the project. My experience with the four participants who did have time to join me was insightful and really helped form and tune my 
understanding of IDG issues in Canada; as such, it would have been useful to secure an interview with an Inuit professional from the ITK for instance, or a private enterprise perspective from someone at an institution like ICES. These may be future collaborations in the Canadian discourse to consider.

Future work could focus on distinct First Nations, Inuit, or Métis approaches to data governance and sovereignty, on the emergence of IDG particularly at the community-level, or how these issues might be resolved in specific domains (legally, in health, security/privacy, etc.). Additionally, there is a pressing need for future work to consider these contexts in the wake of rapidly evolving digital innovations and big data which may challenge notions of IDS even as state-held governance capacities are returned to First Nations, Inuit, and Métis. 


\title{
Appendices
}

\section{Appendix 1: Ethics Approval Documentation}

\author{
F) Carleton \\ Canada's Capital University \\ Office of Research Ethics \\ 4500 ARISE Building | 1125 Colonel By Drive \\ Ottawa, Ontario K1S 5B6 \\ 613-520-2600 Ext: 2517 \\ ethics@carleton.ca
}

\section{CERTIFICATION OF INSTITUTIONAL ETHICS CLEARANCE}

The following research has been granted clearance by the Carleton University Research Ethics Board-A (CUREB-A). CUREB-A is constituted and operates in compliance with the Tri-Council Policy Statement: Ethical Conduct for Research Involving Humans (TCPS2).

Ethics Clearance ID: Project \# 114810

Project Team Members: Donato Leone (Primary Investigator)

Tracey Lauriault (Research Supervisor)

Study Title: Data Colonialism in Canada: Decolonizing Data through Indigenous Data Governance

Funding Source: (If applicable):

Effective: December 08, 2020

Expires: December 31, 2021

This certification is subject to the following conditions:

1. Clearance is granted only for the research and purposes described in the application.

2. Any modification to the approved research must be submitted to CUREB-A via a Change to Protocol Form. All changes must be cleared prior to the continuance of the research.

3. An Annual Status Report for the renewal or closure of ethics clearance must be submitted and cleared by the renewal date listed above. Failure to submit the Annual Status Report will result in the closure of the file. If funding is associated, funds will be frozen.

4. During the course of the study, if you encounter an adverse event, material incidental finding, protocol deviation or other unanticipated problem, you must complete and submit a Report of Adverse Events and Unanticipated Problems Form.

5. It is the responsibility of the student to notify their supervisor of any adverse events, changes to their application, or requests to renew/close the protocol.

6. Failure to conduct the research in accordance with the principles of the Tri-Council Policy Statement: Ethical Conduct for Research Involving Humans 2 nd edition and the Carleton 
University Policies and Procedures for the Ethical Conduct of Research may result in the suspension or termination of the research project.

\section{IMPORTANT: Special requirements for COVID-19:}

If this study involves in-person research interactions with human participants, whether on- or off-campus, the following rules apply:

1. Upon receiving clearance from CUREB, please seek the approval of the relevant Dean for your research. Provide a copy of your CUREB clearance to the Dean for their records. Please contact your Dean's Office for more information about obtaining their approval. See Principles and Procedures for On-campus Research at Carleton University and note that this document applies both to on- and off-campus research that involves human participants.

2. Provide a copy of the Dean's approval to the Office of Research Ethics prior to starting any in-person research activities.

3. If the Dean's approval requires any significant change(s) to any element of the study, you must notify the Office of Research Ethics of such change(s).

Upon reasonable request, it is the policy of CUREB, for cleared protocols, to release the name of the PI, the title of the project, and the date of clearance and any renewal(s).

Please email the Research Compliance Coordinators at ethics@carleton.ca if you have any questions.

\section{CLEARED BY:}

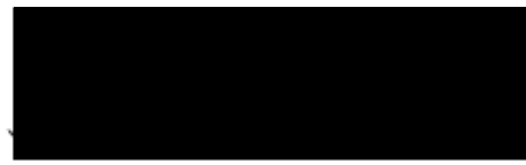

Bernadette Campbell, PhD., Chair, CUREB-A

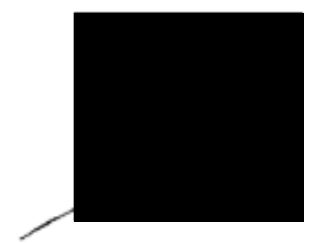

Natasha Artemeva, PhD, Vice-Chair, CUREB-A
Date: December 08, 2020 


\section{Appendix 2: Research Interview Semi-Structured Question Base}

\section{Semi-Structured Interview Questions to be asked to a selection of Civil Society Indigenous Data Governance Experts}

\begin{tabular}{|c|c|}
\hline Interview Topic & Potential Questions \\
\hline Indigenous data & $\begin{array}{l}\text { - What are Indigenous data? } \\
\text { - What kind of Indigenous data does your organization } \\
\text { govern and/or manage and/or collect? } \\
\text { Is your organization involved in the reclaiming of } \\
\text { ownership of any Indigenous data? If so, can you } \\
\text { explain? }\end{array}$ \\
\hline Indigenous data governance & $\begin{array}{l}\text { - What does Indigenous data governance look like in } \\
\text { - } \text { Is Indigenous data governance related to the } \\
\text { reconciliation process? } \\
\text { - Is your organization working on any current } \\
\text { frameworks/projects related to Indigenous data } \\
\text { governance? } \\
\text { - Can your organization's [method/policy/framework] be } \\
\text { adapted to the situation of diverse Indigenous } \\
\text { communities across Canada? } \\
\text { - What policy tools can be utilized to establish Indigenous } \\
\text { principles and established data governance practices? } \\
\text { - Do you apply any particular standards? } \\
\text { gow do your Indigenous data governance practices } \\
\text { align with open data, etc.? } \\
\text { - How could privately-owned software (that may track and } \\
\text { collect user data) about Indigenous peoples be governed? }\end{array}$ \\
\hline Data Sovereignty & $\begin{array}{l}\text { What does Indigenous data sovereignty mean to your } \\
\text { organization? How can it be achieved? How are } \\
\text { Indigenous data governance and data sovereignty related? } \\
\text { - What forms of data diplomacy do you think are required } \\
\text { to reclaim Indigenous data? Is this to either re-claim data } \\
\text { collected by others and/or ensure the sovereignty of the } \\
\text { data you collect? } \\
\text { Which intellectual property regimes help your } \\
\text { organization assert ownership and control of Indigenous } \\
\text { data? }\end{array}$ \\
\hline
\end{tabular}




\section{Appendix 3: BCFNDGI Data Governance \& Accountability Model (BCFNDGI, n.d.)}

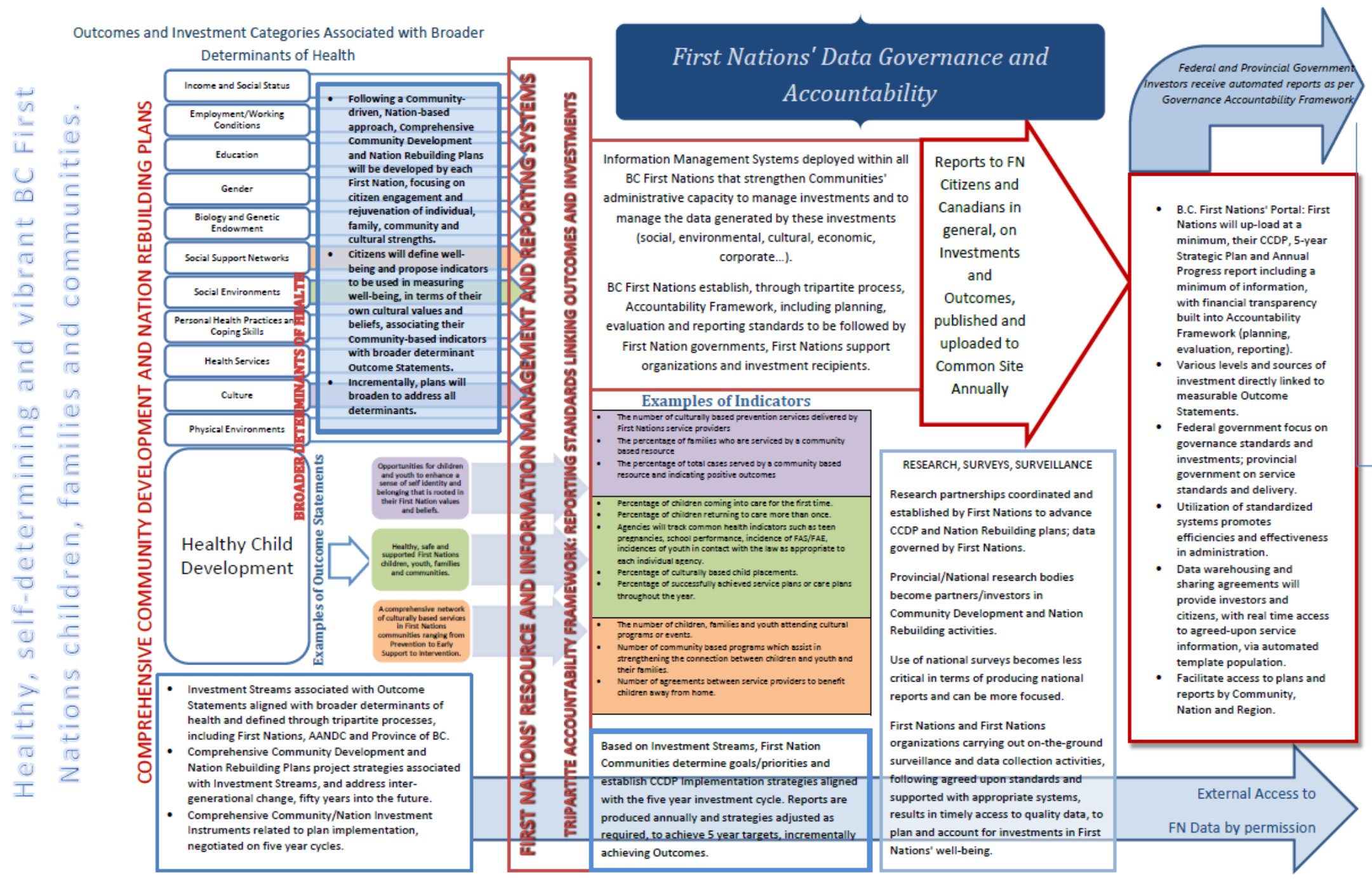




\section{Appendix 4: Statistics Canada (2018), First Nations Health and Wellness Indicators}

\begin{tabular}{|c|c|c|c|c|}
\hline \multicolumn{5}{|c|}{ First Nations in Canada Health and Wellness Indicators, Quick Stats, 2018 Edition } \\
\hline Indicator Group & Indicator Measure(s) & Latest Data & Data source & Data Year \\
\hline \multicolumn{5}{|l|}{ Demographics } \\
\hline \multirow[t]{3}{*}{ Population } & Population with status under the Indian Act living in First Nations communities & 509,016 & $\begin{array}{l}\text { CIRNAC/ISC, Indian Register } \\
\text { unadjusted counts }\end{array}$ & 2017 \\
\hline & $\begin{array}{l}\text { Population with status under the Indian Act living outside First Nations } \\
\text { communities }\end{array}$ & 478,504 & $\begin{array}{l}\text { CIRNAC/ISC, Indian Register } \\
\text { unadjusted counts }\end{array}$ & 2017 \\
\hline & $\begin{array}{l}\text { \% of population with status under the Indian Act' living in First Nations } \\
\text { communities under the age of } 25\end{array}$ & $46 \%$ & $\begin{array}{l}\text { CIRNAC/ISC, Indian Register } \\
\text { adjusted, projected counts }\end{array}$ & 2016 \\
\hline \multirow[t]{5}{*}{ Vital statistics } & Total fertility rate, First Nations females with status (on and off-reserve) & 2.7 children & $\begin{array}{c}\text { Statcan, Projections of } \\
\text { Aboriginal Population and } \\
\text { Households }\end{array}$ & 2011 \\
\hline & $\begin{array}{l}\text { Life expectancy at birth (projected), First Nations people (status and non-status, } \\
\text { on and off-reserve), both sexes }\end{array}$ & 77.9 years & $\begin{array}{c}\text { StatCan, Projections of } \\
\text { Aboriginal Population and } \\
\text { Households }\end{array}$ & 2017 \\
\hline & $\begin{array}{l}\text { Life expectancy at birth (projected), First Nations males (status and non-status, } \\
\text { on and off-reserve) }\end{array}$ & 76.4 years & $\begin{array}{c}\text { StatCan, Projections of } \\
\text { Aboriginal Population and } \\
\text { Households }\end{array}$ & 2017 \\
\hline & $\begin{array}{l}\text { Life expectancy at birth (projected), First Nations females (status and non- } \\
\text { status, on and off-reserve) }\end{array}$ & 79.3 years & $\begin{array}{c}\text { StatCan, Projections of } \\
\text { Aboriginal Population and } \\
\text { Households }\end{array}$ & 2017 \\
\hline & $\begin{array}{l}\text { Infant mortality rate, First Nations people (status and non-status, on and off- } \\
\text { reserve), both sexes }\end{array}$ & 9.2 per 1,000 live births & $\begin{array}{c}\begin{array}{c}\text { StatCan, } 2006 \text { Canadian Birth- } \\
\text { Census Cohort database }\end{array} \\
\end{array}$ & 2004-2006 \\
\hline \multicolumn{5}{|c|}{ Health status and outcomes } \\
\hline \multirow[t]{3}{*}{ Health status } & $\begin{array}{l}\text { \% reporting excellent or very good health, First Nations people aged } 18 \text { and over } \\
\text { in First Nations communities }\end{array}$ & $44.1 \%$ & FNIGC, RHS & $2008 / 10$ \\
\hline & $\%$ of First Nations infants (on and off reserve) born small for gestational age & $5.8 \%$ & $\begin{array}{l}\text { StatCan, } 2006 \text { Canadian Birth- } \\
\text { Census Cohort database }\end{array}$ & 2004-2006 \\
\hline & $\%$ of First Nations infants (on and off reserve) born large for gestational age & $20.9 \%$ & $\begin{array}{c}\text { StatCan, } 2006 \text { Canadian Birth- } \\
\text { Census Cohort database }\end{array}$ & 2004-2006 \\
\hline \multirow[t]{4}{*}{ Oral health } & $\begin{array}{l}\text { Average number of decayed, missing and filled teeth, First Nations people aged } \\
3-5 \text { years in First Nations communities }\end{array}$ & 7.6 & $\begin{array}{l}\text { FNIGC, First Nations Oral Health } \\
\text { Survey }\end{array}$ & $2009 / 10$ \\
\hline & $\begin{array}{l}\text { Average number of decayed, missing and filled teeth, First Nations people aged } \\
\text { 6-11 years in First Nations communities }\end{array}$ & 6.6 & $\begin{array}{l}\text { FNIGC, First Nations Oral Health } \\
\text { Survey }\end{array}$ & $2009 / 10$ \\
\hline & $\begin{array}{l}\text { Average number of decayed, missing and filled teeth, First Nations people aged } \\
12-19 \text { years in First Nations communities }\end{array}$ & 6.2 & $\begin{array}{l}\text { FNIGC, First Nations Oral Health } \\
\text { Survey }\end{array}$ & $2009 / 10$ \\
\hline & $\begin{array}{l}\text { Average number of decayed missing and filled teeth, First Nations people aged } \\
20 \text { years and over in First Nations communities }\end{array}$ & 13.7 & $\begin{array}{l}\text { FNIGC, First Nations Oral Health } \\
\text { Survey }\end{array}$ & $2009 / 10$ \\
\hline \multirow[t]{2}{*}{$\begin{array}{l}\text { Infectious } \\
\text { disease }\end{array}$} & $\begin{array}{l}\text { Rate of tuberculosis, First Nations people with status in First Nations } \\
\text { communities }\end{array}$ & \begin{tabular}{|c|}
26.6 per 100,000 \\
population ( 3 yr. average)
\end{tabular} & PHAC, CTBRS & $2014 / 2016$ \\
\hline & $\begin{array}{l}\text { Rate of newly reported cases of HIV among First Nations people on and off- } \\
\text { reserve }\end{array}$ & $\begin{array}{c}20.3 \text { per } 100,000 \\
\text { population ( } 3 \text { yr. average) }\end{array}$ & $\begin{array}{l}\text { PHAC, Canadian HIV/AIDS } \\
\text { Reporting System }\end{array}$ & $2013 / 2015$ \\
\hline \multirow[t]{6}{*}{ Chronic disease } & $\begin{array}{l}\text { \% reporting having been diagnosed with heart disease, First Nations people } \\
\text { aged } 18 \text { and over in First Nations communities }\end{array}$ & $4.2 \%$ & FNIGC, RHS & $2015 / 16$ \\
\hline & $\begin{array}{l}\text { \% reporting having been diagnosed with the effects of stroke, First Nations } \\
\text { people aged } 18 \text { and over in First Nations communities }\end{array}$ & $1.4 \%$ & FNIGC, RHS & $2015 / 16$ \\
\hline & $\begin{array}{l}\text { \% reporting having been diagnosed with high blood pressure, First Nations } \\
\text { people aged } 18 \text { and over in First Nations communities }\end{array}$ & $17.2 \%$ & FNIGC, RHS & $2015 / 16$ \\
\hline & $\begin{array}{l}\text { Hospitalization rate for circulatory disease, First Nations people in First Nations } \\
\text { communities }\end{array}$ & $\begin{array}{c}991 \text { per } 100,000 \\
\text { population }\end{array}$ & $\begin{array}{l}\text { StatCan, Census-Discharge } \\
\text { Abstract Database linkage }\end{array}$ & $\begin{array}{c}2006 / 07- \\
2008 / 09\end{array}$ \\
\hline & $\begin{array}{l}\text { \% reporting having been diagnosed with type } 2 \text { diabetes, First Nations people } \\
\text { aged } 18 \text { and over in First Nations communities }\end{array}$ & $12.9 \%$ & FNIGC, RHS & $2008 / 10$ \\
\hline & $\begin{array}{l}\text { Hospitalization rate for type } 2 \text { diabetes, First Nations people in First Nations } \\
\text { communities }\end{array}$ & $\begin{array}{l}366 \text { per } 100,000 \\
\text { population }\end{array}$ & $\begin{array}{l}\text { StatCan, Census-Discharge } \\
\text { Abstract Database linkage }\end{array}$ & $\begin{array}{c}2006 / 07- \\
2008 / 09\end{array}$ \\
\hline Injury & $\begin{array}{l}\text { Hospitalization rate for unintentional injury, First Nations people in First Nations } \\
\text { communities }\end{array}$ & $\begin{array}{l}836 \text { per } 100,000 \\
\text { population }\end{array}$ & $\begin{array}{l}\text { StatCan, Census-Discharge } \\
\text { Abstract Database linkage }\end{array}$ & $\begin{array}{c}2006 / 07- \\
2008 / 09\end{array}$ \\
\hline \multirow[t]{2}{*}{ Mental health } & $\begin{array}{l}\text { Hospitalization rate for intentional self-harm, First Nations people in First } \\
\text { Nations communities }\end{array}$ & $\begin{array}{l}146 \text { per } 100,000 \\
\text { population }\end{array}$ & $\begin{array}{l}\text { StatCan, Census-Discharge } \\
\text { Abstract Database linkage }\end{array}$ & $\begin{array}{c}2006 / 07- \\
2008 / 09\end{array}$ \\
\hline & $\begin{array}{l}\text { Hospitalization rate for a depressive episode, First Nations people in First } \\
\text { Nations communities }\end{array}$ & $\begin{array}{l}84 \text { per } 100,000 \\
\text { population }\end{array}$ & $\begin{array}{l}\text { StatCan, Census-Discharge } \\
\text { Abstract Database linkage }\end{array}$ & $\begin{array}{c}2006 / 07- \\
2008 / 09\end{array}$ \\
\hline
\end{tabular}




\begin{tabular}{|c|c|c|c|c|}
\hline \multicolumn{5}{|c|}{ Determinants of health } \\
\hline \multirow{5}{*}{$\begin{array}{l}\text { Person-related } \\
\text { factors } \\
\text { (individual and } \\
\text { behavioural) }\end{array}$} & $\begin{array}{l}\text { \% overweight (self-reported), First Nations people aged } 18 \text { and over in First } \\
\text { Nations communities }\end{array}$ & $34.2 \%$ & FNIGC, RHS & $2008 / 10$ \\
\hline & $\begin{array}{l}\text { \% obese (self-reported), First Nations people aged } 18 \text { and over in First Nations } \\
\text { communities }\end{array}$ & $40.2 \%$ & FNIGC, RHS & $2008 / 10$ \\
\hline & $\begin{array}{l}\text { \% reporting drinking } 5 \text { or more alcoholic drinks on one occasion at least once a } \\
\text { month, First Nations people aged } 18 \text { and over in First Nations communities }\end{array}$ & $40.5 \%$ & FNIGC, RHS & $2008 / 10$ \\
\hline & $\begin{array}{l}\text { \% reporting smoking cigarettes daily, First Nations people aged } 18 \text { and over in } \\
\text { First Nations communities }\end{array}$ & $40.3 \%$ & FNIGC, RHS & $2015 / 16$ \\
\hline & $\begin{array}{l}\text { \% reporting being physically active or moderately active in their leisure time, } \\
\text { First Nations people aged } 18 \text { and over in First Nations communities }\end{array}$ & $53.5 \%$ & FNIGC, RHS & $2008 / 10$ \\
\hline \multirow[t]{5}{*}{$\begin{array}{l}\text { Social and } \\
\text { economic factors }\end{array}$} & $\begin{array}{l}\text { \% whe completed high school and/or post-secondary studies, First Nations } \\
\text { people aged } 25-64 \text { in First Nations communities }\end{array}$ & $56.9 \%$ & StatCan, Census & 2016 \\
\hline & $\begin{array}{l}\text { Unemployment rate, First Nations people aged } 25-64 \text { in First Nations } \\
\text { communities }\end{array}$ & $22.5 \%$ & StatCan, Census & 2016 \\
\hline & Employment rate, First Nations people aged $25-64$ in First Nations communities & $46.8 \%$ & StatCan, Census & 2016 \\
\hline & \begin{tabular}{|l|} 
Median individual income, First Nations people aged 15 and over in First Nations \\
communities
\end{tabular} & $\$ 16,907$ & StatCan, Census & 2015 \\
\hline & $\begin{array}{l}\text { \% in a food insecure household, First Nations people aged } 18 \text { and over in First } \\
\text { Nations communities }\end{array}$ & $54 \%$ & FNIGC, RHS & $2008 / 10$ \\
\hline \multirow{2}{*}{$\begin{array}{l}\text { Physical and } \\
\text { environment } \\
\text { factors }\end{array}$} & $\%$ in crowded homes, First Nations people in First Nations communities & $36.8 \%$ & StatCan, Census & 2016 \\
\hline & $\begin{array}{l}\text { \% in dwellings requiring major repairs, First Nations people in First Nations } \\
\text { communities }\end{array}$ & $44.1 \%$ & StatCan, Census & 2016 \\
\hline \multicolumn{5}{|c|}{ Health system performance } \\
\hline \multirow[t]{2}{*}{ Access } & \% of clients who accessed at least one Non-Insured Health Benefit per year & $71 \%$ & FNIHB, HICPS & $2016 / 17$ \\
\hline & $\begin{array}{l}\text { \% that reported that the unavailability of a doctor or nurse was a barrier to } \\
\text { receiving health care, First Nations people aged } 18 \text { and over in First Nations } \\
\text { communities }\end{array}$ & $22.6 \%$ & FNIGC, RHS & $2015 / 16$ \\
\hline Effectiveness & $\begin{array}{l}\text { \% patients diagnosed as a new active or re-treatment case of tuberculosis (TB) } \\
\text { who completed treatment, First Nations people in First Nations communities }\end{array}$ & $92.9 \%$ & PHAC, CTBRS & 2014 \\
\hline \multirow[t]{3}{*}{ Prevention } & $\begin{array}{l}\text { \% up to date on measles, mumps and rubella (MMR) vaccination, First Nations } \\
\text { children at age } 2 \text { in First Nations communities }\end{array}$ & $80.4 \%$ & FNIHB Program statistics & 2016 \\
\hline & \begin{tabular}{|l|}
$\%$ that had a mammogram in the past 3 years, First Nations women aged 50-74 \\
in First Nations communities
\end{tabular} & $62.8 \%$ & FNIGC, RHS & $2008 / 10$ \\
\hline & $\begin{array}{l}\text { \% that had a pap test in the past three years, First Nations women aged } 18 \text { and } \\
\text { over in First Nations communities }\end{array}$ & $68.5 \%$ & FNIGC, RHS & $2015 / 16$ \\
\hline \multirow[t]{2}{*}{ Water safety } & $\begin{array}{l}\text { \% of First Nations communities that are in compliance with national water } \\
\text { monitoring guidelines }\end{array}$ & $41 \%$ & $\begin{array}{l}\text { FNIHB, Environmental Public } \\
\text { Health program statistics }\end{array}$ & 2013-14 \\
\hline & $\begin{array}{l}\% \text { of the recommended number of sampling weeks that public water systems in } \\
\text { First Nations communities were monitored for bacteria }\end{array}$ & $80 \%$ & $\begin{array}{l}\text { FNIHB, Environmental Public } \\
\text { Health program statistics }\end{array}$ & 2017 \\
\hline
\end{tabular}

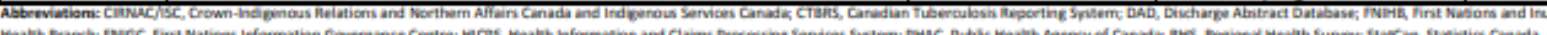

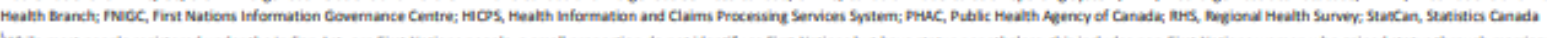

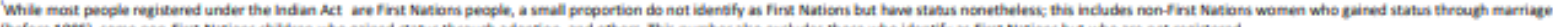

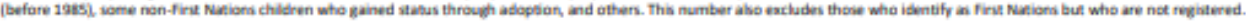

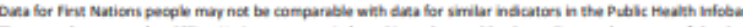

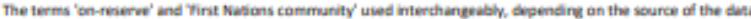

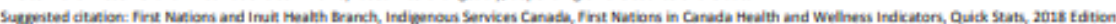

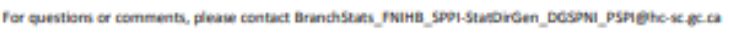




\section{Appendix 5: BCFNDGI Data Standard Template (BCFNDGI, 2015b)}

Data Standard Template

Data Standard Inventory List: The following list summarizes all of the data elements that form the consolidated list of Data Standards approved via the Data Governance Board. Refer to the Data Governance Board approval process for further details on background of the Standard

\begin{tabular}{|l|l|l|l|}
\hline Data Sector: & Data Element: & Purposes for collection and use of the data & Purposes for disclosure of the data \\
\hline & & & \\
\hline
\end{tabular}

Data Standard Specifications: The following list outlines the technical specifications for each data element. Refer to the Data Governance Board approval process for further details on background of the Standard.

\begin{tabular}{|c|c|c|c|c|c|c|}
\hline $\begin{array}{l}\text { Data } \\
\text { Sector: }\end{array}$ & $\begin{array}{l}\text { Data } \\
\text { Element: }\end{array}$ & $\begin{array}{l}\text { Mandatory } \\
\text { or } \\
\text { Optional? }\end{array}$ & $\begin{array}{l}\text { Does the data need to } \\
\text { support alphabetical } \\
\text { (mixed case or all } \\
\text { uppercase or all } \\
\text { lowercase), numeric, } \\
\text { and/or special } \\
\text { characters? If numeric } \\
\text { what are the values? If } \\
\text { special characters } \\
\text { what are they? }\end{array}$ & $\begin{array}{l}\text { Will the data be included in an } \\
\text { aggregated report? If 'yes', } \\
\text { what are the list of values that } \\
\text { must be available for the staff to } \\
\text { select? If 'no', it means the staff } \\
\text { can enter free form text. }\end{array}$ & $\begin{array}{l}\text { Is there a requirement to } \\
\text { know who changed data } \\
\text { and when it was changed? } \\
\text { If so is there a requirement } \\
\text { to know what the data was } \\
\text { prior to it being changed? }\end{array}$ & Business rules: \\
\hline
\end{tabular}




\section{References}

Access to Information Act, R.S.C., 1985, c. A-1. https://www.laws-lois.justice.gc.ca/eng/acts/A1/page-1.html

AFNIGC. (n.d.a). Framework for a Data Sharing Agreement. http://www.afnigc.ca/main/includes/media/pdf/community\%20resources/Data_Sharing $\underline{\text { Agreement.pdf }}$

AFNIGC. (n.d.b). Privacy Law Template. http://www.afnigc.ca/main/includes/media/pdf/community\%20resources/Privacy_Law_T emplate.pdf

Andersen, C. (2016). The Colonialism of Canada's Métis Health Population Dynamics: Caught Between Bad Data and No Data at All. Journal of population research (Canberra, A.C.T.) 33.1: 67-82. https://doi.org/10.1007/s12546-016-9161-4

Anderson, B. R. (1983). Imagined Communities: Reflections on the Origin and Spread of Nationalism. London: Verso.

Anderson, J. E. (2015). Indigenous Knowledge and Intellectual Property Rights. International Encyclopaedia of the Social \& Behavioral Sciences (Second Edition), p.769-778. http://dx.doi.org/10.1016/B978-0-08-097086-8.64078-3

Assembly of First Nations. (n.d.a). About AFN. https:/www.afn.ca/description-of-the-afn/

Assembly of First Nations. (n.d.b). What is Bill C-31 and Bill C-3? https://www.afn.ca/wpcontent/uploads/2020/01/16-19-02-06-AFN-Fact-Sheet-Bill-C-31-Bill-C-3-finalrevised.pdf

Assembly of First Nations. (n.d.c). National Inquiry into Missing and Murdered Indigenous Women and Girls. https://www.afn.ca/category/policy-sectors/mmiwg/

B.C. Environmental Assessment Office. (n.d.). Free, Prior, and Informed Consent. https://www2.gov.bc.ca/assets/gov/environment/natural-resourcestewardship/environmental-assessments/environmental-assessmentrevitalization/documents/free_prior_informed_consent_in_an_ea_context.pdf 
Barclay, B. (2005). Those two pages. In Mana tuturu: Maori treasures \& intellectual property rights (p.93-136). Honolulu: University of Hawaii Press.

Bayly, C. (1996). Empire and Information: Intelligence Gathering and Social Communication in India, 1780-1870 (Cambridge Studies in Indian History and Society). Cambridge: Cambridge University Press. doi:10.1017/CBO978051158328

BCFNDGI. (2015a). Data Governance Framework: Framework and Associated Tools. Mustimuhw Information Solutions Inc. Accessible at: https://www.bcfndgi.com/datagovernance

BCFNDGI. (2015b). Data Governance Framework: Data Governance Policy Manual. Mustimuhw Information Solutions Inc. Accessible at: https://www.bcfndgi.com/datagovernance

BCFNDGI. (2015c). Data Governance Framework: Privacy and Security Policy Manual. Mustimuhw Information Solutions Inc. Accessible at: https://www.bcfndgi.com/datagovernance

BCFNDGI. (2016a). BC First Nations' Data Governance Initiative Strategic Framework. Accessible at: https://www.bcfndgi.com/data-governance

BCFNDGI. (2016b). The 7 Cs: A First Nations' Guide to Planning and Reporting Standards. https://static1.squarespace.com/static/558c624de4b0574c94d62a61/t/577e5cf9d482e9494 05cfd23/1467899162776/THE_7_CS - PLANNING_AND_REPORTING_GUIDE FINAL_2015-2016.PDF

BCFNDGI. (n.d.). First Nations’ Data Governance and Accountability Model. https://static1.squarespace.com/static/558c624de4b0574c94d62a61/t/558c6f76e4b054838 $\underline{\text { 5136649/1435266934237/BCFNDGI-Data-Governance-and-Accountability-Model.pdf }}$

Beer, D. (2019). The Data Gaze. London: SAGE Publications.

Bishop, D. (2016). Indigenous peoples and the official statistics system in Aotearoa/New Zealand. In Kukutai, T. \& Taylor, J. (Eds.), Indigenous Data Sovereignty: Toward an agenda (p.291-304). Acton ACT, Australia: ANU Press. 
Bonney, R., Dickinson, J., Fitzpatrick, J., \& Louv, R. (2012). Citizen Science : Public

Participation in Environmental Research. Cornell University Press. https://doi.org/10.7591/9780801463952

Braun, K., Browne, C., Ka’opua, L., Kim, B., \& Mokuau, N. (2013). Research on Indigenous Elders: From Positivistic to Decolonizing Methodologies. The Gerontologist, 54(1), 117126. https://doi.org/10.1093/geront/gnt067

Bruhn, J. (2014). Identifying Useful Approaches to the Governance of Indigenous Data. International Indigenous Policy Journal, 5(2), 5-. https://doi.org/10.18584/iipj.2014.5.2.5

Brunette-Debassige, C., Rowe, R., \& Neglia, K. (2021, March 10). Indigenist Research Symposium [Webinar]. https://students.wlu.ca/student-life/indigenous-student$\underline{\text { services/event-recordings.html }}$

Calzati, S. (2020). Decolonising "Data Colonialism": Propositions for Investigating the Realpolitik of Today's Networked Ecology. Television \& New Media. https://doi.org/10.1177/1527476420957267

Canadian Institute for Health Information (CIHI). (2020a). A Path Forward: Toward Respectful Governance of First Nations, Inuit and Métis Data Housed at CIHI. Ottawa, ON: CIHI. https://www.cihi.ca/sites/default/files/document/path-toward-respectful-governancefnim-2020-report-en.pdf

Canadian Institute for Health Information (CIHI). (2020b). Proposed Standards for Race-Based and Indigenous Identity Data Collection and Health Reporting in Canada. Ottawa, ON: CIHI. https://www.cihi.ca/sites/default/files/document/proposed-standard-for-race-baseddata-en.pdf

Canadian Institutes of Health Research (CIHR), Natural Sciences and Engineering Research Council of Canada (NSERC), and Social Sciences and Humanities Research Council of Canada (SSHRC). (2019). Tri-Council Policy Statement: Ethical Conduct for Research Involving Humans - TCPS2 2018. Government of Canada. https://ethics.gc.ca/eng/documents/tcps2-2018-en-interactive-final.pdf 
Canadian Internet Policy and Public Interest Clinic (CIPPIC) \& Geomatics and Cartographic Research Centre (GCRC). (2016). A Proposal: An Open Licensing Scheme for Traditional Knowledge (Fewer, D., Lauriault, T.P., \& Scassa, T., eds.). Retrieved from https://cippic.ca/sites/default/files/file/CIPPIC_GCRC--TK_License_Proposal-July 2016.pdf

Caragliu, A., D Bo, C., Kourtit, K., \& Nijkamp, P. (2015). Smart cities. International Encyclopaedia of the Social \& Behavioral Sciences (Second Edition) (p.113-117). doi: https://doi-org.proxy.library.carleton.ca/10.1016/B978-0-08-097086-8.74017-7

Carroll, S. R., Rodriguez-Lonebear, D., \& Martinez, A. (2019). Indigenous Data Governance: Strategies from United States Native Nations. Data Science Journal, 18(1). doi:10.5334/dsj-2019-03

Carroll, S.R., Garba, I., Figueroa-Rodriguez, O.L., Holbrook, J., Lovett, R., Materachera, S., Parsons, M., Raseroka, K., Rodriguez-Lonebear, D., Rowe, R., Rodrigo, S., Walker, J.D., Anderson, J., \& Hudson, M. (2020). The CARE Principles for Indigenous Data Governance. Data Science Journal, 19(1). https://doi.org/10.5334/dsj-2020-043

CBC News. (2013). Aboriginal nutritional experiments had Ottawa's approval. https://www.cbc.ca/news/canada/thunder-bay/aboriginal-nutritional-experiments-hadottawa-s-approval-1.1404390

Centre for Digital Scholarship and Curation. (2021). Mukurtu CMS. https://mukurtu.org/

Clancy, P. (1987). The Making of Eskimo Policy in Canada, 1952-62: The Life and Times of the Eskimo Affairs Committee. Arctic, 40(3), p. 191-197. Retrieved from http://pubs.aina.ucalgary.ca/arctic/Arctic40-3-191.pdf

Constitution Act, 1867, 30 \& 31 Victoria, c. 3 (U.K.). https://lawslois.justice.gc.ca/eng/const/FullText.html

Constitution Act, 1982, Schedule B to the Canada Act 1982 (UK), 1982, c 11. https://lawslois.justice.gc.ca/eng/const/page-12.html\#h-39

Cormack, D., Reid, P., \& Kukutai, T. (2019). Indigenous data and health: critical approaches to "race"/ethnicity and Indigenous data governance. Public Health (London), 172, 116-118. https://doi.org/10.1016/j.puhe.2019.03.026 
Couldry, N., \& Mejias, U. A. (2019). The Costs of Connection: How Data is Colonizing Human Life and Appropriating it for Capitalism. Stanford, California: Stanford University Press.

Crown-Indigenous Relations and Northern Affairs Canada. (2019). Historic self-government agreements signed with the Métis Nation of Alberta, the Métis Nation of Ontario, and the Métis Nation-Saskatchewan. https://www.canada.ca/en/crown-indigenous-relationsnorthern-affairs/news/2019/06/historic-self-government-agreements-signed-with-themetis-nation-of-alberta-the-metis-nation-of-ontario-and-the-metis-nationsaskatchewan.html

Crown-Indigenous Relations and Northern Affairs Canada. (2020). Self-government. https://cirnac.gc.ca/eng/1100100032275/1529354547314

Curtis, B. (2002). The Eyes of Politics \& Making Up Population. Ch. $1 \& 2$ in State Formation, Statistics, and the Census of Canada, 1840-1875. University of Toronto Press.

Daniels v. Canada (Indian Affairs and Northern Development), 2016 SCC 12, [2016] 1 S.C.R. 99 . https://scc-csc.lexum.com/scc-csc/scc-csc/en/item/15858/index.do

Daniels, H.W. (2004). Bill C-31: The Abocide Bill - Introduction. Congress of Aboriginal Peoples. https://web.archive.org/web/20130624235020/http:/www.abo-peoples.org/wpcontent/uploads/2012/10/Copier_20121003_135617resources.pdf

Data Management Association (DAMA). (2017). DAMA-DMBOK2. Technics Publications. https://technicspub.com/dmbok/

Data Management Association (DAMA). (2021). Mission, Vision, Purpose, and Goals. https://www.dama.org/cpages/mission-vision-purpose-and-goals

Davis, M. (2016). Data and the United Nations Declaration on the Rights of Indigenous Peoples. In T. Kukutai \& J. Taylor (eds.), Indigenous Data Sovereignty (pp. 25-38). ANU Press. https://doi.org/10.22459/CAEPR38.11.2016

Di Leo Browne, T. (2012). Consent and Ethics on Local Traditional Knowledge in the Internet Era: Some Key Questions. Presented to D.R. Fraser Taylor and Canadian International Polar Year Federal Program Office, Ottawa. Carleton University. 
de los Monteros, P. (2019). Decolonial Information Practices: Repatriating and Stewarding the Popol Vuh Online. Preservation, Digital Technology \& Culture, 48(3-4), 107-119. https://doi.org/10.1515/pdtc-2019-0009

DeLanda, M. (2006). A New Philosophy of Society : Assemblage Theory and Social Complexity. Continuum. https://doi.org/10.5040/9781472546043

Deleuze, G., \& Guattari, F. (1987). A thousand plateaus: Capitalism and schizophrenia. University of Minnesota Press.

Department of Finance Canada. (2021). Budget 2021 - A Recovery Plan for Jobs, Growth, and Resilience. https://www.budget.gc.ca/2021/home-accueil-en.html

Department of Health and Community Services. (2017, December). Newfoundland and Labrador Indigenous Administrative Data Identifier Standard. Newfoundland and Labrador Centre for Health Information, Government of Newfoundland, and Labrador. https://www.mmiwg-ffada.ca/wp-content/uploads/2019/05/40-

NL_Indigenous_Administrative_Data_Identifier_Standard_FINAL_2017-12-12.pdf

Department of Indigenous Services Act, S.C. 2019, c. 29, s. 336. https://lawslois.justice.gc.ca/eng/acts/I-7.88/page-1.html

Duarte, M. E., \& Belarde-Lewis, M. (2015). Imagining: Creating Spaces for Indigenous Ontologies. Cataloging \& Classification Quarterly, 53(5-6), 677-702. https://doi.org/10.1080/01639374.2015.1018396

Engler, N., Scassa, T., \& Taylor, D. (2013). Mapping Traditional Knowledge: Digital Cartography in the Canadian North. Cartographica, 48(3), 189-199. https://doi.org/10.3138/carto.48.3.1685

Feger, H. (2015). Classification, Understandings in the Social Sciences. In J.D. Wright (ed.) International Encyclopedia of the Social \& Behavioral Sciences (Second Edition, pp. 805-810). Elsevier. https://doi.org/10.1016/B978-0-08-097086-8.44007-9

First Nations Health Authority (FNHA), Province of British Columbia, \& Government of Canada. (2020). Tripartite Data Quality and Sharing Agreement: 2018-2019 Annual Report on Progress. Tripartite First Nations Health Plan. https://www.fnha.ca/Documents/TDQSA-2018-2019-Annual-Report-On-Progress.pdf 
First Nations Information Governance Centre (FNIGC). (2007). First Nations Regional Longitudinal Health Survey (RHS) - Code of Research Ethics. https://nwtspor.ca/sites/default/files/2007_rhs-code-of-research-ethics_copy.pdf

First Nations Information Governance Centre (FNIGC). (2014). Ownership, Control, Access, and Possession (OCAPTM): The Path to First Nations Information Governance. Ottawa: The First Nations Information Governance Centre. https://fnigc.ca/wpcontent/uploads/2020/09/5776c4ee9387f966e6771aa93a04f389_ocap_path_to_fn_inform ation_governance en final.pdf

First Nations Information Governance Centre (FNIGC). (2016). Pathways to First Nations' data and information sovereignty. (2016). In T. Kukutai \& J. Taylor (eds.), Indigenous Data Sovereignty (pp. 139-156). ANU Press. https://doi.org/10.22459/CAEPR38.11.2016

First Nations Information Governance Centre (FNIGC). (2019). First Nations data sovereignty in Canada. Statistical Journal of the IAOS, 35(1), 47-69. https://doi.org/10.3233/SJI-180478

First Nations Information Governance Centre (FNIGC). (2020a). Introducing A First Nations Data Governance Strategy. https://fnigc.ca/news/introducing-first-nations-datagovernance-strategy.html

First Nations Information Governance Centre (FNIGC). (2020b). Fundamentals of OCAP® [Training course]. Algonquin College. Accessed through https://fnigc.ca/training/fundamentals-ocap.html

Fox, K. (2020). The Illusion of Inclusion - The "All of Us" Research Program and Indigenous Peoples' DNA. The New England Journal of Medicine, 383(5), 411-413. https://doi.org/10.1056/NEJMp1915987

Gadacz, R. (2019). First Nations. The Canadian Encyclopedia. https://www.thecanadianencyclopedia.ca/en/article/firstnations

Geddes, B. (2015). Measuring Wellness: An Indicator Development Guide for First Nations. BCFNDGI. https://www.bcfndgi.com/community-planning-tools/ 
Geomatics and Cartographic Research Centre (GCRC) \& Canadian Internet Policy and Public Interest Clinic (CIPPIC). (2016). A Proposal: An Open Licensing Scheme for Traditional Knowledge (Fewer, D., Lauriault, T.P., \& Scassa, T., eds.). Retrieved from https://cippic.ca/sites/default/files/file/CIPPIC_GCRC--TK_License_Proposal-July_2016.pdf

Geomatics and Cartographic Research Centre (GCRC). (2018). Nunaliit Atlas Framework. http://nunaliit.org/

Government of Canada. (2013). The Numbered Treaties (1871-1921). https://www.rcaanccirnac.gc.ca/eng/1360948213124/1544620003549

Government of Canada. (2017). Indigenous Peoples and human rights. https://www.canada.ca/en/canadian-heritage/services/rights-indigenous-peoples.html

Government of Canada. (2018). Report to the Clerk of the Privy Council: A Data Strategy Roadmap for the Federal Public Service. https://www.canada.ca/en/privycouncil/corporate/clerk/publications/data-strategy.html

Government of Canada. (2020a). What is Indian status. https://www.sacisc.gc.ca/eng/1100100032463/1572459644986

Government of Canada. (2020b). Crown-Indigenous Relations and Northern Affairs Canada. https://www.canada.ca/en/crown-indigenous-relations-northern-affairs.html

Government of Canada. (2020c). Setting new directions to support Indigenous research and research training in Canada 2019 - 2022. https://www.canada.ca/en/researchcoordinating-committee/priorities/indigenous-research/strategic-plan-2019-2022.html

Government of Canada. (2021). Indigenous peoples. https://www.canada.ca/en/services/indigenous-peoples.html

Government of Ontario. (2020). Data Standards for the Identification and Monitoring of Systematic Racism. https://www.ontario.ca/document/data-standards-identification-and$\underline{\text { monitoring-systemic-racism }}$ 
Gupta, N., Blair, S., \& Nicholas, R. (2020). What We See, What We Don't See: Data Governance, Archaeological Spatial Databases, and the Rights of Indigenous Peoples in an Age of Big Data. Journal of Field Archaeology: Big Archaeology: Horizons and Blindspots, 45(sup1), S39-S50. https://doi.org/10.1080/00934690.2020.1713969

Hackett, J., Olson, R., \& The Firelight Group. (2019). Dissemination of Open Geospatial Data under the Open Government Licence-Canada through OCAP® Principles (Canadian Geospatial Data Infrastructure Information Product 57e). Natural Resources Canada. Retrieved from https://geoscan.nrcan.gc.ca/starweb/geoscan/servlet.starweb?path=geoscan/fulle.web\&se $\operatorname{arch} 1=\mathrm{R}=314977$

Hacking, I. (1986). Making Up People. In T. Heller (ed.), Reconstructing Individualism (pp.222236). Stanford: Stanford University Press.

Hacking, I. (2007). Kinds of People, Moving Targets. Proceedings of the British Academy, 151 (pp.285-318). https://www.thebritishacademy.ac.uk/documents/2043/pba151p285.pdf

Harley, J. B. (1989). Deconstructing the Map. Cartographica, 26 (2), pp.1-20. DOI: 10.3138/E635-7827-1757-9T53

Harvey, D. (2003). The New Imperialism (Paperback ed.). Oxford, NY: Oxford University Press.

Holland, J. (2013). Who Counts?: the power of participatory statistics. Practical Action Pub.

Hsieh, H., \& Shannon, S. (2016). Three Approaches to Qualitative Content Analysis. Qualitative Health Research, 15(9), 1277-1288. https://doi.org/10.1177/1049732305276687

Hudson, M., Garrison, N., Sterling, R., Caron, N., Fox, K., Yracheta, J., Anderson, J., Wilcox, P., Arbour, L., Brown, A., Taualii, M., Kukutai, T., Haring, R., Te Aika, B., Baynam, G., Dearden, P., Chagné, D., Malhi, R., Garba, I., \& Carroll, S. (2020). Rights, interests, and expectations: Indigenous perspectives on unrestricted access to genomic data. Nature Reviews. Genetics, 21(6), 377-384. https://doi.org/10.1038/s41576-020-0228-X 
Huggan, G. (2008). Decolonizing the map: Postcolonialism, poststructuralism and the cartographic connection. In Interdisciplinary measures: Literature and the future of postcolonial studies (1st ed., p.21-33). Liverpool University Press. Retrieved from https://ebookcentral-proquest-com.proxy.library.carleton.ca/lib/oculcarletonebooks/detail.action?docID $=380674$

Hunt, D. \& Stevenson, S.A. (2017). Decolonizing geographies of power: indigenous digital counter-mapping practices on turtle Island. Settler Colonial Studies, 7:3, 372-392, DOI: 10.1080/2201473X.2016.1186311

Huria, T., Palmer, S., Pitama, S., Beckert, L., Lacey, C., Ewen, S., \& Smith, L. (2019). Consolidated criteria for strengthening reporting of health research involving indigenous peoples: the CONSIDER statement. BMC Medical Research Methodology, 19(1), 173179. https://doi.org/10.1186/s12874-019-0815-8

Hurley, M.C. and Simeone, T. (2010). Bill C-3: Gender Equity in Indian Registration Act. Library of Parliament, Social Affairs Division. https://lop.parl.ca/staticfiles/PublicWebsite/Home/ResearchPublications/LegislativeSum maries/PDF/40-3/40-3-c3-e.pdf

ICES. (2021). Indigenous Portfolio. https://www.ices.on.ca/About-ICES/Collaborations-andPartnerships/Indigenous-Portfolio

Iliadis, A., \& Russo, F. (2016). Critical data studies: An introduction. Big Data \& Society, 3(2). https://doi.org/10.1177/2053951716674238

Indian Act, R.S.C., 1985, c. I-5. https://laws-lois.justice.gc.ca/eng/acts/i-5/page-1.html

Indigenous Services Canada (ISC). (2021). The Government of Canada reaches an Agreement in Principle to resolve class action litigation related to safe drinking water in First Nations communities. https://www.canada.ca/en/indigenous-services-canada/news/2021/07/thegovernment-of-canada-reaches-an-agreement-in-principle-to-resolve-class-actionlitigation-related-to-safe-drinking-water-in-first-nations-commu.html

Infrastructure Canada (INFC). (2018). Smart cities finalist guide. Retrieved from https://impact.ca/en/challenges/smart-cities/challenge 
Inuit Tapiriit Kanatami (ITK). (2018). National Inuit Strategy on Research. Retrieved from https://www.irc.inuvialuit.com/sites/default/files/ITK_NISR-Report_English_low_res.pdf

Inuit Tapiriit Kanatami (ITK). (2020). 2020-2023 Strategy and Action Plan.

https://www.itk.ca/2020-2023-strategy-and-action-plan/

Inuit Tapiriit Kanatami (ITK). (2021). National Voice for Communities in the Canadian Arctic. https://www.itk.ca/national-voice-for-communities-in-the-canadian-arctic/

Inuit Tapiriit Kanatami (ITK). (n.d.). Inuit Nunangat Research Program: Program Guide. https://www.itk.ca/wp-content/uploads/2020/11/inrp-program-guide_en.pdf

Isin, E., \& Ruppert, E. (2019). Data's empire: Postcolonial data politics. In Data Politics (1st ed., pp. 207-227). Routledge. https://doi.org/10.4324/9781315167305-11

Kavita, P. (2015). Indigenous Knowledge: Science and Technology Studies, International Encyclopaedia of the Social \& Behavioral Sciences (Second Edition), Pages 779-783. http://dx.doi.org/10.1016/B978-0-08-097086-8.85012-6

Kitchin, R. \& Lauriault, T.P. (2018). Toward Critical Data Studies: Charting and Unpacking Data Assemblages and Their Work. In Thinking Big Data in Geography (p. 3-20). UNP Nebraska.

Kitchin, R. (2014). The Data Revolution. Sage. Available from https://www.amazon.ca/Data$\underline{\text { Revolution-Infrastructures-Their-Consequences- }}$ ebook/dp/B00L1GM1XG/ref=sr 1 1? ie $=$ UTF8\&qid=1521653701\&sr=8$\underline{1 \& \text { keywords }=\text { the }+ \text { data }+ \text { revolution }}$

Know History. (2021). Genealogy and Citizenship Registries. https://indigenous.knowhistory.ca/our-services/genealogy-and-citizenship-registries

Kukutai, T., \& Cormack, D. (2019). Mana motuhake ā-raraunga: datafication and social science research in Aotearoa. Kōtuitui, 14(2), 201-208. https://doi.org/10.1080/1177083x.2019.1648304

Kukutai, T., \& Taylor, J. (2016). Indigenous Data Sovereignty: Toward an Agenda. Canberra: ANU Press. doi:10.22459/CAEPR38.11.2016 
Ladley, J. (2012). Data Governance: How to Design, Deploy, and Sustain an Effective Data Governance Program. Morgan Kaufmann.

Lauriault, T.P. (2012). Data, infrastructures and geographical imaginations [Doctoral dissertation, Carleton University]. Carleton University Research Virtual Environment (CURVE).

Library and Archives Canada. (n.d.). Terminology Guide: Research on Aboriginal Heritage. https://www.bac-lac.gc.ca/eng/discover/aboriginalheritage/Documents/Terminology $\% 20$ Guide $\% 20 \% 20$ Aboriginal $\% 20$ Heritage.pdf

Library and Archives of Canada Act, S.C. 2004, c. 11. https://laws-lois.justice.gc.ca/eng/acts/17.7/FullText.html

Library of Parliament. (2010). Bill C-3: Gender Equity in Indian Registration Act (Pub. No. 403-C3-E).

https://lop.parl.ca/staticfiles/PublicWebsite/Home/ResearchPublications/LegislativeSum $\underline{\text { maries/PDF/40-3/40-3-c3-e.pdf }}$

Liebler, C. (2018). Counting America's First Peoples. The Annals of the American Academy of Political and Social Science, 677(1), 180-190. https://doi.org/10.1177/0002716218766276

Lourie, A., Kojovic, N., Hodgson, K., \& Alimardanian, M. (2019). Native Title Archives: Traditional Owner community owned and controlled repositories. Journal of Colonialism \& Colonial History, 20(2), 0-0. https://doi.org/10.1353/cch.2019.0020

Manitoba Act, 1870, SC, c 3, reprinted in RSC 1985, App II, No. 8. http://efc.ca/pages/law/cons/Constitutions/Canada/English/ma 1870.html

Manitoba First Nations Education Resource Centre Inc. (MFNERC). (2014). Guidelines for Ethical Research in Manitoba First Nations: Principles, practices, and templates. https://www.mfnerc.org/wp-content/uploads/2014/03/Ethical-Research-in-ManitobaFirst-Nations.pdf

Manitoba Métis Federation Inc. v. Canada (Attorney General), 2013 SCC 14, [2013] 1 S.C.R. 623. https://scc-csc.lexum.com/scc-csc/scc-csc/en/item/12888/index.do 
Mann, M., \& Daly, A. (2019). (Big) Data and the North-in-South: Australia's Informational Imperialism and Digital Colonialism. Television \& New Media, 20(4), 379-395. https://doi.org/10.1177/1527476418806091\}

Marcus, A.R.. (1995). Relocating Eden: The Image and Politics of Inuit Exile in the Canadian Arctic. University Press of New England (pp. 70-71). Available at: $\underline{\text { https://books.google.ca/books?id=0rt1AAAAMAAJ\&pg=PA70\&redir esc }=\mathrm{y}}$

Marley, T. (2019). Indigenous Data Sovereignty: University Institutional Review Board Policies and Guidelines and Research with American Indian and Alaska Native Communities. American Behavioral Scientist, 63(6), 722-742. https://doi.org/10.1177/0002764218799130

Marshall, T. (2020). Oka Crisis. The Canadian Encyclopedia. https:/www.thecanadianencyclopedia.ca/en/article/oka-crisis

Martínez Cobo, J. (1982). Study of the Problem of Discrimination Against Indigenous Populations (Report). Retrieved from https://www.un.org/development/desa/indigenouspeoples/publications/martinez-cobostudy.html

McCracken, K. (2019). Challenging Colonial Spaces: Reconciliation and Decolonizing Work in Canadian Archives. The Canadian Historical Review, 100(2), 182-201. doi:10.3138/chr.2018-0033

Merriam-Webster. (n.d.). Indigenous. https://www.merriam-webster.com/dictionary/indigenous

Métis Nation British Columbia (MNBC) \& Government of British Columbia. (2016). Métis Nation Relationship Accord II. https://www2.gov.bc.ca/assets/gov/british-columbiansour-governments/indigenous-people/aboriginal-peoplesdocuments/Métis_nation_reconciliation_accord_ii - nov_16_2016.pdf

Métis Nation British Columbia (MNBC). (2021a). MNBC Picks Successful Proponent for New Central Registry Database. https://www.mnbc.ca/news/2021/mnbc-picks-successfulproponent-for-new-central-registry-database/

Métis Nation British Columbia (MNBC). (2021b). Governance \& Policy Committee. https://www.mnbc.ca/boardcommittees/governance-policy-committee/ 
Métis Nation British Columbia (MNBC). (n.d.a). A Guide to the Métis Nation British Columbia. https://icer.ok.ubc.ca/wpcontent/uploads/sites/88/2018/06/metisnationbritishcolumbia21948.pdf

Métis Nation British Columbia (MNBC). (n.d.b). Métis Nation British Columbia Registry Database RFP. https://www.mnbc.ca/wp-content/uploads/2021/02/MNBC-RegistryDatabase-RFP Feb-8.2021.pdf

Métis Nation of Ontario. (2019). Policy on MNO Registry and Research. https://www.metisnation.org/wp-content/uploads/2015/07/mno-registry-and-researchpolicy_may312019.pdf

Métis National Council (MNC). (2021). Citizenship. https://www2.metisnation.ca/about/citizenship/

Miner, J.D. (2020). Informatic tactics: Indigenous activism and digital cartographies of genderbased violence. Information, Communication \& Society, DOI:

10.1080/1369118X.2020.1797851

Ministry of Aboriginal Relations and Reconciliation. (2007, March 22). Aboriginal Administrative Data Standard [Version 1.0]. Government of British Columbia. https://www2.gov.bc.ca/assets/gov/government/services-for-government-and-broaderpublic-sector/information-technology-services/standardsfiles/aboriginal administrative data standards.pdf

Mohawk Council of Akwesasne. (2018). Smart cities challenge proposal [Project proposal]. Retrieved from https://www.infrastructure.gc.ca/cities-villes/profiles-profils-eng.html

Métis National Council (MNC). (2019). Métis Nations Gateway portal. https://politics.Métisportals.ca/Menu/

Montenegro, M. (2019). Subverting the Universality of Metadata Standards: The TK labels as a Tool to Promote Indigenous Data Sovereignty. Journal of Documentation, 75(4), 731749. https://doi.org/10.1108/JD-08-2018-0124

Morphy, F. (2016). Indigenising demographic categories: a prolegomenon to indigenous data sovereignty. In Kukutai, T. \& Taylor, J. (Eds.), Indigenous Data Sovereignty: Toward an agenda (p.99-116). Acton ACT, Australia: ANU Press. 
Morris, J. (2021). Report: Over 600 Bodies Found at Indigenous School in Canada. ABC News. https://abcnews.go.com/International/wireStory/report-751-bodies-found-indigenousschool-canada-78466234

Municipal Property Assessment Corp. (MPAC). (2021). VoterLookup.ca. https://www.mpac.ca/en/OurServices/VoterLookupca

Nation Aboriginal Health Organization (NAHO). (n.d.). Principles of Ethical Métis Research. https://ruor.uottawa.ca/bitstream/10393/30555/1/2011_04_ethics.pdf

National Centre for First Nations Governance (NCFNG). (n.d.a). Meaningful Information Sharing: Squiala First Nation. https://fngovernance.org/wpcontent/uploads/2020/06/MIS Squiala.pdf

National Centre for First Nations Governance (NCFNG). (n.d.b). Meaningful Information Sharing: Miawpukek First Nation. https://wp74066.wpdns.ca/wpcontent/uploads/2020/06/MIS_Miawpukek.pdf

National Centre for Truth and Reconciliation. (n.d.). Truth and Reconciliation Web Archive. Retrieved from http://nctr.ca/archives-pages.php\#truth

National Collaborating Centre for Aboriginal Health (NCCAH). (2010). Inuit Qaujimajatuqangit: The role of Indigenous knowledge in supporting wellness in Inuit communities in Nunavut. https://www.ccnsanccah.ca/docs/fact $\% 20$ sheets/child\%20and\%20youth/Inuit $\% 20 \mathrm{IQ} \% 20 \mathrm{EN} \% 20$ web.pdf

National Post Staff. (2013). Dwight Newman: Of aboriginals, Métis, First Nations, Inuit, and Indians (status-holding and otherwise). National Post. https://nationalpost.com/opinion/dwight-newman-of-aboriginals-metis-first-nations-inuitand-indians-status-holding-and-otherwise

Oguamanam, C. (2019). Indigenous Data Sovereignty: Retooling Indigenous Resurgence for Development. Centre for International Governance Innovation.

Omand, G. (2018). '60s Scoop group educates survivors, pushes rejection of federal settlement deal. CTV News. https://www.ctvnews.ca/politics/60s-scoop-group-educates-survivorspushes-rejection-of-federal-settlement-deal-1.3809936 
Outhwaite, R. (2015). Positivism, Sociological. In International Encyclopedia of the Social \& Behavioral Sciences (Vol. 18, pp. 625-629).

Peluso, N.L (1995). Whose Woods are These? Counter-Mapping Forest Territories in Kalimantan, Indonesia. Antipode. 4. 27: 383-406. doi:10.1111/j.14678330.1995.tb00286.x.

Personal Information Protection and Electronic Documents Act (PIPEDA), S.C. 2000, c 5, $<$ https://canlii.ca/t/541b8 $>$ retrieved on 2021-08-22

Peters, E. (2011). Still Invisible: Enumeration of Indigenous Peoples in Census Questionnaires Internationally. Aboriginal Policy Studies, 1(2). doi:10.5663/aps.v1i2.11685

Phillips, G. (2017, June). Keynote: Indigenous Data Sovereignty and Reconciliation. Data Power 2017. Talk presented at Data Power 2017 conference at Carleton University, Ottawa, Ontario. Retrieved from https://www.youtube.com/watch?v=4I 3figC3B0

Phillips, G. (n.d.). CRIMSIN: An Accountability Tool for Self-Governing Nations. https://static1.squarespace.com/static/558c624de4b0574c94d62a61/t/558c75e4e4b081b4e 6ed3d96/1435268580099/CRIMSIN-First-Nations-Integrated-Data-ManagementSystem.pdf

Pool, I. (2016). Colonialism's and postcolonialism's fellow traveller: the collection, use and misuse of data on indigenous people. In Kukutai, T. \& Taylor, J. (Eds.), Indigenous Data Sovereignty: Toward an agenda (p.57-78). Acton ACT, Australia: ANU Press.

Population and Public Health Division. (2018, January $1^{\text {st }}$ ). Relationship with Indigenous Communities Guideline. Ministry of Health and Long-Term Care. https://health.gov.on.ca/en/pro/programs/publichealth/oph standards/docs/protocols guid elines/Relationship_with_Indigenous_Communities_Guideline_en.pdf

Price, J. \& Gadacz, R. (2020). Band (Indigenous Peoples in Canada). The Canadian Encyclopedia. https://www.thecanadianencyclopedia.ca/en/article/band

Privacy Act, R.S.C., 1985, c. P-21. https://laws-lois.justice.gc.ca/eng/acts/P-21/FullText.html R. v. Powley, [2003] 2 S.C.R. 207, 2003 SCC 43. https://scc-csc.lexum.com/scc-csc/scccsc/en/item/2076/index.do 
Rainie, S., Schultz, J., Briggs, E., Riggs, P., \& Palmanteer-Holder, N. (2017). Data as a Strategic Resource: Self-determination, Governance, and the Data Challenge for Indigenous Nations in the United States. International Indigenous Policy Journal, 8(2). https://doi.org/10.18584/iipj.2017.8.2.1

Rea, J.E. \& Scott, J. (2006). Manitoba Act. In The Canadian Encyclopedia. https://www.thecanadianencyclopedia.ca/en/article/manitoba-act

Reference Re Eskimos (Reference as to whether "Indians" includes in s. 91 (24) of the B.N.A. Act includes Eskimo in habitants of the Province of Quebec), [1939] S.C.R. 104. https://scccsc.lexum.com/scc-csc/scc-csc/en/item/8531/index.do

Reinhard, W. (2015). Colonization and Colonialism, History of. In J.D. Wright (ed.) International Encyclopedia of the Social \& Behavioral Sciences (Second Edition, pp. 223-227). Elsevier. https://doi.org/10.1016/B978-0-08-097086-8.62081-0.

Ricaurte, P. (2019). Data Epistemologies, The Coloniality of Power, and Resistance. Television \& New Media, 20(4), 350-365. https://doi.org/10.1177/1527476419831640

Richardson, L., \& Crawford, A. (2020). COVID-19 and the decolonization of Indigenous public health. Canadian Medical Association Journal (CMAJ), 192(38), E1098-E1101. https://doi.org/10.1503/cmaj.200852

Rowe, R., Bull, J. \& Walker, J. (2021). Indigenous self-determination and data governance in the Canadian policy context. In M. Walter, T. Kukutai, S.R. Carroll, S.R., \& D. RodriguezLonebear (Eds.), Indigenous Data Sovereignty and Policy (pp.81-98). Routledge: New York.

Royal Commission on Aboriginal Peoples (RCAP). (1996a). Volume 3: Gathering Strength. Canada Communication Group Publishing. https://data2.archives.ca/e/e448/e01118823003.pdf

Royal Commission on Aboriginal Peoples (RCAP). (1996b). Volume 5: Renewal: A Twenty-Year Commitment. Canada Communication Group Publishing. https://data2.archives.ca/e/e448/e011188230-05.pdf

Saetnan, A.R., Lomell, H.M., \& Hammer, S. (2010). By the Very Act of Counting - The Mutual Construction of Statistics and Society. In Saetan, A.R, Lomell, H.M., \& Hammer, S. 
(eds), The Mutual Construction of Statistics and Society, (p.1-18). Retrieved from https://ebookcentral-proquest-com.proxy.library.carleton.ca

Scassa, T., Taylor, D.R.F., \& Lauriault, T.P. (2014). Cybercartography and Traditional Knowledge: Responding to legal and ethical challenges, developments in the theory and practice of cybercartography: Applications and indigenous mapping. In Taylor, D.R.F. \& Lauriault, T.P. (eds), Modern Cartography Series: Volume 5 (p.279-295). Amsterdam, Elsevier. doi: http://dx.doi.org/10.1016/B978-0-444-62713-1.00019-2

Schatsky, D., Camhi, J. \& Muraskin, C. (2019). Data ecosystems: How third-party information can enhance data analytics. Deloitte. https://www2.deloitte.com/content/dam/insights/us/articles/4603 Dataecosystems/DI_Data-ecosystems.pdf

Segura, M. S., \& Waisbord, S. (2019). Between Data capitalism and Data Citizenship. Television \& New Media, 20(4), 412-419. doi:10.1177/1527476419834519

Shapin, S. (2001). Truth and Credibility in Science. In International Encyclopaedia of the Social \& Behavioral Sciences (Second Edition, pp. 673-677). http://dx.doi.org/10.1016/B978-008-097086-8.85039-4

Smith, D. (2016). Governing Data and Data for governance: The Everyday Practice of Indigenous Sovereignty. In Kukutai, T. \& Taylor, J. (Eds.), Indigenous Data Sovereignty: Toward an agenda (p.117-136). Acton ACT, Australia: ANU Press. Retrieved from www.jstor.org/stable/j.ctt1q1crgf.14

Smith, L. (1999). Decolonizing Methodologies : Research and Indigenous peoples . Zed Books.

Smith, S.A. (2019). Rupert's Land. The Canadian Encyclopedia. https://www.thecanadianencyclopedia.ca/en/article/ruperts-land

Smylie, J., Firestone, M., Cochran, L., Prince, C., Maracle, S., Morley, M., Mayo, S., Spiller, T., \& McPherson, B. (2011). Our Health Counts: Urban Aboriginal Health Database Research Project - Community Report. Prepared for Aboriginal Health Centre, Ontario Federation of Indian Friendship Centres, Hamilton Executive Director's Aboriginal Coalition, \& Our Health Counts Governing Council. https://www.metisnation.org/wpcontent/uploads/2020/04/COLLAB-Our-Health-Counts-Full-Report-April-2011.pdf 
Snipp, M. (2016). What does data sovereignty imply: what does it look like? In Kukutai, T. \& Taylor, J. (Eds.), Indigenous Data Sovereignty: Toward an agenda (p.39-56). Acton ACT, Australia: ANU Press.

Sparke, M. (1998). A Map that Roared and an Original Atlas: Canada, Cartography, and the Narration of Nation. Annals of the Association of American Geographers, Volume 88, Issue 3:463-495. DOI: 10.1111/0004-5608.00109.

Statistics Canada. (2017). Aboriginal Peoples Reference Guide, Census of Population, 2016. https://www12.statcan.gc.ca/census-recensement/2016/ref/guides/009/98-500-x2016009eng.cfm

Statistics Canada. (2018). First Nations and Inuit Health and Wellness Indicators. https://healthinfobase.canada.ca/fnih/

Statistics Canada. (2020). 2016 Census of Population Long-form Guide. https://www.statcan.gc.ca/eng/statistical-programs/document/3901_D18_T1_V1

Stern, P. (2019). The 'Eskimo Problem': Legitimizing Canadian Arctic Administration, 19601975. Urbanities, Vol. 9 (pp.61-66). https://www.anthrojournal-urbanities.com/wpcontent/uploads/2019/04/11-Stern.pdf

Taylor, D. (2005). Cybercartography: Theory and Practice (1st ed.). Elsevier.

Taylor, D., \& Lauriault, T. (2014). Developments in the Theory and Practice of Cybercartography: Applications and Indigenous Mapping. In Developments in the Theory and Practice of Cybercartography. Elsevier Science \& Technology.

Thatcher, J., O’Sullivan, D., \& Mahmoudi, D. (2016). Data Colonialism through Accumulation by Dispossession: New Metaphors for Daily Data. Environment and Planning D: Society and Space, 34(6), 990-1006. doi:10.1177/0263775816633195

The Canadian Press and News Staff. (2021, Aug. 10). Ottawa allocates millions to searches for unmarked residential school graves. CityNews. https://edmonton.citynews.ca/2021/08/10/ottawa-residential-school-funding/

The Métis Nation British Columbia Citizenship Act, as ratified September 2019, Annual General Meeting. https://www.mnbc.ca/wp-content/uploads/2020/09/Citizenship-Act.pdf 
Treasury Board of Canada Secretariat. (2019). Digital Operations Strategic Plan: 2018-2022. Government of Canada. Retrieved from https://www.canada.ca/en/government/system/digital-government/digital-operationsstrategic-plan-2018-2022.html\#ToC12

Truth and Reconciliation Commission (TRC). (2015a). What We Have Learned: Principles of Truth and Reconciliation. https://ehprnh2mwo3.exactdn.com/wpcontent/uploads/2021/01/Principles_English_Web.pdf

Truth and Reconciliation Commission (TRC). (2015b). Canada's Residential Schools: The History, Part 1 Origins to 1939. https://ehprnh2mwo3.exactdn.com/wpcontent/uploads/2021/01/Volume_1_History_Part_1_English_Web.pdf

Truth and Reconciliation Commission (TRC). (2015c). Canada's Residential Schools: The Inuit and Northern Experience. https://ehprnh2mwo3.exactdn.com/wpcontent/uploads/2021/01/Volume_2_Inuit_and_Northern_English_Web.pdf

Truth and Reconciliation Commission (TRC). (2015d). Canada's Residential Schools: The Métis Experience. https://ehprnh2mwo3.exactdn.com/wpcontent/uploads/2021/01/Volume_3_Metis_English_Web.pdf

Tsosie, R. (2021). Indigenous Data Sovereignty, governance and the link to Indigenous policy. In M. Walter, T. Kukutai, S.R. Carroll, S.R., \& D. Rodriguez-Lonebear (Eds.), Indigenous Data Sovereignty and Policy (pp.204-225). Routledge: New York.

Tui'kn Partnership. (2015). Privacy Policy and Procedures. http://www.tuikn.ca/wpcontent/uploads/2014/01/Privacy-Policy-Unamaki-Health-Centres-April-2015.pdf

Tui'kn Partnership. (n.d.). About Tui'kn. http://www.tuikn.ca/about-tuikn/

United Nations. (2004). The Concept of Indigenous Peoples. Background paper prepared by the Secretariat of the Permanent Forum on Indigenous Issues (PFI/2004/WS.1/3). Download link: https://www.un.org/esa/socdev/unpfii/documents/workshop data background.doc

United Nations. (2007). United Nations Declaration on the Rights of Indigenous Peoples. https://www.un.org/development/desa/indigenouspeoples/wpcontent/uploads/sites/19/2018/11/UNDRIP_E_web.pdf 
United Nations. (n.d.a). Who are indigenous peoples? (Factsheet). U.N. Permanent Forum on Indigenous Issues. https://www.un.org/esa/socdev/unpfii/documents/5session_factsheet1.pdf

United Nations. (n.d.b). Home: United Nations Declaration on the Rights of Indigenous Peoples. https://www.un.org/development/desa/indigenouspeoples/declaration-on-the-rights-ofindigenous-peoples.html

University of Manitoba. (n.d.). Framework for Research Engagement with First Nation, Métis, and Inuit Peoples. https://www.umanitoba.ca/faculties/health_sciences/medicine/media/UofM_Framework_ Report_web.pdf

Villani, M. (2021). Calgary Indigenous woman walks to raise awareness and seek justice for residential school victims. CTV News. https://calgary.ctvnews.ca/calgary-indigenouswoman-walks-to-raise-awareness-and-seek-justice-for-residential-school-victims$\underline{1.5556389}$

Walker, J., Healy, B., Healy, C., Apsassin, T., Wadsworth, W., Jones, C., Reading, J., LemchukFavel, L., Lovett, R., Cormack, D., Rainie, S., Rodriguez-Lonebear, D., \& Rowe, R. (2018). Perspectives on Linkage Involving Indigenous data. International Journal of Population Data Science, 3(4). https://doi.org/10.23889/ijpds.v3i4.999

Walker, J., Lovett, R., Kukutai, T., Jones, C., \& Henry, D. (2017). Indigenous health data and the path to healing. The Lancet (British Edition), 390(10107), 2022-2023. https://doi.org/10.1016/s0140-6736(17)32755-1

Walker, J., Pyper, E., Jones, C., Khan, S., Chong, N., Legge, D., Schull, M., \& Henry, D. (2018). Unlocking First Nations health information through data linkage. International Journal of Population Data Science, 3(1). https://doi.org/10.23889/ijpds.v3i1.450

Walter, M. \& Carroll, S.R. (2021). Indigenous Data Sovereignty, governance and the link to Indigenous policy. In M. Walter, T. Kukutai, S.R. Carroll, S.R., \& D. RodriguezLonebear (Eds.), Indigenous Data Sovereignty and Policy (pp. 1-20). Routledge: New York. 
Walter, M. (2016). Data politics and Indigenous representation in Australian statistics. In T. Kukutai \& J. Taylor (Eds.), Indigenous data sovereignty: Toward an agenda (pp. 79-87). Canberra, Australia: ANU Press. doi:10.22459/CAEPR38.11.2016

Walter, M., \& Andersen, C. (2013). Indigenous Statistics: A Quantitative Research Methodology. Routledge. https://doi.org/10.4324/9781315426570

Walter, M., \& Suina, M. (2019). Indigenous data, indigenous methodologies and indigenous data sovereignty. International Journal of Social Research Methodology, 22(3), 233-243. https://doi.org/10.1080/13645579.2018.1531228

Walter, M., Kukutai, T., Carroll, S.R., \& Rodriguez-Lonebear, D. (2021). Indigenous data sovereignty and policy. Routledge: New York.

Wilks, J., Kennedy, G., Drew, N., \& Wilson, K. (2018). Indigenous Data Sovereignty in Higher Education : Towards a Decolonised Data Quality Framework. The Australian Universities' Review, 60(2), 4-14.

Yale, E. (2015). The History of Archives: The State of the Discipline. Book History 18, 332359. doi:10.1353/bh.2015.0007.

Zuboff, S. (2019). The Age of Surveillance Capitalism: The Fight for a Human Future at the New Frontier of Power (First ed.). New York: Public Affairs.

OCAP ${ }^{\circledR}$ is a registered trademark of the First Nations Information Governance Centre (FNIGC): https://fnigc.ca/OCAP. 